\title{
Metodologia para determinação dos parâmetros utilizados em uma nova superfície de escoamento anisotrópica para processos de conformação de chapas metálicas
}

\section{ALEXANDRE TÁCITO MALAVOLTA}

Tese apresentada à Escola de Engenharia de São Carlos da Universidade de São Paulo, como parte dos requisitos para obtenção do título de Doutor em Engenharia Mecânica

Orientador: Prof. Dr. João Lirani 


\section{Dedicatória}

Aos meus pais, Américo e Irene, à minha irmã, Marília e ao meu filho Gabriel. 
Agradeço:

Ao Professor João Lirani, pela dedicação, orientação e amizade.

Aos Professores Ernesto Massaroppi Jr. e Hazim Ali-Qureshi, pela amizade e pelas contribuições dadas a este trabalho.

Aos amigos Sérgio e Mariano, pelas discussões e sugestões.

Aos amigos: Thiago, Arai, Américo, Marcos, Rafael, Daniel e Anderson pela eterna amizade.

Ao demais colegas, professores e funcionários do Departamento de Engenharia Mecânica.

Ao CNPq, Conselho Nacional de Desenvolvimento Científico e Tecnológico, pela bolsa de estudo sem a qual seria impossível a realização deste trabalho. 


\section{Sumário}

$\begin{array}{ll}\text { Lista de Figuras } & \text { ix }\end{array}$

$\begin{array}{ll}\text { Lista de Tabelas } & \text { xv }\end{array}$

Lista de Símbolos $\quad$ xvii

Resumo xxiii

Abstract $\quad$ xxv

1 Introdução 1

$\begin{array}{llr}2 & \text { Objetivos } & 7\end{array}$

3 Revisão Conceitual $\quad 11$

3.1 Análise de tensões . . . . . . . . . . . . . . . . . . . . . . . . . . . 12

3.2 Análise de deformações . . . . . . . . . . . . . . . . . . . . 20

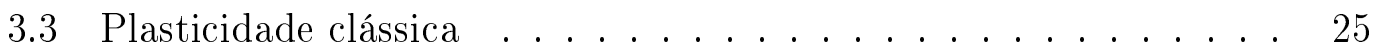

3.3.1 Critérios de escoamento . . . . . . . . . . . . . 34

3.4 Plasticidade computacional . . . . . . . . . . . . . . . 37

3.4.1 Plasticidade unidimensional . . . . . . . . . . . . . . . 38

3.4.2 Plasticidade multidimensional . . . . . . . . . . . . . 43

3.5 Algoritmos de integração . . . . . . . . . . . . . . . . . 45

3.5.1 Forward Euler . . . . . . . . . . . . . . . . . . 46

3.5.2 Backward Euler . . . . . . . . . . . . . . . . . 47 
3.6 Método dos elementos finitos . . . . . . . . . . . . . . . . . . 48

4 Estado da Arte - Anisotropia 53

4.1 Introdução . . . . . . . . . . . . . . . . . . . . . 53

4.2 Anisotropia . . . . . . . . . . . . . . . . . 54

4.3 Critério de Hill . . . . . . . . . . . . . . . . . . . 55

4.4 Índice de anisotropia plástica . . . . . . . . . . . . . . . . . 60

4.5 Outras superfícies de escoamento . . . . . . . . . . . . 63

4.6 Recentes desenvolvimentos . . . . . . . . . . . . . . . 66

5 Metodologia e Nova Superfície de Escoamento $\quad 75$

5.1 Cálculo de evolução da anisotropia . . . . . . . . . . . . . . . 75

5.1.1 Estado de tensão-deformação em flexão . . . . . . . . . . . 76

5.1.2 Equacionamento proposto . . . . . . . . . . . . . . 82

5.1 .3 Metodologia . . . . . . . . . . . . . . . 96

5.2 Nova Superfície de Escoamento . . . . . . . . . . . . . . . . . 100

5.3 Considerações Finais . . . . . . . . . . . . . . . . . . . . . 102

6 Resultados e Discussões 105

6.1 Validação do algoritmo de previsão-correção . . . . . . . . . . 106

6.2 Ensaios de caracterização de material . . . . . . . . . . . . . 117

6.2 .1 Ensaio de tração . . . . . . . . . . . . . . . . . . 117

6.2.2 Ensaio de anisotropia . . . . . . . . . . . . . . . . 120

6.3 Aplicação da metodologia . . . . . . . . . . . . . . . . . . . . . 124

6.3.1 Curvas tensão x deformação . . . . . . . . . . . . . 126

6.3.2 Coeficientes $\beta_{i}^{(\alpha)}$ do conjunto de equações . . . . . . . . . 128

6.3.3 Evolução dos parâmetros de anisotropia . . . . . . . . . . 130 
6.3.4 Fator de correção $\Psi$ e evolução da superfície de escoamento $F_{m} \ldots \ldots \ldots \ldots \ldots \ldots$

6.4 Resultados teóricos . . . . . . . . . . . . . . . . 136

6.5 Exemplos de aplicação . . . . . . . . . . . . . . . . . . . . . 141

6.5.1 Dobramento em $V$. . . . . . . . . . . . . . . . . 141

6.5.2 Embutimento .................. 150

6.6 Discussões gerais . . . . . . . . . . . . . . . . . . . . 157

7 Conclusões e Sugestões para Trabalhos Futuros 159

Referências Bibliográficas $\quad 163$ 


\section{Lista de Figuras}

FIGURA3.1 Definição do vetor de tração . . . . . . . . . . . . . . 13

FIGURA3.2 Vetor de tração atuando sobre um plano arbitrário . . . 13

FIGURA3.3 Decomposição do vetor de tração . . . . . . . . . . . . . 14

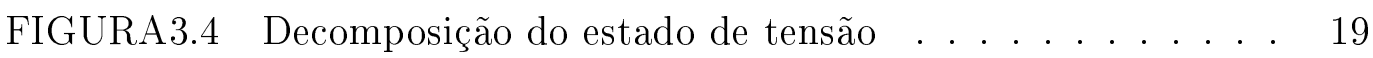

FIGURA3.5 Configuração original e deformada de um corpo . . . . . 21

FIGURA3.6 Diagrama esquemático de tensão-deformação . . . . . . . 27

FIGURA3.7 Representação do efeito Bauschinger . . . . . . . . . . 28

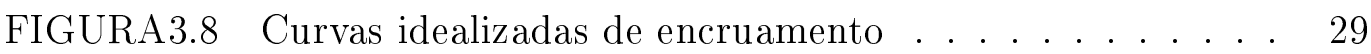

FIGURA3.9 Evolução da superfície com encruamento isotrópico . . 31

FIGURA3.10 Evolução da superfície com encruamento cinemático . . . 32

FIGURA3.11 Evolução da superfície com encruamento combinado . . . 34

FIGURA3.12 Comparação entre as superfícies de escoamento de von

Mises e Tresca . . . . . . . . . . . . . . . . . 37 
FIGURA3.13 Modelo idealizado de encruamento . . . . . . . . . . . . 38

FIGURA4.1 Falhas no repuxamento de copos . . . . . . . . . . . 62

FIGURA4.2 Superfície de escoamento em função de $R_{m} \ldots$. . . . . . 63

FIGURA4.3 Superfície de escoamento BARLAT e LIAN (1989) . . . 65

FIGURA4.4 Superfície de escoamento BANABIC et al. (2004) . . . . 66

FIGURA4.5 Superfície de escoamento SINOU e MACQUAIRE (2003) 68

FIGURA4.6 Evolução de $R_{\alpha}$ - CHAMANFAR e MAHMUDI (2005) 70

FIGURA4.7 Evolução de $R_{\alpha}$ - DANCKERT e NIELSEN (1998) . . . 71

FIGURA4.8 Evolução de $R_{\alpha}$ - GILMOUR, LEACOCK e ASHBRIDGE

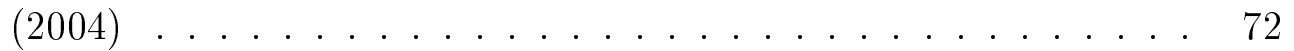

FIGURA5.1 Estado tensão-deformação base da formulação . . . . . 77

FIGURA5.2 Diferentes formas de dobramento . . . . . . . . . 77

FIGURA5.3 Principais parâmetros associados ao dobramento . . . . . 78

FIGURA5.4 Deformação na flexão . . . . . . . . . . . . . . . 79

FIGURA5.5 Relação entre a biaxialidade e a geometria da chapa . . . 80

FIGURA5.6 Estado tensão-deformação: $\alpha=0^{\circ} \ldots$. . . . . . . . . 86

FIGURA5.7 Estado tensão-deformação: $\alpha=90^{\circ} \ldots \ldots$. . . . . . 87 
FIGURA5.8 Estado tensão-deformação: $\alpha=45^{\circ} \ldots \ldots$. . . . . . 88

FIGURA5.9 Metodologia para aplicação do procedimento proposto 96

FIGURA5.10 Esquema geral do algoritmo de previsão-correção . . . . 99

FIGURA6.1 Estado tensão-deformação do modelo MEF . . . . . . . . 107

FIGURA6.2 Tensão Equivalente - Caso 1 . . . . . . . . . . . . . . 109

FIGURA6.3 Tensões Principais - Caso 1 . . . . . . . . . . . . . . 109

FIGURA6.4 Tensão Equivalente - Caso 2 . . . . . . . . . . . . . . 110

FIGURA6.5 Tensões Principais - Caso $2 \ldots \ldots 110$

FIGURA6.6 Tensão Equivalente $\alpha=0^{\circ}$ e $\alpha=90^{\circ}$ - Caso $3 \ldots 112$

FIGURA6.7 Tensões Principais $\alpha=0^{\circ}$ e $\alpha=90^{\circ}$ - Caso $3 \ldots 112$

FIGURA6.8 Componentes de tensão $\alpha=45^{\circ}$ - Caso $3 \ldots 113$

FIGURA6.9 Tensão Equivalente $\alpha=0^{\circ}$ e $\alpha=90^{\circ}$ - Caso $4 \ldots 114$

FIGURA6.10 Tensões Principais $\alpha=0^{\circ}$ e $\alpha=90^{\circ}$ - Caso $4 \ldots 115$

FIGURA6.11 Componentes de tensão $\alpha=45^{\circ}$ - Caso 4 . . . . . . . . 115

FIGURA6.12 Tensão Equivalente $\alpha=0^{\circ}$ e $\alpha=90^{\circ}$ - Caso $5 \ldots 116$

FIGURA6.13 Tensões Principais $\alpha=0^{\circ}$ e $\alpha=90^{\circ}$ - Caso $5 \ldots 116$

FIGURA6.14 Componentes de tensão $\alpha=45^{\circ}$ - Caso 5 . . . . . . . 117 
FIGURA6.15 Montagem do CDP no ensaio de tração . . . . . . . . . . 118

FIGURA6.16 Curvas experimentais e ajustadas do ensaio de tração . 119

FIGURA6.17 Diagrama Força x deslocamento CDP-0 : Ensaio 1 . . 121

FIGURA6.18 Evolução experimental de $R_{0}$. . . . . . . . . . . . . . 122

FIGURA6.19 Evolução experimental de $R_{45}$. . . . . . . . . . . 123

FIGURA6.20 Evolução experimental de $R_{90}$. . . . . . . . . . . . . 123

FIGURA6.21 Comparação entre estados de tensão-deformação . . . . . 125

FIGURA6.22 Tensão equivalente . . . . . . . . . . . . . . . . . 126

FIGURA6.23 Tensões principais _. . . . . . . . . . . . . 127

FIGURA6.24 Componentes de tensão $\alpha=45^{\circ} \ldots$. . . . . . . . . . 127

FIGURA6.25 Evolução dos coeficientes $\beta_{i}^{\left(0^{\circ}\right)}$ para $\alpha=0^{\circ} \ldots \ldots$. . . . 128

FIGURA6.26 Evolução dos coeficientes $\beta_{i}^{\left(90^{\circ}\right)}$ para $\alpha=90^{\circ} \ldots \ldots . . .129$

FIGURA6.27 Evolução dos coeficientes $\beta_{i}^{\left(45^{\circ}\right)}$ para $\alpha=45^{\circ} \ldots \ldots . . .129$

FIGURA6.28 Evolução dos parâmetro $\hat{F}$. . . . . . . . . . . . . 130

FIGURA6.29 Evolução do parâmetro $\hat{G}$. . . . . . . . . . . . . . . . . 131

FIGURA6.30 Evolução do parâmetro $\hat{H}$. . . . . . . . . . . . . . . 131

FIGURA6.31 Evolução do parâmetro $\hat{N}$. . . . . . . . . . . . . . 132

FIGURA6.32 Comparação da evolução de $R_{0}$. . . . . . . . . . . 133 
FIGURA6.33 Comparação da evolução de $R_{45}$. . . . . . . . . . . . 133

FIGURA6.34 Comparação da evolução de $R_{90}$. . . . . . . . . . . . . . 134

FIGURA6.35 Evolução do fator de correção $\Psi$. . . . . . . . . . . . . 135

FIGURA6.36 Comparação da evolução das superfícies de escoamento · 135

FIGURA6.37 Evolução do parâmetro $\hat{F}$ - caso teórico . . . . . . . . . 137

FIGURA6.38 Evolução do parâmetro $\hat{G}$ - caso teórico . . . . . . . . 138

FIGURA6.39 Evolução do parâmetro $\hat{H}$ - caso teórico . . . . . . . . . 138

FIGURA6.40 Evolução do parâmetro $\hat{N}$ - caso teórico . . . . . . . . . 139

FIGURA6.41 Evolução do fator de correção $\Psi$. . . . . . . . . . . . . . 140

FIGURA6.42 Evolução da superfície de escoamento Fm . . . . . . . . 140

FIGURA6.43 Comparação da evolução das superfícies de escoamento 141

FIGURA6.44 Esquema do processo de dobramento em $V$. . . . . . . 142

FIGURA6.45 Malha do modelo MEF do dobramento em $V$. . . . . . 143

FIGURA6.46 Distribuição da tensão equivalente $[\mathrm{Pa}]-\alpha=0^{\circ} \ldots \ldots$

FIGURA6.47 Histórico de deformação obtido via MEF . . . . . . . . . 145

FIGURA6.48 Evolução de $\sigma_{e q}$ - Dobramento . . . . . . . . . . . . 146

FIGURA6.49 Evolução do parâmetro $\hat{F}$ - Dobramento . . . . . . . . . 147

FIGURA6.50 Evolução do parâmetro $\hat{G}$ - Dobramento . . . . . . . . . 147 
FIGURA6.51 Evolução do parâmetro $\hat{H}$ - Dobramento . . . . . . . . . 148

FIGURA6.52 Evolução do parâmetro $\hat{N}$ - Dobramento . . . . . . . . . 148

FIGURA6.53 Evolução do fator de correção $\Psi$. . . . . . . . . . . . . . 149

FIGURA6.54 Comparação da evolução das superfícies de escoamento 149

FIGURA6.55 Esquema do embutimento, YOON et al. (2006) . . . . . 150

FIGURA6.56 Malha do modelo MEF do embutimento . . . . . . . . . 151

FIGURA6.57 Tensão equivalente [Pa] no início do carregamento ... 152

FIGURA6.58 Tensão equivalente [Pa] no final do carregamento . . . . 152

FIGURA6.59 Evolução das componentes de deformação . . . . . . . 153

FIGURA6.60 Evolução do parâmetro $\hat{F}$ - Embutimento . . . . . . . . 154

FIGURA6.61 Evolução do parâmetro $\hat{G}$ - Embutimento . . . . . . . . 154

FIGURA6.62 Evolução do parâmetro $\hat{H}$ - Embutimento ...... 155

FIGURA6.63 Evolução do parâmetro $\hat{N}$ - Embutimento . . . . . . . . 155

FIGURA6.64 Evolução do fator de correção $\Psi$. . . . . . . . . . . . . . 156

FIGURA6.65 Comparação da evolução das superfícies de escoamento 156 


\section{Lista de Tabelas}

TABELA3.1 Resumo da relações do modelo elasto-plástico unidimensional . . . . . . . . . . . . . . . . . . . . . . 40 40

TABELA6.1 Dados de material com modelo isotrópico . . . . . . . . 108

TABELA6.2 Dados de material com modelo anisotrópico . . . . . . . 111

TABELA6.3 Dados de material obtidos pelo ajuste . . . . . . . . . . 119

TABELA6.4 Dados de material . . . . . . . . . . . . 136

TABELA6.5 Dados de geometria do modelo . . . . . . . . . . . . . . 142

TABELA6.6 Dados de material do modelo . . . . . . . . . . . . . . . 142

TABELA6.7 Dados de geometria do modelo de embutimento . . . . . 150 


\section{Lista de Símbolos}

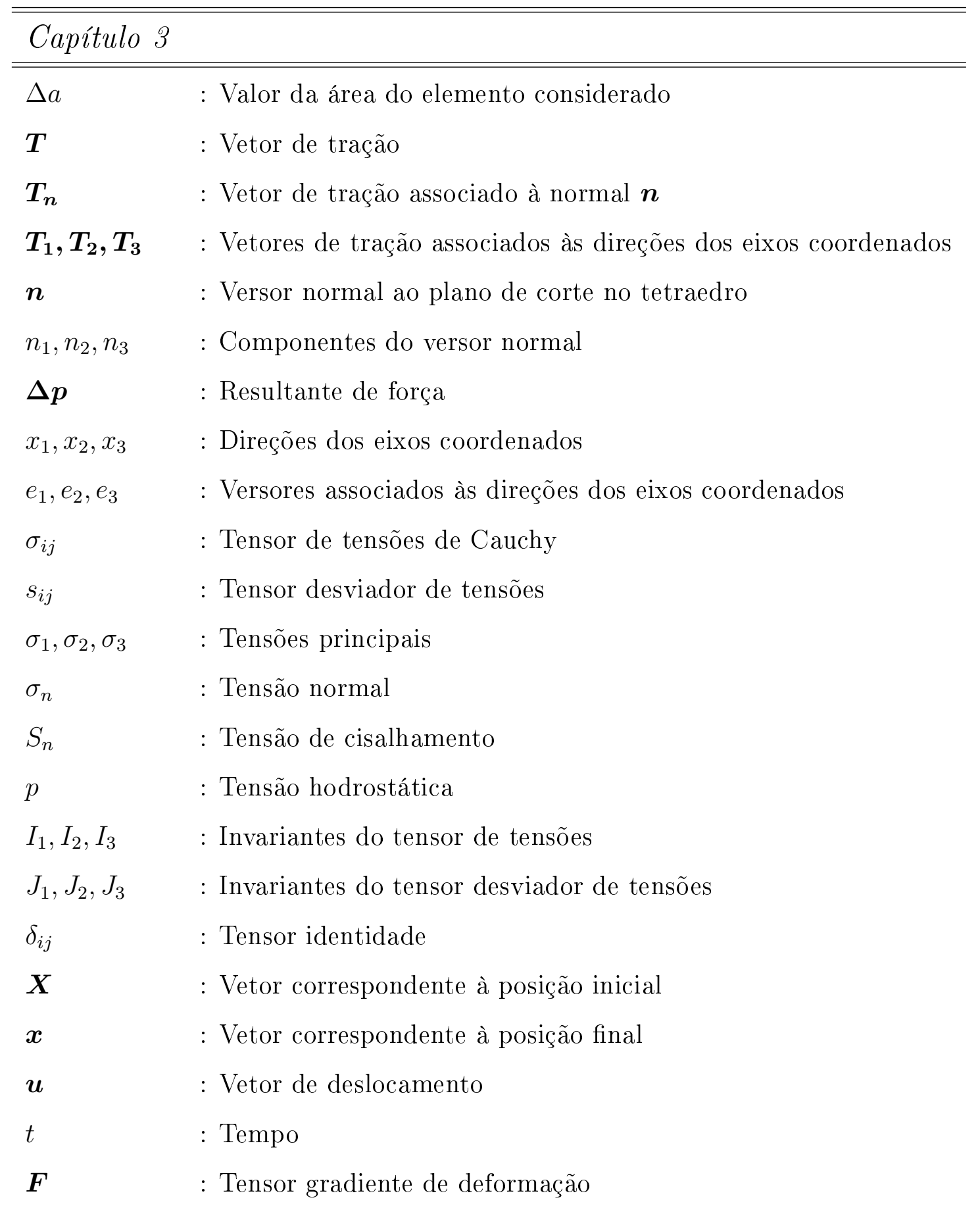




\begin{tabular}{|c|c|}
\hline$C$ & : Tensor de Cauchy-Green direito \\
\hline$b$ & : Tensor de Cauchy-Green esquerdo \\
\hline$E$ & : Tensor de Green \\
\hline$\varepsilon_{i j}$ & : Tensor de derformações \\
\hline$\varepsilon^{e}$ & : Parcela de deformação elástica \\
\hline$\varepsilon^{p}$ & : Parcela de deformação plástica \\
\hline$\hat{\varepsilon}$ & : Deformação nominal \\
\hline$\varepsilon$ & : Deformação verdadeira \\
\hline$\sigma_{o}$ & : Tensão de escoamento \\
\hline$\sigma_{e q}$ & : Tensão equivalente \\
\hline$\hat{\sigma}$ & : Tensão nominal \\
\hline$\sigma$ & : Tensão verdadeira \\
\hline$q_{i}$ & : Conjunto de variáveis internas \\
\hline$f$ & : Função de escoamento \\
\hline$E$ & : Módulo de elasticidade \\
\hline$E_{t}$ & : Módulo tangente \\
\hline$W^{p}$ & : Trabalho plástico \\
\hline$\alpha_{i j}$ & : Tensor das tensões de retorno \\
\hline$[M]$ & : Matriz de massa \\
\hline$[C]$ & : Matriz de amortecimento \\
\hline$[K]$ & : Matriz de rigidez \\
\hline$\left[\nwarrow \bar{K}_{\searrow}\right]$ & Matriz de rigidez efetiva diagonal \\
\hline$\left[{ }^{\nwarrow} M \searrow\right]$ & Matriz de massa diagonal \\
\hline$\left[\nwarrow C_{\searrow}\right]$ & Matriz de amortecimento diagonal \\
\hline$\{F\}$ & : Vetor de forças externas aplicadas \\
\hline$\{u\}$ & : Vetor dos deslocamentos nodais \\
\hline$\{\dot{u}\}$ & : Vetor das velocidades nodais \\
\hline$\{\ddot{u}\}$ & : Vetor das acelerações nodais \\
\hline$\Delta t$ & : Incremento de tempo \\
\hline
\end{tabular}




\begin{tabular}{ll}
\hline \hline Capítulo 4 & \\
\hline \hline$F, G, H, M, N, L$ & $:$ Parâmetros de anisotropia do critério de Hill \\
$R_{0}, R_{45}, R_{90}$ & $:$ Índices de anisotropia \\
$\Delta R$ & $:$ Índice de anisotropia planar \\
$R_{m}$ & $:$ Índice de anisotropia normal \\
$\alpha$ & $:$ Ângulo em relação à direção de laminação \\
$w$ & $:$ Largura final do CDP \\
$w_{o}$ & $:$ Largura inicial do CDP \\
$l$ & $:$ Comprimento final do CDP \\
$l_{o}$ & $:$ Comprimento inicial do CDP \\
$t$ & $:$ Espessura final do CDP \\
$t_{o}$ & $:$ Espessura inicial do CDP \\
$\varepsilon_{w}^{p}$ & $:$ Deformação plástica na largura \\
$\varepsilon_{t}^{p}$ & $:$ Deformação plástica na espessura
\end{tabular}




\begin{tabular}{ll}
\hline \hline Capítulo 5 & \\
\hline \hline$\alpha$ & $:$ Angulo em relação a direção de laminação \\
$m$ & $:$ Parâmetro de ductilidade \\
$C$ & $:$ Matriz constitutiva elástica \\
$E$ & $:$ Módulo de elasticidade \\
$v$ & $:$ Coeficiente de Poisson \\
$a_{i}$ & $:$ Componentes do vetor relacionados com a regra de fluxo \\
$w_{i j}$ & $:$ Coeficientes da matriz Caa $C$ \\
$Z_{1}$ & $:$ Escalar resultante do produto $a^{t} C a$ \\
$K_{0}, K_{45}, K_{90}$ & $:$ Parâmetros de proporcionalidade \\
$\beta_{i}^{\left(0^{\circ}\right)}, \beta_{i}^{\left(45^{\circ}\right)}, \beta_{i}^{\left(90^{\circ}\right)}$ & $:$ Coeficientes do sistema de equações \\
$\hat{F}, \hat{G}, \hat{H}, \hat{N}$ & $:$ Parâmetros evolutivos de anisotropia \\
$\sigma_{b}$ & $:$ Tensão de escoamento biaxial \\
$\Psi$ & $:$ Fator de correção \\
$F_{m}$ & $:$ Nova superfície de escoamento
\end{tabular}




\section{Resumo}

MALAVOLTA, A. T. (2008). Metodologia para determinação dos parâmetros utilizados em uma nova superfície de escoamento anisotrópica para processos de conformação de chapas metálicas. São Carlos, 2008. 168p. Tese (Doutorado) Escola de Engenharia de São Carlos, Universidade de São Paulo.

Este trabalho é definido a partir da elaboração de uma metodologia de cálculo para a determinação da evolução dos parâmetros de anisotropia em chapas metálicas e na definição de uma nova superfície de escoamento anisotrópica. A metodologia proposta é fundamentada nas relações incrementais entre tensão e deformação da teoria clássica da plasticidade utilizando-se do critério de escoamento de Hill e baseado em um estado particular de tensão-deformação comum em processos de conformação mecânica, principalmente em regiões da peça onde ocorram dobras. A nova superfície de escoamento é definida a partir da superfície de Hill original, porém ponderada por um fator de correção o qual contempla uma evolução anisotrópica do encruamento. Este fator de correção é definido em função dos parâmetros evolutivos de anisotropia determinados pela metodologia proposta e um conceito particular é então adotado para a complementação deste novo modelo de superfície de escoamento. A contribuição científica apresentada estabelece o desenvolvimento do conjunto de equações que permite determinar a evolução dos parâmetros de anisotropia com o carregamento plástico e adicionalmente permite avaliar a evolução da nova superfície servindo como indicativo da formabilidade do material. Os resultados teóricos são comparados e discutidos com evoluções obtidas via ensaio normalizado de anisotropia. 
Além disso é realizada a aplicação do procedimento proposto em conjunto com análises numéricas via método dos elementos finitos para dois casos de processos de conformação. Desta forma tem-se uma contribuição para a representação do fenômeno de anisotropia plástica dado por um modelo evolutivo, cuja aplicação tem interesse em aprimoramento de algoritmos computacionais bem como em aplicações de cunho experimental como validações, predições e aprimoramentos de processos de conformação e outros.

Palavras-Chave: Anisotropia, Plasticidade, Conformação Mecânica, Método dos Elementos Finitos. 


\section{Abstract}

MALAVOLTA, A. T. (2008). Methodology for determination of parameters applied in a new anisotropic yield surface for sheet metal forming processes. São Carlos, 2008. 168p. Thesis (Doctoral) - Escola de Engenharia de São Carlos, Universidade de São Paulo.

This work is aimed to the elaboration of a new approach for prediction of anisotropy parameters evolution in sheet metal as well as definition of a new anisotropic yield surface. This approach is based on incremental relation between stress and strain from classical plasticity theory by using the Hill-48 yield criteria. Also, it is based on a particular stress-strain state, common to bending regions found in several sheet forming processes. The new yield surface is derived from the original Hill criteria, which was modified by a correcting factor proposed to represent an anisotropic evolution of the continuing plastic loading. This factor is a strict function of the evolutive anisotropy parameters generated by the present methodology. From this point, is adopted a special concept in order to reach a complete definition of the new model for yield surfaces. The scientific contribution presents the development of a set of equations in order to predict the evolution of the anisotropy parameters as function of plastic loading, and additionally, it is taken this new yield surface as an evaluation of material formability degree. The theoretical results are discussed and compared with results obtained from standardized anisotropy tests. Besides, the proposed procedure is applied, aided by numerical analysis using the finite element method to simulate two cases of sheet forming processes. Therefore it is presented a contribution to the repre- 
sentation of plastic anisotropy phenomenon using an evolutive model. The main interests for practical application of this work range from improvement of computational algorithms as well as experimental tests investigations, which are related to validation of this model, prediction and improvement of sheet metal forming processes.

Keywords: Anisotropy, Plasticity, Metal Forming, Finite Element Method. 


\section{Capítulo 1}

\section{Introdução}

O Brasil detem uma das maiores reservas minerais do mundo e os processos de transformação desta matéria prima em produtos acabados representam um importante aspecto para garantir a competitividade dos produtos nacionais no mercado mundial. Dentre estes processos de transformação destaca-se a fabricação de componentes através dos processos de conformação mecânica de chapas metálicas.

Tais processos possibilitam a fabricação de peças com propriedades mecânicas de alta qualidade que atendem um compromisso entre resistência e tenacidade. Além disto, com o constante desenvolvimento de novos equipamentos e materiais, é possível obter-se a fabricação de peças com altas velocidades de produção e com uma perda mínima de material. Dentre os principais processos de conformação tem-se a laminação de chapas, forjamento, extrusão, trefilação, dobramento e a estampagem em geral.

No projeto de peças conformadas vários requisitos são necessários ao produto final. Por exemplo em peças conformadas que possuam uma função estrutural é necessário que a mesma tenha uma resistência mecânica mínima pré-estabelecida. Ao mesmo tempo é interessante que a peça apresente uma ductilidade que permita absorver uma sobrecarga, nos casos em que a tensão de escoamento é excedida, sem sofrer uma falha brusca. No caso de peças com utilização em estruturas 
secundárias, para se evitar rejeição, o produto não deve apresentar fissuras, rasgos ou estriç̧ões. Outro ponto importante em processos de conformação é o controle da variação de espessura da chapa. Em muitos produtos deve haver uma espessura mínima necessária para suportar os carregamentos.

Todas essas exigências funcionais estão relacionadas com a formabilidade do material da chapa. A formabilidade indica a capacidade da chapa em suportar as deformações decorrentes do processo de conformação e está estritamente relacionada com as propriedades mecânicas do material. Dentre os vários fatores que influenciam na formabilidade destaca-se o fenômeno de anisotropia plástica do material.

Isto reflete a motivação dada à execução deste trabalho, o qual busca estudar o fenômeno de anisotropia plástica em chapas metálicas. Um dos grandes desafios atuais na modelagem numérica dos processos de conformação dos metais é utilizar um modelo de material que represente de maneira satisfatória o comportamento da peça no processo em questão. Existem diversos modelos matemáticos que podem ser aplicados para caracterizar o comportamento anisotrópico elasto-plástico dos materiais. Mas devida a própria natureza complexa do fenômeno e com o constante desenvolvimento de novos materiais, tratamentos térmicos e processos de fabricação, não existem procedimentos bem estabelecidos para a representação anisotrópica do material.

Neste sentido, uma questão a ser considerada trata da determinação dos parâmetros de anisotropia que ajustem os modelos de encruamento e caracterizem satisfatoriamente o comportamento mecânico das peças conformadas. Esta questão orienta o principal objetivo do trabalho, definido pela apresentação de uma nova metodologia de determinação da evolução dos parâmetros de anisotropia em chapas metálicas em função do carregamento plástico e pela posterior definição de uma nova superfície de escoamento anisotrópica. O equacionamento gerado para o cálculo de evolução dos parâmetros de anisotropia é fundamentado nas equações incrementais entre tensão e deformação da Teoria da Clássica da Plasticidade utilizando o critério de escoamento de Hill. A nova superfície de escoamento proposta 
é definida a partir de um fator de correção, escrito em termos dos parâmetros de anisotropia evolutivos, o qual pondera a superfície de Hill original.

A partir da delimitação do trabalho com a definição de seu escopo, são apresentados a seguir os diversos capítulos da tese, organizados em função da revisão de conceitos, do desenvolvimento da metodologia, da definição da nova superfície proposta e da apresentação e discussão de resultados obtidos com a aplicação desta nova abordagem de tratamento da anisotropia.

\section{Capítulo 1: Introdução}

Neste tópico é apresentada a motivação e delimitação do trabalho a partir da visão geral e contextual do problema tratado, como orientação à organização do trabalho como um todo.

Capítulo 2: Objetivos

A partir da apresentação do escopo de estudo, são estabelecidos os diversos objetivos do trabalho. Tais objetivos foram estrategicamente organizados para a consecução do objetivo principal, que é a proposta de uma nova abordagem para o cálculo da evolução dos parâmetros de anisotropia e pela posterior definição de uma nova superfície de escoamento anisotrópica para chapas metálicas.

\section{Capítulo 3: Revisão Conceitual}

Este capítulo abrange uma revisão geral sobre os diversos tópicos relacionados com a Teoria Clássica da Plasticidade e a Mecânica dos Meios Sólidos e Contínuos a serem utilizados no decorrer do trabalho. Inicialmente são descritos alguns tópicos relacionados com os tensores de tensão e de deformação, critérios e superfícies de escoamento. Adicionalmente são apresentados alguns conceitos relativos à formulação e implementação computacional das relações incrementais entre tensão e deformação da teoria da plasticidade, com destaque para o algoritmo de previsão-correção. Ao final do capítulo uma síntese sobre o Método dos Elementos Finitos é apresentada como suporte conceitual ao uso deste método nos capítulos posteriores. 
Capítulo 4: Estado da Arte - Anisotropia

Neste capítulo é realizado um levantamento geral sobre o estado da arte dos aspectos relacionados com a anisotropia de chapas metálicas. Inicialmente é apresentada uma descrição geral sobre o fenômeno de anisotropia dos materiais e suas influências no comportamento mecânico em peças conformadas. A seguir é descrito o clássico critério de escoamento de Hill, como uma introdução ao problema matemático a ser resolvido posteriormente. Após esta introdução geral é apresentado um levantamento sobre o estado da arte de diversos estudos relacionados com a anisotropia, com destaque para a definição de superfícies de escoamento anisotrópicas e determinação experimental dos parâmetros de anisotropia e constantes de material associados com os modelos de encruamento utilizados.

Capítulo 5: Metodologia e Nova Superfície de Escoamento

Neste capítulo é apresentada a contribuição científica inédita do trabalho a qual é estabelecida através da proposta de uma nova metodologia para o cálculo da evolução dos parâmetros de anisotropia em chapas metálicas com o decorrer do carregamento plástico do material e pela definição de uma nova superfície de escoamento anisotrópica. A metodologia desenvolvida é baseada em um estado particular de tensão-deformação bastante comum nos processos de conformação, principalmente em regiões de peças conformadas onde ocorram dobras. A partir desta consideração, utilizando-se das equações incrementais entre tensão e deformação da teoria da plasticidade, um conjunto de equações que permitem o cálculo da evolução dos parâmetros de anisotropia é desenvolvido. A nova superfície de escoamento proposta é então escrita em função dos parâmetros evolutivos determinados pela metodologia, através de um fator de correção, o qual pondera a superfície de Hill original ao longo do carregamento.

Capítulo 6: Resultados e Discussões

Neste tópico são apresentados e discutidos os diversos resultados obtidos com a aplicação da metodologia e pela definição da nova superfície de escoamento. Inicialmente é apresentada uma validação do algoritmo de previsão-correção im- 
plementado externamente, como suporte para a determinação dos parâmetros evolutivos de anisotropia. Tal validação é realizada através da comparação entre as curvas de tensão obtidas pelo pacote comercial de elementos finitos Ansys 9.0 e o programa implementado. Em seguida são apresentados alguns resultados experimentais obtidos via ensaios normalizados para uma liga de alumínio aeronáutica Al 7475-O estudada. Estes resultados experimentais são utilizados como dados de entrada e como fonte de comparação com os resultados obtidos pela aplicação da metodologia. Adicionalmente, como exemplos de aplicação, são estudados um processo de dobramento em $V$ e o embutimento de um copo circular.

Capítulo 7: Conclusões e Sugestões para Trabalhos Futuros

Aqui são apresentadas as diversas conclusões extraídas a partir do desenvolvimento e do estudo do equacionamento proposto e dos resultados obtidos, além das demais reflexões acerca do trabalho. Finalmente, a partir das discussões e considerações apresentadas, são indicadas algumas sugestões para trabalhos futuros. 


\section{Capítulo 2}

\section{Objetivos}

O principal objetivo do trabalho consiste no desenvolvimento de uma metodologia para o cálculo de evolução dos parâmetros de anisotropia do critério de Hill com o carregamento plástico e na posterior definição de uma nova superfície de escoamento anisotrópica para chapas metálicas.

O desenvolvimento matemático para o cálculo de evolução dos parâmetros de anisotropia é fundamentado nas relações incrementais da Teoria Clássica da Plasticidade e baseado em um estado de tensão-deformação particular, comumente encontrado em processos de conformação de chapas principalmente em regiões da peça onde ocorram dobras. A nova superfície de escoamento proposta é definida a partir da superfície de Hill original, porém ponderada por um fator de correção o qual contempla uma evolução anisotrópica do encruamento. Este fator de correção é definido em função dos parâmetros evolutivos de anisotropia determinados pela metodologia proposta e um conceito particular é então adotado para a complementação deste novo modelo de superfície de escoamento.

A contribuição científica inédita é dada pela definição da nova superfície e pelo desenvolvimento matemático do conjunto de equações que resultam na evolução dos parâmetros de anisotropia em função do carregamento plástico. Desta forma busca-se representar o comportamento anisotrópico do material através de uma abordagem alternativa com um modelo evolutivo, em contraste com os modelos 
matemáticos atuais que assumem os parâmetros de anisotropia constantes com o decorrer do carregamento. Assim, o interesse maior está na possibilidade de aperfeiçoar a qualidade dos modelos numéricos de simulação de processos de conformação de chapas, a partir de um modelo matemático evolutivo que contemple uma melhor caracterização da anisotropia do material.

Para alcançar o objetivo principal, o trabalho foi organizado com várias metas descritas a seguir.

(a) Revisão conceitual dos diversos tópicos relacionados com a Teoria Clássica da Plasticidade e a Mecânica dos Meios Sólidos e Contínuos. Tais tópicos são necessários para a padronização e organização da elaboração da metodologia de cálculo de evolução dos parâmetros de anisotropia e para a definição da nova superfície de escoamento.

(b) Levantamento do estado da arte sobre os conceitos gerais relacionados com a anisotropia de chapas metálicas. Com isto pode-se buscar alguns indicativos atuais sobre o tratamento deste fenômeno.

(c) Apresentação da contribuição científica inédita do trabalho, na qual é desenvolvida uma nova metodologia de cálculo de evolução dos parâmetros de anisotropia do critério de Hill e definida uma nova superfície de escoamento anisotrópica.

(d) Desenvolvimento e implementação computacional de um algoritmo numérico para aplicação da metodologia proposta de cálculo de evolução dos parâmetros de anisotropia e para avaliação e comparação do comportamento da nova superfície de escoamento com o carregamento plástico.

(e) Execução de ensaios experimentais de caracterização de material, ensaio de tração, e determinação da evolução dos parâmetros de anisotropia através do ensaio de anisotropia convencional para posterior comparação com resultados teóricos obtidos a partir da metodologia proposta.

(f) Apresentação dos diversos resultados e discussões acerca dos dados obtidos a partir da aplicação da metodologia. Aplicação do procedimento em conjunto 
com exemplos de aplicação de alguns processos de conformação de chapas modelados pelo Método dos Elementos Finitos.

(g) Descrição das conclusões obtidas no trabalho, com destaque para as contribuições científicas e tecnológicas obtidas, as limitações observadas e sugestões para trabalhos futuros. 


\section{Capítulo 3}

\section{Revisão Conceitual}

Neste capítulo são tratados alguns conceitos gerais referentes a Mecânica dos Meios Sólidos e Contínuos e da Teoria Clássica da Plasticidade a serem utilizados posteriormente no desenvolvimento do equacionamento proposto para cálculo da evolução dos parâmetros de anisotropia e na definição da nova superfície de escoamento. A organização dos tópicos foi baseada em referências clássicas como: MALVERN (1969), MENDELSON (1968), JOHNSON e MELLOR (1962) e KHAN e HUANG (1995).

Inicialmente é apresentada a definição de tensões em corpos sólidos em conjunto com a dedução do tensor de tensões de Cauchy, as definições das tensões e direções principais, dos invariantes de tensão e da decomposição deste tensor em sua parcela hidrostática e desviadora. No tópico seguinte são apresentados alguns aspectos relativos ao tensor de deformações e as diversas interpretações matemáticas relacionadas com este conceito.

Em seguida são descritos os aspectos gerais da Teoria Clássica da Plasticidade com destaque às definições da superfície e critérios de escoamento e dos modelos de encruamento isotrópico, cinemático e combinado, usualmente utilizados para descrever o comportamento do material. Adicionalmente, como suporte à implementação computacional da metodologia proposta, é descrito um tópico denominado de Plasticidade Computacional, onde as diferentes variáveis rela- 
cionadas com o fenômeno da plasticidade são escritas em sua forma incremental para posterior implementação computacional. Ao final do capítulo é apresentado um tópico acerca do Método dos Elementos Finitos como suporte conceitual e para melhor entendimento dos modelos numéricos utilizados nos capítulos posteriores.

É importante destacar que os diferentes campos abordados neste tópico, que abrange desde a mecânica do contínuo, método dos elementos finitos e métodos numéricos; classicamente não apresentam uma notação matemática única e padronizada. No intuito de manter o desenvolvimento matemático o mais claro possível, são utilizadas ao longo deste trabalho as notações indicial, tensorial e matricial, sendo que cada uma destas notações é aplicada nos tópicos na forma em que são mais comumente encontradas na literatura clássica.

\subsection{Análise de tensões}

As tensões internas em corpos sólidos em equilíbrio sob um certo estado de carregamento são resultados da interação física entre suas porções interiores. Para desenvolver os conceitos de tensão é então necessário estudar a interação entre

forças aplicadas sobre uma região $R_{1}$ com a parte em contato remanescente $R_{2}$ em um corpo deformável conforme ilustrado na Figura 3.1.

Seja um elemento de área $\Delta a$ na vizinhança do ponto espacial $p$ cortado por um plano cuja normal é $\boldsymbol{n}$. Se a resultante de força nesta área é $\Delta \boldsymbol{p}$, o vetor de tração $\boldsymbol{T}_{n}$ correspondente à normal $\boldsymbol{n}$ no ponto $p$ é definido como:

$$
\boldsymbol{T}_{n}=\lim _{\Delta a \rightarrow 0} \frac{\Delta \boldsymbol{p}}{\Delta a}
$$

O estado de tensão do ponto $p$ é então caracterizado por infinitos vetores de tração correspondentes aos infinitos planos que podem cortar tal ponto. Felizmente é possível mostrar que se três vetores de tração $\boldsymbol{T}_{n}$ atuando sobre três planos mutuamente ortogonais entre si forem conhecidos, torna-se possível 
determinar-se um vetor de tração sobre qualquer outro plano contendo esse ponto.

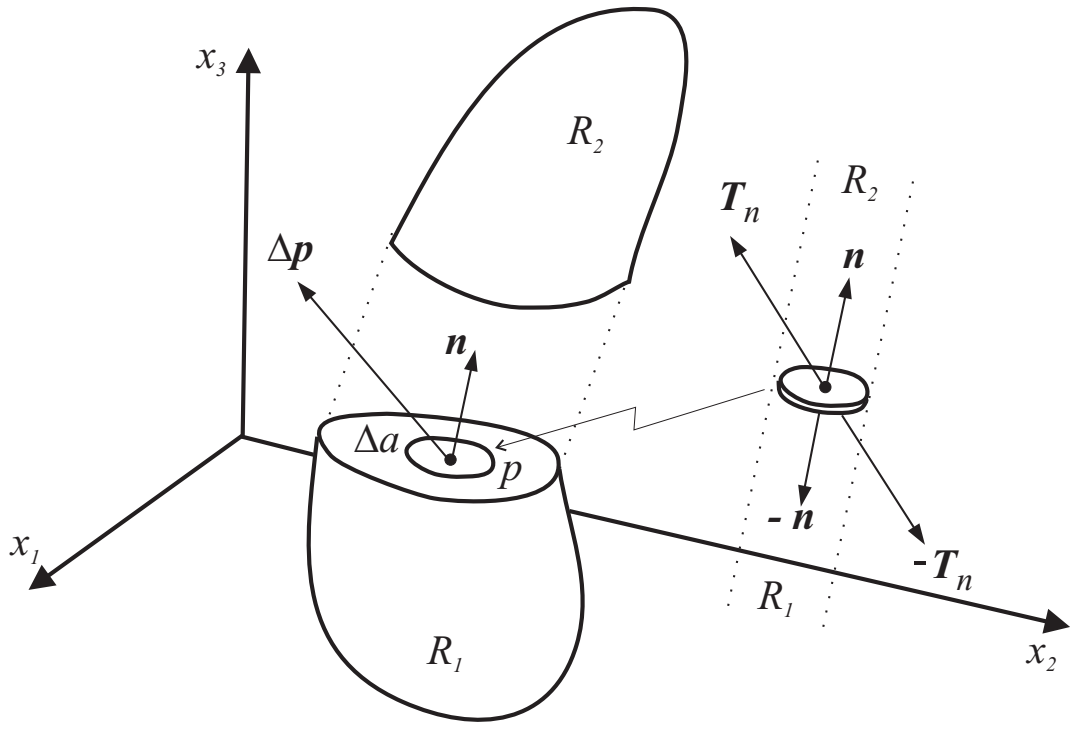

Figura 3.1: Definição do vetor de tração

Classicamente esta dedução é realizada a partir de um elemento tetraédrico infinitesimal representativo do ponto, conforme esquematizado na Figura 3.2.

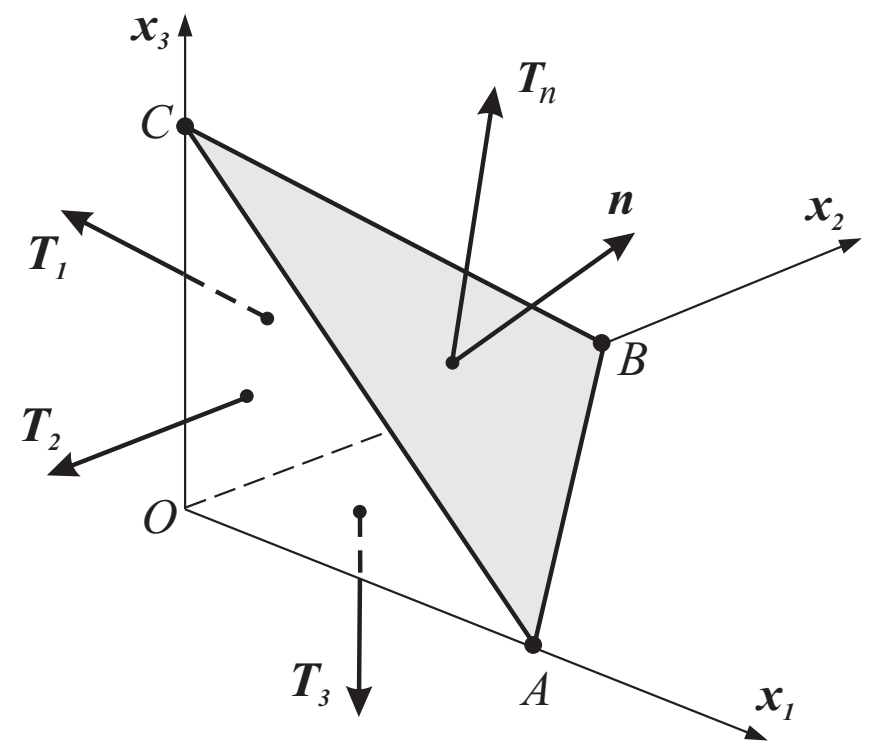

Figura 3.2: Vetor de tração atuando sobre um plano arbitrário

Neste elemento $O A B C$, os vetores $\boldsymbol{T}_{1}, \boldsymbol{T}_{2}, \boldsymbol{T}_{3}$ e $\boldsymbol{T}_{n}$ atuam sobre as faces $O B C, O A C, O A B$ e $A B C$ respectivamente. Seja o versor $\boldsymbol{n}$ normal à face $A B C$ 
com componentes dadas por $\left(n_{1}, n_{2}, n_{3}\right)$. Então, a partir da condição de equilíbrio pode-se mostrar que:

$$
\boldsymbol{T}_{n}=\boldsymbol{T}_{1} n_{1}+\boldsymbol{T}_{2} n_{2}+\boldsymbol{T}_{3} n_{3}
$$

A eq. 3.2 expressa o vetor de tração $\boldsymbol{T}_{n}$ associado à normal $\boldsymbol{n}$ em termos dos vetores atuando sobre os planos ortogonais aos três eixos coordenados $x_{1}, x_{2}$ e $x_{3}$ do ponto. Desta forma $\boldsymbol{T}_{1}, \boldsymbol{T}_{2}$ e $\boldsymbol{T}_{3}$ definem o estado de tensão do ponto completamente.

Por outro lado, os vetores $\boldsymbol{T}_{1}, \boldsymbol{T}_{2}$ e $\boldsymbol{T}_{3}$ associados com cada um dos planos também podem ser decompostos em componentes nas direções dos eixos coordenados. A Figura 3.3 ilustra a decomposição do vetor $\boldsymbol{T}_{1}$ atuando no plano normal à direção $x_{1}$. Neste caso tem-se uma componente normal $\sigma_{11}$ e duas componentes de cisalhamento, $\sigma_{12}$ e $\sigma_{13}$ nas direções $x_{1}, x_{2}$ e $x_{3}$ respectivamente. O mesmo se aplica para os planos restantes de forma que:

$$
\begin{aligned}
& \boldsymbol{T}_{1}=\sigma_{11} \boldsymbol{e}_{\mathbf{1}}+\sigma_{21} \boldsymbol{e}_{\mathbf{2}}+\sigma_{31} \boldsymbol{e}_{\mathbf{3}} \\
& \boldsymbol{T}_{2}=\sigma_{12} \boldsymbol{e}_{\mathbf{1}}+\sigma_{22} \boldsymbol{e}_{\mathbf{2}}+\sigma_{32} \boldsymbol{e}_{\mathbf{3}} \\
& \boldsymbol{T}_{3}=\sigma_{13} \boldsymbol{e}_{\mathbf{1}}+\sigma_{23} \boldsymbol{e}_{\mathbf{2}}+\sigma_{33} \boldsymbol{e}_{\mathbf{3}}
\end{aligned}
$$

onde $\boldsymbol{e}_{\boldsymbol{i}}$ representam os versores associados com as direções $x_{i}$.

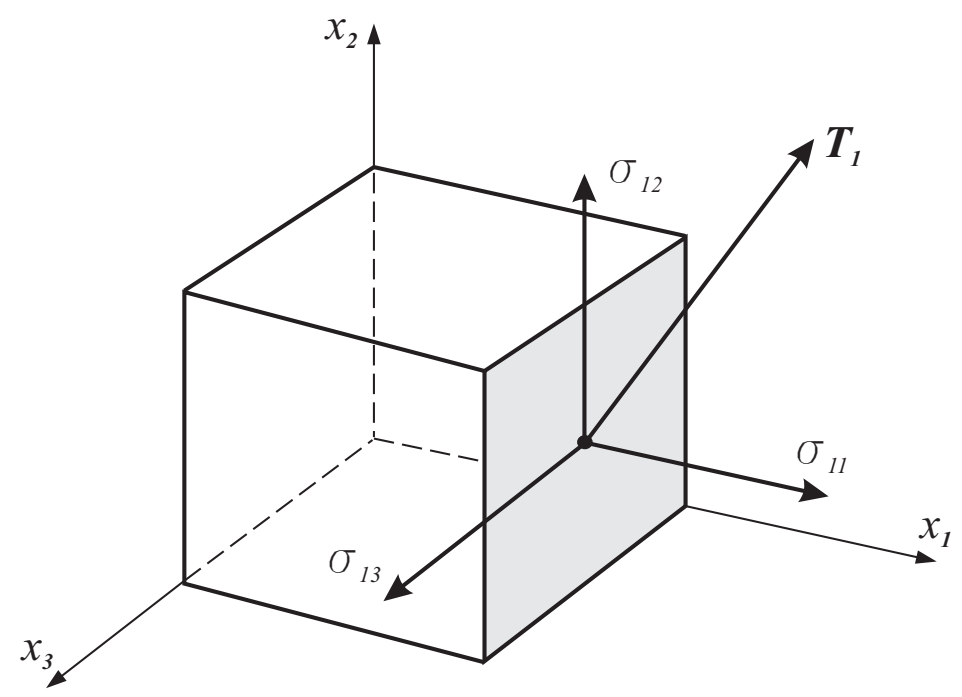

Figura 3.3: Decomposição do vetor de tração 
As eq. 3.3 a 3.5 anteiores podem ser compactadas de maneira mais conveniente em sua forma indicial:

$$
T_{i}=\sigma_{i j} \boldsymbol{e}_{j}
$$

O conjunto dos noves valores necessários para definir os vetores de tração $\boldsymbol{T}_{1}$, $\boldsymbol{T}_{2}$ e $\boldsymbol{T}_{3}$ é denominado de tensor de tensões de Cauchy, representado por $\sigma_{i j}$. Pode-se mostrar por meio das relações de equilíbrio de momento sobre o ponto material que este tensor é simétrico, ou seja, $\sigma_{i j}=\sigma_{j i}$. A eq. 3.7 expressa na forma matricial o tensor $\sigma_{i j}$ em duas representações usualmente utilizadas na literatura.

$$
\sigma_{i j}=\left[\begin{array}{ccc}
\sigma_{11} & \sigma_{12} & \sigma_{13} \\
\sigma_{21} & \sigma_{22} & \sigma_{23} \\
\sigma_{31} & \sigma_{32} & \sigma_{33}
\end{array}\right] \equiv\left[\begin{array}{ccc}
\sigma_{x x} & \sigma_{x y} & \sigma_{x z} \\
\sigma_{y x} & \sigma_{y y} & \sigma_{y z} \\
\sigma_{z x} & \sigma_{z y} & \sigma_{z z}
\end{array}\right]
$$

Conforme será apresentado, para o caso unidimensional a tensão de Cauchy pode ser interpretada como a força por unidade de área final corresponde à configuração deformada do carregamento. Por este motivo a tensão de Cauchy é usualmente chamada de tensão verdadeira, em contraste com a tensão nominal definida como a força por unidade de área original. Outras medidas de tensão também podem ser definidas, como a tensão de Piola-Kirchhoff de $1^{a}$ e $2^{a}$ espécie, tensão de Kirchhoff, tensão corrotacionais, entre outras. Estas outras definições de tensões fogem do escopo deste trabalho, o qual é delimitado no uso da tensão de Cauchy nos desenvolvimentos matemáticos realizados para alcançar os objetivos propostos.

As componentes $T_{i}$ do vetor de tração $\boldsymbol{T}$ atuando sobre um plano arbitrário com normal $\boldsymbol{n}$ em um dado ponto, podem ser escritas em termos das componentes do tensor de tensão $\sigma_{i j}$ conforme a eq. 3.8:

$$
T_{i}=\sigma_{i j} n_{j}
$$

Conforme observado na Figura 3.2, o vetor de tração $\boldsymbol{T}_{n}$ não necessariamente 
é perpendicular ao plano em que atua. Desta forma $\boldsymbol{T}$ pode ser decomposto em duas componentes, uma normal ao plano denominada de tensão normal $\sigma_{n}$, e outra paralela a este plano, chamada de tensão de cisalhamento $S_{n}$. A magnitude da tensão normal $\sigma_{n}$ é dada pela projeção do vetor $\boldsymbol{T}$ na direção da normal $\boldsymbol{n}$ ou seja, é dada pelo produto escalar entre esses dois vetores.

$$
\sigma_{n}=\boldsymbol{T} \cdot \boldsymbol{n}=T_{i} n_{i}
$$

Substituindo-se a eq. 3.8 na eq. 3.9 tem-se na forma indicial:

$$
\sigma_{n}=\sigma_{i j} n_{i} n_{j}
$$

No caso da tensão de cisalhamento $S_{n}$, a magnitude pode ser obtida a partir das relações entre os vetores $\boldsymbol{T}$ e $\sigma_{n}$, de forma que:

$$
S_{n}=\sqrt{T^{2}-\sigma_{n}^{2}}
$$

onde $T^{2}$ é dado por:

$$
T^{2}=\boldsymbol{T} \cdot \boldsymbol{T}=T_{i} T_{i}=\left(\sigma_{i j} n_{j}\right)\left(\sigma_{i k} n_{k}\right)=\sigma_{i j} \sigma_{i k} n_{j} n_{k}
$$

Para o desenvolvimento dos conceitos relacionados com as tensões e direções principais considere a situação em que o vetor de tração $\boldsymbol{T}$ está alinhado com a normal $\boldsymbol{n}$ de forma que $\boldsymbol{T}=\boldsymbol{\sigma}_{n}$ e $\boldsymbol{S}_{n}=0$. Neste caso a normal $\boldsymbol{n}$ é chamada de direção principal e a tensão $\sigma_{n}$ de tensão principal. Para um estado geral de tensões existe no mínimo três direções principais associadas ao ponto material analisado.

A determinação destas tensões e direções principais pode ser realizada desenvolvendo as relações conforme a seguir. Denotando por $\sigma$ a magnitude da tensão quando a componente $\boldsymbol{S}_{n}$ é nula tem-se as componentes do vetor de tração $\boldsymbol{T}$ 
dadas por:

$$
T_{i}=\sigma n_{i}
$$

Por outro lado, aplicando-se a eq. 3.8 para as componentes $T_{i}$ tem-se:

$$
\sigma_{i j} n_{j}=\sigma n_{i}
$$

De onde:

$$
\left(\sigma_{i j}-\sigma \delta_{i j}\right) n_{j}=0
$$

onde: $\delta_{i j}$ representa o tensor identidade definido como

$$
\delta_{i j}=\left\{\begin{array}{lll}
1 & \text { se } & i=j \\
0 & \text { se } & i \neq j
\end{array}\right.
$$

A condição necessária para garantir a solução não trivial do conjunto de equações dado pela expressão acima, é dada a partir da seguinte igualdade com o seu determinante:

$$
\left|\left(\sigma_{i j}-\sigma \delta_{i j}\right)\right|=0
$$

A eq. 3.16 pode ser expandida de forma que a seguinte equação cúbica, também conhecida como equação característica, é obtida:

$$
\sigma^{3}-I_{1} \sigma^{2}+I_{2} \sigma-I_{3}=0
$$

As raízes da equação característica denominadas por $\left(\sigma_{1}, \sigma_{2}, \sigma_{3}\right)$ correspondem as tensões principais e suas direções principais associadas podem ser determinadas a partir da eq. 3.14. Os termos $I_{1}, I_{2}$ e $I_{3}$ são chamados de primeiro, segundo e terceiro invariantes do tensor de tensões, respectivamente, e seus valores são independentes do sistema de coordenadas. 
Os invariantes podem ser escritos em termos das tensões principais como:

$$
\begin{aligned}
& I_{1}=\sigma_{1}+\sigma_{2}+\sigma_{3} \\
& I_{2}=\sigma_{1} \sigma_{2}+\sigma_{2} \sigma_{3}+\sigma_{1} \sigma_{3} \\
& I_{3}=\sigma_{1} \sigma_{2} \sigma_{3}
\end{aligned}
$$

Outro aspecto importante relacionado ao tensor de tensões $\sigma_{i j}$ trata de sua decomposição em dois tensores, um chamado de hidrostático ou esférico e outro de desviador $s_{i j}$ conforme a eq. 3.21:

$$
\sigma_{i j}=p \delta_{i j}+s_{i j}
$$

onde: $p \delta_{i j}$ é chamado de tensor hidrostático, sendo que $p$ representa a tensão hidrostática dada por:

$$
p=\frac{1}{3}\left(\sigma_{x x}+\sigma_{y y}+\sigma_{z z}\right)=\frac{1}{3}\left(\sigma_{1}+\sigma_{2}+\sigma_{3}\right)
$$

O tensor desviador de tensões $s_{i j}$ é calculado pela subtração da parcela hidrostática do tensor de tensões $\sigma_{i j}$, de forma que:

$$
s_{i j}=\sigma_{i j}-p \delta_{i j}=\left[\begin{array}{ccc}
s_{x x} & s_{x y} & s_{x z} \\
s_{y x} & s_{y y} & s_{y z} \\
s_{z x} & s_{z y} & s_{z z}
\end{array}\right]=\left[\begin{array}{ccc}
\sigma_{x x}-p & \sigma_{x y} & \sigma_{x z} \\
\sigma_{y x} & \sigma_{y y}-p & \sigma_{y z} \\
\sigma_{z x} & \sigma_{z y} & \sigma_{z z}-p
\end{array}\right]
$$

Da mesma forma que para o tensor $\sigma_{i j}$, as tensões principais $s_{1}, s_{2}$ e $s_{3}$ do tensor desviador de tensões $s_{i j}$ podem ser obtidas pela solução da seguinte equação característica:

$$
s^{3}-J_{1} s^{2}-J_{2} s-J_{3}=0
$$

onde: $J_{1}, J_{2}$ e $J_{3}$ são os invariantes do tensor desviador de tensões $s_{i j}$ os quais 
podem ser relacionados com os invariantes do tensor $\sigma_{i j}$ como:

$$
\begin{aligned}
& J_{1}=0 \\
& J_{2}=\frac{I_{1}^{2}}{3}-I_{2} \\
& J_{3}=\frac{2 I_{1}^{3}}{27}-\frac{I_{2} I_{1}}{3}+I_{3}
\end{aligned}
$$

Estas definições indicam que uma vantagem de se trabalhar com o tensor desviador é que seu primeiro invariante é nulo. Além disto, os invariantes $J_{2}$ e $J_{3}$ são particularmente importantes no desenvolvimento de critérios de escoamento da teoria da plasticidade.

Com a determinação das tensões principais e a decomposição do tensor de tensões $\sigma_{i j}$ em sua parcela hidrostática e desviadora, torna-se possível definir um espaço de tensões no qual as direções das três tensões principais são utilizadas como eixos coordenados. Cada ponto neste domínio com coordenadas $\left(\sigma_{1}, \sigma_{2}, \sigma_{3}\right)$ corresponde a um possível estado de tensão. Esta representação é conhecida como espaço de tensão de Haigh-Westergaard e é esquematizada na Figura 3.4.

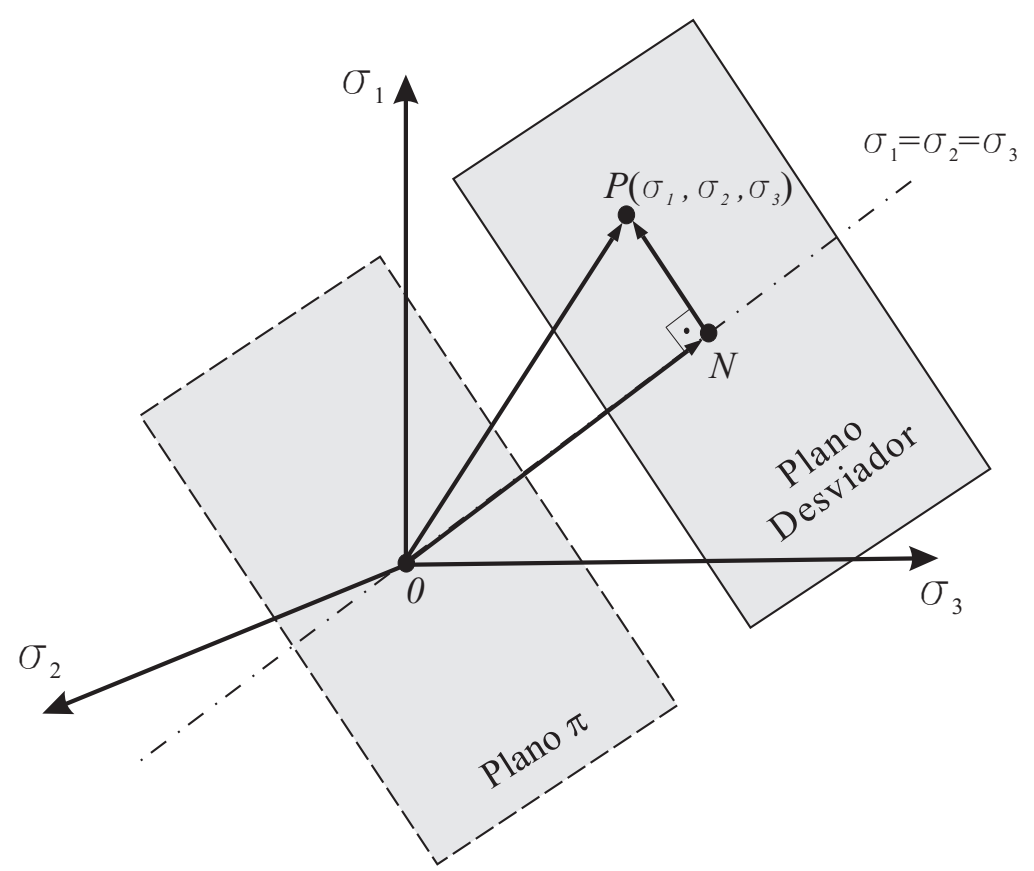

Figura 3.4: Decomposição do estado de tensão 
A partir da figura, considere o vetor $O N$ passando pela origem e fazendo o mesmo ângulo com os eixos coordenados de forma que todos pontos ao longo desta linha representem um estado hidrostático de tensão, ou seja, $\sigma_{1}=\sigma_{2}=\sigma_{3}$ e com tensões desviadoras nulas, $s_{1}=s_{2}=s_{3}=0$. Qualquer plano perpendicular à esta direção é chamado de plano octaédrico ou desviador e pode ser representado pela equação:

$$
\sigma_{1}+\sigma_{2}+\sigma_{3}=\sqrt{3} d
$$

onde $d$ é a distância do plano até a origem. Quando $d=0$ este plano é denominado de plano $\pi$.

Qualquer estado arbitrário de tensão pode ser representado pela soma da parcela hidrostática, representada pelo vetor $O N$, com a parcela desviadora representada por um vetor $N P$ sobre o plano desviador.

Assim foram apresentados alguns conceitos básicos acerca das tensões de Cauchy, as quais serão utilizadas ao longo do trabalho. A seguir são descritos alguns conceitos relacionados com o tensor de deformações.

\subsection{Análise de deformações}

As medidas de deformação em um corpo contínuo deformável estão relacionadas com o estudo da variação da posição relativa entre quaisquer dois pontos deste corpo. É importante destacar que este estudo representa um problema puramente geométrico, independente das propriedades do material em questão. Em geral duas abordagens podem ser aplicadas para descrever as deformações em corpos contínuos, a primeira é conhecida como descrição material ou Lagrangiana e a segunda chamada de descrição espacial ou Euleriana. Um breve resumo relacionado com estas abordagens é descrito a seguir.

Considere um corpo ocupando a região $R_{0}$ num instante inicial $t_{0}$ que passa ocupar a região $R$ num instante subsequente $t$. Todas as partículas deste corpo são assumidas estarem continuamente distribuídas e a configuração $R$ é deformada 
em relação a configuração inicial $R_{0}$. Com isso pontos, linhas, áreas e volumes em $R_{0}$ podem ser transformados em seus correspondentes pares na configuração R. A idéia principal do estudo cinemático dos corpos deformáveis é determinar a relação entre estes entes geométricos nas duas configurações.

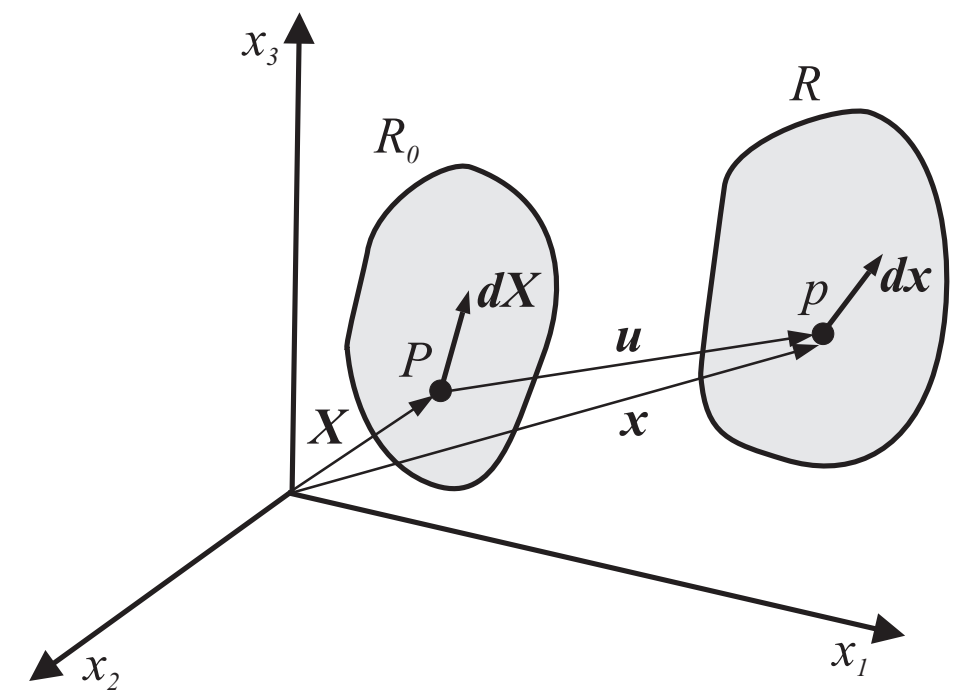

Figura 3.5: Configuração original e deformada de um corpo

Seja uma partícula $P$ do corpo com posição inicial $\boldsymbol{X}$ no instante $t_{0}$, que passa a ocupar a posição $\boldsymbol{x}$ no instante $t$ e é denotada por $p$, conforme ilustrado na Figura 3.5. O movimento deste ponto pode ser descrito introduzindo-se o vetor de deslocamentos $\boldsymbol{u}$ que relaciona $\boldsymbol{X}$ à $\boldsymbol{x}$ como:

$$
\boldsymbol{x}=\boldsymbol{X}+\boldsymbol{u}
$$

Na descrição material ou Lagrangiana, o vetor de deslocamento $\boldsymbol{u}$ é representado como uma função de $\boldsymbol{X}$ e $t$, conforme eq. 3.30. Alternativamente a descrição espacial ou Euleriana escreve o deslocamento $\boldsymbol{u}$ como uma função de $\boldsymbol{x}$ e $t$, conforme eq. 3.31.

$$
\begin{aligned}
\boldsymbol{u}(\boldsymbol{X}, t) & =\boldsymbol{x}(\boldsymbol{X}, t)-\boldsymbol{X} \\
\boldsymbol{u}(\boldsymbol{x}, t) & =\boldsymbol{x}-\boldsymbol{X}(\boldsymbol{x}, t)
\end{aligned}
$$


É importante observar que as equações anteriores têm significados físicos diferentes. A eq. 3.30 expressa o deslocamento do ponto com posição inicial $\boldsymbol{X}$ na configuração de referência no instante $t$. Por outro lado a eq. 3.31 representa o deslocamento de qualquer ponto que esteja ocupando a posição $\boldsymbol{x}$ no instante t. Ou seja, na descrição material uma partícula qualquer com posição $\boldsymbol{X}$ na configuração de referência é seguida ao longo do tempo, enquanto que na descrição espacial é estudado um ponto fixo no espaço na qual diferentes partículas podem ocupar esta posição em diferentes instantes de tempo.

Para determinar a relação entre elementos de linha é necessário considerar um elemento de linha no ponto $\boldsymbol{X}$ denotada por $d \boldsymbol{X}$ e seu par correspondente na configuração deformada $d \boldsymbol{x}$. Esta relação pode ser obtida definindo-se o seguinte tensor, denominado de tensor gradiente de deformação $F$ como:

$$
F=\frac{\partial \boldsymbol{x}}{\partial \boldsymbol{X}}
$$

O tensor gradiente de deformação é um operador linear que mapeia cada elemento linha da configuração $R_{0}$ à seu par correspondente na configuração $R$. Utilizando-se as equações anteriores, o tensor $\boldsymbol{F}$ pode ser reescrito em termos do campo de deslocamentos como:

$$
\boldsymbol{F}=\boldsymbol{I}+\nabla \boldsymbol{u}
$$

onde: $\boldsymbol{I}$ é tensor identidade e $\nabla$ o operador diferencial gradiente.

Da mesma forma que para os elementos de linha $d \boldsymbol{X}$ e $d \boldsymbol{x}$, as relações de elementos de área e de volume entre a configuração original e deformada também podem ser obtidas a partir do tensor gradiente de deformação.

Com a determinação das relações entre a configuração original e deformada, torna-se possível definir algumas medidas de deformação. Uma medida geral de deformação, considera a mudança do produto escalar de dois vetores $d \boldsymbol{X}_{1}$ e $d \boldsymbol{X}_{2}$ na configuração inicial, para $d \boldsymbol{x}_{1}$ e $d \boldsymbol{x}_{2}$ na configuração deformada. Esta alteração envolve os estiramentos, que representam as mudanças no comprimento, 
e a alteração do ângulo entre os vetores. Utilizando a definição do tensor gradiente de deformação $\boldsymbol{F}$ pode-se chegar a seguinte relação:

$$
d \boldsymbol{x}_{1} \cdot d \boldsymbol{x}_{2}=d \boldsymbol{X}_{1} \cdot \boldsymbol{C} d \boldsymbol{X}_{2}
$$

onde $\boldsymbol{C}$ é denominado de tensor de deformação de Cauchy-Green direito que é dado em termos do tensor gradiente de deformação como:

$$
\boldsymbol{C}=\boldsymbol{F}^{T} \boldsymbol{F}
$$

Alternativamente o produto escalar dos vetores da configuração inicial também pode ser escrito em termos dos vetores da configuração de referência como:

$$
d \boldsymbol{X}_{1} \cdot d \boldsymbol{X}_{2}=d \boldsymbol{x}_{1} \cdot \boldsymbol{b}^{-1} d \boldsymbol{x}_{2}
$$

onde $\boldsymbol{b}$ é o tensor de deformação de Cauchy-Green esquerdo ou tensor de Finger e é dado em termos do tensor gradiente de deformação como:

$$
\boldsymbol{b}=\boldsymbol{F} \boldsymbol{F}^{T}
$$

Note que o tensor $\boldsymbol{C}$ opera sobre os vetores da configuração de referência e por isso é chamado de tensor material. Por outro lado, o tensor $\boldsymbol{b}$ atua sobre o vetores da configuração deformada e assim é chamado de tensor espacial. Vários aspectos da deformação são descritos a partir dos tensores de Cauchy-Green. Porém podese observar que para um movimento de corpo rígido estes tensores não assumem o valor nulo conforme usualmente esperado. No caso de movimento de corpo rígido tem-se $\boldsymbol{C}=\boldsymbol{I}$ e $\boldsymbol{b}=\boldsymbol{I}$.

Esta desvantagem pode ser compensada definindo-se outro tensor de deformação conhecido como tensor de Green, conforme a eq. 3.38:

$$
\boldsymbol{E}=\frac{1}{2}(\boldsymbol{C}-\boldsymbol{I})
$$


Utilizando-se as definições dos tensores $\boldsymbol{F}$ e $\boldsymbol{C}$, o tensor de Green também pode ser escrito em termos do campo de deslocamentos como:

$$
\boldsymbol{E}=\nabla^{s} \boldsymbol{u}+\frac{1}{2} \nabla \boldsymbol{u}^{t} \nabla \boldsymbol{u}
$$

onde: $\nabla^{s}$ representa o operador gradiente simétrico.

No caso de pequenas deformações os termos de alta ordem do produto da eq. 3.39 podem ser desprezados. Neste caso a diferença entre a descrição espacial e material não é significativa e o tensor de deformações passa a ser denotado por $\varepsilon_{i j}$ cujas componentes são usualmente escritas conforme a eq. 3.40:

$$
\varepsilon_{i j}=\nabla^{s} \boldsymbol{u}=\left[\begin{array}{ccc}
\varepsilon_{x x} & \varepsilon_{x y} & \varepsilon_{x z} \\
\varepsilon_{y x} & \varepsilon_{y y} & \varepsilon_{y z} \\
\varepsilon_{z x} & \varepsilon_{z y} & \varepsilon_{z z}
\end{array}\right]
$$

O tensor de deformações $\varepsilon_{i j}$ pode ser escrito em termos do vetor de deslocamentos $\boldsymbol{u}$ a partir de suas componentes $u, v, w$ correspondentes as direções cartesianas $x, y, z$ respectivamente, conforme a eq. 3.41 :

$$
\varepsilon_{i j}=\left[\begin{array}{ccc}
\frac{\partial u}{\partial x} & \frac{1}{2}\left(\frac{\partial u}{\partial y}+\frac{\partial v}{\partial x}\right) & \frac{1}{2}\left(\frac{\partial u}{\partial z}+\frac{\partial w}{\partial x}\right) \\
\frac{1}{2}\left(\frac{\partial u}{\partial y}+\frac{\partial v}{\partial x}\right) & \frac{\partial v}{\partial y} & \frac{1}{2}\left(\frac{\partial v}{\partial z}+\frac{\partial w}{\partial y}\right) \\
\frac{1}{2}\left(\frac{\partial u}{\partial z}+\frac{\partial w}{\partial x}\right) & \frac{1}{2}\left(\frac{\partial v}{\partial z}+\frac{\partial w}{\partial y}\right) & \frac{\partial w}{\partial z}
\end{array}\right]
$$

Na análise de tensões, as forças externas e as tensões internas no corpo devem estar em equilíbrio, enquanto que na análise de deformações algumas restrições devem ser impostas nas componentes de deformação para que o corpo deformado permaneça contínuo. Essas restrições são chamadas de condições de compatibilidade e são dadas por: 


$$
\begin{aligned}
\frac{\partial^{2} \varepsilon_{x}}{\partial y^{2}}+\frac{\partial^{2} \varepsilon_{y}}{\partial x^{2}} & =2 \frac{\partial^{2} \varepsilon_{x y}}{\partial x \partial y} \\
\frac{\partial^{2} \varepsilon_{y}}{\partial z^{2}}+\frac{\partial^{2} \varepsilon_{z}}{\partial y^{2}} & =2 \frac{\partial^{2} \varepsilon_{y z}}{\partial y \partial z} \\
\frac{\partial^{2} \varepsilon_{z}}{\partial x^{2}}+\frac{\partial^{2} \varepsilon_{x}}{\partial z^{2}} & =2 \frac{\partial^{2} \varepsilon_{z x}}{\partial z \partial x} \\
\frac{\partial}{\partial x}\left(-\frac{\partial \varepsilon_{y z}}{\partial x}+\frac{\partial \varepsilon_{z x}}{\partial y}+\frac{\partial \varepsilon_{x y}}{\partial z}\right) & =\frac{\partial^{2} \varepsilon_{x}}{\partial y \partial z} \\
\frac{\partial}{\partial y}\left(-\frac{\partial \varepsilon_{z x}}{\partial y}+\frac{\partial \varepsilon_{x y}}{\partial z}+\frac{\partial \varepsilon_{y z}}{\partial x}\right) & =\frac{\partial^{2} \varepsilon_{y}}{\partial z \partial x} \\
\frac{\partial}{\partial z}\left(-\frac{\partial \varepsilon_{x y}}{\partial z}+\frac{\partial \varepsilon_{y z}}{\partial x}+\frac{\partial \varepsilon_{z x}}{\partial y}\right) & =\frac{\partial^{2} \varepsilon_{z}}{\partial x \partial y}
\end{aligned}
$$

Essas seis equações são necessárias e suficientes para assegurar que as componentes de deformação gerem um campo de deslocamentos contínuo em uma determinada região do corpo estudado.

Conforme visto, da mesma maneira que para o tensor de tensões, a definição do tensor de deformações não é única. O requisito básico para este tensor é descrever completamente o estado de deformação de qualquer ponto material incluindo os estiramentos e as distorções em qualquer direção. Com base nestas condições, outros tipos de tensores de deformação também podem ser definidos. Porém, o presente trabalho limita os seus estudos no âmbito das pequenas deformações de forma que o tensor $\varepsilon_{i j}$ definido na eq. 3.40, é utilizado no decorrer do trabalho.

\subsection{Plasticidade clássica}

Neste tópico são formalizados os principais conceitos referentes à Teoria Clássica da Plasticidade. Tal revisão conceitual é necessária para um melhor entendimento dos mecanismos de deformação plástica nos processos de conformação e no desenvolvimento de modelos matemáticos representativos deste fenômeno. Esta revisão é organizada conforme os trabalhos de HILL(1950), CHEN e HAN (1988) e LUBLINER (1990), entre outros. 
A abordagem estudada no presente trabalho é baseada no enfoque macroscópico do fenômeno. No âmbito macroscópico, a teoria da plasticidade busca descrever por meio de modelos matemáticos, o comportamento das relações entre tensões e deformações observadas experimentalmente. Usualmente, o ensaio normalizado de tração em corpos de prova uniaxiais é aplicado para caracterização de algumas propriedades do material utilizadas nestes modelos. Para descrever o comportamento da curva obtida no ensaio, são definidas tensões e deformações nominais como:

$$
\begin{aligned}
\hat{\sigma} & =\frac{P}{A_{0}} \\
\hat{\varepsilon} & =\frac{L-L_{0}}{L_{0}}
\end{aligned}
$$

onde: $P$ é carga axial aplicada, $A_{0}$ é a área inicial da secção tranversal, $L_{0}$ e $L$ são os comprimentos inicial e final do corpo de prova respectivamente.

Entretando, os modelos matemáticos clássicos são apresentados principalmente em termos de tensões e deformações verdadeiras definidas como:

$$
\begin{aligned}
\sigma & =\frac{P}{A} \\
\varepsilon & =\int_{L_{0}}^{L} \frac{d L}{L}=\ln \left(\frac{L}{L_{0}}\right)
\end{aligned}
$$

onde: $A$ é a área da secção transversal e $L$ o comprimento do corpo de prova medidos na configuração deformada e atualizados conforme a circunstância do carregamento.

Usualmente a tensão verdadeira dada pela eq. 3.50 é denominada de tensão de Cauchy, e a deformação verdadeira calculada conforme a eq. 3.51 é denominada de deformação logarítmica ou deformação de Hencky.

A Figura 3.6 representa de forma esquemática o diagrama de tensão-deformação típico para a maioria dos metais submetidos ao ensaio uniaxial de tração. Pode ser observado que inicialmente a relação entre $\sigma$ e $\varepsilon$ é linear, até o nível de tensão alcançar o ponto $\sigma_{y 0}$ denominado de ponto de escoamento inicial. Além 
deste ponto à relação entre $\sigma$ e $\varepsilon$ não obedece mais a teoria da elasticidade e o material entra no regime plástico.

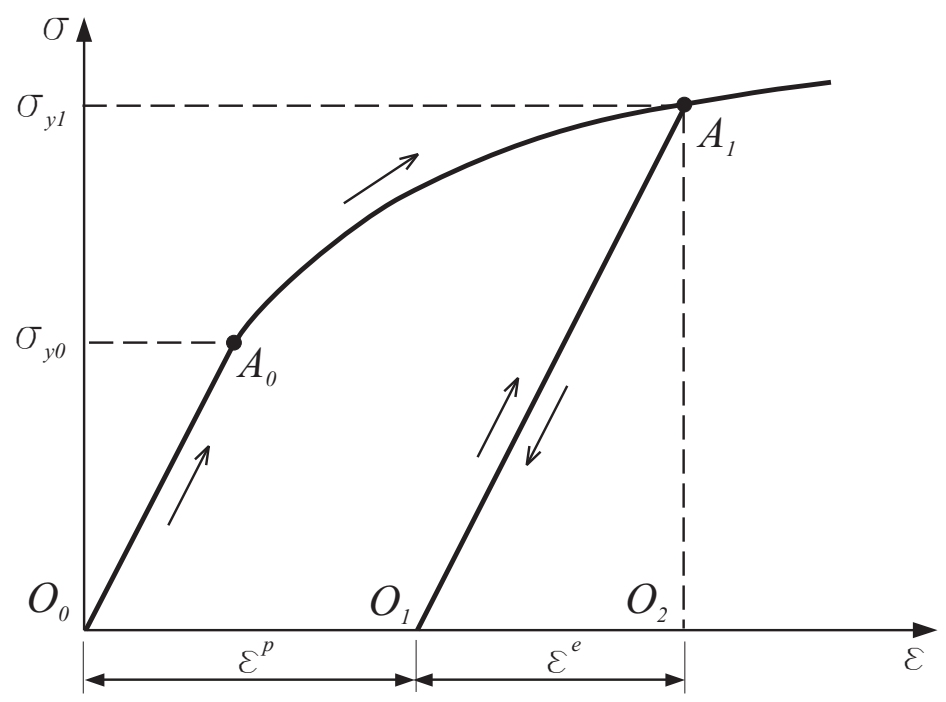

Figura 3.6: Diagrama esquemático de tensão-deformação

Na região plástica, a deformação total $O_{0} O_{2}$ em um ponto arbritário $A_{1}$, é dada pela soma da deformação plástica $O_{0} O_{1}$ e elástica $O_{1} O_{2}$. Esta consideração pode ser generalizada para um estado geral de deformações $\varepsilon_{i j}$ e representa uma regra básica usada na teoria da plasticidade conhecida como decomposição aditiva do tensor de deformações.

A deformação plástica está associada com a dissipação de energia e é um processo irreversível. Este fato pode ser observado quando o descarregamento ocorre em um determinado instante caracterizado por um ponto $A_{1}$. Neste caso apenas a parcela de deformação elástica, $\varepsilon^{e}$, é recuperada enquanto que a parcela de deformação plástica, $\varepsilon^{p}$, permanece após a remoção da carga. A área do triângulo $O_{1} A_{1} O_{2}$ representa a parcela de energia elástica recuperável, enquanto que a área $O_{0} A_{0} A_{1} O_{1}$ representa a parcela de energia dissipada durante o processo, produzindo a deformação plástica $\varepsilon^{p}$. Devida sua natureza dissipativa, o processo de deformação plástica é dependente do histórico de carregamento, path dependent. Com isso as relações constitutivas relacionadas com a deformação plástica são usualmente escritas em termos de equações diferenciais ou na sua forma incremental. 
Outro aspecto experimental observado no comportamento plástico dos materiais está associado com o escoamento na compressão. Para a maioria dos metais, a curva de tensão-deformação em compressão simples é a mesma da de tração. Por outro lado, quando o material é tracionado além do limite elástico e posteriormente descarregado e recarregado em compressão, a curva tensão-deformação obtida em compressão pode ser significativamente diferente daquela obtida sem o pré-carregamento. Este fenômeno é conhecido como efeito Bauschinger e está ilustrado na Figura 3.7. Pela curva, a nova tensão de escoamento em compressão no ponto $B$ denotada por $\sigma_{y B}$ é menor que a tensão de escoamento inicial em tração $\sigma_{o}$ e muito menor que a tensão subsequente de escoamento devido ao encruamento do ponto $A$. Os modelos matemáticos que buscam representar este comportamento são denominados de modelos cinemáticos de encruamento.

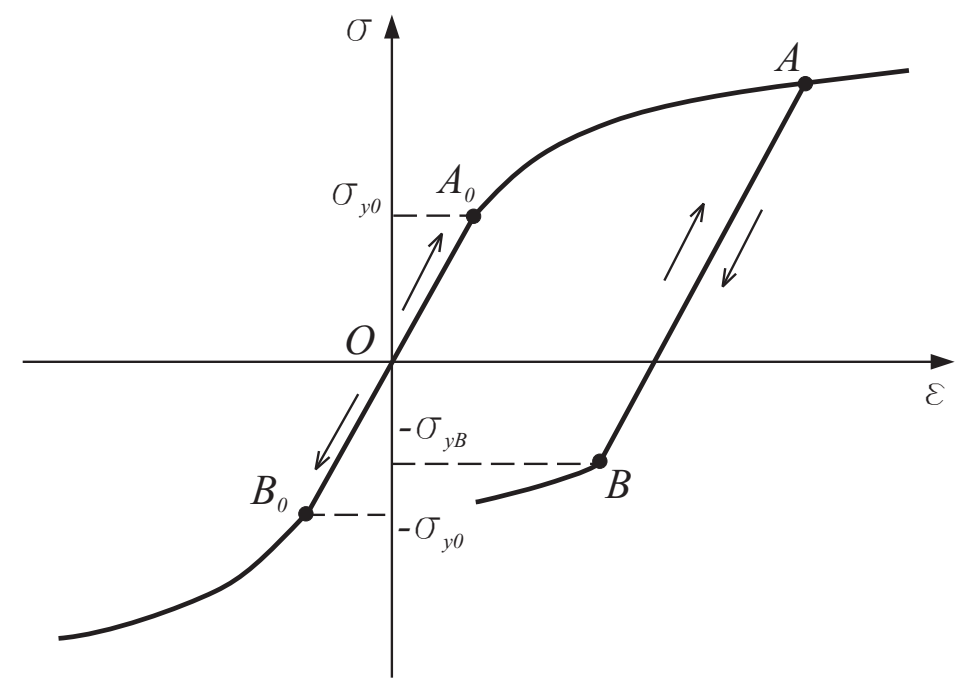

Figura 3.7: Representação do efeito Bauschinger

Conforme apresentado, para a maioria dos materiais, após o ponto de escoamento inicial ser alcançado, a curva tensão-deformação continua crescente. Com isso a tensão de escoamento subsequente também cresce com a deformação caracterizando o efeito conhecido como encruamento. Como as curvas tensãodeformação apresentam formas distintas de encruamento dependendo do tipo de material, torna-se conveniente idealizar alguns destes comportamentos. $\mathrm{Na}$ Figura 3.8 são ilustrados os principais tipos de modelos idealizados para descrever o comportamento elasto-plástico do material. 

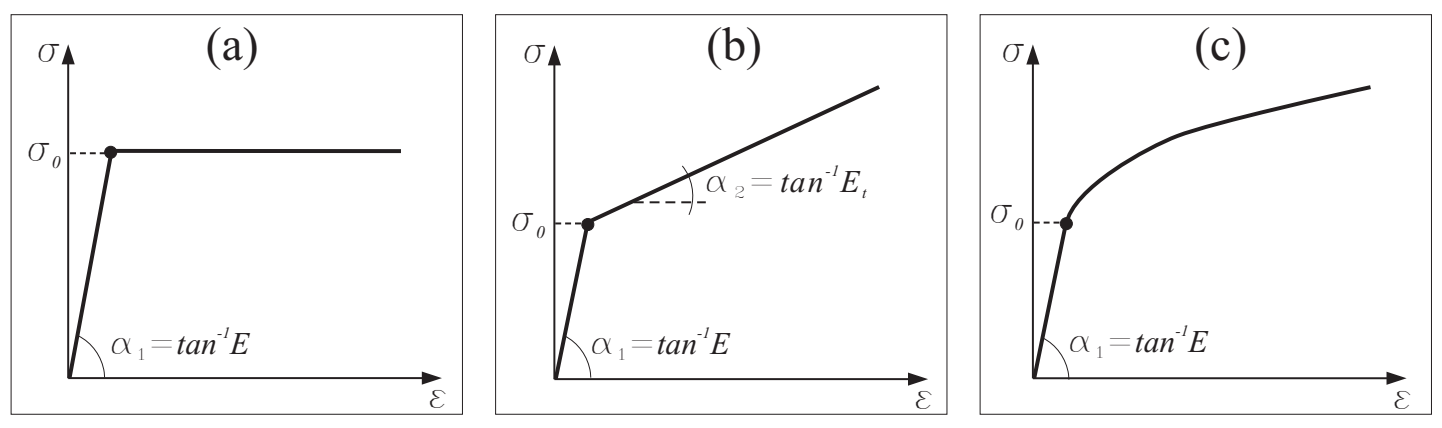

Figura 3.8: Curvas idealizadas de encruamento

O caso (a) corresponde ao chamado modelo elástico perfeitamente plástico. Neste modelo o material tem um trecho elástico representado pela reta com inclinação $\alpha_{1}=\tan ^{-1} E$ onde $E$ é o módulo de elasticidade. Após alcançar o escoamento $\sigma_{0}$ o material permanece com o mesmo nível de tensão na medida em que a deformação aumenta.

A situação (b) representa o modelo elasto-plástico bilinear. Aqui a primeira reta com inclinação $\alpha_{1}$ corresponde ao trecho elástico. Após alcançar o escoamento $\sigma_{0}$ tem-se início a segunda reta com inclinação $\alpha_{2}=\tan ^{-1} E_{t}$ que representa o trecho plástico. A constante $E_{t}$ é conhecida como módulo tangente.

O caso (c) corresponde ao modelo elasto-plástico não-linear. Neste caso, após alcançar o escoamento $\sigma_{0}$, o encruamento passa a ser descrito por uma lei nãolinear. A lei de potência, dada pela eq. 3.52 e a lei de Voce, eq. 3.53, são as mais comuns aplicadas com o modelo de encruamento não-linear.

$$
\begin{aligned}
\sigma & =K \varepsilon^{n} \\
\sigma & =\sigma_{0}+Q\left(1-e^{(-b \varepsilon)}\right)
\end{aligned}
$$

onde: $K, n$ e $Q, b$ são constantes de material obtidas a partir do ajuste com a curva experimental.

O fenômeno de encruamento implica na alteração da superfície de escoamento na medida em que o carregamento plástico ocorre. Particularmente no caso do modelo perfeitamente plástico a superfície de escoamento permanece fixa, enquanto que nos outros casos, os modelos de encruamento são as expressões 
matemáticas que controlam a evolução desta superfície.

Definindo-se a função de escoamento como:

$$
f\left(\sigma_{i j}\right)=\Omega
$$

tal que quando a função de escoamento $f$ torna-se igual a constante $\Omega$ o escoamento se inicia. Desta forma $\Omega$ representa a superfície de escoamento inicial no espaço de tensões. Após o escoamento do material $\Omega$ assume novos valores dependendo das propriedades adotadas de encruamento do material. Quando o material é descarregado e então carregado novamente, o escoamento só terá início quando o novo valor de $\Omega$ for alcançado.

Podem-se então distinguir três situações possíveis durante o carregamento:

$$
\begin{array}{ll}
f\left(\sigma_{i j}\right)=\Omega & d f=\frac{\partial f}{\partial \sigma_{i j}} d \sigma_{i j}>0 \\
f\left(\sigma_{i j}\right)=\Omega & d f=\frac{\partial f}{\partial \sigma_{i j}} d \sigma_{i j}=0 \\
f\left(\sigma_{i j}\right)=\Omega & d f=\frac{\partial f}{\partial \sigma_{i j}} d \sigma_{i j}<0
\end{array}
$$

A condição $f\left(\sigma_{i j}\right)=\Omega$ indica que o estado de tensão está sobre a superfície de escoamento. Quando $d f>0$ o ponto está sofrendo um carregamento plástico e movendo-se no sentido de expandir a superfície. A situação em que $d f<0$ corresponde ao descarregamento quando o ponto está movendo-se no sentido interno da superfície. Finalmente $d f=0$ representa um carregamento neutro na qual o estado de tensão permanece sobre a superfície.

A seguir são apresentados os modelos de encruamento clássicos, que controlam a evolução da superfície de escoamento e que são utilizados na maioria dos programas comerciais de elementos finitos. 


\section{Encruamento Isotrópico}

O modelo com encruamento isotrópico assume que a superfície de escoamento sofre uma expansão uniforme na medida em que o carregamento plástico ocorre e seu centro permanece fixo. A Figura 3.9 ilustra este modelo com a expansão isotrópica da elipse do critério de von Mises no plano $\sigma_{1}-\sigma_{2}$.

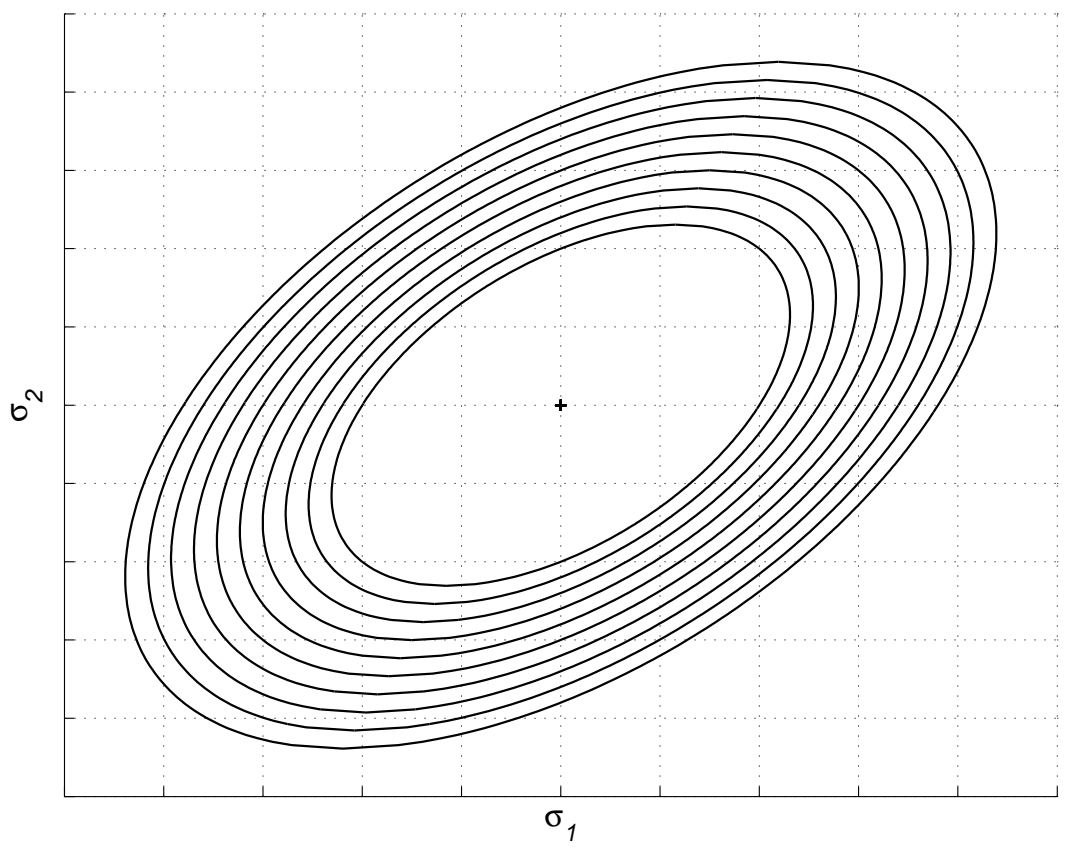

Figura 3.9: Evolução da superfície com encruamento isotrópico

Matematicamente o comportamento isotrópico pode ser escrito como:

$$
f\left(\sigma_{i j}, q_{i}\right)=\sigma_{e q}-\sigma_{0}\left(q_{i}\right)
$$

onde: $\sigma_{e q}$ corresponde a tensão equivalente e $\sigma_{0}$ a tensão de escoamento uniaxial do material que representa a parcela do encruamento isotrópico que varia na medida em que ocorre o carregamento plástico.

A evolução de $\sigma_{0}$ é escrita em função do conjunto de variáveis internas $q_{i}$ que geralmente estão associadas à deformação plástica equivalente $\varepsilon_{e q}^{p}$ ou ao trabalho plástico $W^{p}$ na forma de leis idealizadas. 


\section{Encruamento Cinemático}

No modelo com encruamento cinemático a superfície de escoamento permanece com sua configuração original, porém é transladada no espaço de tensões na medida em que ocorre o carregamento plástico, conforme pode ser observado na Figura 3.10. Este modelo permite descrever o efeito Bauschinger descrito anteriormente.

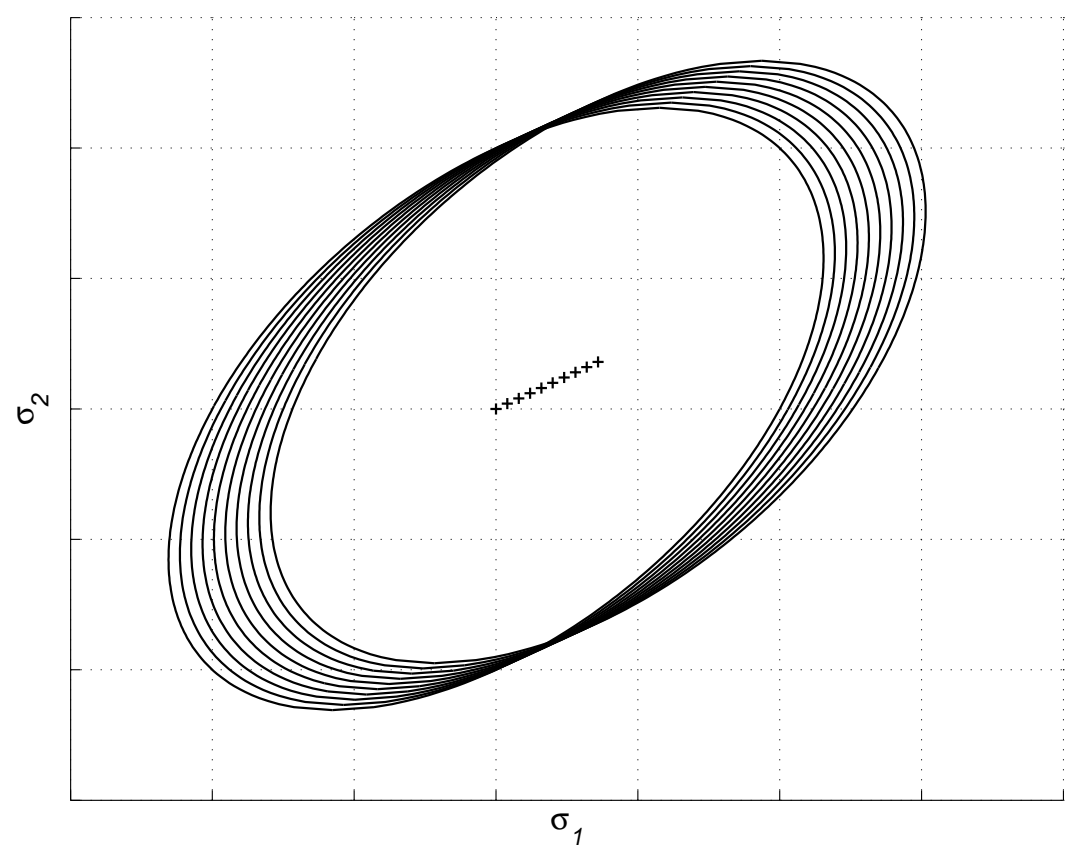

Figura 3.10: Evolução da superfície com encruamento cinemático

Neste caso a função de escoamento é reescrita substituindo-se as componentes de tensão do tensor $\sigma_{i j}$ por $\bar{\sigma}_{i j}=\sigma_{i j}-\alpha_{i j}$ onde o tensor $\alpha_{i j}$ é denominado de tensão de retorno (backstress) e define a origem da superfície na condição do estado atual de tensão.

Existem vários modelos de encruamento propostos para representar o comportamento cinemático. Dentre os mais conhecidos destaca-se o modelo de Prager onde a evolução da tensão de retorno $\boldsymbol{\alpha}$ é calculada conforme eq. 3.59:

$$
d \alpha i j=C d \varepsilon_{i j}^{p}
$$

onde: $C$ é uma constante do material. 
De acordo com este modelo, a superfície de escoamento mantem sua forma original e seu centro translada na direção do incremento de deformação plástica $d \varepsilon^{p}$. Conforme será apresentado, devido à condição de normalidade, a direção do incremento de deformação plástica corresponde a normal a superfície de escoamento.

Outro modelo aplicado para descrever a evolução da tensão de retorno é o modelo de Zigler escrito na forma:

$$
d \alpha_{i j}=\left(\sigma_{i j}-\alpha_{i j}\right) d \mu
$$

onde $d \mu$ é uma constante determinada em função do critério de escoamento adotado.

Ao invés de assumir que a superfície de escoamento move-se na direção do incremento de deformação plástica, o modelo de Zigler assume que a translação do centro da superfície acontece na direção radial determinada pelo vetor $\sigma_{i j}-\alpha_{i j}$.

Outro modelo mais recente de evolução da tensão de retorno é devido a LEMAITRE e CHABOCHE (1990). Neste modelo, os autores definem a tensão de retorno conforme a eq. 3.61:

$$
d \alpha_{i j}=\frac{2}{3} c d \varepsilon_{i j}^{p}-\gamma \alpha_{i j} d \varepsilon_{e q}^{p}
$$

onde: $c$ e $\gamma$ são constantes de material e $d \varepsilon_{e q}^{p}$ representa o incremento de deformação plástica equivalente.

\section{Encruamento combinado}

Quando as duas situações anteriores são levadas em consideração tem-se o chamado modelo combinado de encruamento isotrópico-cinemático. Em muitas situações, a aplicação deste tipo de modelo permite caracterizar o comportamento mecânico de materiais de forma mais acurada. Por outro lado, a maior desvantagem da aplicação do modelo combinado é a necessidade da determinação de um 
número grande de parâmetros de material. A Figura 3.11 ilustra a evolução da superfície de escoamento para este caso, compreendendo sua translação e expansão.

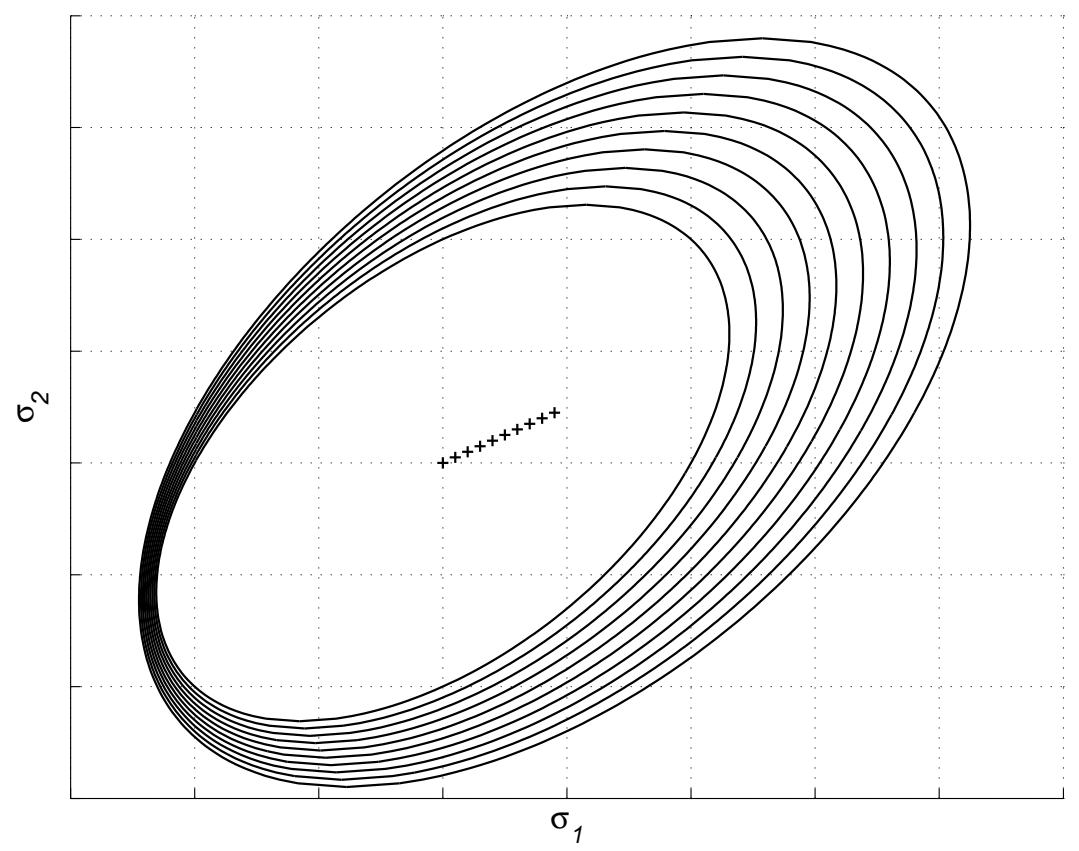

Figura 3.11: Evolução da superfície com encruamento combinado

Desta forma foram apresentados os principais modelos de encruamento utilizados nos algoritmos de plasticidade. A seguir são discutidos alguns pontos relacionados com os critérios de escoamento.

\subsubsection{Critérios de escoamento}

Para o caso uniaxial representado pelo ensaio de tração, a transição do regime elástico para o regime plástico é caracterizada pela tensão de escoamento. No caso de um estado geral de tensões quando as seis componentes independentes de tensão são consideradas, a caracterização do escoamento é idealizada por uma superfície de escoamento. Esta superfície pode ser representada matematicamente por uma função de escoamento que divide o espaço de tensões em um domínio elástico e em outro plástico. A funções matemáticas que representam a superfície de escoamento do material são denominadas de critérios de escoamento. 
Como padronização da formulação geralmente os critérios são escritos da seguinte forma:

$$
f\left(\sigma_{i j}, q_{i}\right)=\sigma_{e q}-\sigma_{0}\left(q_{i}\right)<=0
$$

onde: $f$ representa a função de escoamento dependente do estado de tensão $\sigma_{i j} \mathrm{e}$ de um conjunto de variáveis internas $q_{i}, \sigma_{e q}$ é a chamada tensão equivalente e $\sigma_{0}$ é a tensão de escoamento associada com o encruamento do material.

Neste tópico são apresentados apenas os critérios de escoamento de von Mises e Tresca para materiais isotrópicos. Outros critérios que consideram a anisotropia do material, serão apresentados em separado no capítulo seguinte, juntamente com outros aspectos relacionados com o fenômeno de anisotropia plástica de chapas metálicas.

\section{Critério de von Mises}

O critério de escoamento de von Mises é o mais conhecido e aplicado para os metais. Este critério assume que o escoamento do material inicia-se quando a energia de distorção produzida em um elemento unitário sujeito a tensão combinada, atinge o valor da energia de distorção de um elemento sujeito à tração simples. Esta definição pode ser representada através da igualdade entre a tensão equivalente $\sigma_{e q}$ e o valor limite $\sigma_{0}$, o qual representa o ponto de escoamento inicial no estado uniaxial de tensão.

Como a tensão equivalente $\sigma_{e q}$ é função do estado geral de tensões e pode ser escrita em termos do segundo invariante $J_{2}$ do tensor desviador de tensões, a função de escoamento $f$ para o critério de von Mises pode ser escrita como:

$$
f=\sigma_{e q}-\sigma_{0}=\sqrt{3 J_{2}}-\sigma_{0}=0
$$

A partir das relações entre os invariantes de tensão dadas nas eq. 3.25 a 3.27, a tensão equivalente de von Mises $\sigma_{e q}$ pode ser reescrita em termos das tensões 
principais como:

$$
\sigma_{e q}=\frac{1}{\sqrt{2}} \sqrt{\left[\left(\sigma_{1}-\sigma_{2}\right)^{2}+\left(\sigma_{2}-\sigma_{3}\right)^{2}+\left(\sigma_{3}-\sigma_{1}\right)\right]}
$$

No caso de tensão plana, com $\sigma_{3}=0$, o critério de von Mises é simplificado conforme a eq. 3.65 :

$$
f=\left(\sigma_{1}^{2}+\sigma_{2}^{2}-\sigma_{1} \sigma_{2}\right)^{1 / 2}-\sigma_{0}=0
$$

Pode-se observar pela eq. 3.63 e eq. 3.64 que a superfície de escoamento deste critério representa um cilindro no espaço das tensões principais. Já para o caso de tensão plana, a eq. 3.65 indica que a superfície de Mises representa uma elipse no plano $\sigma_{1} \times \sigma_{2}$.

\section{Critério de Tresca}

O critério de Tresca assume que o escoamento do material sob um estado geral de tensões inicia-se quando a máxima tensão de cisalhamento atinge o valor da máxima tensão de cisalhamento em tração uniaxial.

A tensão de cisalhamento máxima é dada pela metade da diferença entre a máxima e mínima tensão principal. Particularmente para um estado de tração uniaxial, desde que $\sigma_{2}=\sigma_{3}=0$, a máxima tensão de cisalhamento no escoamento é igual a $\frac{1}{2} \sigma_{0}$, onde $\sigma_{0}$ é a tensão de escoamento em tração simples. O critério de Tresca então assegura que o escoamento ocorre quando quaisquer umas das seis condições forem satisfeitas:

$$
\begin{aligned}
& \sigma_{1}-\sigma_{2}= \pm \sigma_{0} \\
& \sigma_{2}-\sigma_{3}= \pm \sigma_{0} \\
& \sigma_{3}-\sigma_{1}= \pm \sigma_{0}
\end{aligned}
$$


A projeção da superfície de escoamento de Tresca no plano $\pi$ é um hexágono regular cujos vértices estão alinhados com os eixos das tensões principais. A Figura 3.12 compara as superfícies de escoamento para o critério de Tresca e para o de von Mises no espaço de tensões principais e no plano $\sigma_{1}-\sigma_{2}$.

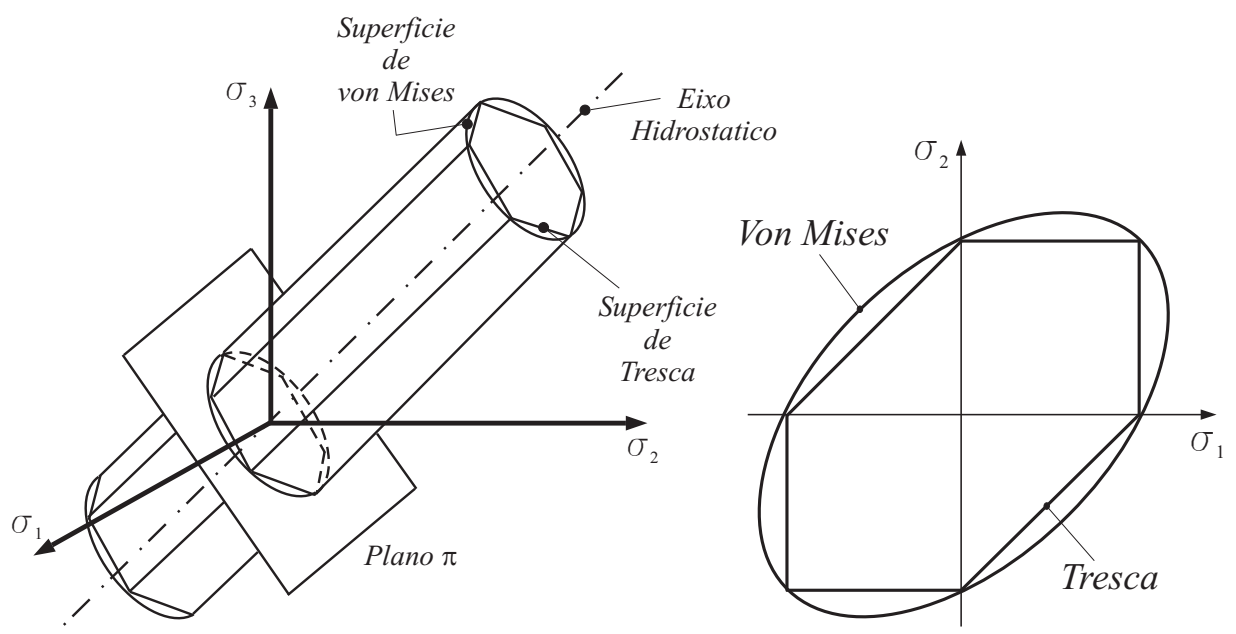

Figura 3.12: Comparação entre as superfícies de escoamento de von Mises e Tresca

A grande dificuldade em se aplicar o critério de Tresca é a necessidade de se conhecer as tensões principais máxima e mínima. Adicionalmente, do ponto de vista de implementação computacional, este critério também apresenta desvantagens por apresentar arestas na superfície. Tais arestas podem representar pontos de descontinuidade no cálculo das derivadas parciais relacionadas com a regra de fluxo.

\subsection{Plasticidade computacional}

Neste tópico são apresentados alguns conceitos relativos à formulação e implementação computacional das relações incrementais entre tensão-deformação da teoria da plasticidade no âmbito das pequenas deformações. Os tópicos são organizados com base nos trabalhos de BELYTSCHKO et al. (2000), SIMO e HUGES (1998), CRISFIELD (1997) e CRISFIELD (1991).

Inicialmente são apresentadas as convenções e hipóteses da formulação para os 
modelos unidimensionais de encruamento que posteriormente são generalizadas para o caso multidimensional. Ao longo do desenvolvimento das equações, a notação indicial e matricial é aplicada conforme a conveniência. Em seguida são apresentados alguns algoritmos de integração que fazem parte da implementação computacional propriamente dita.

\subsubsection{Plasticidade unidimensional}

Para o caso unidimensional o modelo matemático desenvolvido é baseado na resposta mecânica do dispositivo ilustrado na Figura 3.13. Assume-se que este dispositivo possui um comprimento unitário (e área unitária) e consiste de uma mola, com constante elástica $E$, em conjunto com um elemento que obedece o modelo de Coulomb de atrito, com constante $\sigma_{0}>0$.

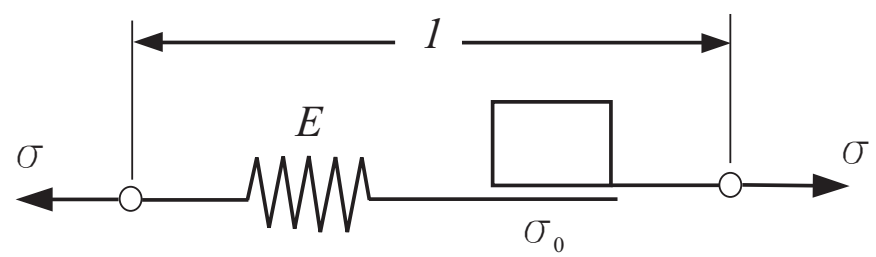

Figura 3.13: Modelo idealizado de encruamento

Seja $\sigma$ a tensão aplicada e $\varepsilon$ a deformação total no dispositivo. A deformação total $\varepsilon$ pode então ser dividida em uma parcela elástica $\varepsilon^{e}$ devida a constante de mola $E$ e em outra parcela plástica $\varepsilon^{p}$ devido ao modelo de atrito. Esta consideração é conhecida como decomposição aditiva do tensor de deformações e escrita como:

$$
\varepsilon=\varepsilon^{e}+\varepsilon^{p}
$$

Pela consideração de equilíbrio, a tensão sobre a mola $\sigma$ obedece à relação elástica, e combinada com a decomposição aditiva dada pela eq. 3.69 é possível escrever as seguintes relações:

$$
\sigma=E \varepsilon^{e} \equiv E\left(\varepsilon-\varepsilon^{p}\right)
$$


Admitindo que o material se comporte de maneira simétrica em tração e em compressão, verifica-se que a tensão aplicada no dispositivo não pode ser maior, em valor absoluto, que $\sigma_{0}$. Assim pode-se definir um conjunto $E_{\sigma}$ que contem as tensões admissíveis para o modelo como:

$$
E_{\sigma}=\left\{\sigma \in \mathbb{R} \quad / \quad f(\sigma)=|\sigma|-\sigma_{0} \leq 0\right\}
$$

Desta forma, estados de tensões chamados de admissíveis devem obedecer a seguinte condição:

$$
f(\sigma)=|\sigma|-\sigma_{0} \leq 0
$$

onde a função $f$ é denominada de condição de escoamento e corresponde à função matemática representativa da superfície de escoamento.

Admitindo que $\varepsilon, \sigma$ e $\varepsilon^{p}$ sejam funções contínuas no tempo, pode-se definir $\dot{\varepsilon}^{p}$ como a velocidade ou taxa de deformação plástica. A deformação plástica só sofre alteração quando $\dot{\varepsilon}^{p} \neq 0$.

Se para um dado instante a resposta imediata do material não proporcionar alteração da deformação plástica acumulada, ou seja $\dot{\varepsilon}^{p}=0$, a condição $f(\sigma)<$ 0 deve ser satisfeita e consequentemente a resposta instantânea do material é puramente elástica. Portanto pode-se definir um outro domínio com pontos no interior de $E_{\sigma}$ cujas tensões são elásticas. Isto é representado pelo conjunto aberto dado por:

$$
\operatorname{int} E_{\sigma}=\left\{\sigma \in \mathbb{R} \quad / \quad f(\sigma)=|\sigma|-\sigma_{0}<0\right\}
$$

Por outro lado a mudança da deformação plástica acumulada, $\dot{\varepsilon}^{p} \neq 0$, só é possível se $f(\sigma)=0$. Seja $\dot{\lambda}$ o valor absoluto da velocidade de deformação plástica que possa ocorrer quando $f(\sigma)=0$. Então a seguinte relação, conhecida como regra de fluxo, pode ser escrita:

$$
\dot{\varepsilon}^{p}=\dot{\lambda} \operatorname{sign}(\sigma)
$$


onde :

$$
\operatorname{sign}(\sigma)=\left\{\begin{array}{lll}
+1 & \text { se } & \sigma>0 \\
-1 & \text { se } & \sigma<0
\end{array}\right.
$$

A regra de fluxo pode ser relacionada com a função de escoamento $f$ através da relação:

$$
\dot{\varepsilon}^{p}=\dot{\lambda} \frac{\partial f}{\partial \sigma}
$$

onde : $\frac{\partial f}{\partial \sigma}=\operatorname{sign}(\sigma)$.

Pode-se observar que $\dot{\lambda}$ e $f(\sigma)$ respeitam certas condições unilaterais, isto é $: \dot{\lambda} \geq 0$ e $f(\sigma) \leq 0$. Além disso, se $\dot{\lambda} \geq 0$ então $f(\sigma)=0$ e se $f(\sigma)<0$ então $\dot{\lambda}=0$. Portanto vale a relação $\dot{\lambda} f(\sigma)=0$. Estas condições são conhecidas como condições de Kuhn-Tucker ou condições de carregamento e descarregamento. Pode-se mostrar também que a relação $\dot{\lambda} \dot{f}(\sigma)=0$ também é sempre válida quando $f(\sigma)=0$. Esta relação é denominada de condição de consistência.

A Tabela 3.1 apresenta um resumo do conjunto de equações relacionados com este modelo constitutivo elasto-plástico.

Tabela 3.1: Resumo da relações do modelo elasto-plástico unidimensional

\begin{tabular}{|ll|l|}
\hline 1. & Decomposição aditiva & $\varepsilon=\varepsilon^{e}+\varepsilon^{p}$ \\
2. & Relação elástica & $\sigma=E\left(\varepsilon-\varepsilon^{e}\right)$ \\
3. & Regra de fluxo & $\dot{\varepsilon}^{p}=\dot{\lambda} \frac{\partial f}{\partial \sigma}$ \\
4. & Condição de escoamento & $f(\sigma)=|\sigma|-\sigma_{0} \leq 0$ \\
5. & Condições de Kuhn-Tucker & $\dot{\lambda} \geq 0, f(\sigma) \leq 0, \dot{\lambda} f(\sigma)=0$ \\
6. & Condição de consistência & $\dot{\lambda} \dot{f}(\sigma)=0$ \\
\hline
\end{tabular}

Quando o encruamento do material é considerado, o domínio elástico $E_{\sigma}$ se expande em função da deformação plástica. Particularmente no caso do encruamento isotrópico, conforme apresentado anteriormente, o domínio $E_{\sigma}$ se expande de maneira simétrica com seu centro fixo na origem. 
Neste caso a condição de escoamento assume a forma:

$$
f(\sigma, \beta)=|\sigma|-\left(\sigma_{0}+p\right) \leq 0
$$

Desta forma, o espaço das tensões admissíveis passa a ser escrito como:

$$
E_{\sigma}=\left\{\sigma \in \mathbb{R} \quad / \quad f(\sigma)=|\sigma|-\left(\sigma_{0}+p\right)<0\right\}
$$

onde : $p$ contém o registro da deformação plástica e define o tamanho do domínio elástico. Este valor é conhecido como uma variável interna do processo.

A evolução da variável interna $p$ é definida em função da lei de encruamento adotada. Conforme visto anteriormente, várias leis idealizadas podem ser aplicadas para descrever o encruamento do material. Particularmente para o caso com encruamento linear, a variável interna $p$ pode ser escrita na forma:

$$
p=K \beta
$$

onde : $K$ é usualmente chamado de módulo de encruamento isotrópico e a variável $\beta \geq 0$ é uma função do fluxo plástico denominada como uma variável interna do tipo deformação. Quando o módulo de encruamento isotrópico $K$ é positivo tem-se o chamado encruamento positivo (hardening) e quando $K<0$ tem-se o chamado encruamento negativo (softening).

A evolução da variável interna $\beta$ pode ser descrita a partir de duas abordagens. A primeira, quando $\beta$ é escrito em função da deformação plástica, é chamada de encruamento por deformação ou strain hardening. A segunda é conhecida como encruamento por trabalho ou work hardening, quando $\beta$ é escrito em função do trabalho plástico $W^{p}$.

A partir das condições apresentadas anteriormente e resumidas na Tabela 3.1, é possível obter-se a seguinte equação constitutiva relacionando as taxas entre 
tensão e deformação:

$$
\begin{array}{lll}
\dot{\sigma}=\left(\frac{E K}{E+K}\right) \dot{\varepsilon} & \text { se } & \dot{\lambda}>0 \\
\dot{\sigma}=E \dot{\varepsilon} & \text { se } & \dot{\lambda}=0
\end{array}
$$

onde $\frac{E K}{E+K}$ é denominado de módulo elasto-plástico tangente o qual relaciona os incrementos de tensão e deformação no regime plástico.

Quando o encruamento isotrópico é desprezado e o modelo de encruamento cinemático é considerado, o intervalo elástico inicial não sofre alteração, porém muda de posição no espaço das tensões de acordo com a evolução do processo de plastificação. Com isso condição de escoamento passa a ser escrita na seguinte forma:

$$
f(\sigma, \alpha)=|\sigma-\alpha|-\left(\sigma_{0}\right) \leq 0
$$

onde a variável interna $\alpha$ está relacionada com a nova posição do centro do intervalo elástico.

Conforme visto anteriormente, existem diferentes leis que podem descrever a evolução da variável interna $\alpha$. No caso mais simples pode-se adotar:

$$
\dot{\alpha}=H \dot{\varepsilon}^{p}
$$

onde : $H$ é chamado de módulo de encruamento cinemático.

Em um caso mais geral, é possível combinar os modelos de encruamento isotrópico e cinemático em um modelo combinado. Neste caso ocorre a translação e a expansão da superfície de forma que a condição de escoamento assume a forma:

$$
f(\sigma, p, \alpha)=|\sigma-\alpha|-\left(\sigma_{0}+p\right) \leq 0
$$

Neste modelo combinado, as condições apresentadas anteriormente e resumidas na Tabela 3.1 permitem escrever a seguinte equação constitutiva relacionando 
as taxas entre tensão e deformação:

$$
\begin{aligned}
\dot{\sigma} & =\left(\frac{E(H+K)}{E+K+H}\right) \dot{\varepsilon} & \text { se } & \dot{\lambda}>0 \\
\dot{\sigma}=E \dot{\varepsilon} & \text { se } & \dot{\lambda} & =0
\end{aligned}
$$

onde o novo módulo elasto-plástico é escrito em termos das constantes relacionadas com as parcelas cinemática e isotrópica do encruamento.

A seguir, as equações e considerações apresentadas para o caso unidimensional são generalizadas para um estado geral de tensões.

\subsubsection{Plasticidade multidimensional}

A formulação das relações incrementais entre tensão-deformação para o caso multidimensional é fundamentada na generalização do caso unidimensional descrito no tópico anterior. Para tanto é assumida a decomposição aditiva do tensor de deformações conforme:

$$
\varepsilon_{i j}=\varepsilon_{i j}^{e}+\varepsilon_{i j}^{p}
$$

Para o caso multidimensional no regime elástico, a relação entre o tensor de tensões de Cauchy $\sigma_{i j}$ e o tensor de deformações, é escrito em termos do tensor constitutivo elástico de quarta ordem $C_{i j k l}$. A eq. 3.82 representa esta relação em conjunto com a aplicação da decomposição aditiva do tensor de deformações da eq. 3.81:

$$
\sigma_{i j}=C_{i j k l} \varepsilon_{k l}^{e} \equiv C_{i j k l}\left(\varepsilon_{k l}-\varepsilon_{k l}^{p}\right)
$$

A função de escoamento $f$, neste caso, é escrita em termos do tensor de tensões $\sigma_{i j}$ e de um conjunto de variáveis internas denotadas coletivamente por $q_{\alpha}$. Representando estas grandezas na forma matricial, a função de escoamento $f$ fica escrita como:

$$
f(\boldsymbol{\sigma}, \boldsymbol{q})=0
$$

onde a evolução do conjunto de variáveis internas $\boldsymbol{q}$ pode ser especificada na 
seguinte forma:

$$
\dot{\boldsymbol{q}}=-\dot{\lambda} \boldsymbol{h}(\boldsymbol{\sigma}, \boldsymbol{q})
$$

onde: $\boldsymbol{h}$ representa as variáveis que reúnem os parâmetros de encruamento do material.

De forma geral, a regra de fluxo para o caso multidimensional é escrita conforme a eq. 3.85:

$$
\dot{\varepsilon}^{p}=\dot{\lambda} \boldsymbol{r}(\boldsymbol{\sigma}, \boldsymbol{q})
$$

onde : $\boldsymbol{r}(\boldsymbol{\sigma}, \boldsymbol{q})$ representa a direção do fluxo plástico que na maioria dos casos é relacionada com a função de escoamento na forma $\boldsymbol{r}=\partial f / \partial \boldsymbol{\sigma}$. Neste caso a direção do fluxo plástico é normal à superfície de escoamento recaindo assim na chamada regra de fluxo associativa. Neste caso a eq. 3.85 é simplificada conforme:

$$
\dot{\varepsilon}=\dot{\lambda}\left(\frac{\partial f}{\partial \boldsymbol{\sigma}}\right)=\dot{\lambda} \boldsymbol{a}
$$

onde: $\boldsymbol{a}$ representa um vetor cujas componentes são determinadas a partir das derivadas parciais da função de escoamento em relação as componentes do tensor de tensões.

A título de exemplo, aplicando-se a regra de fluxo associativa da eq. 3.86 para o critério de von Mises apresentado na secção anterior, tem-se que os incrementos de deformação plástica são dados conforme:

$$
\begin{aligned}
& d \varepsilon_{x}^{p}=d \lambda \frac{\partial f}{\partial \sigma_{x}}=d \lambda\left[\frac{2 \sigma_{x}-\sigma_{y}-\sigma_{z}}{2 \sigma_{e}}\right] \\
& d \varepsilon_{y}^{p}=d \lambda \frac{\partial f}{\partial \sigma_{y}}=d \lambda\left[\frac{2 \sigma_{y}-\sigma_{x}-\sigma_{z}}{2 \sigma_{e}}\right] \\
& d \varepsilon_{z}^{p}=d \lambda \frac{\partial f}{\partial \sigma_{z}}=d \lambda\left[\frac{2 \sigma_{z}-\sigma_{x}-\sigma_{y}}{2 \sigma_{e}}\right] \\
& d \gamma_{x y}^{p}=d \lambda \frac{\partial f}{\partial \sigma_{x y}}=d \lambda\left[\frac{3 \sigma_{x y}}{\sigma_{e}}\right] \\
& d \gamma_{y z}^{p}=d \lambda \frac{\partial f}{\partial \sigma_{y z}}=d \lambda\left[\frac{3 \sigma_{y z}}{\sigma_{e}}\right] \\
& d \gamma_{x z}^{p}=d \lambda \frac{\partial f}{\partial \sigma_{x z}}=d \lambda\left[\frac{3 \sigma_{x z}}{\sigma_{e}}\right]
\end{aligned}
$$


onde: $\sigma_{e}$ representa a tensão equivalente do critério de von Mises.

A relação entre os incrementos de tensão e deformação é obtida aplicando-se a condição de consistência, juntamente com a decomposição aditiva do tensor de deformação, a regra de fluxo associativa e a equações de evolução das variáveis internas, de forma que:

$$
\dot{\sigma}=C^{e p}: \dot{\varepsilon}
$$

onde: $C^{e p}$ é um tensor de quarta ordem dos módulos elasto-plásticos tangentes dado por:

$$
\boldsymbol{C}^{\boldsymbol{e p}}=\left\{\begin{array}{lll}
\boldsymbol{C} & \text { se } & \dot{\lambda}=0 \\
\boldsymbol{C}-\frac{\boldsymbol{C a a}^{t} \boldsymbol{C}}{\boldsymbol{a}^{t} \boldsymbol{C a}+A_{e n c}} & \text { se } & \dot{\lambda}>0
\end{array}\right.
$$

onde: a parcela $A_{\text {enc }}$ representa um escalar associado com as parcelas de encruamento isotrópica e cinemática do modelo e pode ser determinada a partir da evolução das variáveis internas definidas na eq. 3.84 como:

$$
A_{\text {enc }}=\frac{\partial f}{\partial \boldsymbol{q}} \cdot \boldsymbol{h}
$$

O conjunto de equações apresentado, pode ser resolvido numericamente a cada incremento de tempo por meio de procedimentos adequados, denominados de algoritmos de integração conforme descritos a seguir.

\subsection{Algoritmos de integração}

Os algoritmos numéricos aplicados para fazer a integração das taxas das equações constitutivas apresentadas no tópico anterior são chamados de algoritmos de integração constitutivos.

O propósito destes procedimentos numéricos é, dado o conjunto inicial de parâmetros $\left(\boldsymbol{\sigma}_{n}, \boldsymbol{\varepsilon}_{n}, \boldsymbol{\varepsilon}_{n}^{p}, \boldsymbol{q}_{n}\right)$ em um instante de tempo $n$ e o incremento de deformação total $\Delta \boldsymbol{\varepsilon}=\Delta t \dot{\boldsymbol{\varepsilon}}$, determinar o conjunto $\left(\boldsymbol{\sigma}_{n+1}, \boldsymbol{\varepsilon}_{n+1}, \boldsymbol{\varepsilon}_{n+1}^{p}, \boldsymbol{q}_{n+1}\right)$ no instante 
$n+1$ que satisfaça as condições de carregamento e descarregamento discutidas no tópico anterior.

É importante destacar que estes processos de integração assumem como variável independente a deformação total, sendo assim denominados de processos dirigidos por deformação ou strain driven. A seguir são descritos os principais algoritmos implementados computacionalmente e aplicados para a solução do problema elasto-plástico associado.

\subsubsection{Forward Euler}

O esquema de integração mais simples para determinar o conjunto de valores $\left(\boldsymbol{\sigma}_{n+1}, \boldsymbol{\varepsilon}_{n+1}, \boldsymbol{\varepsilon}_{n+1}^{p}, \boldsymbol{q}_{n+1}\right)$ no instante $n+1$ é conhecido como Forward Euler. Este procedimento assume as seguintes relações:

$$
\begin{aligned}
\varepsilon_{n+1} & =\varepsilon_{n}+\Delta \varepsilon \\
\varepsilon_{n+1}^{p} & =\varepsilon_{n}^{p}+\Delta \lambda_{n} \boldsymbol{r}_{n} \\
\boldsymbol{q}_{n+1} & =\boldsymbol{q}_{n}+\Delta \lambda_{n} \boldsymbol{h}_{n} \\
\boldsymbol{\sigma}_{n+1} & =\boldsymbol{C}:\left(\varepsilon_{n+1}-\varepsilon_{n+1}^{p}\right)=\boldsymbol{\sigma}_{n}+\boldsymbol{C}^{e p}: \Delta \boldsymbol{\varepsilon}
\end{aligned}
$$

onde : $\Delta \lambda_{n}=\Delta t \dot{\lambda}_{n}$

Porém os valores atualizados da tensão e das variáveis internas neste procedimento não satisfazem a condição de escoamento no passo $n+1$ ou seja, $f_{n+1}=f\left(\boldsymbol{\sigma}_{n+1}, \boldsymbol{q}_{n+1}\right) \neq 0$. Desta forma, o ponto representativo do estado de tensão não está sobre a superfície de escoamento e frequentemente os resultados obtidos não apresentam soluções precisas.

Para minimizar esta deficiência existem inúmeros outros métodos alternativos. Um amplo resumo de tais métodos é descrito em SIMO e HUGES (1998). Os métodos denominados de algoritmos de retorno mapeados (return mapping algorithms) são os mais robustos e amplamente aplicados na prática. Estes métodos transformam o conjunto de equações incrementais em um conjunto de equações 
algébricas não lineares. A seguir é apresentado uma alternativa para solução destas equações baseada no método Backward Euler.

\subsubsection{Backward Euler}

Neste procedimento, os incrementos de deformação plástica e das variáveis internas são calculados ao final do passo $n+1$, conforme as relações abaixo:

$$
\begin{aligned}
\boldsymbol{\varepsilon}_{n+1} & =\boldsymbol{\varepsilon}_{n}+\Delta \boldsymbol{\varepsilon} \\
\boldsymbol{\varepsilon}_{n+1}^{p} & =\boldsymbol{\varepsilon}_{n}^{p}+\Delta \lambda_{n+1} \boldsymbol{r}_{n+1} \\
\boldsymbol{q}_{n+1} & =\boldsymbol{q}_{n}+\Delta \lambda_{n+1} \boldsymbol{h}_{n+1} \\
\boldsymbol{\sigma}_{n+1} & =\boldsymbol{C}:\left(\boldsymbol{\varepsilon}_{n+1}-\boldsymbol{\varepsilon}_{n+1}^{p}\right) \\
f_{n+1} & =f\left(\boldsymbol{\sigma}_{n+1}, \boldsymbol{q}_{n+1}\right)=0
\end{aligned}
$$

Substituindo-se a eq. 3.101 referente ao incremento de deformação plástica, na equação constitutiva do material, podem-se desenvolver as seguintes relações:

$$
\begin{aligned}
\boldsymbol{\sigma}_{n+1} & =\boldsymbol{C}:\left(\varepsilon_{n+1}-\varepsilon_{n}^{p}-\Delta \varepsilon_{n+1}^{p}\right) \\
\boldsymbol{\sigma}_{n+1} & =\boldsymbol{C}:\left(\varepsilon_{n}+\Delta \varepsilon-\varepsilon_{n}^{p}-\Delta \varepsilon_{n+1}^{p}\right)=\boldsymbol{C}:\left(\varepsilon_{n}-\varepsilon_{n}^{p}\right)+\boldsymbol{C}: \Delta \varepsilon-\boldsymbol{C}: \Delta \varepsilon_{n+1}^{p} \\
\boldsymbol{\sigma}_{n+1} & =\left(\boldsymbol{\sigma}_{n}+\boldsymbol{C}: \Delta \boldsymbol{\epsilon}\right)-\boldsymbol{C}: \Delta \varepsilon_{n+1}^{p} \\
\boldsymbol{\sigma}_{n+1} & =\boldsymbol{\sigma}^{\text {tent }}-\boldsymbol{C}: \Delta \varepsilon_{n+1}^{p} \\
\boldsymbol{\sigma}_{n+1} & =\boldsymbol{\sigma}^{\text {tent }}-\Delta \lambda_{n+1} \boldsymbol{C}: \boldsymbol{r}_{n+1}
\end{aligned}
$$

onde : $\boldsymbol{\sigma}^{\text {tent }}=\left(\boldsymbol{\sigma}_{n}+\boldsymbol{C}: \Delta \boldsymbol{\varepsilon}\right)$ é chamada de tensão de tentativa ou preditor elástico e a quantidade $\Delta \lambda_{n+1} \boldsymbol{C}: \boldsymbol{r}_{n+1}$ é chamada de corretor plástico que retorna ou projeta a tensão de tentativa sobre a superfície de escoamento ao longo de uma direção especificada pela direção do fluxo plástico. Por este motivo, usualmente este procedimento é denominado de algoritmo de previsão-correção.

Computacionalmente o algoritmo de integração Backward Euler é mais robusto e permite que a solução do problema não linear associado tenha uma con- 
vergência mais rápida quando comparada com os outros algoritmos.

\subsection{Método dos elementos finitos}

O Método dos Elementos Finitos (MEF) é uma ferramenta computacional que permite avaliar de forma rápida e com menor custo conceitos e detalhes de projetos em substituição a protótipos de testes. Uma ampla bibliografia relacionada com o desenvolvimento teórico e aplicações do método pode ser encontrada, com destaque para ZIENKIEWICZ e TAYLOR (2000), HUGHES (2000), BONET e WOOD (1997) e BATHE (1996).

Particularmente em problemas de conformação mecânica o MEF pode ser aplicado como recurso auxiliar na previsão de possíveis falhas em peças conformadas como a formação de orelhas ou o enrugamento em repuxos de copos, o afinamento excessivo de espessura, retorno elástico e ruptura. A modelagem desses processos requer uma escolha adequada das condições de contorno, carregamentos e modelos de material para que a simulação represente de maneira satisfatória o processo em questão. É o que pode ser encontrado nos diversos trabalhos disponíveis na literatura, especialmente sobre a modelagem de processos de estampagem e repuxo, laminação e forjamento.

Autores como BATHE (1996) apresentam um esquema geral do método, o qual é geralmente organizado em três etapas:

1. Pré-processamento: corresponde a etapa de preparação do modelo, onde é feita a escolha do tipo de análise, definição dos tipos de elementos, propriedades dos materiais, condições de contorno e carregamentos.

2. Solução Numérica: a partir das definições estabelecidas na etapa anterior é executada a solução do problema utilizando-se dos algoritmos numéricos implementados nos programas.

3. Pós-processamento: nesta etapa são analisados os diversos resultados obtidos a partir dos recursos gráficos e outras ferramentas disponíveis nos pro- 
gramas.

Para a solução numérica associada aos problemas estruturais mecânicos, a equação de equilíbrio a ser resolvida pelo método correspondente a resposta dinâmica linear de um sistema mecânico dada por:

$$
[M]\{\ddot{u}\}+[C]\{\dot{u}\}+[K]\{u\}=F
$$

onde: $[M],[C]$ e $[K]$ são as matrizes de massa, amortecimento e rigidez respectivamente; $\{F\}$ é o vetor de forças externas aplicadas e $\{\ddot{u}\},\{\dot{u}\}$ e $\{u\}$ são os vetores de aceleração, velocidade e deslocamentos nodais respectivamente.

Matematicamente a equação 3.105 representa um sistema de equações diferenciais de segunda ordem, e em princípio, sua solução pode ser obtida por procedimentos padrões de solução de equações diferenciais com coeficientes constantes. Na análise pelo MEF dois principais métodos são aplicados: o método de integração direta e o de sobreposição modal.

No caso dos métodos de integração a idéia básica é de tentar satisfazer a equação 3.105 em intervalos de tempo discretos $\Delta t$ assumindo uma variação dos vetores de deslocamento, velocidade e aceleração dentro destes intervalos. A forma de variação destes vetores é que determina a acuracidade e estabilidade dos métodos.

Diferentes expressões para a aproximação dos vetores de aceleração e velocidade em termos dos deslocamentos podem ser obtidas a partir do método de diferenças finitas. Dentre as possibilidades destaca-se o método das diferenças centrais que considera:

$$
\begin{aligned}
& \{\ddot{u}\}_{(t)}=\frac{1}{\Delta t^{2}}\left[\{u\}_{(t-\Delta t)}-2\{u\}_{(t)}+\{u\}_{(t+\Delta t)}\right] \\
& \{\dot{u}\}_{(t)}=\frac{1}{2 \Delta t}\left[\{u\}_{t+\Delta t}-\{u\}_{t-\Delta t}\right]
\end{aligned}
$$

O valor de deslocamento no passo seguinte $\{u\}_{t+\Delta t}$ é obtido substituindo-se as eq. 3.106 e 3.107 na equação de equilíbrio 3.105 de forma que: 


$$
\begin{aligned}
\left(\frac{[M]}{\Delta t^{2}}+\frac{[C]}{2 \Delta t}\right)\{u\}_{(t+\Delta t)}= & \{F\}_{(t)}-\left([K]-\frac{2}{\Delta t^{2}}[M]\right)\{u\}_{(t)} \\
& -\left(\frac{1}{\Delta t^{2}}[M]-\frac{1}{2 \Delta t}[C]\right)\{u\}_{(t-\Delta t)}
\end{aligned}
$$

Esta equação pode ser reescrita na seguinte forma:

$$
[\bar{K}]\{u\}_{(t+\Delta t)}=\{\bar{F}\}_{(t)}
$$

onde:

$$
\begin{aligned}
{[\bar{K}] } & =\frac{1}{\Delta t^{2}}[M]+\frac{1}{2 \Delta t}[C] \\
\{\bar{F}\}_{(t)} & =\{F\}_{(t)}-\left([K]-\frac{2}{\Delta t^{2}}[M]\right)\{u\}_{(t)}-\left(\frac{1}{\Delta t^{2}}[M]-\frac{1}{2 \Delta t}[C]\right)\{u\}_{(t-\Delta t)}
\end{aligned}
$$

No caso em que as matrizes de massa e amortecimento são consistentes, a equação 3.109 caracteriza o algoritmo implícito desde que um conjunto de equações algébricas tem que ser resolvido simultaneamente a cada passo de tempo, ou seja, as equações estão acopladas e é preciso inverter a matriz de rigidez efetiva $[\bar{K}]$ em cada passo de solução.

Dentre as principais vantagens do algoritmo implícito destaca-se:

- Convergência garantida independente do tamanho do incremento de tempo $\Delta t$, ou seja, ele é incondicionalmente convergente.

- A solução do problema não contem simplificações de diagonalização das matrizes.

Dentre as desvantagens requer grandes recursos computacionais de memória e processamento, além de ser sensível a instabilidades quando em situações especiais a matriz de rigidez tende a singularidade.

Por outro lado, quando são utilizadas matrizes de massa e amortecimento diagonalizadas na equação 3.109 , a matriz de rigidez efetiva $[\bar{K}]$ torna-se diagonal 
$[\backslash \bar{K} \backslash]$ e o sistema de equações algébricas fica desacoplado. Com isso não é necessário inverter a matriz de rigidez efetiva a cada passo de tempo.

$$
[\nwarrow \bar{K} \backslash]\{u\}_{(t+\Delta t)}=\{\bar{F}\}_{(t)}
$$

onde:

$$
\begin{aligned}
& {\left[\nwarrow \bar{K}_{\searrow}\right]=\frac{1}{\Delta t^{2}}\left[{ } M_{\searrow}\right]+\frac{1}{2 \Delta t}\left[{ }^{\nwarrow} C_{\searrow}\right]} \\
& \{\bar{F}\}_{(t)}=\{F\}_{(t)}-\left([K]-\frac{2}{\Delta t^{2}}[\nwarrow \backslash]\right)\{u\}_{(t)}- \\
& \left(\frac{1}{\Delta t^{2}}\left[{ }^{\nwarrow} M_{\searrow}\right]-\frac{1}{2 \Delta t}\left[{ } C_{\searrow}\right]\right)\{u\}_{(t-\Delta t)}
\end{aligned}
$$

A eq. 3.110 caracteriza o algoritmo explícito cujas principais vantagens são: robustez, implementação computacional mais simples e menor tempo de processamento. A principal desvantagem deste método é que sua convergência depende da escolha do incremente de tempo $\Delta t$, ou seja, o algoritmo é condicionalmente convergente.

Nos casos em que os deslocamentos $\{u\}$ não variam linearmente com a carga aplicada, como nos problemas de conformação mecânica, tem-se caracterizado um problema não-linear. Em linhas gerais a não linearidade pode ser atribuída a três fatores principais:

- Grandes deslocamentos, rotações e deformações, caracterizando uma não linearidade geométrica

- Plasticidade e viscoplasticidade, caracterizando uma não linearidade de material

- Contato e atrito, caracterizando uma não linearidade das condições de contorno

Neste caso a eq. 3.105 torna-se:

$$
[M]\{\ddot{u}\}+[C]\{\dot{u}\}+[K(u)]\{u\}=\{F\}
$$


Nestas situações, para cada incremento de tempo, são determinados os valores nodais de deslocamento $\{u\}$ e são realizadas algumas iterações para determinação dos incrementos de deformação, divididos em sua parcela elástica e plástica, e dos incrementos de tensão associados. Estes valores devem satisfazer as condições de carregamento e descarregamento discutidas anteriormente. Depois de determinado o estado de tensão-deformação para cada nó da malha é verificada a condição de equilíbrio do modelo e então passa-se para um novo incremento de tempo. 


\section{Capítulo 4}

\section{Estado da Arte - Anisotropia}

\subsection{Introdução}

Neste capítulo são apresentados os diversos aspectos referentes ao fenômeno de anisotropia plástica de chapas metálicas de forma a se obter indicativos atuais do tratamento deste fenômeno em processos de conformação.

Inicialmente é apresentada uma introdução geral sobre o assunto descrita a partir do ponto de vista microestrutural do material. Em seguida é realizada a apresentação do clássico critério de escoamento anisotrópico de HILL (1950), seguido da apresentação e discussão da definição do índice de anisotropia plástica e suas diferentes implicações na formabilidade de chapas metálicas.

Adicionalmente uma revisão bibliográfica é realizada, abrangendo o levantamento sobre os aspectos gerais da anisotropia do material incluindo recentes desenvolvimentos na teoria da plasticidade para implementação de novas superfícies de escoamentos para materiais anisotrópicos.

Na parte final do capítulo, tem-se uma revisão sobre procedimentos experimentais na determinação de parâmetros que caracterizam a anisotropia do material. Algumas novas propostas para a obtenção dos parâmetros de anisotropia via ensaio convencional e via ensaios alternativos são apresentadas e discutidas. 


\subsection{Anisotropia}

O termo anisotropia é empregado na mecânica dos sólidos para indicar que as propriedades físicas do material são dependentes da direção. Do ponto de vista microestrutural, esta não uniformidade está relacionada com o comportamento das discordâncias dos cristais. No caso dos metais policristalinos, a deformação resulta na predominância de uma direção ou plano cristalográfico particular, paralelo à direção de deformação. Desta forma, o processo de deformação aplicado no material, em conjunto com sua estrutura cristalina, implica no desenvolvimento de orientações preferenciais ou texturas dos grãos. Como decorrência das texturas, os materiais adquirem propriedades mecânicas diferentes, que variam de acordo com a direção nas quais são medidas.

Especialmente no caso de chapas metálicas utilizadas em processos de conformação, a anisotropia usualmente tem origem devido as seguintes fontes: a textura cristalográfica e ao fibramento mecânico. A textura cristalográfica é originada pela orientação preferencial dos grãos especialmente em metais não ferrosos. Isto ocorre quando os grãos são alongados na direção de trabalho em processos de conformação como trefilação, extrusão e laminação. A fibração mecânica por outro lado, envolve o alinhamento preferencial de descontinuidades estruturais tais como inclusões, porosidades, segregações e segundas fases.

A anisotropia de chapas tem implicações em diversos fenômenos e requisitos na fabricação de componentes conformados, tais como o uso ferramentais auxiliares para o controle do fluxo plástico como quebra-rugas e prensa-chapas, a formação de orelhas no repuxamento de copos, a localização e orientação de defeitos de afinamento e trincas, entre outros.

No contexto deste trabalho, a anisotropia é estudada no âmbito macroscópico do material, por meio do uso de modelos matemáticos clássicos que buscam representar o comportamento anisotrópico dos materiais. Entretanto deve-se destacar que tais modelos matemáticos carecem de aprimoramentos, em parte devida a própria natureza complexa do fenômeno de anisotropia, como também devidas 
as constantes evoluções dos processos de fabricação, tratamentos térmicos e o desenvolvimento de novos materiais.

A seguir é apresentado o critério de Hill que é um dos mais conhecidos e aplicados na representação da anisotropia do material. Este critério é utilizado como base para o desenvolvimento da metodologia e da nova superfície de escoamento proposta neste trabalho.

\subsection{Critério de Hill}

Dentre os modelos matemáticos que buscam representar o comportamento anisotrópico dos materiais destaca-se o critério de escoamento proposto por HILL (1950). Em seu trabalho, o autor estendeu o campo de validade do critério isotrópico de von Mises para materiais que apresentam tensões de escoamento diferentes de acordo com a direção considerada.

O critério assume um estado geral de anisotropia que possui três planos de simetria mutuamente ortogonais entre si, sendo que a intersecção desses planos fornecem os eixos principais de anisotropia. A função de escoamento representativa do critério de Hill para um estado geral de tensões é definida conforme a eq. 4.1:

$$
\begin{aligned}
f^{2}\left(\sigma_{i j}\right)= & F\left(\sigma_{y}-\sigma_{z}\right)^{2}+G\left(\sigma_{z}-\sigma_{x}\right)^{2}+ \\
& H\left(\sigma_{x}-\sigma_{y}\right)^{2}+2 L \sigma_{y z}^{2}+2 M \sigma_{z x}^{2}+2 N \sigma_{x y}^{2}=1 \\
f\left(\sigma_{i j}\right)= & \sigma_{e}^{2}-1=0
\end{aligned}
$$

onde: $F, G, H, L, M$ e $N$ são os parâmetros característicos do estado de anisotropia do material. Fica evidente verificar que se $L=M=N=3 F=3 G=3 H$ a equação acima se reduz ao critério de von Mises para materiais isotrópicos.

No caso de chapas, que é a forma construtiva de interesse do trabalho, a hipótese de tensão plana é assumida e com isso, o critério de Hill passa a ser 
escrito como:

$$
f=\sqrt{(G+H) \sigma_{x}^{2}-2 H \sigma_{x} \sigma_{y}+(H+F) \sigma_{y}^{2}+2 N \sigma_{x y}^{2}}-1=0
$$

onde $x y$ representa o plano da chapa, sendo $x$ a direção correspondente à direção de laminação.

Para a aplicação do critério em procedimentos analíticos e computacionais, é necessária a determinação dos parâmetros de anisotropia. O autor propõe uma abordagem para determinar estes parâmetros conforme descrito a seguir. Seja $X, Y, Z$ as tensões de escoamento nas direções principais de anisotropia. Nos casos em que o ponto material está submetido a um estado uniaxial de tensão na direção correspondente à tensão de escoamento, a partir da eq. 4.1 pode-se mostrar que:

$$
\begin{array}{ll}
\frac{1}{X^{2}}=G+H & 2 F=\frac{1}{Y^{2}}+\frac{1}{Z^{2}}-\frac{1}{X^{2}} \\
\frac{1}{Y^{2}}=H+F & 2 G=\frac{1}{Z^{2}}+\frac{1}{X^{2}}-\frac{1}{Y^{2}} \\
\frac{1}{Z^{2}}=F+G & 2 H=\frac{1}{X^{2}}+\frac{1}{Y^{2}}-\frac{1}{Z^{2}}
\end{array}
$$

Para a determinação dos parâmetros correspondentes as tensões de cisalhamento, sejam $R, S$ e $T$ as três tensões de escoamento em cisalhamento puro associadas aos planos $y z, z x$ e $x y$ respectivamente, então a partir da eq. 4.1:

$$
2 L=\frac{1}{R^{2}} \quad 2 M=\frac{1}{S^{2}} \quad 2 N=\frac{1}{T^{2}}
$$

O conjunto de eq. 4.3 e 4.4 permitem que os parâmetros de anisotropia sejam determinados a partir das tensões de escoamento correspondentes direções principais e dos planos ortogonais de anisotropia. Pode-se observar matematicamente pelas equações que os coeficientes $L, M, N$ devem ser estritamente positivos, enquanto que um dos coeficientes $F, G, H$ pode ser negativo, o que é possível apenas quando as tensões de escoamento são consideravelmente diferentes, o que na prática não é comum em metais. 
No caso de chapas metálicas, a determinação da tensão de escoamento ao longo da espessura bem como a determinação das tensões de escoamento em cisalhamento puro é uma tarefa complicada e requer a execução de inúmeros ensaios, inviabilizando o procedimento.

Com isto, na prática um procedimento baseado na relação entre o índice de anisotropia plástica $R$ e estes parâmetros é utilizada. Este procedimento é realizado a partir da medida dos incrementos de deformação plástica em corpos de prova submetidos a um estado uniaxial de tensão fornecendo um método indireto na determinação da relação das tensões de escoamentos utilizadas nas eq. $4.3 \mathrm{e}$ eq. 4.4 .

A definição do índice de anisotropia $R$ desenvolvida por Hill é dada pela relação entre o incremento de deformação plástica da largura dividido pelo incremento de deformação plástica na espessura, para um corpo de prova uniaxial cortado em uma direção genérica, orientada de um ângulo $\alpha$ em relação à direção de laminação.

$$
R_{\alpha}=\frac{d \varepsilon_{\left(\alpha+90^{\circ}\right)}^{p}}{d \varepsilon_{z}^{p}}
$$

O incremento de deformação $d \varepsilon_{\left(\alpha+90^{\circ}\right)}^{p}$ pode ser escrito em termos das componentes de deformação orientadas com o sistema $x y$ de coordenadas através da seguinte relação:

$$
d \varepsilon_{\left(\alpha+90^{\circ}\right)}^{p}=d \varepsilon_{x}^{p} \operatorname{sen}^{2} \alpha+d \varepsilon_{y}^{p} \cos ^{2} \alpha-d \varepsilon_{x y}^{p} \operatorname{sen} \alpha \cos \alpha
$$

Conforme visto no capítulo anterior, as componentes dos incrementos de deformação plástica podem ser determinadas a partir da regra de fluxo. Aplicandose a regra de fluxo associativa à eq. 4.1 chega-se as seguintes relações para os incrementos de deformação plástica: 


$$
\begin{aligned}
d \varepsilon_{x}^{p} & =d \lambda \frac{\partial f}{\partial \sigma_{x}}=d \lambda\left[\frac{H\left(\sigma_{x}-\sigma_{y}\right)+G\left(\sigma_{x}-\sigma_{z}\right)}{\sigma_{e}}\right] \\
d \varepsilon_{y}^{p} & =d \lambda \frac{\partial f}{\partial \sigma_{y}}=d \lambda\left[\frac{F\left(\sigma_{y}-\sigma_{z}\right)+H\left(\sigma_{y}-\sigma_{x}\right)}{\sigma_{e}}\right] \\
d \varepsilon_{z}^{p} & =d \lambda \frac{\partial f}{\partial \sigma_{z}}=d \lambda\left[\frac{G\left(\sigma_{z}-\sigma_{x}\right)+F\left(\sigma_{z}-\sigma_{y}\right)}{\sigma_{e}}\right] \\
d \gamma_{x y}^{p} & =d \lambda \frac{\partial f}{\partial \sigma_{x y}}=d \lambda\left[\frac{2 N \sigma_{x y}}{\sigma_{e}}\right] \\
d \gamma_{y z}^{p} & =d \lambda \frac{\partial f}{\partial \sigma_{y z}}=d \lambda\left[\frac{2 L \sigma_{y z}}{\sigma_{e}}\right] \\
d \gamma_{x z}^{p} & =d \lambda \frac{\partial f}{\partial \sigma_{x z}}=d \lambda\left[\frac{2 M \sigma_{x z}}{\sigma_{e}}\right]
\end{aligned}
$$

onde: $d \lambda$ é o multiplicador plástico e $\sigma_{e}$ é a tensão equivalente do critério de Hill dada na eq. 4.1.

Por outro lado, no regime plástico a hipótese de incompressibilidade ou volume constante é assumida, de forma que:

$$
d \varepsilon_{z}^{p}=-\left(d \varepsilon_{x}^{p}+d \varepsilon_{y}^{p}\right)
$$

Para a determinação do índice de anisotropia $R$ assume-se a hipótese de que um estado de tensão orientado segundo a direção $x$ de laminação pode ser gerado a partir de uma solicitação uniaxial em um corpo de prova cortado segundo a direção $\alpha$. Isto é representado pela rotação dada por:

$$
\left[\begin{array}{c}
\sigma_{x} \\
\sigma_{y} \\
\sigma_{x y}
\end{array}\right]=\left[\begin{array}{ccc}
\cos ^{2} \alpha & \operatorname{sen}^{2} \alpha & 2 \operatorname{sen} \alpha \cos \alpha \\
\operatorname{sen}^{2} \alpha & \cos ^{2} \alpha & -2 \operatorname{sen} \alpha \cos \alpha \\
-\operatorname{sen} \alpha \cos \alpha & \operatorname{sen} \alpha \cos \alpha & \cos ^{2} \alpha-\operatorname{sen}^{2} \alpha
\end{array}\right]\left[\begin{array}{l}
\sigma \\
0 \\
0
\end{array}\right]
$$

Desta forma, a eq. 4.5 é finalmente desenvolvida, considerando-se a eq. 4.6, as componentes de deformação plásticas eq. 4.7 a 4.9, a hipótese de volume constante eq. 4.13 e a relação do estado de tensão eq. 4.14 . 
Assim, a expressão final para o índice de anisotropia é dada conforme a eq. 4.15:

$$
R_{\alpha}=\frac{(2 N-F-G-4 H) \operatorname{sen}^{2} \alpha \cos ^{2} \alpha+H}{F \operatorname{sen}^{2} \alpha+G \cos ^{2} \alpha}
$$

Particularmente para as direções $\alpha=0^{\circ}, \alpha=45^{\circ}$ e $\alpha=90^{\circ}$ tem-se:

$$
\begin{aligned}
R_{0} & =\frac{H}{G} \\
R_{45} & =\frac{1}{2}\left(\frac{2 N}{G+F}-1\right) \\
R_{90} & =\frac{H}{F}
\end{aligned}
$$

As equações 4.16 a 4.18 relacionam os parâmetros de anisotropia do critério de Hill, com o índice de anisotropia $R_{\alpha}$. Este índice pode ser determinado experimentalmente através das medições das deformações em corpos de prova uniaxiais cortados fazendo diferentes ângulos em relação à direção de laminação.

Segundo KAWKA e MAKINOUCHI (1996), a determinação dos parâmetros de anisotropia em termos dos índices $R_{\alpha}$ pode ser realizada conforme as equações:

$$
\begin{aligned}
F & =\frac{R_{0}}{R_{90}\left(R_{0}+1\right)} \\
G & =\frac{1}{\left(R_{0}+1\right)} \\
H & =\frac{R_{0}}{\left(R_{0}+1\right)} \\
N & =\frac{\left(R_{0}+R_{90}\right)\left(2 R_{45}+1\right)}{2 R_{90}\left(R_{0}+1\right)}
\end{aligned}
$$

A seguir são apresentados alguns aspectos experimentais relacionados ao índice de anisotropia plástica $R_{\alpha}$ e suas diferentes implicações na formabilidade de chapas metálicas. 


\section{4 Índice de anisotropia plástica}

Conforme visto no tópico anterior, o fenômeno de anisotropia de chapas metálicas pode ser avaliado através de um parâmetro denominado de índice de anisotropia plástica $R_{\alpha}$.

A determinação experimental deste índice é executada através de um ensaio normalizado de anisotropia, conforme especificado na norma ASTM E517-96a. Em contraste com a definição dada pela eq. 4.5, baseada nos incrementos de deformação plástica, o procedimento experimental define um ensaio no qual o cálculo do índice $R_{\alpha}$ é feito em função das deformações totais, a partir da razão entre a deformação plástica verdadeira da largura $\left(\varepsilon_{w}^{p}\right)$ pela deformação da espessura $\left(\varepsilon_{z}^{p}\right)$ de um corpo de prova normalizado. Neste ensaio, o corpo de prova é submetido à um carregamento uniaxial de tração, a partir do qual são medidas as deformações para a determinação da razão conforme a seguir:

$$
R_{\alpha}=\frac{\varepsilon_{w}^{p}}{\varepsilon_{z}^{p}}
$$

A definição apresentada por Hill, eq. 4.5, e a definição apresentada pelo procedimento normalizado, eq. 4.23, são equivalentes uma vez que é assumido que a relação entre as deformações totais permanecem constantes ao longo do carregamento. Conforme será apresentado posteriormente, alguns autores comparam e discutem estas diferentes maneiras utilizadas para determinação dos índices de anisotropia.

Como no caso de chapas finas a medição da deformação ao longo da espessura é susceptível a erros, é comum admitir-se a hipótese de volume constante. Com isto, utilizando-se da definição de deformações logarítmicas, a eq. 4.23 pode ser reescrita como:

$$
R_{\alpha}=\frac{\ln \left(w_{0} / w\right)}{\ln \left(l w / l_{0} w_{0}\right)}
$$

onde: $w_{0}$ e $l_{0}$ são a largura e o comprimento iniciais e $w$ e $l$ são a largura e o comprimento finais do corpo de prova, respectivamente. 
A caracterização da anisotropia do material a partir do índice $R_{\alpha}$ é geralmente realizada com corpos de prova cortados fazendo ângulos de $0^{\circ}, 45^{\circ}$ e $90^{\circ}$ em relação à direção de laminação. Para cada uma destas direções, usualmente um valor de deformação é utilizado como referência e a determinação de $R_{\alpha}$ é executada a partir da eq. 4.24 .

No caso de materiais perfeitamente isotrópicos os valores de $R_{\alpha}$ para qualquer direção $\alpha$ é igual à unidade. Entretanto, para muitos aços e outros materiais é comum uma variação de $R_{\alpha}$ sobre o plano da chapa. Esta variação é denominada de anisotropia planar $\Delta R$ calculada como a diferença entre o valor de $R_{45}$ e os valores médios nas direções de $R_{0}$ e $R_{90}$ :

$$
\Delta R=\frac{R_{0}+R_{90}-2 R_{45}}{2}
$$

onde os subescritos de $R_{0}, R_{45}$ e $R_{90}$ referem-se ao ângulo entre a linha de centro do corpo de prova e a direção de laminação.

O índice de anisotropia planar está relacionado com a tendência de formação de orelhas no repuxamento de copos. A magnitude de $\Delta R$ indica a severidade e seu sinal indica a posição das orelhas na peça. Valores positivos de $\Delta R$ estão associados com a formação de orelhas à $0^{\circ}$ e $90^{\circ}$ da direção de laminação, enquanto que valores negativos implicam em orelhas à $45^{\circ}$. Quando $\Delta R=0$ nenhuma orelha se forma durante o processo.

Em alguns casos a anisotropia ao longo da espessura da chapa é diferente daquela no seu plano. Com isso pode-se definir um outro índice denominado de anisotropia normal $R_{m}$ definido como:

$$
R_{m}=\frac{R_{0}+R_{90}+2 R_{45}}{4}
$$

O índice $R_{m}$ é um parâmetro da formabilidade do material que indica a capacidade da chapa em resistir ao afinamento quando submetida à carragamentos em seu plano. Quando $R_{m}>1$ o material caracteriza-se por ter uma resistência ao afinamento ou seja apresenta uma resistência maior ao longo da espessura. 
Por outro lado $R_{m}<1$ implica em chapas com maior facilidade de afinamento e com uma possível tendência a ruptura com o decorrer do processo.

Na Figura 4.1 são ilustradas as falhas mais comuns na conformação de copos devido ao efeito da anisotropia. Pode-se observar claramente a formação de orelhas devido à anisotropia planar do material para a caneca circular, bem como o enrugamento nas bordas e a ruptura da parede no caso da caneca quadrada.
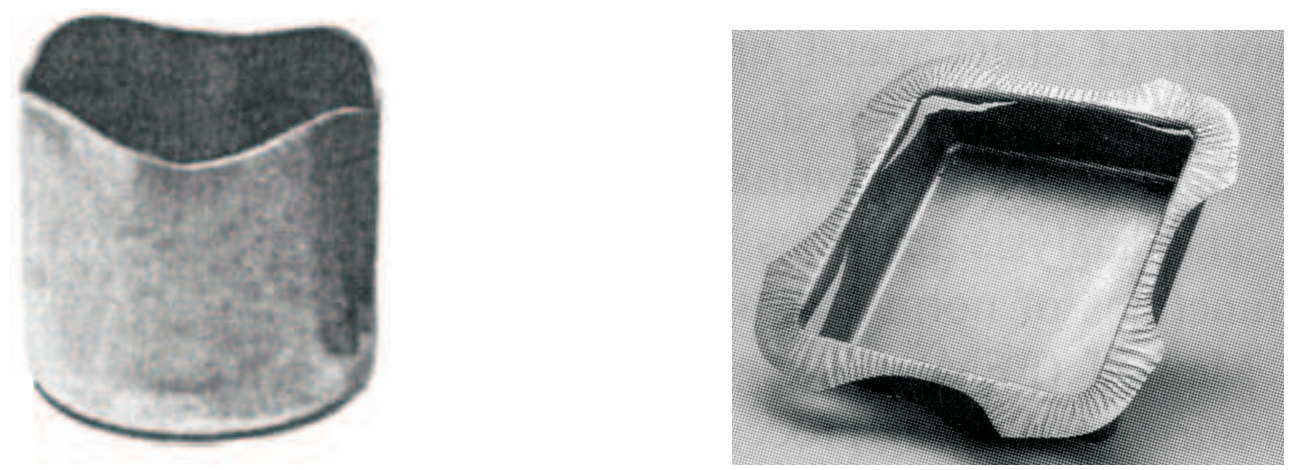

Figura 4.1: Falhas no repuxamento de copos

Utilizando-se as relações entre os parâmetros de anisotropia do critério de Hill e o índice $R_{\alpha}$ em conjunto com a eq. 4.26, o critério de Hill em tensão plana pode ser escrito em função do índice de anisotropia normal $R_{m}$ da seguinte forma:

$$
f=\sigma_{1}^{2}+\sigma_{2}^{2}-\left(\frac{2 R_{m}}{R_{m}+1}\right) \sigma_{1} \sigma_{2}-\sigma_{0}=0
$$

A eq. 4.27 permite avaliar o comportamento da superfície de escoamento para diferentes níveis de anisotropia do material. Esta avaliação pode ser realizada a partir da Figura 4.2 que ilustra a forma da superfície no plano $\sigma_{1} \mathrm{x} \sigma_{2}$ para três situações distintas.

O caso $R_{m}=1$ corresponde à superfície isotrópica, uma vez que a eq. 4.27 com $R_{m}=1$ recupera o critério de von Mises em tensão plana. Quando $R_{m}>1$ a superfície sofre um alongamento quando comparada com a superfície isotrópica. Nos casos em que $R_{m}<1$ pode-se observar o chamado comportamento anômalo que consiste na tensão de escoamento biaxial $\sigma_{b}$ ser maior que a tensão de escoamento uniaxial. Este efeito é caracterizado avaliando a reta $\sigma_{1}=\sigma_{2}$ a qual cruza 
a superfície de escoamento em um ponto cuja tensão de escoamento é menor que o cruzamento em tensão uniaxial.

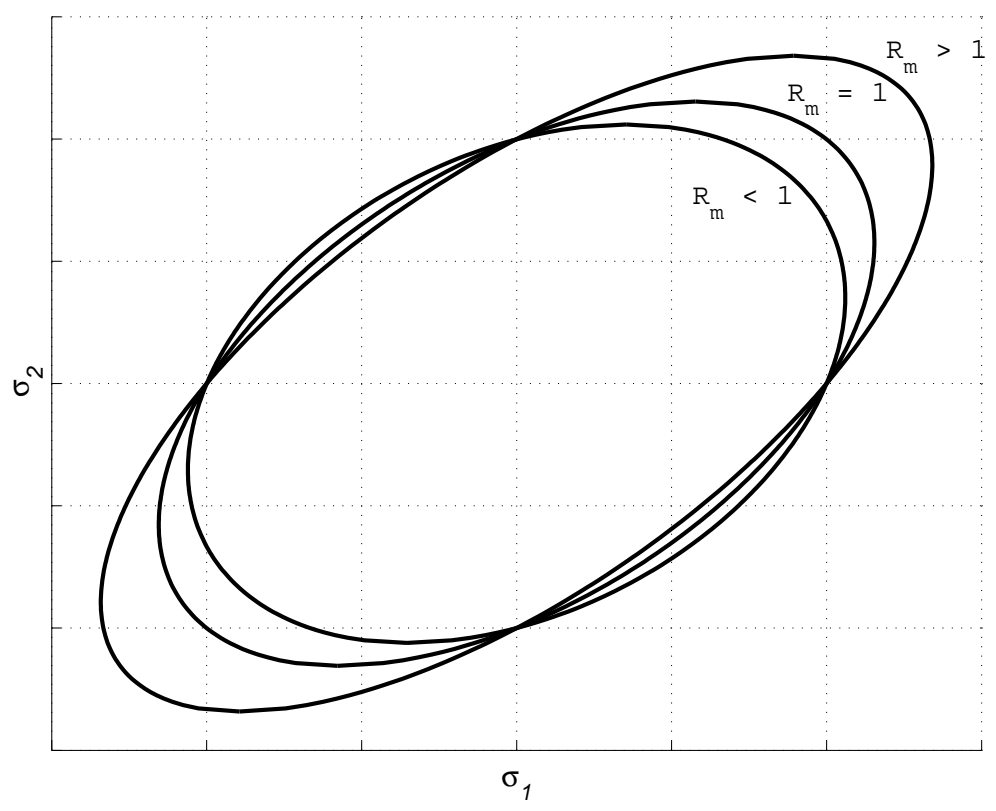

Figura 4.2: Superfície de escoamento em função de $R_{m}$

\subsection{Outras superfícies de escoamento}

Além da superfície proposta pelo critério de HILL (1950), outras diversas superfícies de escoamento anisotrópicas podem ser encontradas na literatura.

Dentre elas destaca-se inclusive novas superfícies propostas pelo próprio Hill. Em HILL (1979) é proposta uma nova função de escoamento não quadrática e com parâmetros de anisotropia adicionais, dada conforme a eq. 4.28, para acomodar o comportamento anômalo descrito no tópico anterior e para descrever mais satisfatoriamente o comportamento de certas ligas.

$$
\begin{aligned}
f= & F\left|\sigma_{2}-\sigma_{3}\right|^{m}+G\left|\sigma_{3}-\sigma_{2}\right|^{m}+H\left|\sigma_{1}-\sigma_{2}\right|^{m}+ \\
& L\left|2 \sigma_{1}-\sigma_{2}-\sigma_{3}\right|^{m}+M\left|2 \sigma_{2}-\sigma_{3}-\sigma_{1}\right|^{m}+N\left|2 \sigma_{3}-\sigma_{1}-\sigma_{2}\right|^{m}-\sigma_{b}^{m}=0
\end{aligned}
$$

onde: $\sigma_{b}$ é a tensão de escoamento biaxial e $m$ um escalar associado ao material. 
Outra superfície de escoamento mais recente desenvolvida por Hill é dada em HILL (1990) e é escrita conforme a eq. 4.29:

$$
\begin{aligned}
f= & \left|\sigma_{1}+\sigma_{2}\right|^{m}+\left(\frac{\sigma_{b}}{\tau_{45}}\right)^{m}\left|\sigma_{1}-\sigma_{2}\right|^{m}+ \\
& \left|\sigma_{1}^{2}+\sigma_{2}^{2}\right|^{(m / 2)-1}\left[-2 a\left(\sigma_{1}^{2}-\sigma_{2}^{2}\right)+b\left(\sigma_{1}-\sigma_{2}\right)^{2} \cos 2 \alpha\right] \cos 2 \alpha-\left(2 \sigma_{b}\right)^{m}=0
\end{aligned}
$$

onde: $\tau_{45}$ é a tensão de escoamento em cisalhamento na direção $45^{\circ}$ em relação à direção de laminação, $a$ e $b$ parâmetros que descrevem a anisotropia do material e $\alpha$ o ângulo entre a tensão principal e a direção de laminação.

No trabalho de WU (2002), o critério de HILL (1950) é generalizado para incluir o conceito de encruamento combinado isotrópico-cinemático. No seu trabalho, o autor considera a parcela de encruamento isotrópica descrita por meio de uma lei exponencial e a parcela cinemática dada pela lei de Prager. O modelo proposto pelo autor é validado por meio de comparações com ensaios experimentais. Com esta generalização o critério de HILL (1950), no caso de tensão plana, passa a ser escrito na forma:

$$
f=\sqrt{(G+H){\overline{\sigma_{x}}}^{2}-2 H \overline{\sigma_{x}} \overline{\sigma_{y}}+(H+F){\overline{\sigma_{y}}}^{2}+2 N \tau_{x y}^{-}}-\sigma_{0}=0
$$

onde: $\sigma_{0}$ corresponde à tensão de escoamento relacionada com a parcela isotrópica do encruamento. A parcela cinemática fica embutida nos termos $\overline{\sigma_{i j}}=\sigma_{i j}-\alpha_{i j}$, sendo $\alpha_{i j}$ as componentes da tensão de retorno.

Além dos critérios baseados nas superfícies de Hill, também destacam-se as inúmeras superfícies de escoamento anisotrópicas propostas por Barlat. O critério desenvolvido por BARLAT e LIAN (1989) para materiais anisotrópicos em tensão plana é um dos mais conhecidos e implementados em pacotes comerciais de elementos finitos. Este critério é escrito na forma:

$$
f=a\left|K_{1}+K_{2}\right|^{m}+a\left|K_{1}-K_{2}\right|^{m}+c\left|2 K_{2}\right|^{m}-2 \sigma_{0}^{m}=0
$$


onde $\sigma_{0}$ é a tensão de escoamento e os parâmetros $K_{1}$ e $K_{2}$ são calculados como:

$$
\begin{aligned}
K_{1} & =\frac{\sigma_{x}+h \sigma_{y}}{2} \\
K_{2} & =\sqrt{\left(\frac{\sigma_{x}-h \sigma_{y}}{2}\right)^{2}+p^{2} \tau_{x y}^{2}}
\end{aligned}
$$

O coeficiente $m$ está relacionado com o arranjo cristalográfico do material e as outras constantes $a, c, h$ e $p$ podem ser obtidas a partir dos índices de anisotropia $R_{\alpha}$. A Figura 4.3 ilustra a forma padrão desta superfície. Pode-se observar pela figura a formação de um "bico"na medida em que o encruamento do material ocorre, o que tende a compensar o efeito anômalo discutido anteriormente.

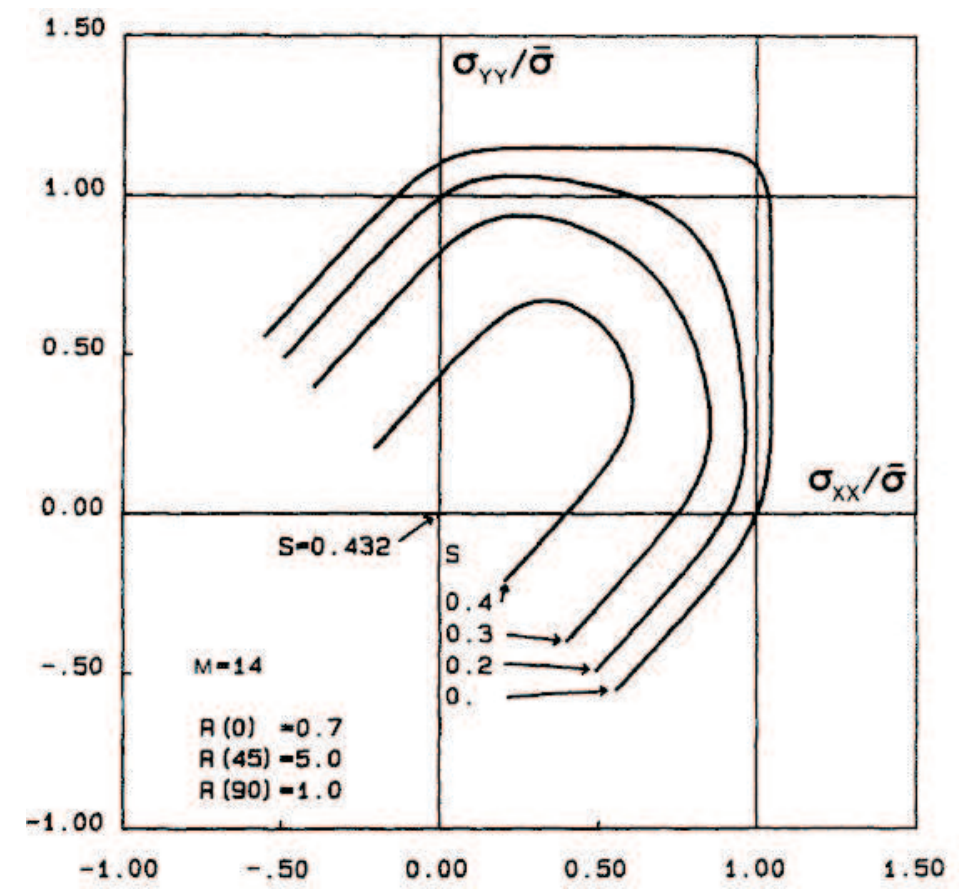

Figura 4.3: Superfície de escoamento BARLAT e LIAN (1989)

BANABIC et al. (2004) apresentam um critério baseado na superfície de BARLAT e LIAN (1989), considerando coeficientes adicionais relacionados com as propriedades do material. A determinação destes coeficientes é executada por meio de uma otimização com dados experimentais. A Figura 4.4 ilustra a forma padrão da superfície proposta pelos autores para uma liga de alumínio de série 6000 . Os pontos localizados no primeiro quadrante representam valores 
determinados experimentalmente, e mostram uma boa correlação com a superfície proposta.

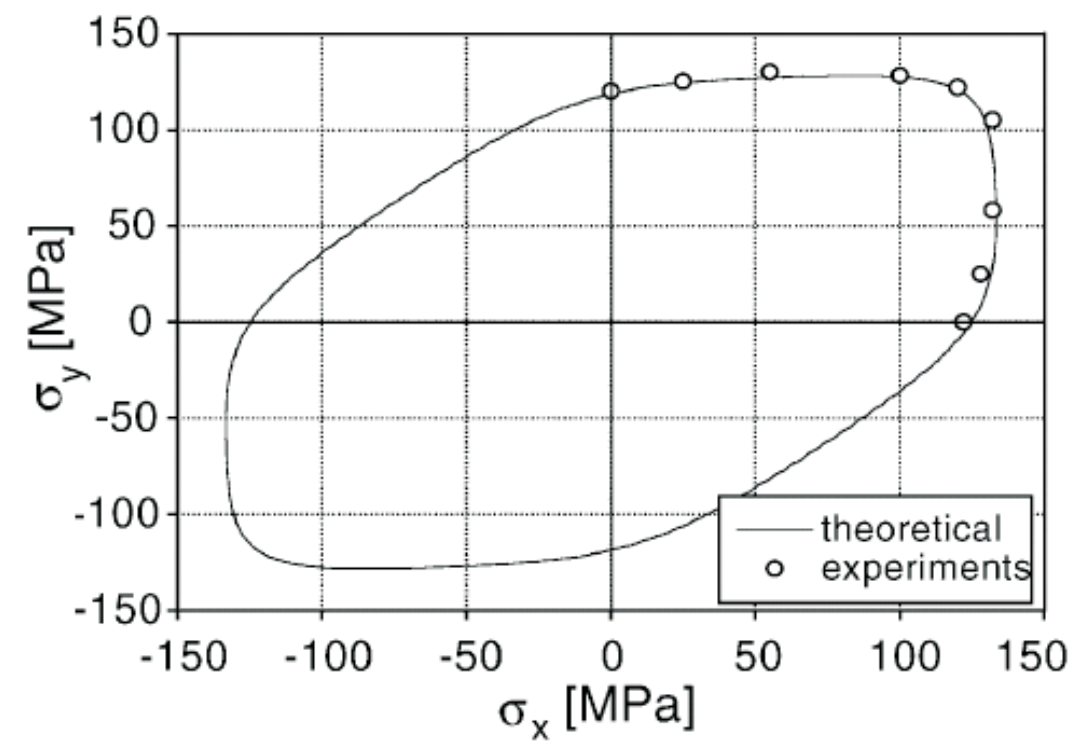

Figura 4.4: Superfície de escoamento BANABIC et al. (2004)

\subsection{Recentes desenvolvimentos}

Outro aspecto relacionado com o estudo do comportamento anisotrópico de chapas metálicas, consiste na aplicação de critérios anisotrópicos combinados com modelos de encruamento que representem o fenômeno. Conforme visto, a grande maioria dos modelos matemáticos aplicados para representar o comportamento anisotrópico, considera os parâmetros de anisotropia constantes no decorrer do carregamento plástico. Desta forma, para melhor representar o comportamento mecânico da chapa conformada, muitas vezes os modelos de encruamento adotados são complexos e necessitam da determinação de um número grande de constantes de material.

Dentre esses modelos, destaca-se o modelo anisotrópico com encruamento combinado (isotrópico-cinemático). Tal modelo é comumente aplicado no caso de carregamentos cíclicos, onde a parcela cinemática torna-se importante para a representação do efeito Bauschinger discutido no capítulo anterior. 
Nestes casos, além do ensaio tradicional de tração para determinação das constantes relacionadas com a parcela isotrópica, torna-se necessário a realização de ensaios cíclicos em corpos de prova para a caracterização das constantes referentes a parcela cinemática. Para estes ensaios o procedimento mais aplicado é o ensaio cíclico de flexão, uma vez que o ensaio de tração-compressão é de difícil execução devida a flambagem dos corpos de prova. Muitos trabalhos aplicam uma análise inversa para a determinação destas constantes de material. Trata-se de uma otimização entre dados experimentais e teóricos.

Nexte contexto, para a determinação das constantes de material BRUNET, MORESTIN e GODEREAUX (2001) realizaram ensaios de carregamentos cíclicos de flexão em uma chapa metálica onde a anisotropia é considerada. Um dispositivo com controlador de torque foi utilizado para efetuar os carregamento cíclicos de flexão nos corpos de prova. Aplicando o conceito de encruamento combinado, as constantes de material foram determinadas a partir de uma análise inversa. $\mathrm{O}$ momento fletor medido experimentalmente é comparado com o momento teórico calculado a partir do perfil de tensões ao longo da espessura da chapa. Como este momento teórico fica escrito em termos das constantes de material aplica-se um procedimento de otimização para que estas constantes sejam identificadas. Assim os autores buscam representar melhor o comportamento de chapas metálicas anisotrópicas.

Utilizando o mesmo conceito, ZHAO e LEE (2001) aplicam um algoritmo de otimização genético para a identificação das constantes de material de uma chapa anisotrópica utilizando o modelo combinado de encruamento. O ensaio cíclico é executado por um dispositivo similar ao ensaio de flexão três pontos. A partir da identificação das constantes de material, os autores buscam prever de maneira mais acurada o efeito do retorno elástico em chapas.

SINOU e MACQUAIRE (2003) também investigaram o comportamento anisotrópico de chapas de ligas de alumínio. A partir de uma série de ensaios (ensaios de tração, compressão e cisalhamento) os autores determinaram a tensão de escoamento do material nos diferentes estados de tensão dados pelos ensaios. Com 
isso, pontos notáveis da superfície de escoamento do material foram caracterizados experimentalmente. A superfície teórica foi determinada particularizando-se os estados de tensão-deformação de cada ensaio nas equações da função de escoamento de Hill com o modelo combinado de encruamento.

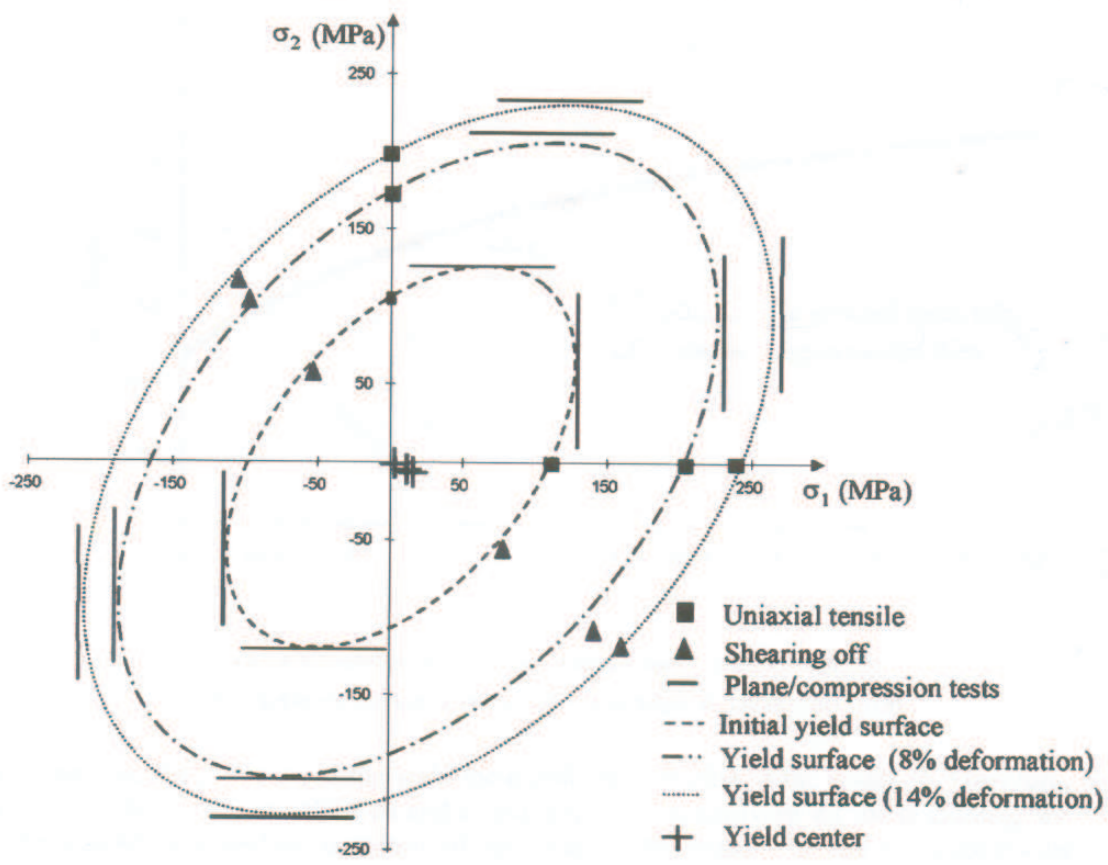

Figura 4.5: Superfície de escoamento SINOU e MACQUAIRE (2003)

Os resultados obtidos mostraram que o critério de escoamento de Hill com encruamento combinado isotrópico e cinemático permite uma boa descrição do fenômeno conforme pode ser observado na Figura 4.5. Nota-se uma boa correlação com os pontos experimentais e a superfície calculada em diferentes níveis de deformação.

Outro campo de pesquisa consiste na determinação dos parâmetros de anisotropia experimentalmente. A partir da definição tradicional para determinação dos índices de anisotropia, alguns trabalhos apresentam estudos e discussões sobre o ensaio padrão de anisotropia em corpos de prova uniaxiais e propostas de ensaios alternativos para a determinação da anisotropia.

Neste contexto, o trabalho de CHAMANFAR e MAHMUDI (2004) avalia a influência da marcação padrão, dada por norma, do comprimento e largura (gage 
lenght, width) de corpos de prova, na medida do índice de anisotropia. No geral os autores observaram um sutil acréscimo nos valores das deformações longitudinais com as marcações mais curtas.

Em outro trabalho mais recente, CHAMANFAR e MAHMUDI (2005) apresentam uma nova proposta para o cálculo dos índices de anisotropia com a compensação das deformações elásticas. Com isso os autores comparam os valores dos índices de anisotropia obtidos com e sem a compensação desta parcela de deformação. Os resultados obtidos mostraram que para materiais onde o retorno elástico é pequeno, a determinação do índice de anisotropia na condição carregada não difere muito daquela sem o carregamento. Entretanto para materiais onde o retorno elástico é alto, como em ligas de titânio, a parcela de deformação elástica é significativa e consequentemente influência nos resultados dos índices de anisotropia. Alguns resultados são mostrados na Figura 4.6 para ligas de alumínio (a) e titânio (b). Na figura $R_{L D}$ e $R_{U L}$ correspondem as curvas calculadas na condição carregada e descarregada, respectivamente. $R_{\text {new }}$ representa a curva calculada pelo equacionamento proposto pelos autores e $R_{D-N}$ a curva calcula com a compensação elástica dada no trabalho de DANCKERT e NIELSEN (1998).

DANCKERT e NIELSEN (1998) apresentam um procedimento para o cálculo da evolução dos parâmetros de anisotropia via ensaio convencional. Os autores propõem um método na qual as parcelas de deformação elástica do corpo de prova tracionado são automaticamente descontadas das medidas das deformações totais realizadas com extensômetros. Desta forma a aquisição de dados é executada sem interrupções e os índices de anisotropia são determinados continuamente ao longo do ensaio. Os autores mostram que os resultados obtidos são compatíveis com os índices de anisotropia medidos na condição descarregada.

A Figura 4.7 ilustra uma comparação da variação dos índices de anisotropia para um corpo de prova de aço inoxidável AISI 304. A curva com a compensação da parcela elástica proposta pelos autores $\left(R_{\text {new }}\right)$ apresentou valores superiores àqueles sem esta compensação $\left(R_{n o}\right)$. A curva $R_{p b}$ representa a variação do $R_{\alpha}$ 

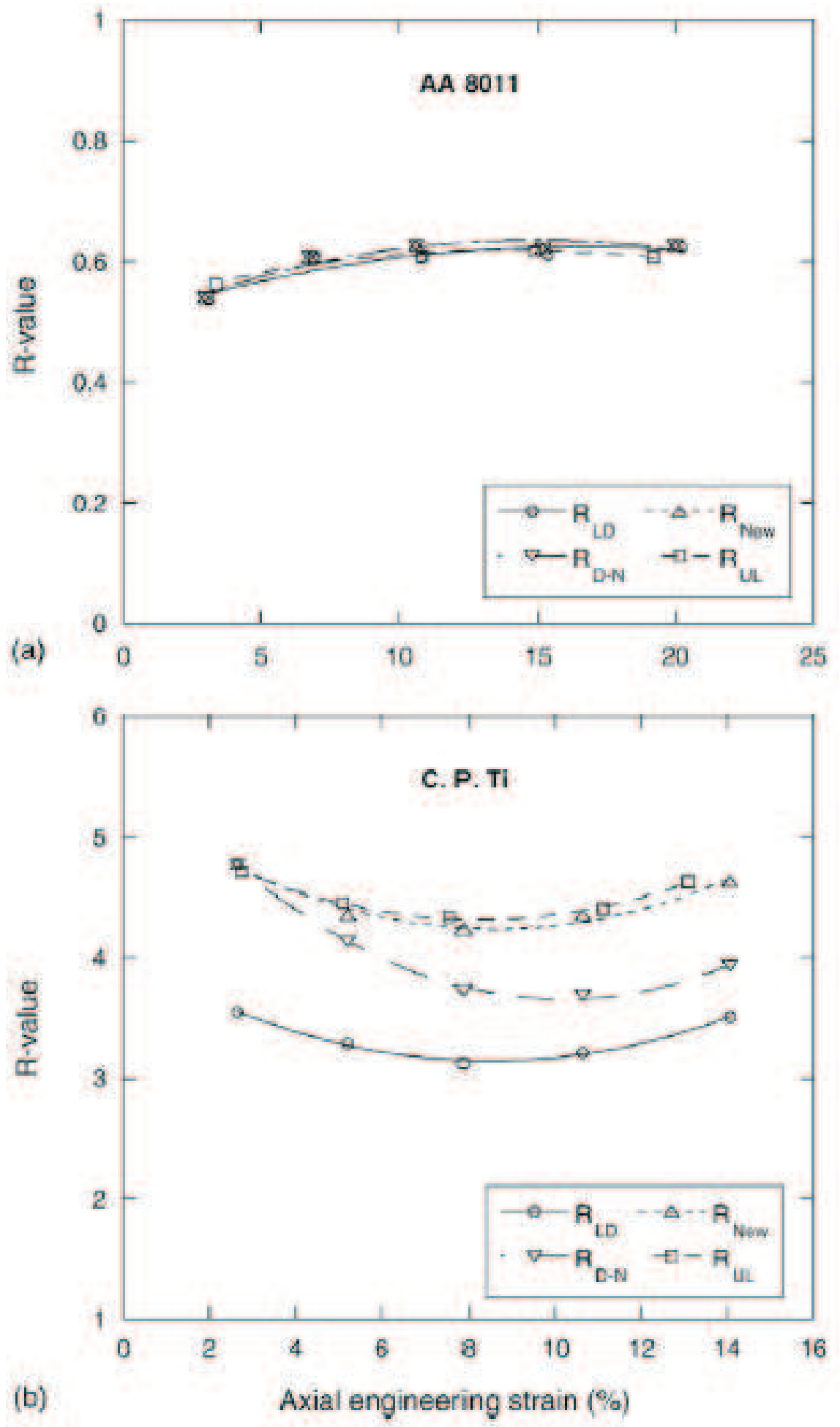

Figura 4.6: Evolução de $R_{\alpha}$ - CHAMANFAR e MAHMUDI (2005) 


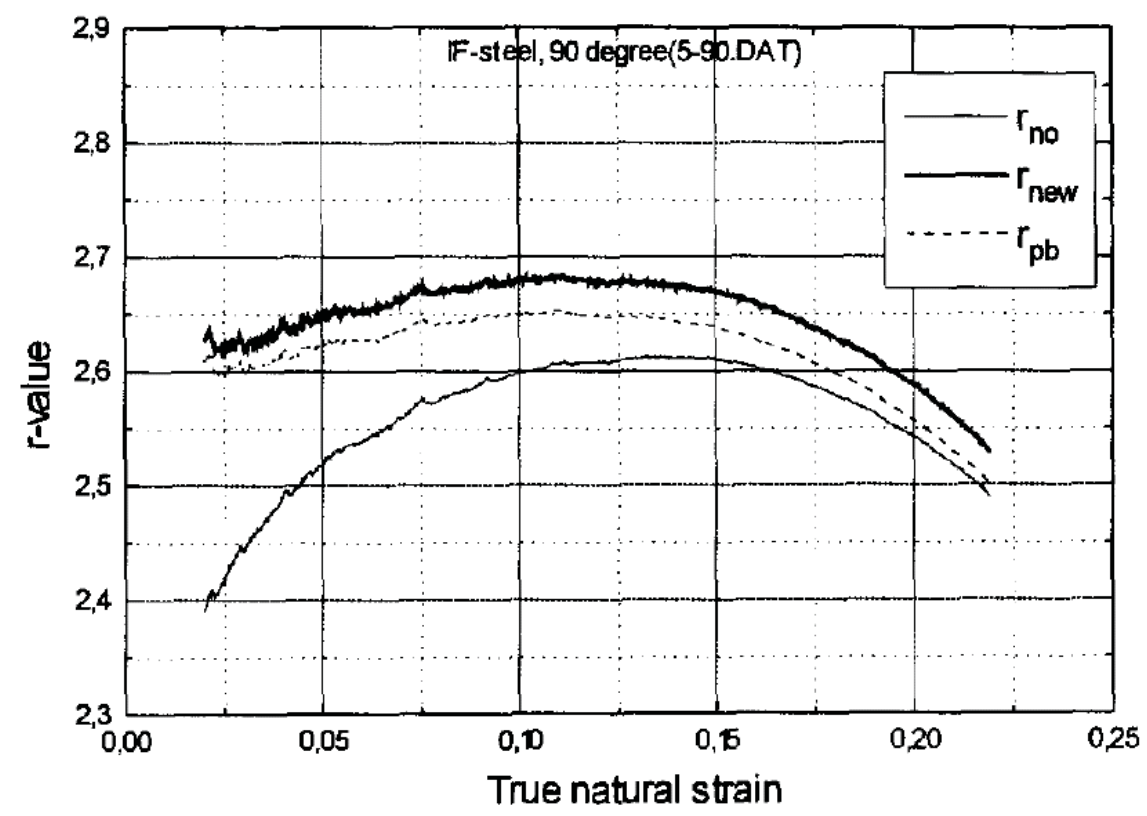

Figura 4.7: Evolução de $R_{\alpha}$ - DANCKERT e NIELSEN (1998)

com a compensação da parcela elástica proposta por outros autores.

RAO e MOHAN (2001) apresentaram uma proposta de integrar o ensaio de tração e anisotropia de forma que as constantes de material e os índices de anisotropia sejam determinados no mesmo ensaio. Para tal, os autores utilizaram um sistema de aquisição de imagens para medir as deformações longitudinal e transversal nos corpos de prova uniaxiais que foram previamente marcados com um sistema de grades.

GILMOUR, LEACOCK e ASHBRIDGE (2004) comparam os valores dos índices de anisotropia em ligas de alumínio obtidos a partir da definição dada na secção anterior, mas considerando-se três situações distintas. A primeira quando as deformações totais são utilizadas diretamente na eq. 4.23, ou seja, sem o desconto da parcela elástica. Na segunda situação, os índices de anisotropia são determinados da maneira tradicional, considerando-se apenas a parcela plástica das deformações. A terceira situação assume a definição dada pela eq. 4.5, em que o índice de anisotropia é calculado a partir dos incrementos de deformação plástica. A variação dos $R_{-} \alpha$ em função do encruamento e do método de cálculo é mostrada na Figura 4.8. A partir destas diferentes evoluções dos índices de 


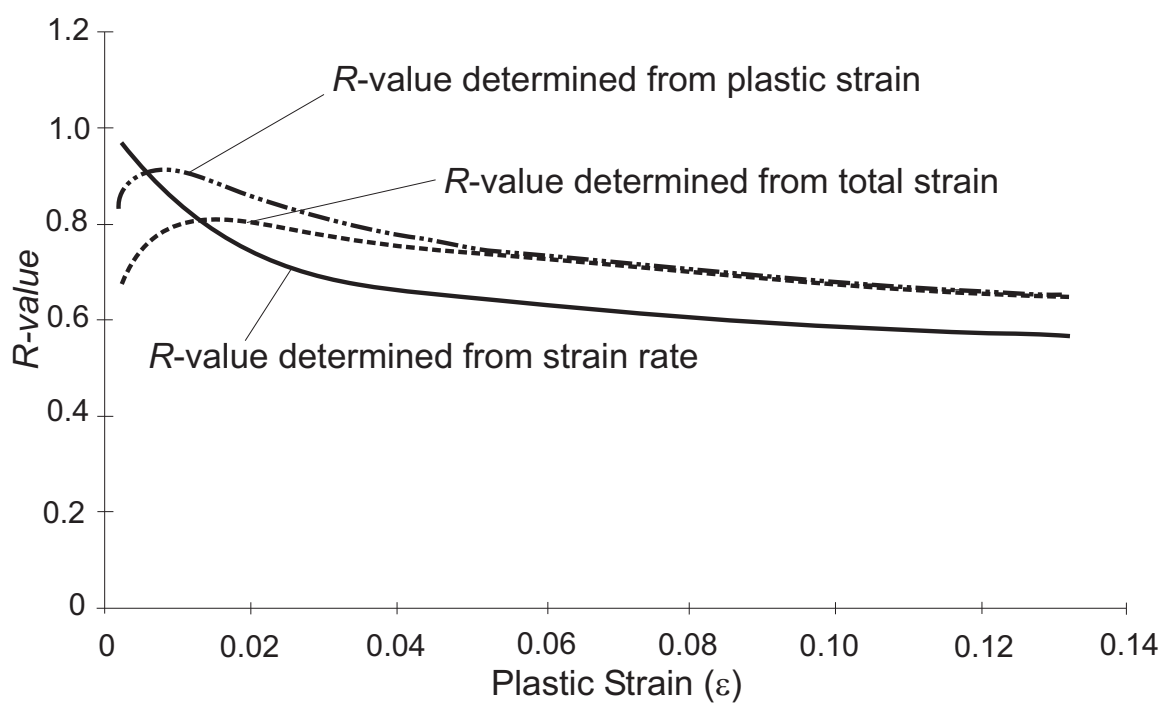

Figura 4.8: Evolução de $R_{\alpha}$ - GILMOUR, LEACOCK e ASHBRIDGE (2004)

anisotropia, os autores avaliam suas implicações na calibração da superfície de escoamento de Hill-1990 e posteriormente na simulação numérica de processos de conformação.

KAWABE et al. (2002) estudam a influência do índice de anisotropia $R_{\alpha}$ na formabilidade de diferentes chapas de aço laminadas à frio. Para tal os autores realizam uma série de ensaios variando parâmetros do processo de conformação como a força do prensa-chapas e condições de atrito.

YOON e HONG (2006) buscaram avaliar os efeitos da anisotropia do material implementando computacionalmente superfícies de escoamento propostas por Barlat no código comercial de elementos finitos LS-DYNA. Os autores constaram, por meio de comparações experimentais, que os modelos implementados representaram satisfatoriamente o comportamento da formação de orelhas no repuxamento de copos e o efeito do retorno elástico na estampagem de um painel automotivo.

Como proposta de ensaios alternativos de determinação da anisotropia, BOUVIER et al. (2006) aplicam o ensaio de cisalhamento para caracterizar o comportamento anisotrópico em ligas de AlMg e aços no âmbito das grandes deformações. No trabalho, os autores também discutem a influência da geometria e fixação do corpo de prova na acuracidade das medidas de deformação e na eliminação de 
efeitos indesejáveis.

Também executando ensaios alternativos, o trabalho de EVANGELISTA (2006) aplica o ensaio de estiramento biaxial em corpos de prova cruciformes feitos de chapas metálicas para o desenvolvimento de um novo enfoque para a determinação dos parâmetros de anisotropia do critério de Hill.

Desta forma foram apresentados alguns aspectos relacionados com o fenômeno de anisotropia de chapas metálicas. Os diversos trabalhos apresentados indicam que o fenômeno de anisotropia ainda é um problema cujos modelos estão em constante desenvolvimento para o aprimoramento de modelos numéricos de processos de conformação. A seguir são apresentadas a nova metodologia de cálculo de evolução dos parâmetros de anisotropia e a nova proposta de superfície de escoamento para chapas metálicas. 


\section{Capítulo 5}

\section{Metodologia e Nova Superfície de Escoamento}

Com base nos conceitos apresentados nos capítulos anteriores, são descritos neste capítulo os diversos tópicos que contribuem para a obtenção do objetivo principal do trabalho. A contribuição científica inédita é dada pelo desenvolvimento matemático do conjunto de equações cuja solução fornece a evolução dos parâmetros de anisotropia do critério de escoamento de Hill com o carregamento plástico e pela posterior definição de uma nova superfície de escoamento anisotrópica para chapas metálicas. Inicialmente são apresentados o desenvolvimento matemático e o conjunto de hipóteses e considerações que permitem a geração das equações que levam ao cálculo de evolução dos parâmetros de anisotropia. Em seguida é apresentada a metodologia para a determinação destes parâmetros seguida da definição da nova superfície de escoamento proposta e discussões gerais.

\subsection{Cálculo de evolução da anisotropia}

Para a elaboração do procedimento de cálculo de evolução, o conceito de anisotropia é tratado de forma alternativa, a partir de um estado particular de 
tensão-deformação na qual o ponto material estudado está submetido ao longo do carregamento. Este estado refere-se ao estado plano de tensão devida a chapa fina, combinado com um estado plano de deformação perpendicular ao plano $x y$ da chapa. Desta forma a abordagem tratada é diferente do enfoque clássico que utiliza um estado uniaxial de tensões na determinação dos parâmetros de anisotropia.

O desenvolvimento completo do equacionamento proposto abrange uma particularização das relações incrementais entre tensão e deformação obtidas a partir da Teoria Clássica da Plasticidade para o estado de tensão-deformação considerado, das hipóteses de carregamentos e sobre os modelos de encruamento adotados. Com estas considerações o algoritmo de previsão-correção é aplicado fornecendo as variáveis necessárias para a geração do sistema de equações e apresentação de sua solução que leva à evolução dos parâmetros de anisotropia com o carregamento plástico.

Desta forma, inicialmente são apresentados alguns aspectos referentes ao estado de tensão-deformação assumido, bem como algumas convenções geométricas para o problema. Em seguida é apresentado o desenvolvimento teórico do conjunto de equações e as hipóteses assumidas para solução do sistema de equações. Com isto é finalizada a apresentação da metodologia proposta.

\subsubsection{Estado de tensão-deformação em flexão}

O estado de tensão-deformação considerado no desenvolvimento do equacionamento é bastante comum em regiões de peças conformadas onde ocorram dobras. Como em geral a maioria dos produtos conformados apresenta regiões submetidas a dobras em sua fabricação, o estado de tensão-deformação base da formulação é comumente observado.

Este estado refere-se ao estado plano de tensão devido à chapa fina, combinado com um estado plano de deformação perpendicular ao plano $x y$ da chapa, conforme esquematizado na Figura 5.1. 

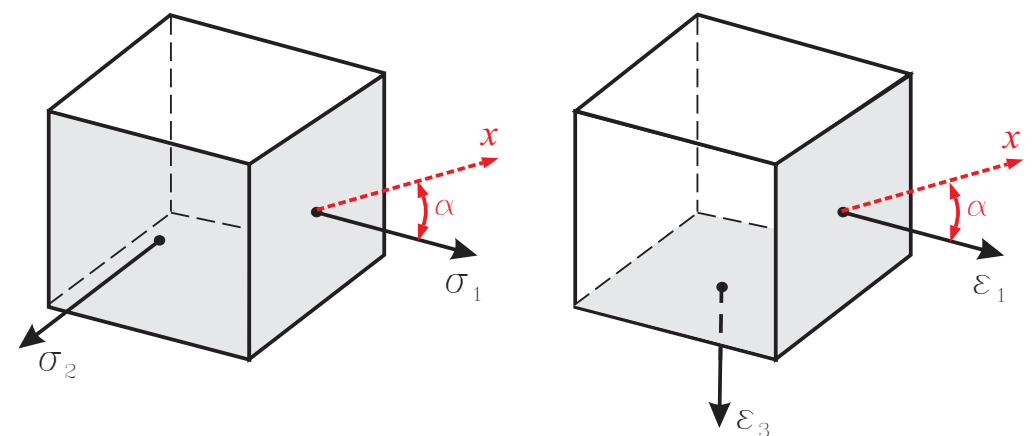

Figura 5.1: Estado tensão-deformação base da formulação

Note que a direção da maior tensão principal faz um ângulo $\alpha$ em relação à direção $x$ de laminação. Por convenção a direção de laminação está sempre alinhada com o eixo $x$ de forma que as componentes $\sigma_{x}$ e $\varepsilon_{x}$ correspondem respectivamente à tensão e deformação na direção de laminação, e $\sigma_{y}$ e $\varepsilon_{y}$ as componentes perpendiculares a esta direção.

Dada a importância deste estado particular na formulação, é apresentado aqui um resumo dos aspectos relacionados com o fenômeno de flexão de chapas, com enfoque no processo de dobramento. Diferentes técnicas podem ser aplicadas no dobramento de chapas onde segmentos retos são transformados em curvos. A Figura 5.2 ilustra algumas destas técnicas para diferentes geometrias e combinações entre matriz e punção.
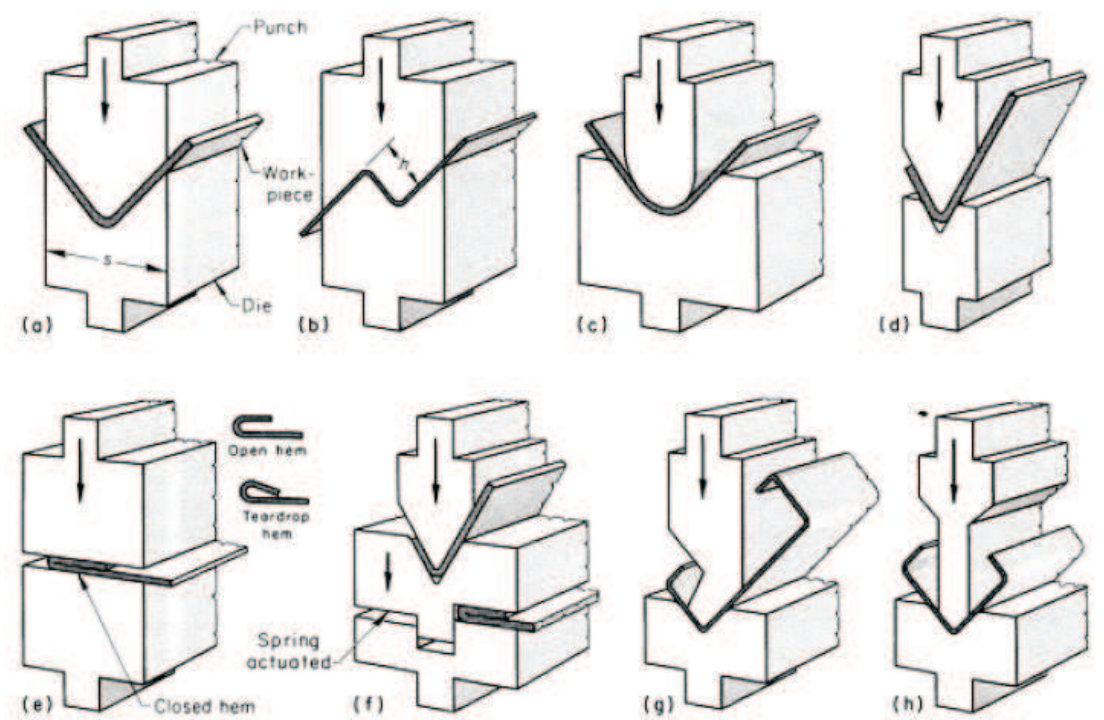

Figura 5.2: Diferentes formas de dobramento 
No dobramento, o ângulo de dobra da peça é função da geometria da matriz e dos ajustes que podem ser feitos no ferramental, sendo também fortemente influenciado pelo retorno elástico (springback). Este fenômeno consiste no relaxamento da peça após sua retirada da matriz e está associado com a redistribuição da energia elástica acumulada durante o processo.

A Figura 5.3 detalha os principais parâmetros associados ao processo de dobramento: o raio de dobra $R$, o ângulo de dobra $\theta$, a espessura $t$ e a largura da chapa $b$.

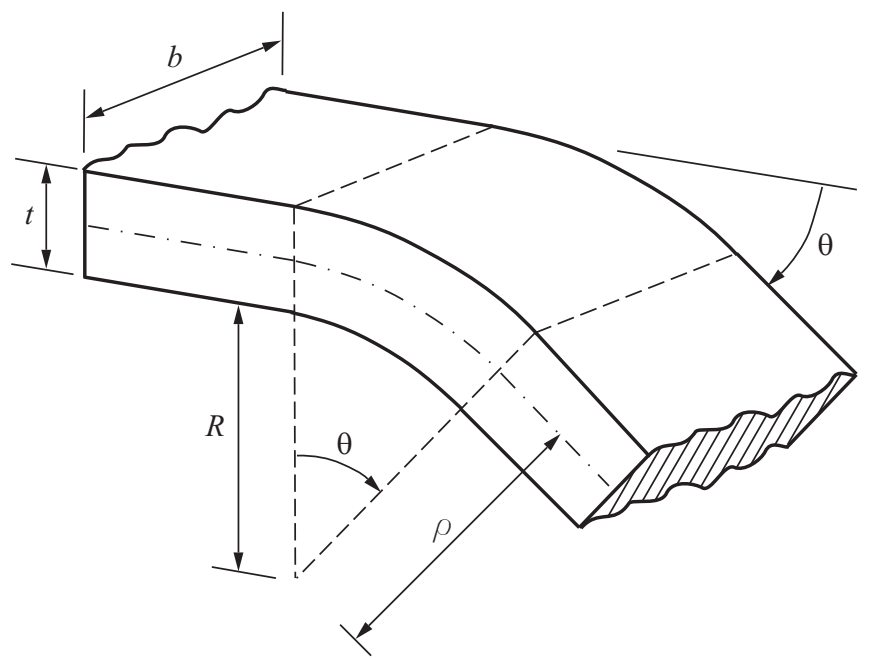

Figura 5.3: Principais parâmetros associados ao dobramento

De acordo com MARCINIAK e DUNCAN (1992), a determinação das deformações no dobramento podem ser realizadas aplicando-se a teoria de vigas simples, assumindo-se a hipótese de que as secções inicialmente planas e perpendiculares ao plano da chapa permanecem planas e perpendiculares após o dobramento. As fibras fora da linha neutra são deformadas conforme ilustrado na Figura 5.4. A fibra $A_{0} B_{0}$ com comprimento inicial $l_{0}$ sob a ação combinada de estiramento e flexão é estendida para o comprimento final $l=\theta(\rho+y)$ onde $\rho$ é o raio de curvatura do centro da superfície. Denotando-se o comprimento final da fibra localizada no centro da superfície por $l_{s}=\theta \rho$, então o comprimento final $l$ da fibra $A B$ pode ser escrito como:

$$
l=l_{s}\left(1+\frac{y}{\rho}\right)
$$



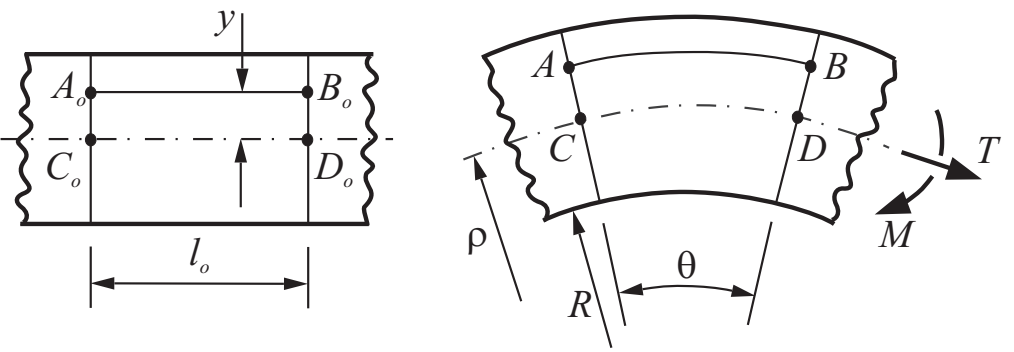

Figura 5.4: Deformação na flexão

A deformação principal na direção axial $\varepsilon_{1}$ pode ser dada, a partir da definição da deformação logarítmica, como:

$$
\varepsilon_{1}=\ln \left(\frac{l}{l_{0}}\right)=\ln \left(\frac{l_{s}}{l_{0}}\right)+\ln \left[\left(1+\frac{y}{\rho}\right)\right]
$$

onde a primeira parcela corresponde à deformação associada ao estiramento e a segunda a deformação devido à flexão.

Outro parâmetro importante no processo de dobramento que influência de maneira direta no estado de tensão-deformação é a relação entre a largura $b$ da chapa e sua espessura $t$. Isto pode ser observado a partir da razão entre as tensões principais $\sigma_{1}$ e $\sigma_{2}$ no plano da chapa. Esta relação, denominada de biaxialidade, pode ser obtida a partir das equações da regra de fluxo. Para o caso isotrópico com o critério de escoamento de von Mises, pode-se mostrar a seguinte relação entre os incrementos de deformação plástica dados pela regra de fluxo e a biaxialidade:

$$
\frac{\sigma_{2}}{\sigma_{1}}=\frac{d \varepsilon_{1}^{p}-d \varepsilon_{2}^{p}}{d \varepsilon_{3}^{p}-d \varepsilon_{1}^{p}}+1
$$

A eq. 5.3 pode ser compactada aplicando-se a hipótese de volume constante, de forma que:

$$
\frac{\sigma_{2}}{\sigma_{1}}=\frac{1+2 m}{2+m}
$$

onde $m$ é um parâmetro de ductilidade do material definido como a razão entre 
os incrementos de deformação plástica no plano da chapa, conforme a eq. 5.5:

$$
m=\frac{d \varepsilon_{2}^{p}}{d \varepsilon_{1}^{p}}
$$

Pela definição da ductilidade pode-se observar que o estado de tensão-deformação base da formulação é obtido quando $m=0$. Neste caso tem-se para o caso isotrópico que a biaxialidade é dada por:

$$
\frac{\sigma_{2}}{\sigma_{1}}=\frac{1}{2}
$$

Como o parâmetro de ductilidade $m$ pode ser obtido experimentalmente, a partir de ensaios de corpos de prova submetidos à flexão, para diferentes razões $b / t$, a biaxialidade também pode ser determinada pelo uso das relações anteriores. A Figura 5.5 ilustra o comportamento típico da biaxialidade e da deformação axial $\varepsilon_{1}^{p}$ em função da geometria $b / t$ da peça.

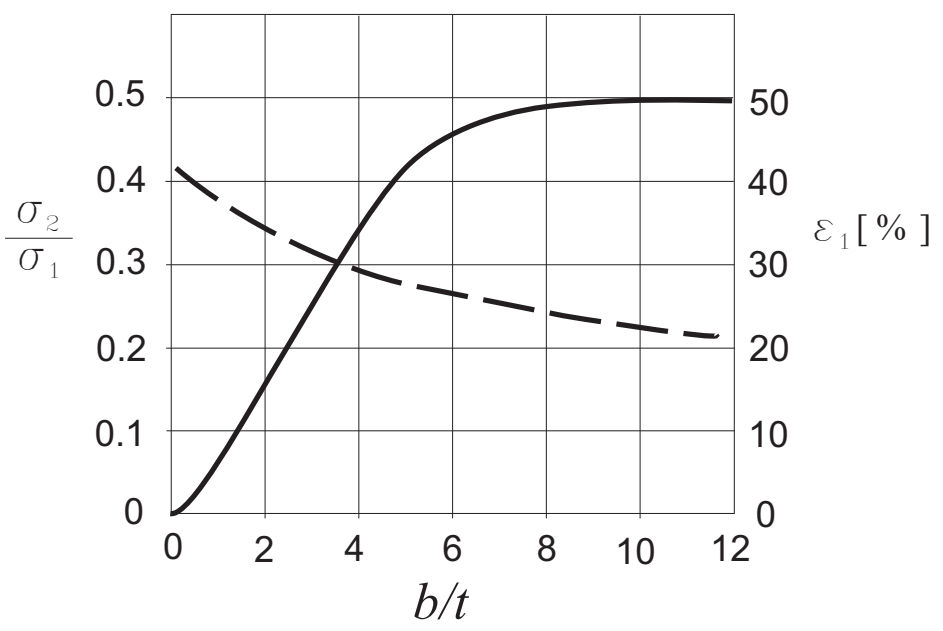

Figura 5.5: Relação entre a biaxialidade e a geometria da chapa

Pode-se observar que a biaxialidade aumenta na medida em que a razão $b / t$ cresce até atingir o valor máximo igual a 0.5 quando $b / t \cong 8$. A partir deste ponto a biaxialidade se mantem praticamente constante com o aumento de $b / t$. Este patamar corresponde à geometria de uma peça na qual o estado de deformação torna-se plano com $\varepsilon_{2}^{p}=0$. Já a deformação axial $\varepsilon_{1}^{p}$ diminui na medida em que $b / t$ cresce, até permanecer constante quando atinge a condição de deformação 
plana.

A dedução da biaxialidade para o caso anisotrópico é realizada a seguir. Para tal são consideradas três situações distintas, onde o ângulo $\alpha$ entre a direção $x$ de laminação e a direção principal é de $\alpha=0^{\circ}, 45^{\circ}$ e $90^{\circ}$.

Quando $\alpha=0^{\circ}$ tem-se que a maior tensão principal $\sigma_{1}$ está alinhada com a direção $x$ de laminação. Com isso, utilizando-se da regra de fluxo para o caso anisotrópico com o critério de Hill, pode-se mostrar que:

$$
\frac{\sigma_{2}}{\sigma_{1}}=\frac{F d \varepsilon_{1}^{p}-G d \varepsilon_{2}^{p}}{H d \varepsilon_{3}^{p}-F d \varepsilon_{1}^{p}}+1
$$

Por outro lado, quando a direção de laminação é perpendicular à maior tensão principal, $\alpha=90^{\circ}$, a biaxilidade torna-se:

$$
\frac{\sigma_{2}}{\sigma_{1}}=\frac{F d \varepsilon_{2}^{p}-G d \varepsilon_{1}^{p}}{G d \varepsilon_{1}^{p}-H d \varepsilon_{3}^{p}}+1
$$

Substituindo-se o parâmetro $m$ de ductilidade, eq. 5.5, nas equações acima tem-se:

$$
\begin{aligned}
& \alpha=0^{\circ} \quad \rightarrow \quad \frac{\sigma_{2}}{\sigma_{1}}=\frac{m(G+H)+H}{H(m+1)+F} \\
& \alpha=90^{\circ} \quad \rightarrow \quad \frac{\sigma_{2}}{\sigma_{1}}=\frac{m(F+H)+H}{H(m+1)+G}
\end{aligned}
$$

Observe que quando $F=G=H$, as equações 5.9 e 5.10 recuperam o caso isotrópico dado pela eq. 5.4. Para a determinação experimental da biaxilidade anisotrópica, além da ductilidade $m$, é necessária a determinação dos parâmetros de anisotropia. Aplicando-se as equações 4.16 a 4.18, que relacionam os parâmetros de anisotropia $F, G, H$ e $N$, com o índice $R_{\alpha}$, tem-se para a situação em deformação plana $(m=0)$ :

$$
\begin{aligned}
& \alpha=0^{\circ} \quad \rightarrow \quad \frac{\sigma_{2}}{\sigma_{1}}=\frac{R_{90}}{R_{90}+1} \\
& \alpha=90^{\circ} \quad \rightarrow \quad \frac{\sigma_{2}}{\sigma_{1}}=\frac{R_{0}}{R_{0}+1}
\end{aligned}
$$


Para o caso $\alpha=45^{\circ}$ buscou-se determinar a relação entre a tensão $\sigma_{x}$ na direção de laminação, com a componente de cisalhamento $\sigma_{x y}$. Assumindo-se a hipótese de volume constante e utilizando-se as relações do círculo de Mohr para as componentes de deformações, pode-se mostrar que:

$$
\begin{array}{r}
\frac{H d \varepsilon_{z}-F d \varepsilon_{x}}{d \gamma_{x y}}=\frac{K d \lambda\left(\sigma_{z}-\sigma_{x}\right)}{2 N d \lambda \sigma_{x y}} \\
\frac{\sigma_{x}}{\sigma_{x y}}=-\frac{2 N}{K}\left(H+\frac{F}{2}\right)
\end{array}
$$

onde $K$ é dado por:

$$
K=F G+G H+H F
$$

Aplicando-se as equações 4.16 a 4.18 tem-se:

$$
\frac{\sigma_{x}}{\sigma_{x y}}=-\frac{\left(R_{0}+R_{90}\right)\left(2 R_{45}+1\right)}{1+R_{0}+R_{90}}\left[\frac{2 R_{90}+1}{2 R_{90}}\right]
$$

As eq. 5.11, 5.12 e 5.16 deduzidas quando a anisotropia do material é levada em consideração, servem como indicativos da biaxialidade de chapas submetidas à flexão. A seguir é apresentado o procedimento proposto de cálculo da evolução dos parâmetros de anisotropia o qual considera as relações apresentadas anteriormente em seu desenvolvimento.

\subsubsection{Equacionamento proposto}

O equacionamento elaborado para determinação da evolução dos parâmetros de anisotropia é fundamentado nos conceitos relativos à função de escoamento de Hill, das deduções da regra de fluxo e da relação entre os incrementos de tensão e deformação desta função. Tais deduções servem como suporte para desenvolvimento do conjunto de equações que permite a determinação da evolução dos parâmetros $F, G, H$ e $N$, fechando assim o conjunto de equações proposto.

Conforme visto no capítulo anterior, a função de escoamento de Hill para o 
caso anisotrópico em tensão plana pode ser escrita na forma:

$$
\begin{aligned}
f & =\sqrt{(G+H) \sigma_{x}^{2}+(F+H) \sigma_{y}^{2}-2 H \sigma_{x} \sigma_{y}+2 N \sigma_{x y}^{2}}-\sigma_{0}=0 \\
f & =\sigma_{e}-\sigma_{0}=0
\end{aligned}
$$

Neste caso, os incrementos de deformação plástica $d \varepsilon_{x}^{p}, d \varepsilon_{y}^{p}$ e $d \gamma_{x y}^{p}$ no plano da chapa são calculados a partir da regra fluxo como:

$$
\begin{aligned}
d \varepsilon_{x}^{p} & =d \lambda \cdot a_{1}=d \lambda\left[\frac{(G+H) \sigma_{x}-H \sigma_{y}}{\sigma_{e}}\right] \\
d \varepsilon_{y}^{p} & =d \lambda \cdot a_{2}=d \lambda\left[\frac{(H+F) \sigma_{y}-H \sigma_{x}}{\sigma_{e}}\right] \\
d \gamma_{x y}^{p} & =d \lambda \cdot a_{3}=d \lambda\left[\frac{N \sigma_{x y}}{\sigma_{e}}\right]
\end{aligned}
$$

Sendo que a componente $d \varepsilon_{z}^{p}$ ao longo da espessura da chapa é determinada a partir da hipótese de volume constante.

Como o critério de Hill foi padronizado com a direção de laminação sempre alinhada com o eixo $x$, o parâmetro $G$ de anisotropia pode ser relacionado com o parâmetro $H$ particularizando-se a eq. 4.1 para um estado uniaxial de tensão na direção de laminação. Com isso, a relação entre os parâmetros $G$ e $H$ torna-se:

$$
G+H=1
$$

Apesar da parcela de deformação elástica em processos de conformação ser praticamente desprezível, para o procedimento proposto faz-se necessário definir sua lei constitutiva. A hipótese assumida é de que o material tem um comportamento elástico isotrópico com a matriz constitutiva elástica $C$ para tensão plana dada por:

$$
C=\frac{E}{1-v^{2}}\left[\begin{array}{ccc}
1 & v & 0 \\
v & 1 & 0 \\
0 & 0 & \frac{1-v}{2}
\end{array}\right]
$$


onde $E$ é o módulo de elasticidade e $v$ o coeficiente de Poisson.

No caso mais geral quando existe a parcela plástica, conforme descrito no capítulo 3, os incrementos de tensão estão relacionados com os incrementos de deformação pela matriz elasto-plástica $C^{e p}$. A eq. 5.24 representa na forma matricial esta relação:

$$
\left[\begin{array}{c}
d \sigma_{x} \\
d \sigma_{y} \\
d \sigma_{x y}
\end{array}\right]=\left[C-\frac{C a^{t} a C}{a^{t} C a+A_{i s o}+A_{k i n}}\right]\left[\begin{array}{c}
d \varepsilon_{x} \\
d \varepsilon_{y} \\
d \gamma_{x y}
\end{array}\right]
$$

Sendo a matriz elasto-plática $C^{e p}$ dada por:

$$
C^{e p}=C-\frac{C a^{t} a C}{a^{t} C a+A_{\text {iso }}+A_{\text {kin }}}
$$

onde: $a$ corresponde ao vetor com componentes $a_{i}(i=1,2,3)$ dado pela regra de fluxo, $A_{i s o}$ é um escalar relacionado com a parcela de encruamento isotrópica e $A_{k i n}$ um escalar relacionado com a parcela de encruamento cinemática. Estes escalares são determinados em função da lei de encruamento adotada para o modelo e estão relacionados com as variáveis internas discutidas no capítulo 3 .

Para facilitar o desenvolvimento da formulação, a matriz resultante do produto $C a a^{t} C$ e o escalar resultante do produto $a^{t} C a$, na eq. 5.24, são desmembrados em termos das constantes elásticas e das componentes $a_{i}$ conforme eq. 5.26 e 5.27.

$$
\begin{aligned}
C a a^{t} C & =\left(\frac{E}{1-v^{2}}\right)^{2}\left[\begin{array}{lll}
w_{11} & w_{12} & w_{13} \\
w_{21} & w_{22} & w_{23} \\
w_{31} & w_{32} & w_{33}
\end{array}\right] \\
a^{t} C a & =\frac{E}{1-v^{2}}\left[a_{1}^{2}+a_{2}^{2}+2 a_{1} a_{2} v+\left(\frac{1-v}{2}\right) a_{3}^{2}\right]
\end{aligned}
$$


onde:

$$
\begin{aligned}
& w_{11}=\left(a_{1}+a_{2} v\right)^{2} \\
& w_{12}=\left(a_{1}+a_{2} v\right)\left(a_{1} v+a_{2}\right) \\
& w_{13}=\left(a_{1}+a_{2} v\right) a_{3}\left(\frac{1-v}{2}\right) \\
& w_{21}=\left(a_{1}+a_{2} v\right)\left(a_{1} v+a_{2}\right) \\
& w_{22}=\left(a_{1} v+a_{2}\right)^{2} \\
& w_{23}=\left(a_{1} v+a_{2}\right) a_{3}\left(\frac{1-v}{2}\right) \\
& w_{31}=\left(a_{1}+a_{2} v\right) a_{3}\left(\frac{1-v}{2}\right) \\
& w_{32}=\left(a_{1} v+a_{2}\right) a_{3}\left(\frac{1-v}{2}\right) \\
& w_{33}=\left[\left(\frac{1-v}{2}\right) a_{3}\right]^{2}
\end{aligned}
$$

Para continuação de todo equacionamento é necessário particularizar a eq. 5.24 referenciando as componentes de tensão de acordo com a direção do carregamento, o qual dita as direções principais do estado de tensão-deformação. Isto é realizado em conjunto com a hipótese de que os incrementos das direções principais de tensão e deformação são coincidentes. Com isto a mesma matriz de rotação pode ser aplicada para relacionar as componentes principais de tensão e deformação com as componentes nas direções $x$ e $y$. Assumindo esta condição, podem-se considerar situações particulares relacionadas com o estado de tensãodeformação da Figura 5.1.

A primeira é quando $\alpha=0^{\circ}$, ou seja, quando a maior tensão principal $\sigma_{1}$ está alinhada com a direção $x$ de laminação, de forma que $\sigma_{1}=\sigma_{x}$ e $\sigma_{2}=\sigma_{y}$. O mesmo vale para a componente de deformação, $\varepsilon_{1}=\varepsilon_{x}$. Esta situação é esquematizada na Figura 5.6. 

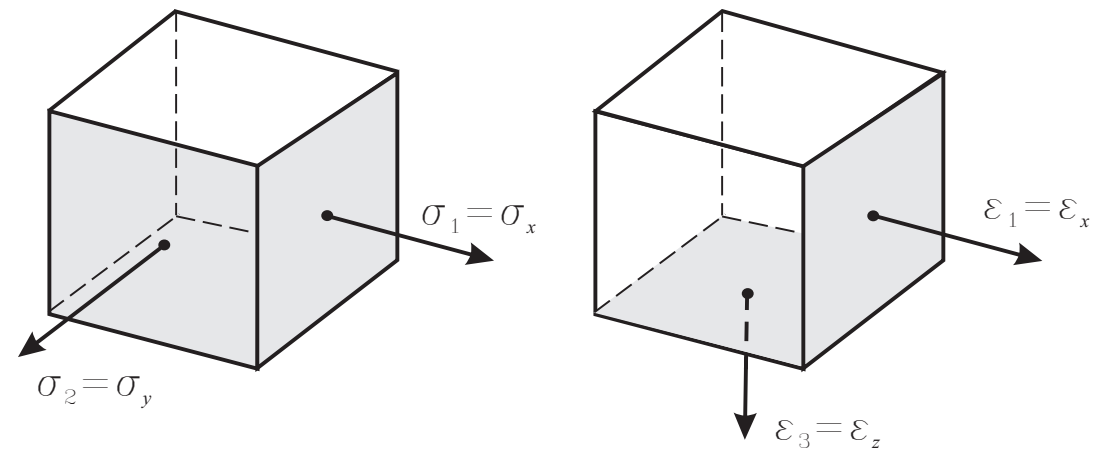

Figura 5.6: Estado tensão-deformação: $\alpha=0^{\circ}$

Neste caso, incremento de deformação plástica na direção de laminação $d \varepsilon_{x}^{p}$ está relacionado com os incrementos de tensão no plano da chapa conforme a eq. 5.37:

$$
\left[\begin{array}{c}
d \sigma_{x} \\
d \sigma_{y} \\
0
\end{array}\right]=\left[C-\frac{C a^{t} a C}{a^{t} C a+A_{i s o}+A_{k i n}}\right]\left[\begin{array}{c}
d \varepsilon_{x} \\
0 \\
0
\end{array}\right]
$$

A eq. 5.37 pode ser reescrita para cada componente de tensão, substituindo-se as parcelas da matriz elasto-plástica $C^{e p}$ dadas nas eq. 5.23, 5.26 e 5.27. Desta forma, após manipulação matemática, as componentes $d \sigma_{x}$ e $d \sigma_{y}$ para $\alpha=0^{\circ}$ podem ser escritas como:

$$
\begin{aligned}
& d \sigma_{x}=\left(\frac{E}{1-v^{2}}\right)\left[1-\left(\frac{E}{1-v^{2}}\right)\left(\frac{w_{11}}{Z_{1}}\right)\right] d \varepsilon_{x} \\
& d \sigma_{y}=\left(\frac{E}{1-v^{2}}\right)\left[v-\left(\frac{E}{1-v^{2}}\right)\left(\frac{w_{21}}{Z_{1}}\right)\right] d \varepsilon_{x}
\end{aligned}
$$

onde : $Z_{1}$ representa um escalar calculado como:

$$
Z_{1}=a^{t} C a+A_{i s o}+A_{k i n}
$$

Por outro lado, quando $\alpha=90^{\circ}$, a maior tensão principal é perpendicular a direção $x$ de laminação conforme ilustrado na Figura 5.7. 

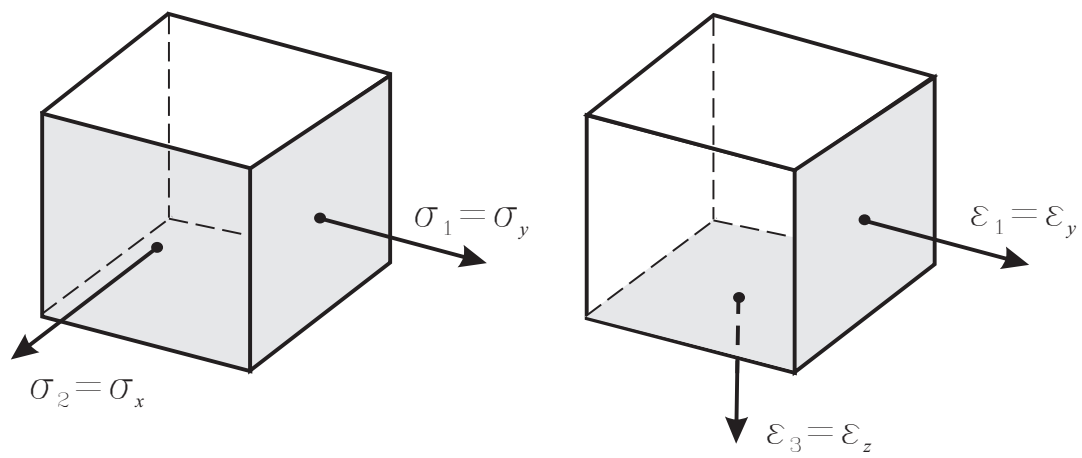

Figura 5.7: Estado tensão-deformação: $\alpha=90^{\circ}$

Neste caso $\sigma_{1}=\sigma_{y}, \sigma_{2}=\sigma_{x}$ e a componente de deformação $\varepsilon_{1}=\varepsilon_{y}$ perpendicular a direção $x$ de laminação está relacionada com os incrementos de tensão conforme a eq. 5.41:

$$
\left[\begin{array}{c}
d \sigma_{x} \\
d \sigma_{y} \\
0
\end{array}\right]=\left[C-\frac{C a^{t} a C}{a^{t} C a+A_{\text {iso }}+A_{k i n}}\right]\left[\begin{array}{c}
0 \\
d \varepsilon_{y} \\
0
\end{array}\right]
$$

Da mesma forma que para o caso anterior, substituindo-se as parcelas da matriz elasto-plástica $C^{e p}$ dadas nas eq. 5.23, 5.26 e 5.27, a eq. 5.41 pode ser reescrita para cada componente de tensão $d \sigma_{x}$ e $d \sigma_{y}$ como:

$$
\begin{aligned}
& d \sigma_{x}=\left(\frac{E}{1-v^{2}}\right)\left[v-\left(\frac{E}{1-v^{2}}\right)\left(\frac{w_{12}}{Z_{1}}\right)\right] d \varepsilon_{y} \\
& d \sigma_{y}=\left(\frac{E}{1-v^{2}}\right)\left[1-\left(\frac{E}{1-v^{2}}\right)\left(\frac{w_{22}}{Z_{1}}\right)\right] d \varepsilon_{y}
\end{aligned}
$$

É importante observar que para o caso $\alpha=0^{\circ}$ a tensão na direção de laminação $\sigma_{x}$ é maior que $\sigma_{y}$. Por outro lado, quando $\alpha=90^{\circ}$ a tensão na direção de laminação $\sigma_{x}$ é menor que $\sigma_{y}$.

A última situação considerada assume a direção principal fazendo um ângulo $\alpha=45^{\circ}$ em relação ao eixo $x$ correspondente a laminação, conforme ilustrado na Figura 5.8. 

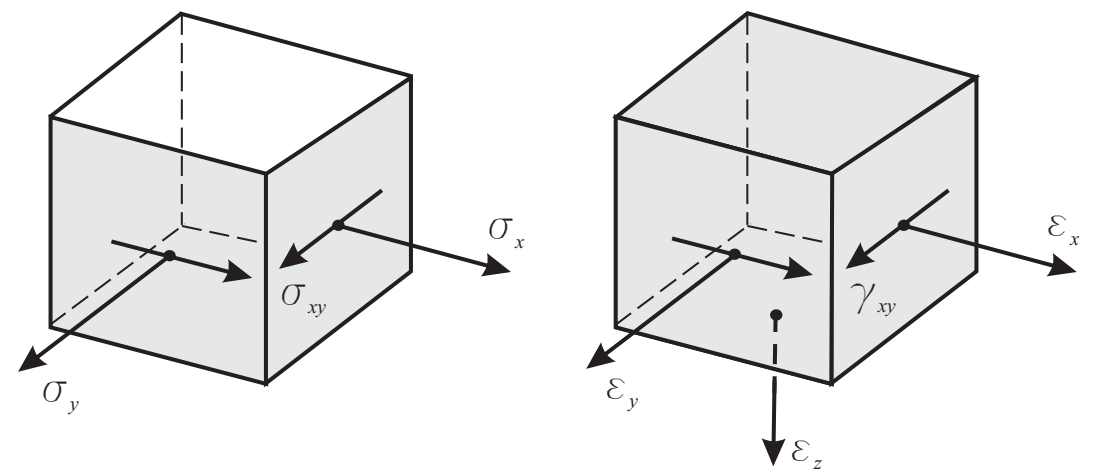

Figura 5.8: Estado tensão-deformação: $\alpha=45^{\circ}$

Neste caso os incrementos principais de deformação no plano da chapa podem ser relacionados com os incrementos alinhados com o sistema de referência $x, y$, a partir da matriz de rotação baseada no círculo de Mohr, conforme a eq. 5.44.

$$
\left[\begin{array}{c}
d \varepsilon_{\alpha} \\
d \varepsilon_{\alpha+90} \\
0
\end{array}\right]=\left[\begin{array}{ccc}
\cos ^{2} \alpha & \operatorname{sen}^{2} \alpha & 2 \operatorname{sen} \alpha \cos \alpha \\
\operatorname{sen}^{2} \alpha & \cos ^{2} \alpha & -2 \operatorname{sen} \alpha \cos \alpha \\
-\operatorname{sen} \alpha \cos \alpha & \operatorname{sen} \alpha \cos \alpha & \cos ^{2} \alpha-\operatorname{sen}^{2} \alpha
\end{array}\right]\left[\begin{array}{c}
d \varepsilon_{x} \\
d \varepsilon_{y} \\
d \gamma_{x y}
\end{array}\right]
$$

Particularizando-se essa relação para o caso $\alpha=45^{\circ}$ com o estado plano de deformação assumido por hipótese tem-se:

$$
\left[\begin{array}{c}
d \varepsilon_{1} \\
0 \\
0
\end{array}\right]=\left[\begin{array}{ccc}
1 / 2 & 1 / 2 & 1 \\
1 / 2 & 1 / 2 & -1 \\
-1 / 2 & 1 / 2 & 0
\end{array}\right]\left[\begin{array}{c}
d \varepsilon_{x} \\
d \varepsilon_{y} \\
d \gamma_{x y}
\end{array}\right]
$$

A eq. 5.45 pode ser desenvolvida de forma que a seguinte relação entre os incrementos de deformação é obtida:

$$
d \varepsilon_{x}=d \varepsilon_{y}=-\frac{d \gamma_{x y}}{2}
$$

Da mesma forma que para os casos anteriores, a eq. 5.24 que relaciona os incrementos de tensão e deformação em termos de suas componentes deve ser desenvolvida com $\alpha=45^{\circ}$. Aplicando-se as eq. 5.23, 5.26 e 5.27, relativas a matriz elasto-plástica $C^{e p}$ e as relações entre os incrementos de deformação dadas 
pela eq. 5.46 tem-se para o caso $\alpha=45^{\circ}$ em termos das componentes:

$$
\begin{aligned}
d \sigma_{x} & =\left(\frac{E}{1-v^{2}}\right)\left[(1+v)-\left(\frac{E}{1-v^{2}}\right)\left(\frac{w_{11}+w_{12}-2 w_{13}}{Z_{1}}\right)\right] d \varepsilon_{x}(5.47) \\
d \sigma_{y} & =\left(\frac{E}{1-v^{2}}\right)\left[(1+v)-\left(\frac{E}{1-v^{2}}\right)\left(\frac{w_{21}+w_{22}-2 w_{23}}{Z_{1}}\right)\right] d \varepsilon_{x}(5.48) \\
d \sigma_{x y} & =\left(\frac{E}{1-v^{2}}\right)\left[(v-1)-\left(\frac{E}{1-v^{2}}\right)\left(\frac{w_{31}+w_{32}-2 w_{33}}{Z_{1}}\right)\right] d \varepsilon_{x}(5.49)
\end{aligned}
$$

O conjunto de equações gerado para as diferentes orientações do ângulo $\alpha$, eq. 5.38 e 5.39 para $\alpha=0^{\circ}$; eq. 5.42 e 5.43 para $\alpha=90^{\circ}$ e eq. 5.47 a 5.49 para $\alpha=45^{\circ}$; é manipulado de forma a isolar os parâmetros de anisotropia $F, G, H$ e $N$, que representam as incógnitas a serem determinadas a cada incremento de deformação. Estes parâmetros estão embutidos nas componentes $a_{i}$ dadas pela regra de fluxo nas eq. 5.19 a 5.21, as quais fazem parte das componentes $w_{i j}$ dadas na eq. 5.28 a 5.36 e do escalar $Z_{1}$ definido na eq. 5.40.

Para isolar os parâmetros de anisotropia, o próximo passo do procedimento consiste em definir uma relação entre os incrementos de tensão no plano da chapa. A hipótese assumida é de que esses incrementos obedecem a uma razão de proporcionalidade para cada incremento de carga, ou seja, os incrementos de tensão mantem uma razão constante com o decorrer do carregamento. As relações assumidas, para cada direção considerada, são dadas nas eq. 5.50 a 5.52.

$$
\begin{aligned}
\alpha=0^{\circ} & \rightarrow & K_{0} & =\frac{d \sigma_{x}}{d \sigma_{y}} \\
\alpha=45^{\circ} & \rightarrow & K_{45} & =\frac{d \sigma_{x}}{d \sigma_{x y}} \\
\alpha=90^{\circ} & \rightarrow & K_{90} & =\frac{d \sigma_{y}}{d \sigma_{x}}
\end{aligned}
$$

A eq. 5.50 e 5.52 relativas as direções $\alpha=0^{\circ}$ e $90^{\circ}$ respectivamente, representam uma razão entre a maior tensão principal $\sigma_{1}$ pela tensão $\sigma_{2}$, sendo que $\sigma_{1}=\sigma_{x}, \sigma_{2}=\sigma_{y}$ para $\alpha=0^{\circ}$ e $\sigma_{1}=\sigma_{y}, \sigma_{2}=\sigma_{x}$ para $\alpha=90^{\circ}$. A eq. 5.51 associada a $\alpha=45^{\circ}$ assume a relação de proporcionalidade entre a tensão na direção de laminação $\sigma_{x}$ com a componente de cisalhamento $\sigma_{x y}$. 
Os parâmetros $K_{0}, K_{45}$ e $K_{90}$ estão diretamente relacionados com a dedução da biaxialidade da chapa discutida anteriormente. Conforme visto, para o caso isotrópico a biaxialidade torna-se constante na condição de deformação plana. Por outro lado, para o caso anisotrópico a expressão da biaxialidade foi deduzida em função dos índices de anisotropia $R_{0}, R_{45}$ e $R_{90}$ para as diferentes orientações do ângulo $\alpha$.

A partir da hipótese assumida, de que os incrementos de tensão obedecem a uma razão constante com o decorrer do carregamento, as eq. 5.11, 5.12 e 5.16 relativas a biaxialidade podem ser relacionadas com as eq. 5.50 a 5.52 de forma que:

$$
\begin{aligned}
K_{0} & =\frac{d \sigma_{x}}{d \sigma_{y}}=\frac{R_{90}+1}{R_{90}} \\
K_{45} & =\frac{d \sigma_{x}}{d \sigma_{x y}}=-\frac{\left(R_{0}+R_{90}\right)\left(2 R_{45}+1\right)}{1+R_{0}+R_{90}}\left[\frac{2 R_{90}+1}{2 R_{90}}\right] \\
K_{90} & =\frac{d \sigma_{y}}{d \sigma_{x}}=\frac{R_{0}+1}{R_{0}}
\end{aligned}
$$

Como os índices de anisotropia $R_{0}, R_{45}$ e $R_{90}$ podem ser determinados experimentalmente pelo ensaio normalizado de anisotropia, os coeficientes de proporcionalidade $K_{0}, K_{45}$ e $K_{90}$ são calculados a partir das eq. 5.53 a 5.55 .

Com as equações disponíveis até o presente desenvolvimento, é possível definir uma estratégia para organização e cálculo da evolução dos parâmetros de anisotropia. A estratégia aplicada consiste em obter a solução do problema em duas partes. A primeira é dada pela composição da eq. 5.38 e 5.39 para $\alpha=0^{\circ}$ em conjunto com a eq. 5.42 e 5.43 para $\alpha=90^{\circ}$ conforme descrito a seguir.

Com os valores de $K_{0}$ e $K_{90}$ definidos anteriormente, pode-se dividir as eq. 5.38 e 5.39 para $\alpha=0^{\circ}$ e as eq. 5.42 e 5.43 para $\alpha=90^{\circ}$ de forma que:

$$
\begin{aligned}
& {\left[1-\left(\frac{E}{1-v^{2}}\right)\left(\frac{w_{11}}{Z_{1}}\right)\right]=K_{0}\left[v-\left(\frac{E}{1-v^{2}}\right)\left(\frac{w_{21}}{Z_{1}}\right)\right]} \\
& {\left[1-\left(\frac{E}{1-v^{2}}\right)\left(\frac{w_{22}}{Z_{1}}\right)\right]=K_{90}\left[v-\left(\frac{E}{1-v^{2}}\right)\left(\frac{w_{12}}{Z_{1}}\right)\right]}
\end{aligned}
$$


Substituindo-se os valores das componentes $w_{i j}$ da matriz resultante $\mathrm{Caa}^{t} \mathrm{C}$ dados pelas eq. 5.28 a 5.36 nas eq. 5.56 e 5.57, pode-se obter, após manipulação matemática, a seguinte relação para $\alpha=0^{\circ}$ e $\alpha=90^{\circ}$ :

$$
P_{1}^{(\alpha)} a_{1}^{2}+P_{2}^{(\alpha)} a_{2}^{2}+P_{3}^{(\alpha)} a_{1} a_{2}-P_{4}^{(\alpha)} Z_{1}=0
$$

onde: o sobrescrito $\alpha$ corresponde a direção considerada, $0^{\circ}$ ou $90^{\circ}$. Os valores dos coeficientes $P_{i}$ são calculados como:

$$
\begin{aligned}
\alpha=0^{o} \quad\left\{\begin{array}{l}
P_{1}^{\left(0^{\circ}\right)}=1-K_{0} v \\
P_{2}^{\left(0^{\circ}\right)}=v^{2}-K_{0} v \\
P_{3}^{\left(0^{\circ}\right)}=2 v-K_{0}-K_{0} v^{2} \\
P_{4}^{\left(0^{\circ}\right)}=\left(1-K_{0} v\right)\left(\frac{1-v^{2}}{E}\right)
\end{array}\right. \\
\alpha=90^{o} \quad\left\{\begin{array}{l}
P_{1}^{\left(90^{\circ}\right)}=v^{2}-K_{90} v \\
P_{2}^{\left(90^{\circ}\right)}=1-K_{90} v \\
P_{3}^{\left(90^{\circ}\right)}=2 v-K_{90}-K_{90} v^{2} \\
P_{4}^{\left(90^{\circ}\right)}=\left(1-K_{90} v\right)\left(\frac{1-v^{2}}{E}\right)
\end{array}\right.
\end{aligned}
$$

Pode-se observar que os coeficientes $P_{i}$ são escritos em termos das constantes elásticas $E, v$ e dos parâmetros de proporcionalidade $K_{0}$ e $K_{90}$ definidos anteriormente, sendo desta forma determinados a partir da caracterização do material em análise.

A eq. 5.58 pode ser desenvolvida, substituindo-se a parcela $Z_{1}$ dada pela eq. 5.40. Com isto, após desenvolvimento matemático, pode-se obter a seguinte equação associada às direções $\alpha=0^{\circ}$ e $90^{\circ}$ :

$$
Q_{1}^{(\alpha)} a_{1}^{2}+Q_{2}^{(\alpha)} a_{2}^{2}+Q_{3}^{(\alpha)} a_{1} a_{2}-Q_{4}^{(\alpha)}=0
$$


onde:

$$
\begin{aligned}
& \alpha=0^{o} \quad\left\{\begin{array}{l}
Q_{1}^{\left(0^{\circ}\right)}=0 \\
Q_{2}^{\left(0^{\circ}\right)}=P_{2}^{\left(0^{\circ}\right)}-P_{4}^{\left(0^{\circ}\right)}\left(\frac{E}{1-v^{2}}\right) \\
Q_{3}^{\left(0^{\circ}\right)}=P_{3}^{\left(0^{\circ}\right)}-2 P_{4}^{\left(0^{\circ}\right)}\left(\frac{E v}{1-v^{2}}\right) \\
Q_{4}^{\left(0^{\circ}\right)}=P_{4}^{\left(0^{\circ}\right)}\left(A_{\text {iso }}+A_{k i n}\right)
\end{array}\right. \\
& \alpha=90^{\circ} \quad\left\{\begin{array}{l}
Q_{1}^{\left(90^{\circ}\right)}=P_{1}^{\left(90^{\circ}\right)}-P_{4}^{\left(90^{\circ}\right)}\left(\frac{E}{1-v^{2}}\right) \\
Q_{2}^{\left(90^{\circ}\right)}=0 \\
Q_{3}^{\left(90^{\circ}\right)}=P_{3}^{\left(90^{\circ}\right)}-2 P_{4}^{\left(90^{\circ}\right)}\left(\frac{E v}{1-v^{2}}\right) \\
Q_{4}^{\left(90^{\circ}\right)}=P_{4}^{\left(90^{\circ}\right)}\left(A_{\text {iso }}+A_{k i n}\right)
\end{array}\right.
\end{aligned}
$$

Os coeficientes $Q_{i}$ são escritos em termos das constantes elásticas, dos coeficientes $P_{i}$ e das variáveis $A_{i s o}$ e $A_{k i n}$ as quais são determinadas a partir do modelo de encruamento adotado. Desta forma estes coeficientes também são determinados a partir da caracterização do material.

Finalmente a eq. 5.61 pode ser desenvolvida substituindo-se as componentes $a_{i}$ dados pela regra de fluxo nas eq. 5.19 a 5.21. Após desenvolvimento matemático é possível isolar os coeficientes de anisotropia $H$ e $F$ na forma:

$$
\left[H^{2}\right] \beta_{1}^{(\alpha)}+\left[F^{2}\right] \beta_{2}^{(\alpha)}+[H] \beta_{3}^{(\alpha)}+[F] \beta_{4}^{(\alpha)}+[H F] \beta_{5}^{(\alpha)}+\beta_{6}^{(\alpha)}=0
$$

onde:

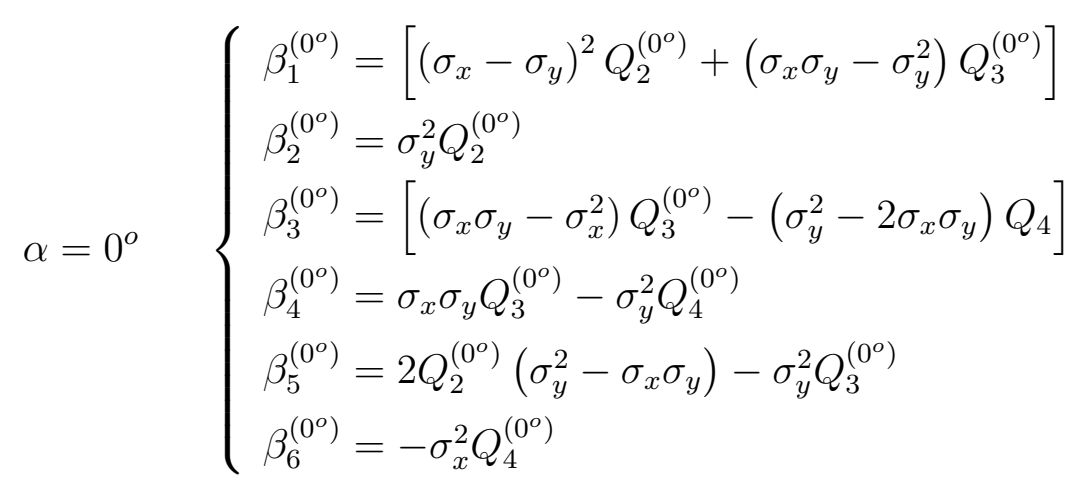




$$
\alpha=90^{\circ} \quad\left\{\begin{array}{l}
\beta_{1}^{\left(90^{\circ}\right)}=\left[\sigma_{y}^{2} Q_{1}^{\left(90^{\circ}\right)}+\left(\sigma_{x} \sigma_{y}-\sigma_{y}^{2}\right) Q_{3}^{\left(90^{\circ}\right)}\right] \\
\beta_{2}^{\left(90^{\circ}\right)}=0 \\
\beta_{3}^{\left(90^{\circ}\right)}=\left[\left(\sigma_{x} \sigma_{y}-\sigma_{x}^{2}\right) Q_{3}^{\left(90^{\circ}\right)}\right] \\
\beta_{4}^{\left(90^{\circ}\right)}=\sigma_{x} \sigma_{y} Q_{3}^{\left(90^{\circ}\right)}-\sigma_{y}^{2} Q_{4}^{\left(90^{\circ}\right)} \\
\beta_{5}^{\left(90^{\circ}\right)}=2 Q_{2}^{\left(90^{\circ}\right)}\left(\sigma_{y}^{2}-\sigma_{x} \sigma_{y}\right)-\sigma_{y}^{2} Q_{3}^{\left(90^{\circ}\right)} \\
\beta_{6}^{\left(90^{\circ}\right)}=\sigma_{x}^{2}\left[Q_{1}^{\left(90^{\circ}\right)}-Q_{4}^{\left(90^{\circ}\right)}\right]
\end{array}\right.
$$

Pode-se observar que os coeficientes $\beta_{i}^{(\alpha)}$ associados a eq. 5.64 são escritos em função do estado atual de tensão, das constantes elásticas e dos escalares $A_{i s o} \mathrm{e}$ $A_{k i n}$. Como as constantes elásticas são dados conhecidos do material e o estado atual de tensão em conjunto com os escalares $A_{i s o}$ e $A_{k i n}$ são determinados pelo algoritmo de previsão-correção, os coeficientes $\beta_{i}^{(\alpha)}$ podem ser calculados para cada incremento de deformação. Desta forma, os coeficientes $\beta_{i}^{(\alpha)}$ variam a cada incremento de deformação na medida em que ocorre o carregamento plástico.

Com isto, conhecidos estes coeficientes, o sistema de equações não lineares dado pela eq. 5.64 referentes a $\alpha=0^{\circ}$ e $\alpha=90^{\circ}$, para cada incremento de deformação, pode ser gerado e posteriormente resolvido. Dentre as possíveis formas para a solução do sistema não linear estão os procedimentos numéricos e os algoritmos de otimização.

No presente trabalho, a solução do sistema de equações foi efetuada numericamente, resultando assim na evolução dos parâmetros de anisotropia $H$ e $F$. A partir da padronização do critério de Hill, na qual a direção de laminação está sempre alinhada com a direção $x$, a eq. 5.22 pode ser utilizada e o parâmetro $G$ determinado em função do parâmetro $H$.

Dando sequência a estratégia de solução do problema, o próximo passo é determinar uma relação para obtenção do parâmetro $N$. Isto é realizado a partir da definição do parâmetro $K_{45}$ associado a direção $\alpha=45^{\circ}$, que permite dividir as eq. 5.47 e 5.49 , de forma que: 


$$
K_{45}=\frac{\left[(1+v)-\left(\frac{E}{1-v^{2}}\right)\left(\frac{w_{11}+w_{12}-2 w_{13}}{Z_{1}}\right)\right]}{\left[(v-1)-\left(\frac{E}{1-v^{2}}\right)\left(\frac{w_{31}+w_{32}-2 w_{33}}{Z_{1}}\right)\right]}
$$

Substituindo-se as parcelas referentes as componentes $w_{i j}$ dadas nas eq. 5.28 a 5.36 e do escalar $Z_{1}$ dado pela eq. 5.40, pode-se mostrar, após desenvolvimento matemático a seguinte relação:

$$
a_{1}^{2} R_{1}+a_{2}^{2} R_{2}+a_{3}^{2} R_{3}+a_{1} a_{2} R_{4}+a_{1} a_{3} R_{5}+a_{2} a_{3} R_{6}-R_{7}=0
$$

onde:

$$
\begin{aligned}
& R_{1}=(1-v) K_{45} \\
& R_{2}=(1-v) K_{45}+\left(v^{2}+1\right) \\
& R_{3}=\left(\frac{1-v^{2}}{2}\right)-(1-v)^{2} K_{45} \\
& R_{4}=\left(v^{2}-1\right)-2 v(v-1) K_{45} \\
& R_{5}=(1-v)+\left(\frac{1-v^{2}}{2}\right) K_{45} \\
& R_{6}=\left(v-v^{2}\right)+\left(\frac{1-v^{2}}{2}\right) K_{45} \\
& R_{7}=\left(\frac{1-v^{2}}{E}\right)\left[(v-1) K_{45}-(1+v)\right]\left(A_{\text {iso }}+A_{\text {kin }}\right)
\end{aligned}
$$

Da mesma forma que para os casos anteriores, substituindo-se as componentes $a_{i}$ dados pela regra de fluxo, na eq. 5.68 tem-se:

$S_{1}+S_{2}+S_{3}-S_{4}+\left(2 N \sigma_{x y}\right)\left[\left(2 N \sigma_{x y}\right) R_{3}+\left(\sigma_{x}-H \sigma_{y}\right) R_{5}+\left[(F+H) \sigma_{y}-H \sigma_{x}\right] R_{6}\right]=0$ 
onde:

$$
\begin{aligned}
S_{1} & =\left(\sigma_{x}-H \sigma_{y}\right)^{2} R_{1} \\
S_{2} & =\left[(F+H) \sigma_{y}-H \sigma_{x}\right]^{2} R_{2} \\
S_{3} & =\left(\sigma_{x}-H \sigma_{y}\right)\left[(F+H) \sigma_{y}-H \sigma_{x}\right] R_{4} \\
S_{4} & =\sigma_{e q}^{2} R_{7}
\end{aligned}
$$

Substituindo-se os coeficientes $S_{i}$ na equação anterior é possível isolar o parâmetro de anisotropia $N$ e obter a seguinte equação:

$$
N^{2} \beta_{1}^{\left(45^{\circ}\right)}+N \beta_{2}^{\left(45^{\circ}\right)}+\beta_{3}^{\left(45^{\circ}\right)}=0
$$

onde:

$$
\begin{aligned}
& \beta_{1}^{\left(45^{\circ}\right)}=4 \sigma_{x y}^{2} R_{3} \\
& \beta_{2}^{\left(45^{\circ}\right)}=2 \sigma_{x y}\left[\left(\sigma_{x}-H \sigma_{y}\right) R_{5}+\left((F+H) \sigma_{y}-H \sigma_{x}\right) R_{6}\right] \\
& \beta_{3}^{\left(45^{\circ}\right)}=S_{1}+S_{2}+S_{3}-S_{4}
\end{aligned}
$$

Os coeficientes $\beta_{i}^{\left(45^{\circ}\right)}$ associados a direção $\alpha=45^{\circ}$ são escritos em termos das constantes elásticas, do estado atual de tensão, do parâmetro $K_{45}$, dos escalares $A_{i s o}$ e $A_{k i n}$ e adicionalmente em função dos parâmetros de anisotropia $F$ e $H$. Desta forma, a partir da caracterização do material e do algoritmo de previsão-correção estes coeficientes podem ser determinados para cada incremento de deformação.

As raízes possíveis da eq. 5.80 obviamente dependem da combição de seus coeficientes $\beta_{i}^{\left(45^{\circ}\right)}$. Como apenas um valor de $N$ deve ser obtido para cada incremento de deformação, torna-se necessário adotar uma das possíveis raízes da eq. 5.80. O critério adotado para a escolha de $N$ foi baseado nas restrições impostas pelo critério de Hill. Conforme será visto, em todos os exemplos estudados a solução escolhida forneceu resultados satisfatórios de evolução deste parâmetro. 
Desta forma foram apresentadas às equações, eq. 5.64 associada as direções $\alpha=0^{\circ}$ e $90^{\circ}$, e eq. 5.80 associada a direção $\alpha=45^{\circ}$, necessárias para a obtenção da evolução dos parâmetros de anisotropia $F, G, H$ e $N$ do critério de Hill. Como padronização da formulação, os parâmetros evolutivos determinados pela solução destas equações são escritos na seguinte forma: $\hat{F}, \hat{G}, \hat{H}$ e $\hat{N}$.

\subsubsection{Metodologia}

Nos tópicos anteriores apresentou-se a elaboração matemática do conjunto de equações que permite a obtenção da evolução dos parâmetros de anisotropia do critério de Hill com o carregamento plástico. Neste tópico é descrita a metodologia proposta para a execução deste procedimento, organizada conforme o fluxograma da Figura 5.9 e cujas etapas são descritas a seguir.

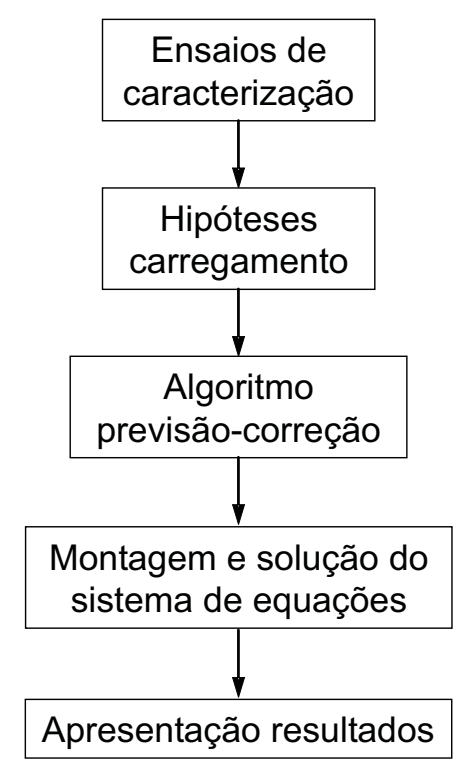

Figura 5.9: Metodologia para aplicação do procedimento proposto

\section{Ensaios de caracterização do material}

Para a execução do procedimento proposto, inicialmente é necessário determinar algumas constantes de material que são utilizadas como informações de entrada e também como base de comparação durante a aplicação do procedi- 
mento. Esta determinação é realizada a partir de ensaios de caracterização com corpos de prova cortados do material analisado. No ensaio normalizado de tração são determinados o módulo de elasticidade, a tensão de escoamento e ruptura do material, além de permitir a determinação das constantes associadas com o modelo de encruamento adotado. No caso do modelo de encruamento isotrópico, as constantes de material são calculadas a partir do ajuste da curva teórica com a experimental. As constantes relacionadas com o modelo cinemático de encruamento são determinadas a partir de relações com as constantes do modelo isotrópico ou para o caso de leis cinemáticas mais complexas, outros ensaios devem ser realizados, como por exemplo ensaios cíclicos de flexão.

Adicionalmente, o ensaio normalizado de anisotropia fornece o conjunto inicial de índices de anisotropia, calculados conforme a eq. 4.23 para os corpos de prova cortados $\operatorname{com} \alpha=0^{\circ}, 45^{\circ}$ e $90^{\circ}$ em relação a direção de laminação.

A partir das eq. 4.19 a 4.22 que relacionam os índices de anisotropia $R_{\alpha}$ com os parâmetros do critério de Hill, um conjunto inicial destes parâmetros é determinado, via ensaio normalizado. Estes parâmetros são então utilizados como dados de entrada e nas comparações e discussões com a evolução obtida pelo procedimento proposto.

\section{Considerações e hipóteses}

Ao longo do desenvolvimento matemático descrito no tópico anterior, foram assumidas várias hipóteses até que o conjunto de equações que permite o cálculo da evolução dos parâmetros de anisotropia fossem obtidos. Uma hipótese fundamental assumida é de que o ponto material analisado deve satisfazer o estado de tensão-deformação base da formulação, Figura 5.1, durante o carregamento. A partir deste estado, as relações entre os incrementos de tensão e deformação dada pela eq. 5.24 são particularizadas conforme as direções consideradas do ângulo $\alpha$. Este estado é bastante característico em regiões da peça nas quais ocorram dobras, porém em problemas com geometria e carregamentos mais complexos, a verificação desta hipótese para o ponto de interesse, pode ser realizada a partir 
de modelos numéricos, aplicando-se por exemplo o método dos elementos finitos.

Outra hipótese assumida trata da proporcionalidade entre os incrementos de tensão no plano da chapa, dados conforme as eq. 5.50 a 5.52. Esta consideração está relacionada com a biaxialidade de chapas previamente definida, de forma que os parâmetros de proporcionalidade $K_{0}, K_{45}$ e $K_{90}$ sejam determinados experimentalmente, a partir de suas relações com os índices de anisotropia dada pelas eq. 5.53 a 5.55 .

Adicionalmente, assume-se que o ponto material em análise é submetido a um carregamento de deformação na direção principal $\varepsilon_{1}$ monotônico crescente, sem alterações bruscas, de forma que sua evolução corresponda a uma rampa linear crescente com o carregamento. Este histórico de deformação é assumido ser idêntico para qualquer orientação do ângulo $\alpha$, uma vez que as deformações são funções apenas da geometria do problema e o ponto material em análise é submetido a um campo de deslocamento prescrito, imposto pela ferramenta.

A determinação do histórico de deformação, no ponto de interesse, pode ser obtida experimentalmente, por meio de procedimentos adequados como o uso de Circle Grids e extensômetros, ou pode ser obtida através de modelos numéricos aplicando o método dos elementos finitos. Este histórico é aplicado como dado de entrada no algoritmo de previsão-correção permitindo determinar as variáveis necessárias para continuidade do procedimento conforme descrito a seguir.

\section{Algoritmo de previsão-correção}

A partir das hipóteses discutidas anteriormente e dos dados de entrada obtidos, a aplicação do algoritmo de previsão-correção fornece como saída o estado atual de tensão-deformação e as variáveis internas que permitem a determinação dos escalares $A_{i s o}$ e $A_{k i n}$ para cada incremento de deformação. Desta forma, o algoritmo de previsão correção é utilizado como suporte para a determinação dos coeficientes $\beta_{i}^{\left(0^{\circ}\right)}, \beta_{i}^{\left(45^{\circ}\right)}$ e $\beta_{i}^{\left(90^{\circ}\right)}$ necessários para obtenção da evolução dos parâmetros de anisotropia. 
Toda formulação do algoritmo foi implementada computacionalmente no software MATLAB e foi efetuada uma vez que os pacotes comerciais de elementos finitos dificultam o acesso a certas grandezas como as variáveis internas do processo. A Figura 5.10 esquematiza os diferentes passos para a implementação computacional do algoritmo, conforme previamente discutidos no capítulo 3 .

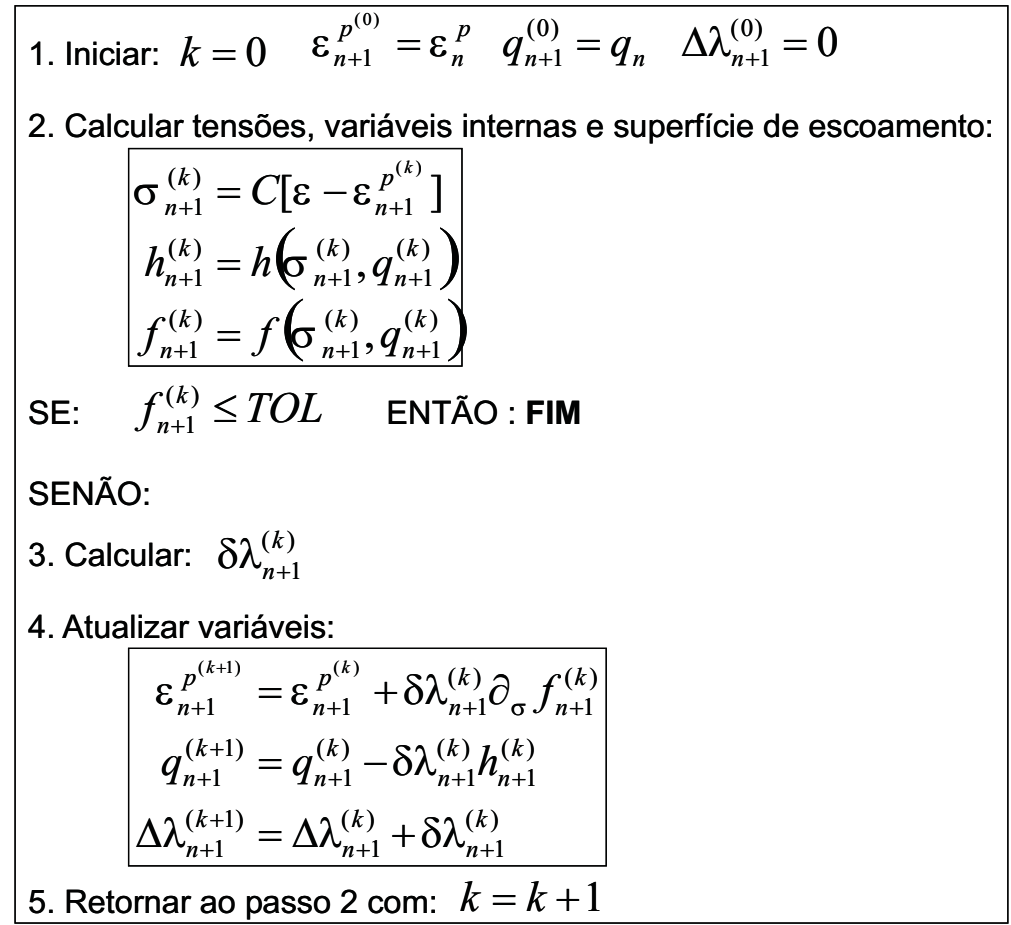

Figura 5.10: Esquema geral do algoritmo de previsão-correção

\section{Montagem e solução}

Para cada incremento de deformação, o algoritmo de previsão-correção fornece o estado atual de tensão e as variáveis internas associadas ao modelo de encruamento adotado. Com determinação das tensões e variáveis internas, os coeficientes $\beta_{i}^{(0)}, \beta_{i}^{(90)}$ e $\beta_{i}^{(45)}$ podem ser determinados à cada incremento de deformação. Desta forma as eq. 5.64 e eq. 5.80 são geradas e resolvidas para cada incremento de deformação, e os parâmetros de anisotropia $\hat{F}, \hat{G}, \hat{H}$ e $\hat{N}$ são determinados e armazenados para posterior apresentação de sua evolução. 


\section{Resultados}

Neste bloco, os diversos resultados gerados pelo programa são organizados e apresentados para posterior análise e discussões. Dentre os principais resultados armazenados tem-se o acompanhamento de variáveis internas do programa, para avaliar a evolução da convergência do algoritmo, os gráficos referentes às evoluções das componentes de tensão e deformação, da evolução da superfície de escoamento. Também são obtidas a evolução dos coeficientes $\beta_{i}^{\left(0^{\circ}\right)}, \beta_{i}^{\left(45^{\circ}\right)}$ e $\beta_{i}^{\left(90^{\circ}\right)}$ e dos parâmetros de anisotropia.

\subsection{Nova Superfície de Escoamento}

Com a determinação dos parâmetros de anisotropia evolutivos $\hat{F}, \hat{G}, \hat{H}$ e $\hat{N}$ a partir da metodologia descrita no tópico anterior, uma nova superfície de escoamento anisotrópica é proposta.

Esta superfície é definida a partir da função de Hill original, dada pela eq. 5.17 , porém ponderada por um fator de correção que altera a forma da superfície de Hill original ao longo do encruamento. Desta forma a nova superfície de escoamento proposta é definida conforme a eq. 5.84:

$$
F_{m}=\left[\sqrt{(G+H) \sigma_{x}^{2}+(F+H) \sigma_{y}^{2}-2 H \sigma_{x} \sigma_{y}+2 N \sigma_{x y}^{2}}\right] \cdot \Psi-\sigma_{0}=0
$$

onde: $\Psi$ representa o fator de correção.

Importante observar que a função original de Hill é escrita em termos dos parâmetros de anisotropia constantes com o carregamento. Estes parâmetros são determinados experimentalmente a partir das relações com os índices de anisotropia dadas nas eq. 4.19 a 4.22. Por outro lado, a hipótese assumida é de que o fator de correção $\Psi$ é escrito em função dos parâmetros de anisotropia evolutivos, determinados pelo procedimento descrito no tópico anterior, de forma que:

$$
\Psi=\Psi(\hat{F}, \hat{G}, \hat{H}, \hat{N})
$$


Assim, a nova superfície de escoamento pode contemplar uma evolução anisotrópica do encruamento, no sentido de sua expansão não ser uniforme com o carregamento plástico e sim ponderada pelo fator de correção $\Psi$. Com isto as evoluções obtidas com o decorrer do carregamento para a superfície original e para a superfície proposta podem ser comparadas e discutidas.

Para a completa definição da nova superfície, um conceito particular para o fator de correção $\Psi$ é adotado neste trabalho. Este conceito é baseado em um parâmetro $\bar{\Psi}$ utilizado no desenvolvimento matemático de determinação da anisotropia em corpos de prova biaxiais, proposto no trabalho de EVANGELISTA (2006).

Este parâmetro é definido a partir da relação entre a tensão de escoamento para um estado equibiaxial de tensão $\sigma_{b}$ e a tensão de escoamento uniaxial na direção de laminação $\sigma_{0}$, conforme a eq. 5.86:

$$
\bar{\Psi}=\frac{\sigma_{b}}{\sigma_{u}}
$$

Esta consideração para o fator de correção $\Psi$ foi assumida, uma vez que as distorções da superfície de escoamento com o decorrer do carregamento implicam em uma mudança na relação entre a tensão equibiaxial $\sigma_{b}$ e a tensão uniaxial $\sigma_{0}$. Desta forma, a relação dada pela eq. 5.86 representa um indicativo da medida de evolução da anisotropia do material.

Utilizando-se da definição dada para a superfície de Hill, eq. 5.17, com o estado de tensão equibiaxial, $\sigma_{1}=\sigma_{2}$, pode-se mostrar que a relação dada pela eq. 5.86 fica escrita em termos dos parâmetros de anisotropia conforme a eq. 5.87:

$$
\bar{\Psi}=\sqrt{\frac{G+H}{1-H+F}}
$$

Para o caso da nova superfície de escoamento proposta, o fator de correção $\Psi$ é baseado na eq. 5.87, porém escrito em termos dos parâmetros de anisotropia 
evolutivos de forma que:

$$
\Psi=\sqrt{\frac{\hat{G}+\hat{H}}{1-\hat{H}+\hat{F}}}
$$

Assim foi apresentada a nova definição da superfície de escoamento anisotrópica para chapas metálicas, eq. 5.84, e as condições matemáticas necessárias para a sua complementação, a partir da determinação do fator correção $\Psi$ dado pela eq. 5.88 ,

\subsection{Considerações Finais}

A metodologia proposta apresentada é fundamentada nas relações incrementais entre tensão e deformação da Teoria Clássica da Plasticidade utilizando-se do critério de escoamento de Hill e baseado em um estado particular de tensãodeformação comum em processos de conformação mecânica, principalmente em regiões da peça onde ocorram dobras.

A partir deste enfoque, um conjunto de equações não lineares é desenvolvido considerando-se três situações distintas, na qual a direção da maior tensão principal do ponto analisado faz diferentes ângulos em relação a direção $x$ de laminação. Apesar disto, estas equações são igualadas e resolvidas uma vez que a hipótese assumida é de que o estado de anisotropia é uma propriedade mecânica do material e independente da orientação $\alpha$ na qual o ponto esta sendo solicitado. Desta forma, a solução destas equações para cada incremento de deformação leva à determinação da evolução dos parâmetros de anisotropia.

A nova superfície de escoamento é definida a partir da superfície de Hill original, porém ponderada por um fator de correção o qual contempla uma evolução anisotrópica do encruamento. Este fator de correção é definido em função dos parâmetros evolutivos de anisotropia determinados pela metodologia proposta e um conceito particular é adotado para a complementação deste novo modelo de superfície de escoamento. 
A seguir são descritos os resultados obtidos dos diversos estudos realizados e relacionados com a aplicação da metodologia proposta e com a nova superfície de escoamento $F_{m}$. 
104CAPÍTULO 5. METODOLOGIA E NOVA SUPERFÍCIE DE ESCOAMENTO 


\section{Capítulo 6}

\section{Resultados e Discussões}

Neste capítulo são apresentados os diversos resultados e discussões dos estudos realizados. Inicialmente é apresentada uma validação do algoritmo de previsãocorreção implementado externamente. Para tal, os valores de tensão obtidos numericamente por meio do pacote comercial de elementos finitos Ansys 9.0 são comparados com os resultados obtidos pela implementação externa para diferentes modelos de encruamento.

Em seguida são descritos os resultados experimentais de ensaios de caracterização de uma liga de alumínio aeronáutica Al 7475-O. Estes resultados consistem na determinação das constantes de material, via ensaio de tração, e da determinação dos índices de anisotropia $R_{\alpha}$ obtidos pelo ensaio normalizado de anisotropia. Os resultados experimentais são então utilizados como fonte de comparação e como dados de entrada para a aplicação da metodologia de cálculo de evolução dos parâmetros de anisotropia proposta.

A partir da determinação dos parâmetros evolutivos $\hat{F}, \hat{G}, \hat{H}$ e $\hat{N}$ fornecidos pela metodologia, o fator de correção $\Psi$ é calculado conforme a proposta apresentada no capítulo anterior, dada pela eq. 5.88. Posteriormente a nova superfície de escoamento dada pela eq. 5.84 é gerada e sua evolução com o decorrer do carregamento plástico é avaliada e comparada com a superfície original de Hill.

Adicionalmente, são apresentados como exemplos de aplicação o dobramento 
em $V$ de uma chapa e o embutimento de um copo circular modelados via método dos elementos finitos. Os resultados gerados pelo modelo numérico também são comparados e discutidos com os obtidos pela aplicação da metodologia e pela definição da nova superfície.

O capítulo é encerrado com discussões gerais acerca dos diferentes resultados obtidos e com os aspectos relacionados com a metodologia proposta e com a definição da nova superfície de escoamento anisotrópica.

\subsection{Validação do algoritmo de previsão-correção}

O algoritmo de previsão-correção implementado externamente no software MATLAB foi validado a partir de comparações com modelos de elementos finitos gerado no software comercial Ansys 9.0. O pacote comercial Ansys aplica a integração implícita no tempo na solução do problema não linear de material associado. É importante destacar que essa validação se dá apenas a nível do algoritmo de previsão-correção, uma vez que o algoritmo implementado externamente corresponde apenas ao looping de material. Ou seja, não existe uma verificação posterior do equilíbrio conforme a sequência padrão do Método dos Elementos Finitos apresentada no capítulo 3.

Por outro lado, para os casos estudados em que o carregamento é bem comportado no sentido de não existir alterações bruscas no histórico de deformação, os valores das tensões obtidas pelo programa externo se mostrou bastante satisfatório conforme observado nas comparações dos resultados.

Para a execução do procedimento de validação, inicialmente foi necessário determinar-se qual tipo de geometria e de carregamento que melhor representasse o estado de tensão-deformação da Fig. 5.1, base da formulação de cálculo da evolução dos parâmetros de anisotropia.

Para o caso de chapas o estado de tensão plana é sempre satisfeito. O desafio foi então satisfazer o estado de deformação plana. Após uma sequência de 
estudos e simulações chegou-se à configuração com uma chapa de comprimento aproximadamente 4 vezes menor que a largura. Nesta configuração o estado base da formulação tornou-se satisfatório. A Figura 6.1 ilustra na configuração deformada, o estado de tensão-deformação típico na fibra mais externa tracionada da região central da chapa. Nota-se claramente o estado plano de tensão indicado pelos vetores em preto $\sigma_{1}>0$ e em verde $\sigma_{2}>0$ e o estado de plano deformação perpendicular ao plano da chapa representados pelos vetores em preto $\varepsilon_{1}>0$ e em azul $\varepsilon_{3}<0$.
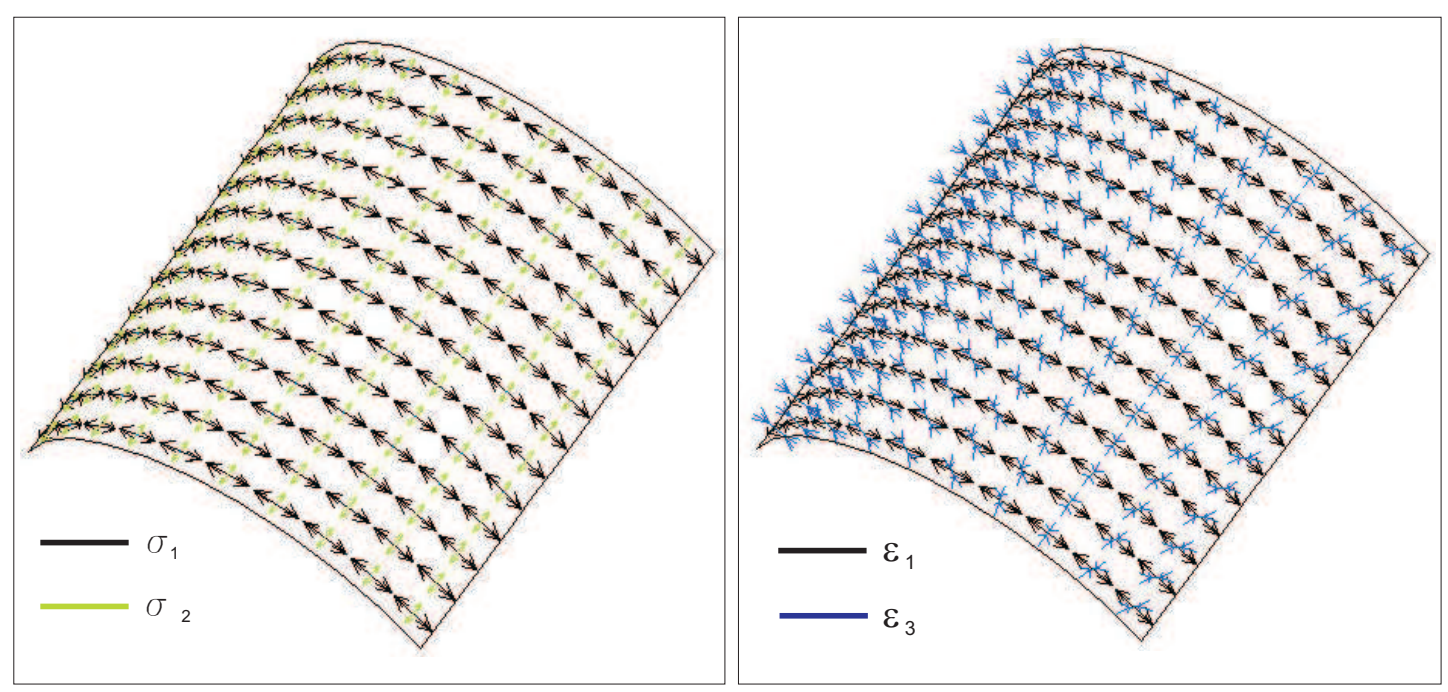

Figura 6.1: Estado tensão-deformação do modelo MEF

Definida a geometria, o modelo numérico foi gerado com elementos do tipo casca (Shell-181) com nove pontos de integração ao longo da espessura. Para todos os casos estudados a geometria da chapa considerada foi com largura $b=$ 200 [mm], comprimento $L=50[\mathrm{~mm}]$ e espessura $t=1[\mathrm{~mm}]$. As condições de contorno e carregamento foram aplicadas nas bordas da chapa impondo-se uma rotação nesta região de forma a obter-se uma flexão pura.

Após o problema ser solucionado pelo pacote comercial de elementos finitos, foi escolhido um nó da malha para comparação com o programa implementado externamente. O nó escolhido para todos os casos estudados foi o nó central da chapa. A partir deste nó, arquivos contendo a evolução das tensões principais $\left(\sigma_{1}\right.$ e $\left.\sigma_{2}\right)$, da tensão equivalente $\left(\sigma_{e q}\right)$ bem como das componentes de deformações to- 
tais $\left(\varepsilon^{t}\right)$ e de suas parcelas plásticas $\left(\varepsilon^{p}\right)$ foram armazenados. Importante destacar que o algoritmo de previsão-correção implementado, considera como dado de entrada o histórico armazenado de deformação total na direção principal $\varepsilon_{1}$ obtido pelo modelo MEF, além de utilizar os mesmos dados de material. Desta forma um conjunto de resultados obtidos via MEF e obtidos via implementação externa foi gerado para diferentes modelos de encruamento. Os casos considerados e os resultados obtidos são descritos a seguir.

Inicialmente considerou-se um material com comportamento isotrópico dado pelo critério de von Mises. O primeiro caso corresponde a situação mais simples com o encruamento isotrópico bilinerar puro. O segundo caso considera o encruamento não linear dado pela lei de Voce, eq. 3.53, combinado com a parcela cinemática dada pela lei de Prager, eq. 3.59. A Tabela 6.1 apresenta as constantes elásticas e os valores dos parâmetros de material relacionados com suas respectivas leis de evolução para o caso 1 (bilinear) e caso 2 (não linear combinado).

Tabela 6.1: Dados de material com modelo isotrópico

$\left.\begin{array}{|c|c|c|c|c|}\hline \begin{array}{c}\text { Parte } \\ \text { elástica }\end{array} & \begin{array}{c}\text { Módulo de elasticidade } \\ \text { Coeficiente de Poisson }\end{array} & \mu & 7,3 & {[\mathrm{GPa}]} \\ & \text { Tensão de escoamento } & \sigma_{0} & 100 & {[-]} \\ {[\mathrm{MPa}]}\end{array}\right]$

A Figura 6.2 mostra a evolução da tensão equivalente $\sigma_{e q}$ em função da deformação $\varepsilon$ obtida pela implementação externa (curva em azul) e pelo software Ansys (curva em vermelho), correspondentes ao caso 1. Para este caso pode-se observar uma perfeita correlação entre os resultados obtidos. O mesmo pode ser observado na Figura 6.3 para as componentes das tensões principais $\sigma_{1}$ e $\sigma_{2}$. 
Apenas para o caso da tensão principal $\sigma_{2}$ é possível observar uma sutil diferença entre as curvas.

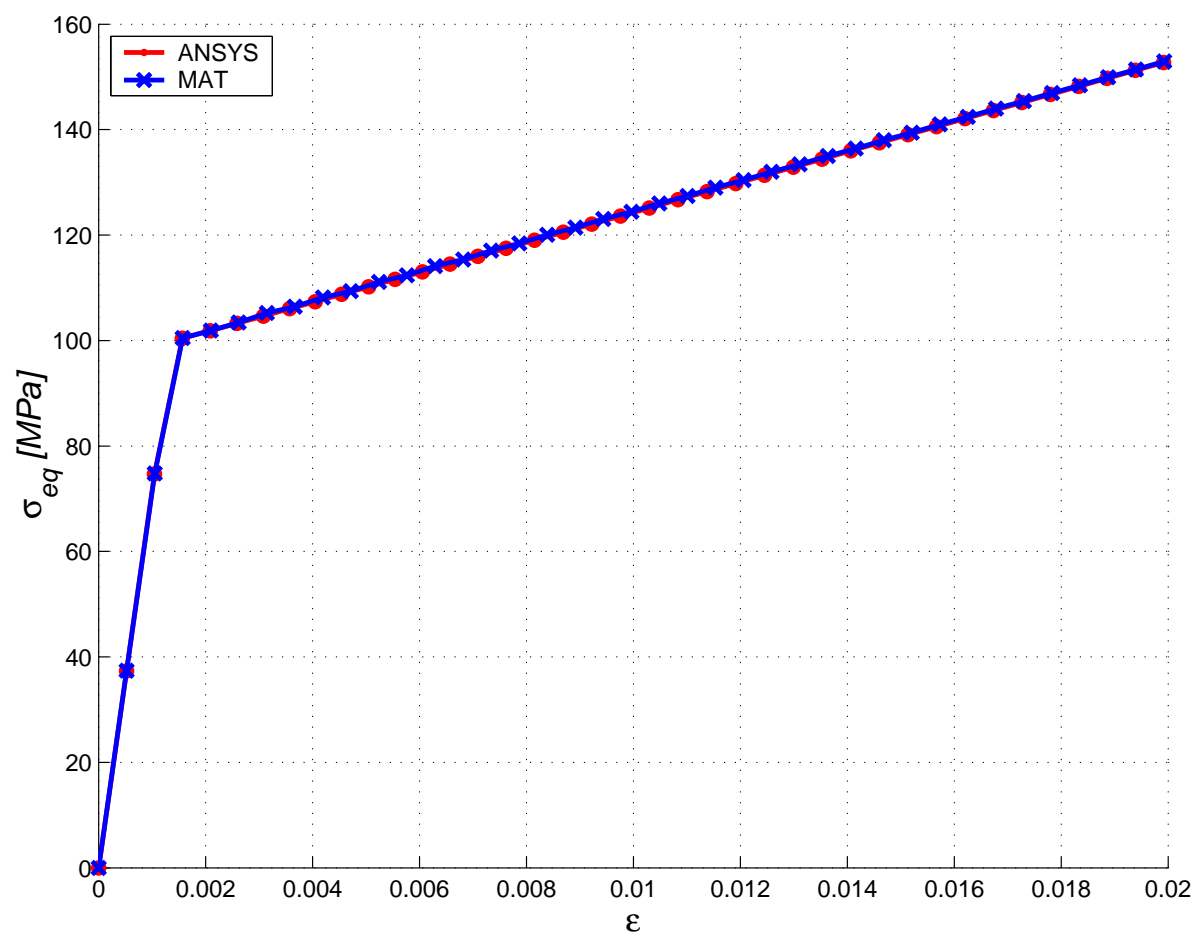

Figura 6.2: Tensão Equivalente - Caso 1
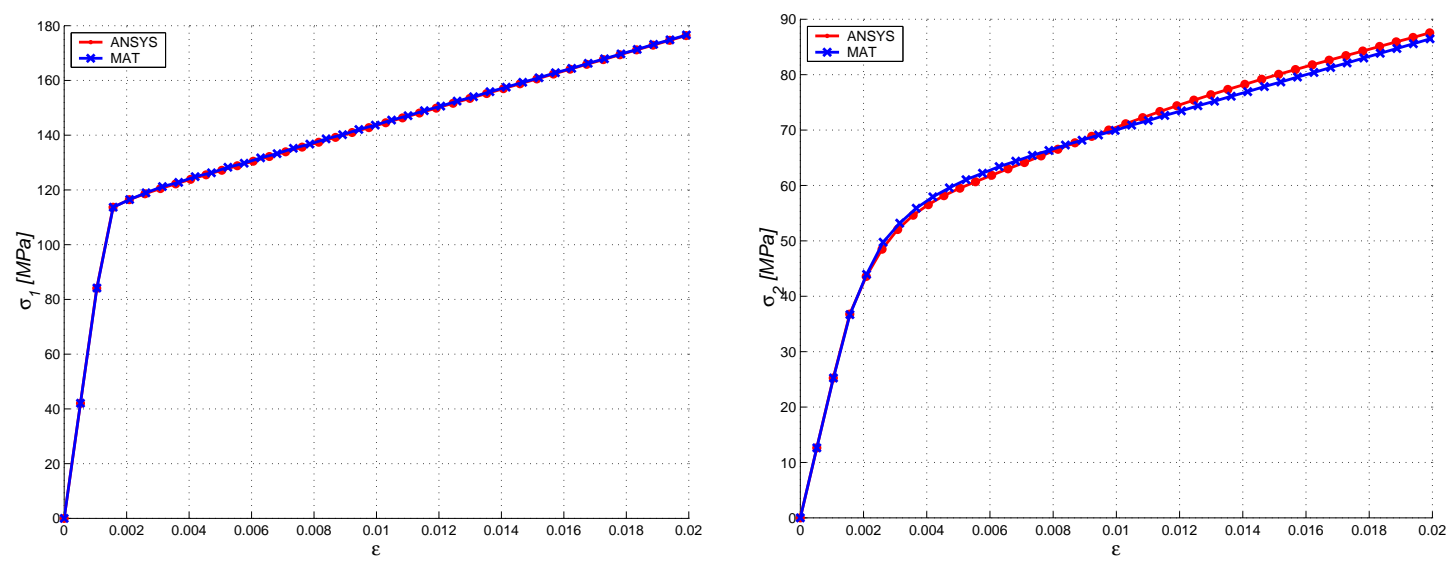

Figura 6.3: Tensões Principais - Caso 1

Para o caso 2 os resultado são mostrados nas Figuras 6.4 e 6.5. Aqui é possível observar um desvio maior entre as curvas na medida em que o encruamento ocorre, tanto para a tensão equivalente quanto para as componentes das tensões principais. Porém, de maneira geral o comportamento não linear das curvas foi satisfatório e a diferença máxima observada foi da ordem de 6\%. Essa maior 
diferença pode ser explicada em parte devida à hipótese de deformação plana com a componente $\varepsilon_{2}=0$ não ser totalmente satisfeita no modelo de elementos finitos.

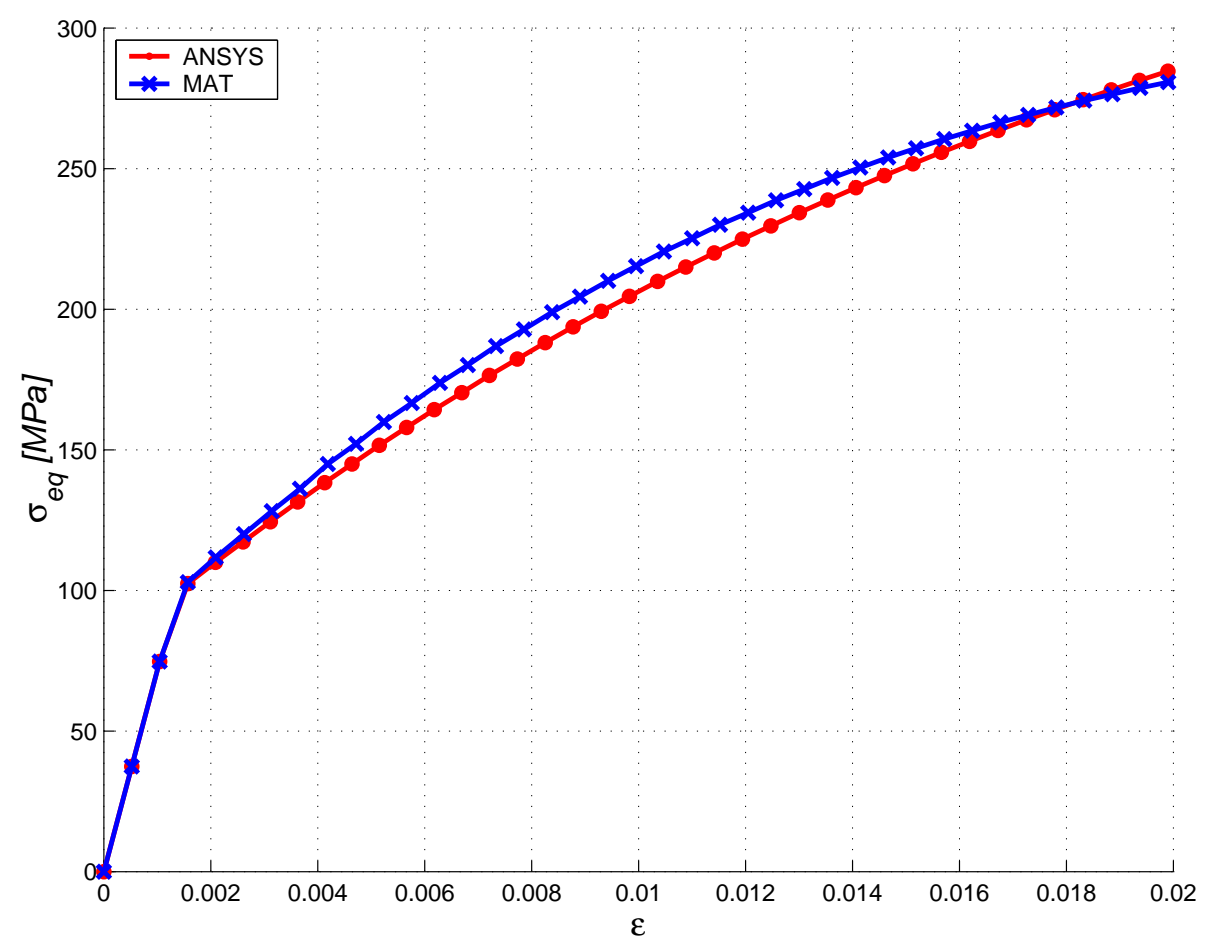

Figura 6.4: Tensão Equivalente - Caso 2
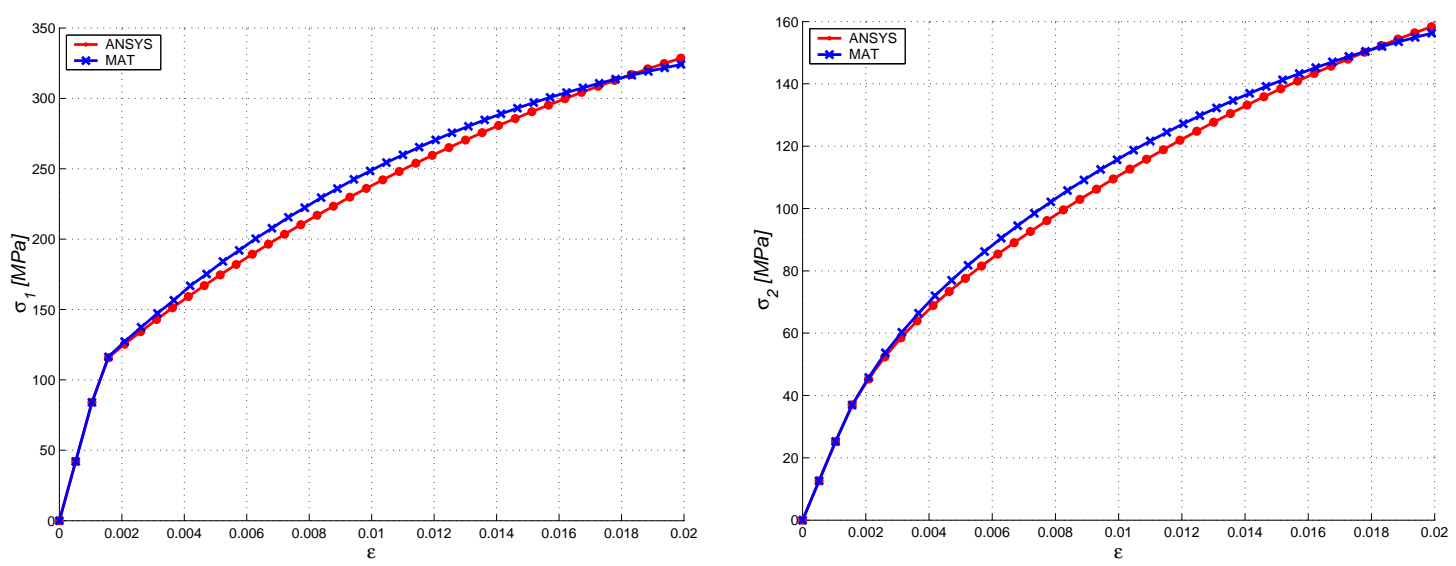

Figura 6.5: Tensões Principais - Caso 2

Dando sequência ao processo de validação, o próximo passo foi a comparação entre os programas quando a anisotropia do material é levada em consideração. Foram estudados mais 3 casos variando-se o modelo de encruamento bem como os índices de anisotropia do material, conforme apresentado na Tabela 6.2. Para 
cada um destes casos o ângulo $\alpha$ entre a direção da maior tensão principal e a direção de laminação foi variado de $\alpha=0^{\circ}, 45^{\circ}$ e $90^{\circ}$.

Os casos 3 e 4 correspondem ao modelo com encruamento isotrópico bilinear, mas com índices de anisotropia distintos entre eles. Já o caso 5 utiliza um modelo de encruamento isotrópico não linear dado pela lei de Voce definida na eq. 3.53.

Tabela 6.2: Dados de material com modelo anisotrópico

\begin{tabular}{|c|c|c|}
\hline & Índice de anisotropia & Modelo de Encruamento \\
\hline \hline \multirow{3}{*}{ Caso 3 } & $R_{0}=2,0$ & $\sigma=E_{t} \varepsilon$ \\
& $R_{45}=1,0$ & $E_{t}=2500[\mathrm{MPa}]$ \\
& $R_{90}=0,5$ & \\
\hline \hline & $R_{0}=0,64$ & $\sigma=E_{t} \varepsilon$ \\
Caso 4 & $R_{45}=0.77$ & $E_{t}=2500[\mathrm{MPa}]$ \\
& $R_{90}=0.57$ & \\
\hline \hline & $R_{0}=2.0$ & $\sigma=\sigma_{0}+Q\left(1-e^{-b \varepsilon}\right)$ \\
Caso 5 & $R_{45}=1.0$ & $Q=100[\mathrm{MPa}]$ \\
& $R_{90}=0.5$ & $b=75$ \\
\hline
\end{tabular}

A Figura 6.6 mostra a evolução da tensão equivalente para o caso 3 quando $\alpha=0^{\circ}$ e $\alpha=90^{\circ}$. Comparando-se seus valores, observa-se que $\sigma_{e q}$ quando $\alpha=0^{\circ}$ é bem maior que $\sigma_{e q}$ quando $\alpha=90^{\circ}$. Essa variação é devida à considerável diferença entre os índices de anisotropia $R_{0}$ e $R_{90}$. Já quando são comparadas as curvas do programa implementado e do modelo de elementos finitos, é possível notar que os resultados obtidos apresentam uma boa correlação. Apenas no caso $\alpha=90^{\circ}$ observa-se uma pequena oscilação no início do escoamento do material. Uma provável explicação para este comportamento deve-se ao fato do programa implementado externamente não apresentar a verificação do equilíbrio de forças, procedimento padrão do método dos elementos finitos. Esta instabilidade numérica logo se estabiliza e a curva passa a acompanhar o comportamento do modelo MEF. 


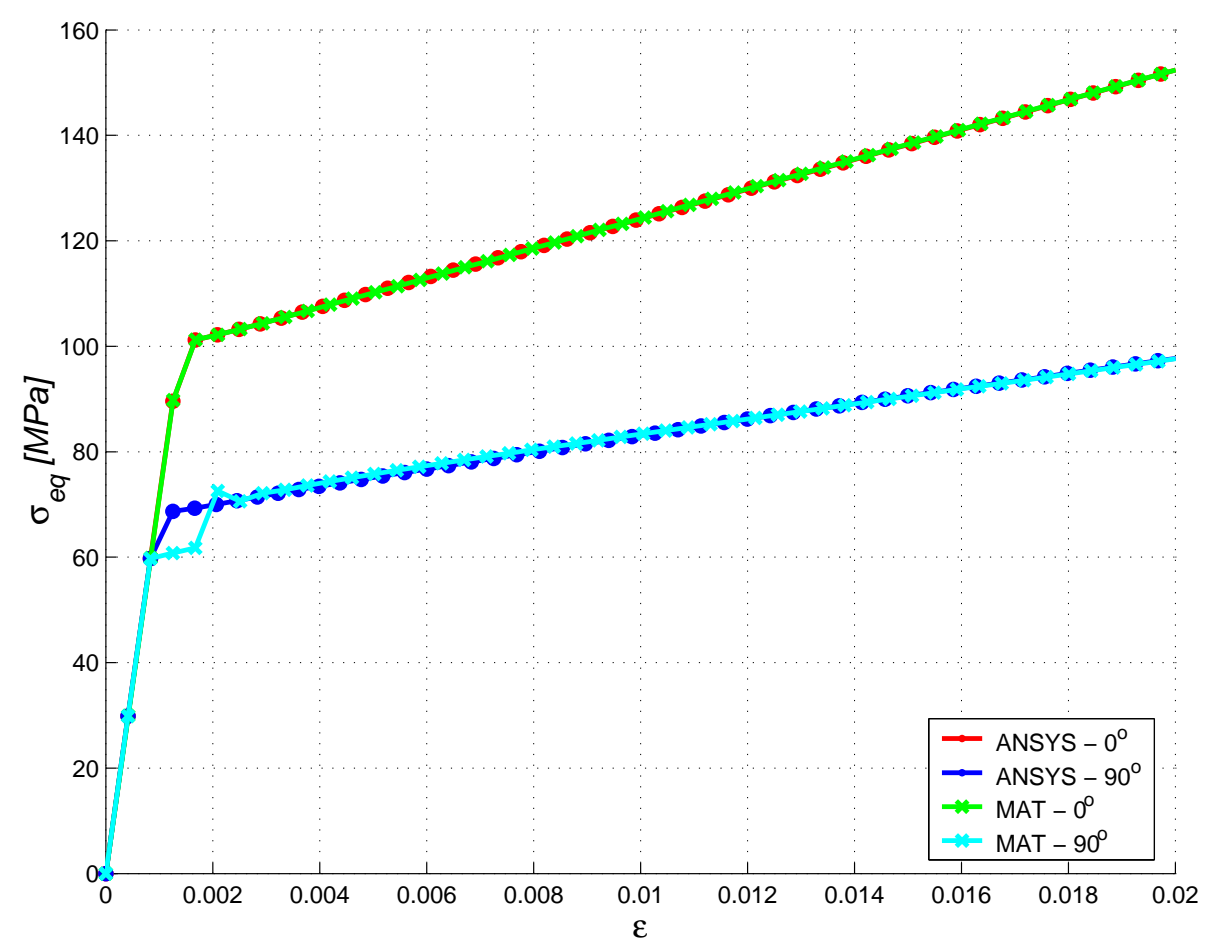

Figura 6.6: Tensão Equivalente $\alpha=0^{\circ}$ e $\alpha=90^{\circ}$ - Caso 3

Os gráficos da Figura 6.7 ilustram, para o caso 3, a evolução das tensões principais $\sigma_{1}$ e $\sigma_{2}$ para $\alpha=0^{\circ}$ e $\alpha=90^{\circ}$. Novamente observa-se uma oscilação no início do escoamento na tensão principal $\sigma_{1}$ quando $\alpha=90^{\circ}$. No caso da tensão principal $\sigma_{2}$ a maior variação entre o programa implementado e o modelo MEF é observada também para $\alpha=90^{\circ}$.
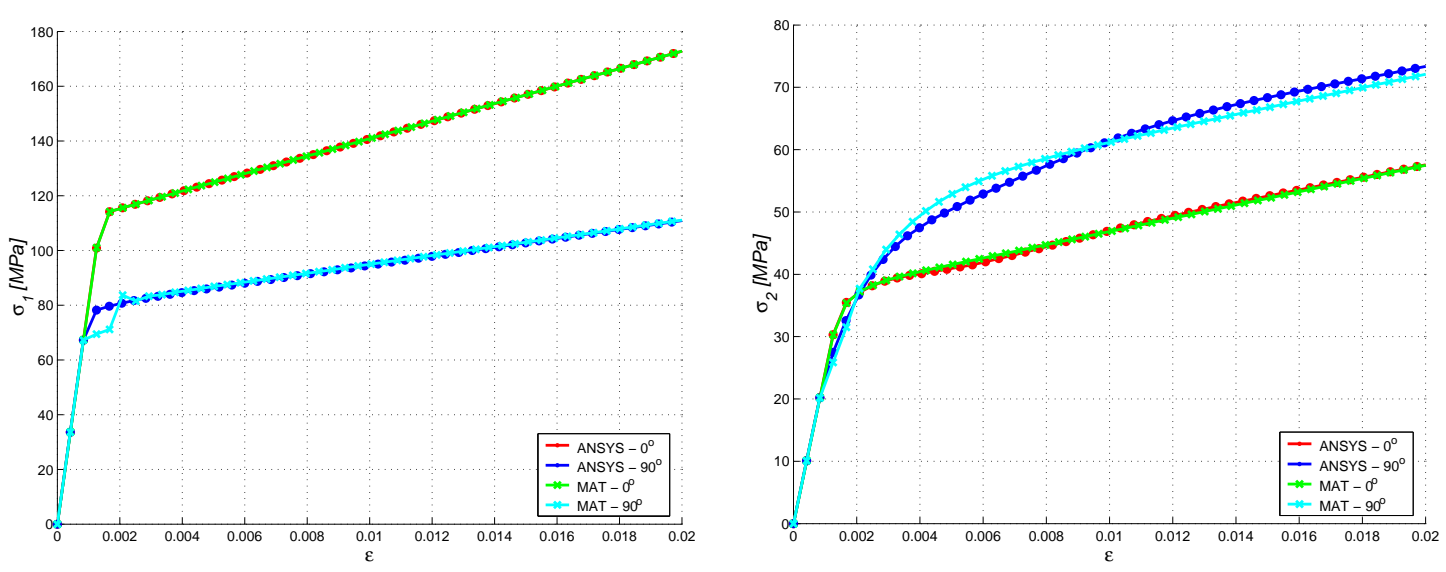

Figura 6.7: Tensões Principais $\alpha=0^{\circ}$ e $\alpha=90^{\circ}$ - Caso 3 
Ainda para o caso 3, a Figura 6.8 mostra a comparação entre as componentes de tensão quando $\alpha=45^{\circ}$. Neste caso a componente $\sigma_{x}$ corresponde a tensão na direção de laminação, $\sigma_{y}$ a tensão perpendicular à laminação e $\sigma_{x y}$ a componente de cisalhamento. Pode-se observar também algumas instabilidades durante a evolução. No caso das componentes $\sigma_{x}$ e $\sigma_{y}$ ocorreu uma diferença quase que permanente durante toda a evolução com erro da ordem de 5\%. Apesar desta diferença, o comportamento das curvas são bastante semelhantes. A componente de cisalhamento apresentou resultados mais próximos inclusive flagrando uma leve alteração de curvatura logo após o escoamento do material.

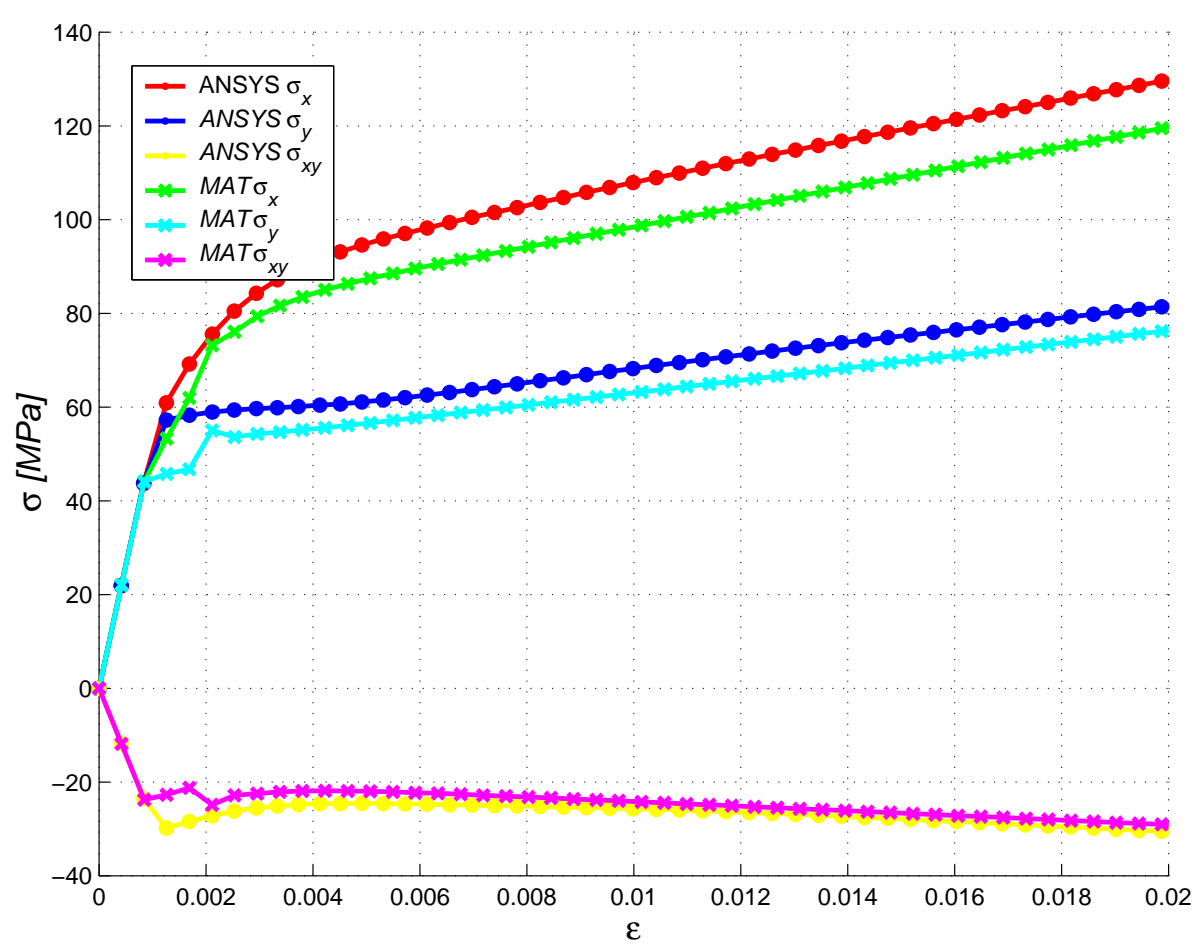

Figura 6.8: Componentes de tensão $\alpha=45^{\circ}$ - Caso 3

A evolução da tensão equivalente $\sigma_{e q}$, para o caso 4 , quando $\alpha=0^{\circ}$ e $\alpha=$ $90^{\circ}$ é dado na Figura 6.9. Neste caso não ocorre uma grande variação entre as tensões equivalentes uma vez que os valores de $R_{0}$ e $R_{90}$ são próximos. Mas pode-se observar que os valores relacionados com a direção $\alpha=0^{\circ}$ são ligeiramente maiores que $\alpha=90^{\circ}$. Este comportamento também se manteve na implementação externa. 


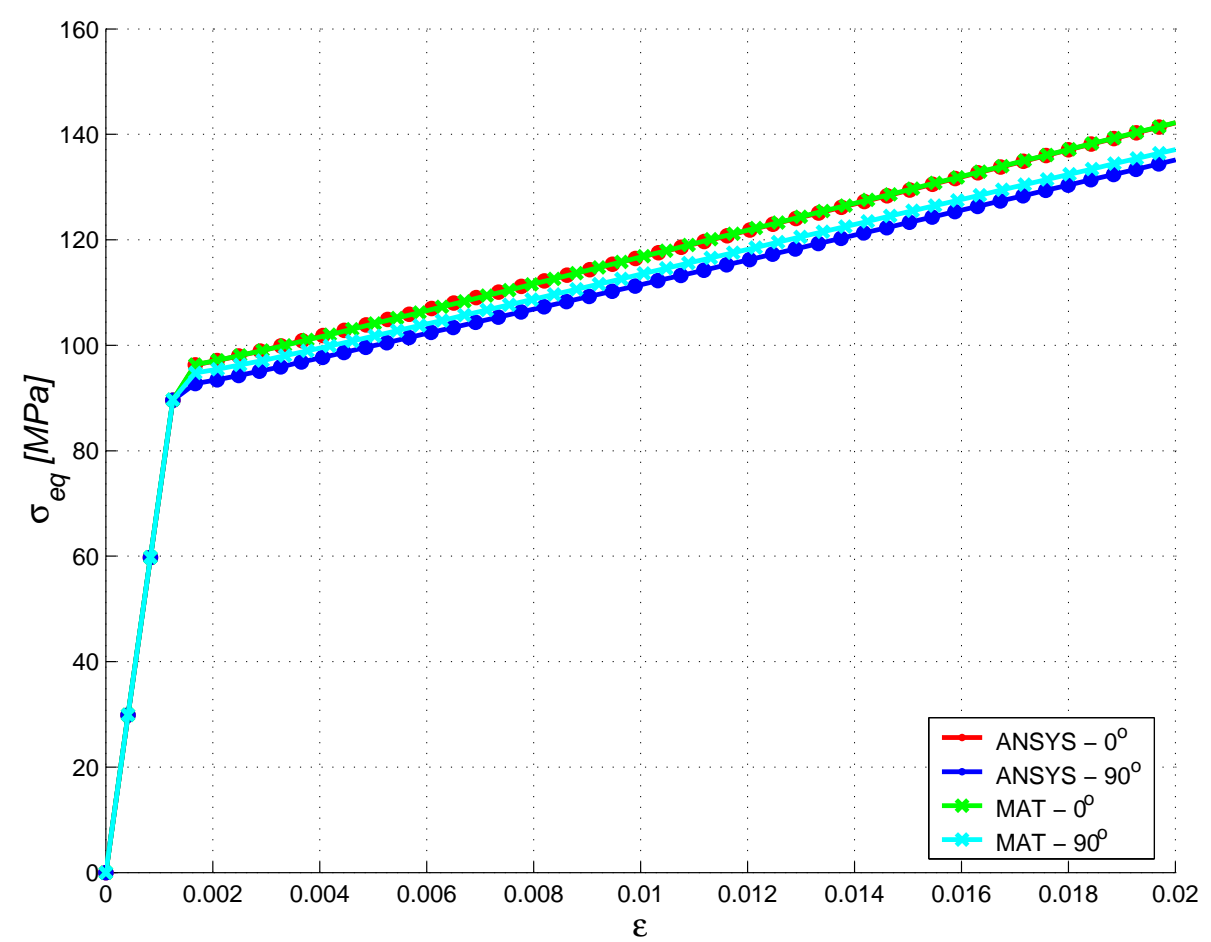

Figura 6.9: Tensão Equivalente $\alpha=0^{\circ}$ e $\alpha=90^{\circ}$ - Caso 4

A Figura 6.10 mostra a evolução das componentes de tensão principal $\sigma_{1}$ e $\sigma_{2}$ para $\alpha=0^{\circ}$ e $\alpha=90^{\circ}$. Aqui os resultados obtidos pela implementação externa também são satisfatórios quando comparados com o modelo MEF. O mesmo ocorreu para as componentes de tensão para o caso $\alpha=45^{\circ}$ dadas na Figura 6.11 .

Os resultados referentes ao modelo não linear, caso 5, são mostrados nas Figuras 6.12, 6.13 e 6.14. Na evolução da tensão equivalente, Figura 6.12, novamente pode-se observar uma pequena descontinuidade na curva dada pela implementação externa para o caso $\alpha=90^{\circ}$. Porém no geral, o comportamento não linear foi mantido pela implementação externa. O mesmo pode ser observado para as componentes de tensão principais, Figura 6.13 e para as componentes de tensão do caso $\alpha=45^{\circ}$, Figura 6.14. 

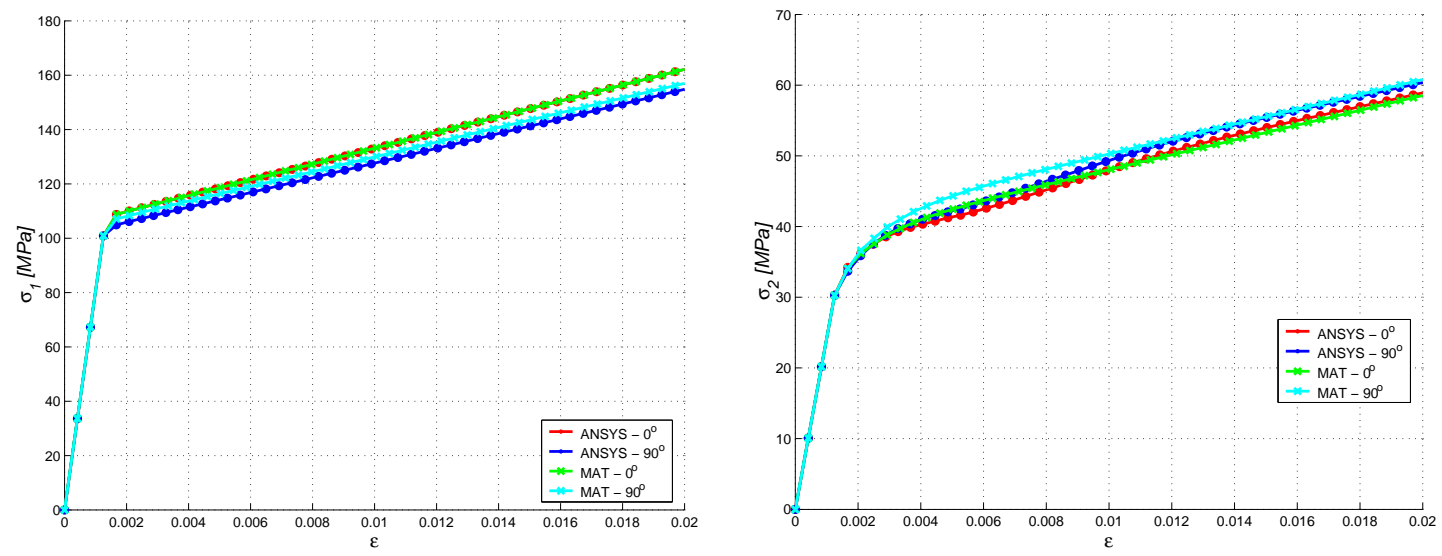

Figura 6.10: Tensões Principais $\alpha=0^{\circ}$ e $\alpha=90^{\circ}$ - Caso 4

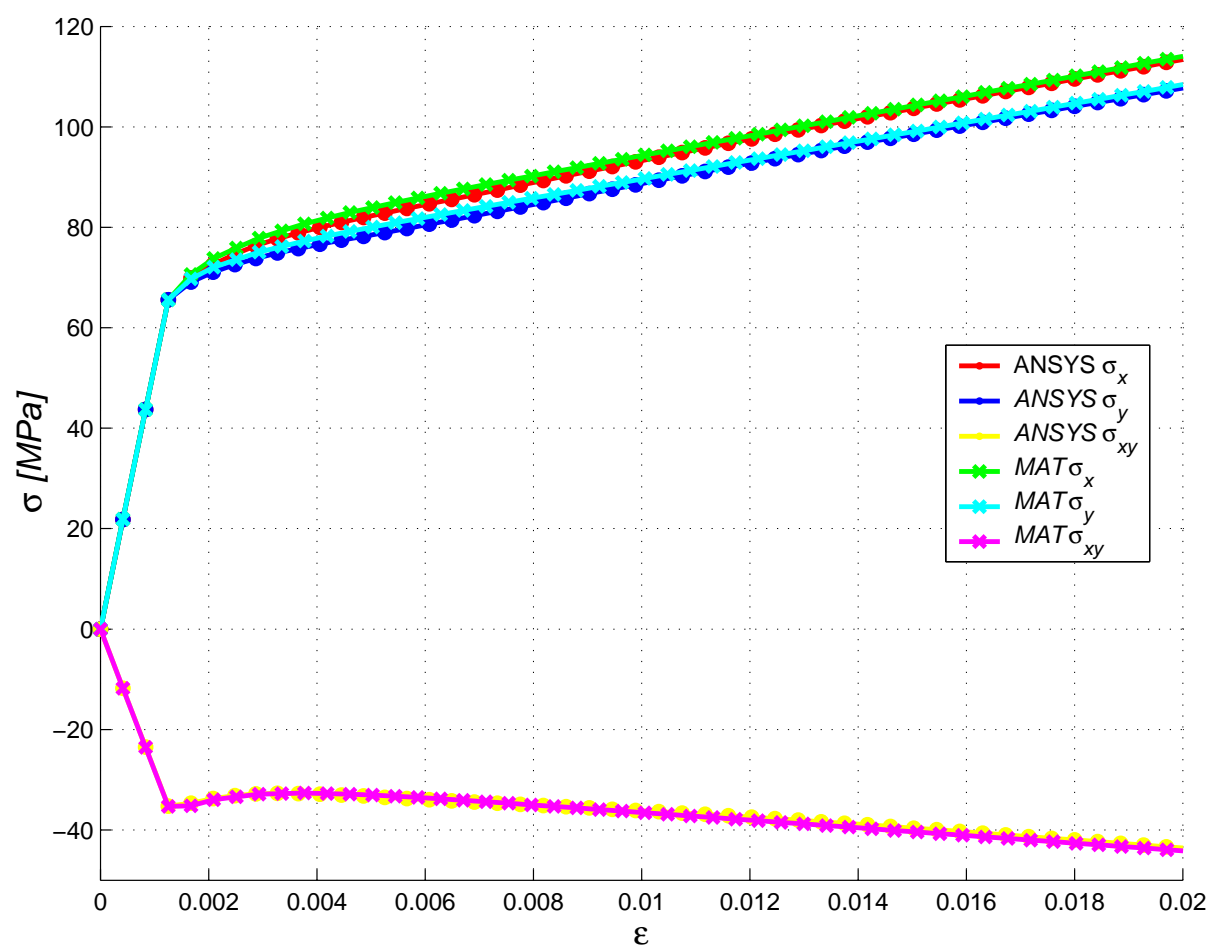

Figura 6.11: Componentes de tensão $\alpha=45^{\circ}$ - Caso 4 


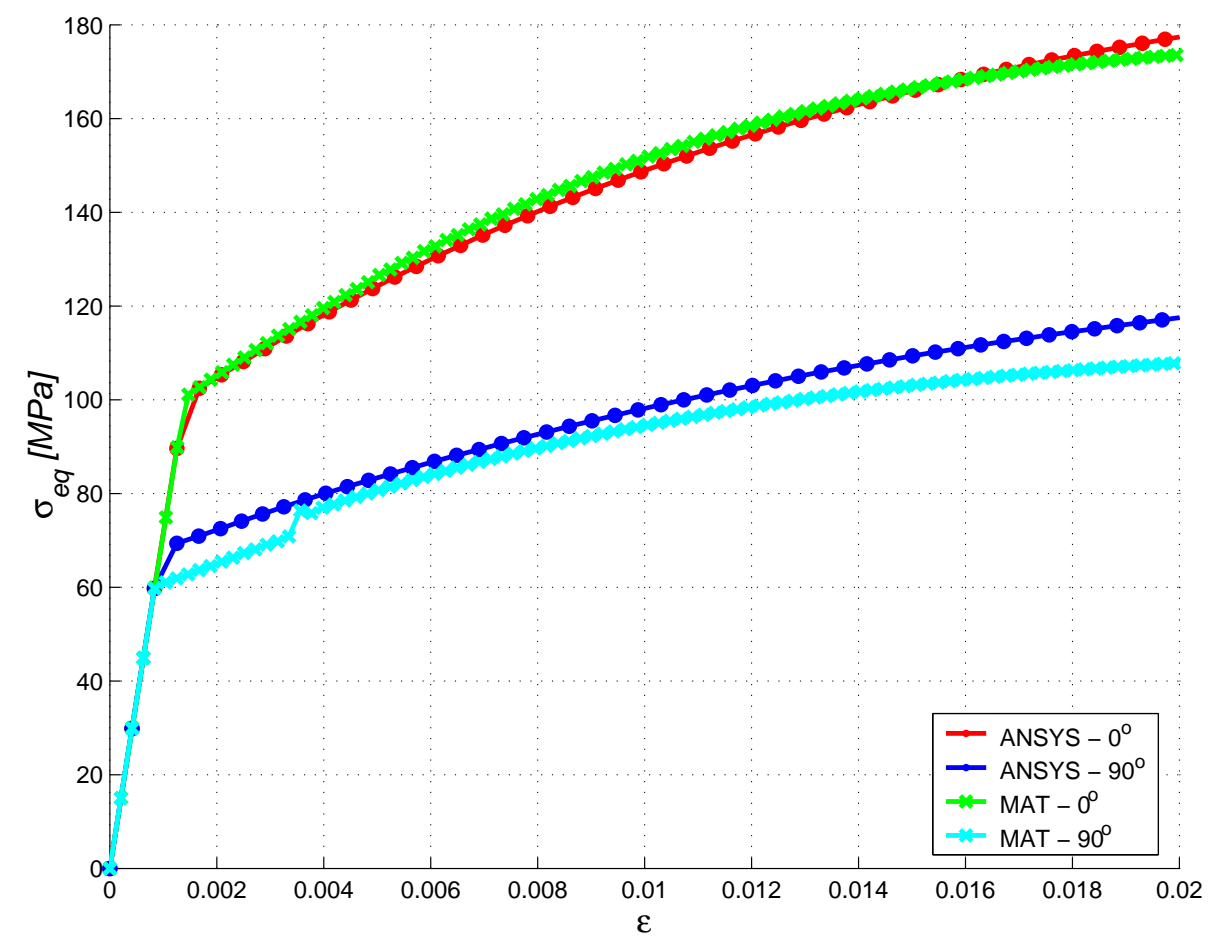

Figura 6.12: Tensão Equivalente $\alpha=0^{\circ}$ e $\alpha=90^{\circ}$ - Caso 5
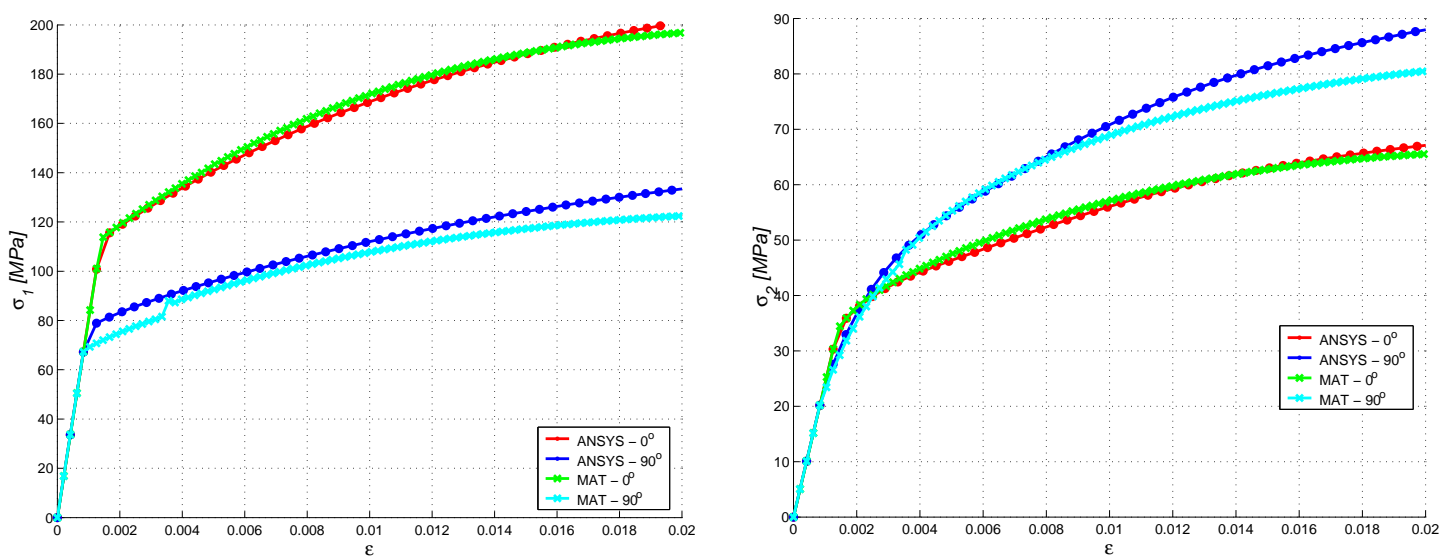

Figura 6.13: Tensões Principais $\alpha=0^{\circ}$ e $\alpha=90^{\circ}$ - Caso 5 


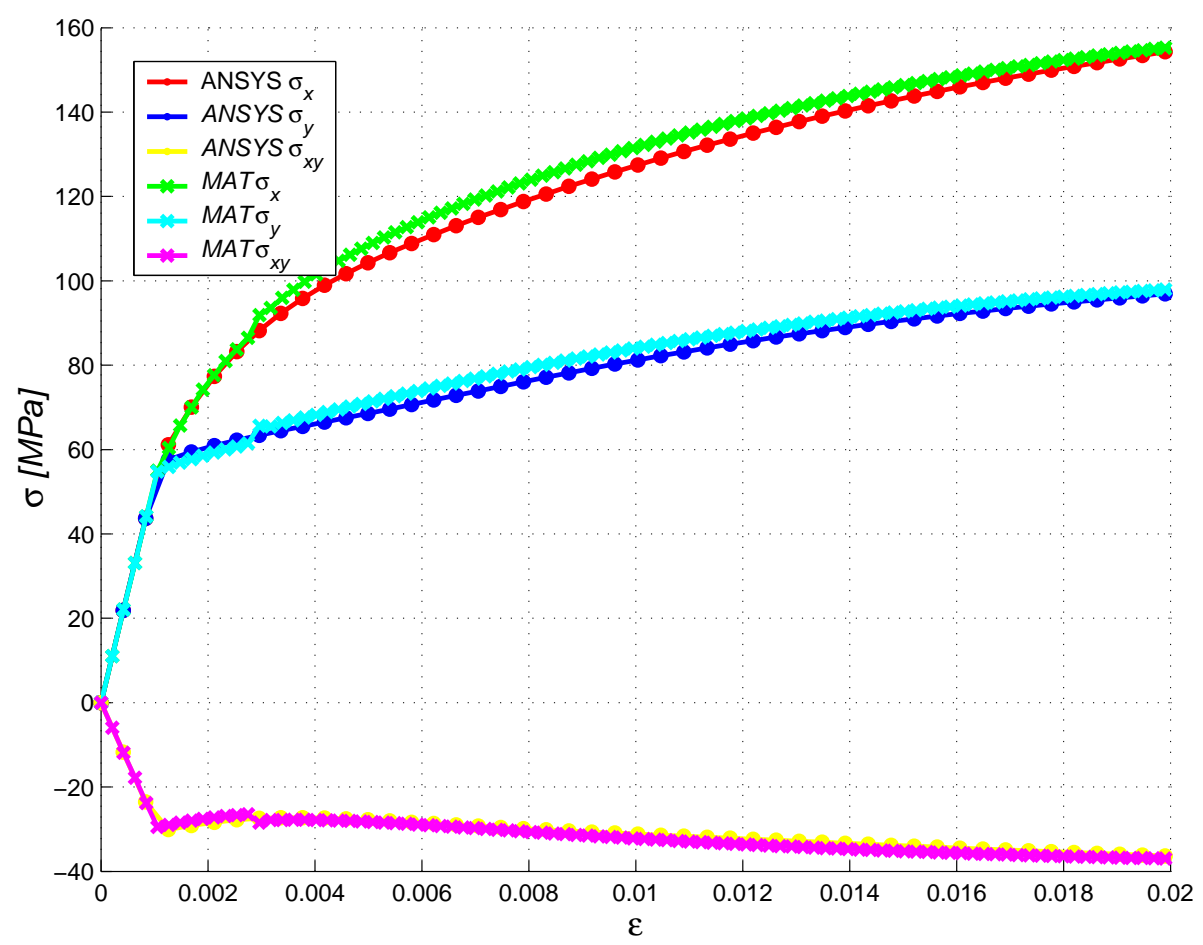

Figura 6.14: Componentes de tensão $\alpha=45^{\circ}$ - Caso 5

Desta forma foram apresentados os resultados para a validação do algoritmo de previsão-correção implementado externamente. No geral, os diferentes casos estudados mostraram uma boa correlação entre as curvas obtidas pela implementação e pelo MEF. A seguir são apresentados os resultados experimentais de caracterização de material para a liga de alumínio Al 7475-O estudada.

\subsection{Ensaios de caracterização de material}

\subsubsection{Ensaio de tração}

A caracterização do material para determinação da curva de tensão-deformação e seus parâmetros associados foi executada a partir do ensaio de tração uniaxial com corpos de prova (CDPs) padrões, normalizados segundo ASTM E8M - 97. Para tal utilizou-se um prensa hidráulica EMIC com capacidade de 10 toneladas. Os corpos de prova foram obtidos a partir de uma chapa de alumínio aeronáutico Al 7475-O com $1 \mathrm{~mm}$ de espessura e foram cortados segundo as direções $\alpha=0^{\circ}$, 
$45^{\circ}$ e $90^{\circ}$ em relação à direção de laminação. Para construção dos CDPs foi utilizado o processo de corte por jato d'água. A Figura 6.15 ilustra a montagem típica de um corpo de prova fixo entre as garras da prensa com o dispositivo para aquisição do estiramento longitudinal, o qual posteriormente é convertido em medida de deformação.

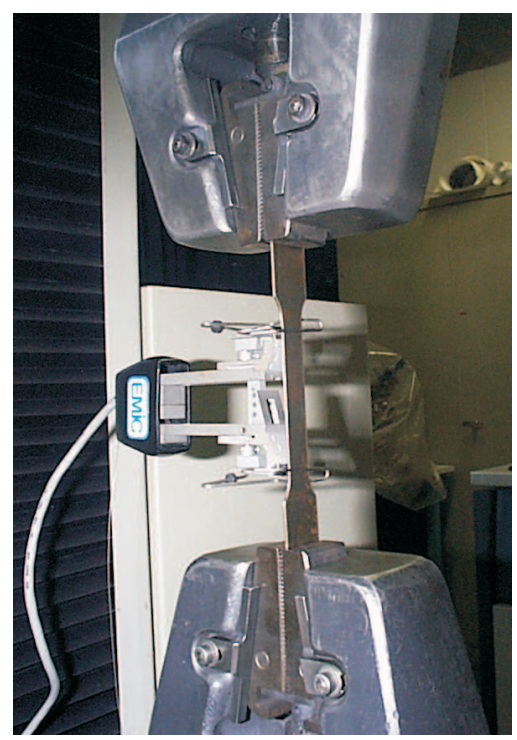

Figura 6.15: Montagem do CDP no ensaio de tração

Os gráficos da Figura 6.16 mostram as curvas experimentais obtidas do ensaio de tração e as curvas ajustadas, a partir da lei de potência, para as três direções $\alpha=0^{\circ}, 45^{\circ}$ e $90^{\circ}$. Pode-se observar o efeito da anisotropia do material caracterizado pelas diferentes evoluções das curvas durante o encruamento. A direção correspondente a $\alpha=0^{\circ}$ apresenta um nível de tensão ligeiramente maior quando comparada com as outras duas direções.

As constantes de material ajustadas são apresentadas na Tabela 6.3. As curvas experimentais foram ajustadas considerando-se dois modelos de encruamento, um dado pela lei de potência conforme eq. 3.52 e o outro pela lei de Voce, eq. 3.53. A tabela também mostra os valores do módulo de elasticidade $E$ e das tensões de escoamento $\sigma_{0}$ determinadas para cada uma das direções ensaiadas. 

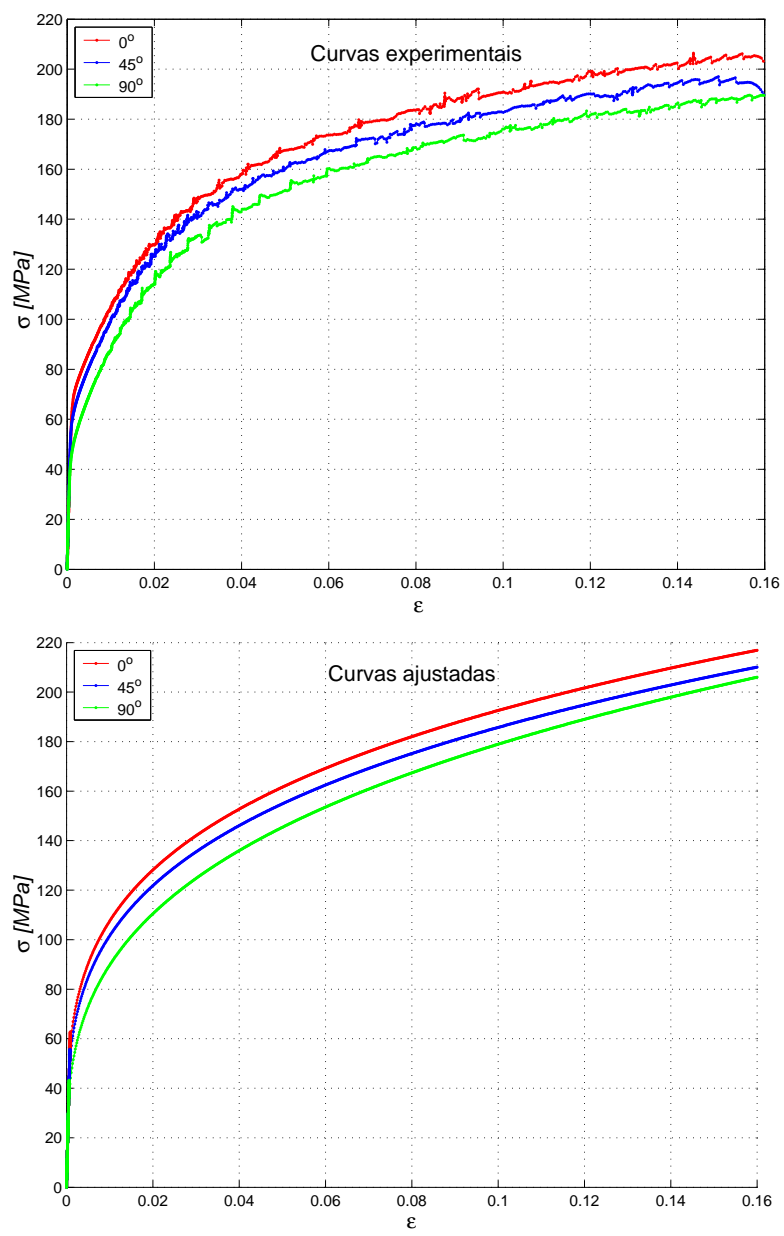

Figura 6.16: Curvas experimentais e ajustadas do ensaio de tração

Tabela 6.3: Dados de material obtidos pelo ajuste

\begin{tabular}{|c|c|c|c|}
\hline & $0^{\circ}$ & $45^{\circ}$ & $90^{\circ}$ \\
\hline \hline$E[G P a]$ & 66.46 & 71.80 & 70.72 \\
$\sigma_{y}[\mathrm{MPa}]$ & 78.90 & 71.75 & 58.70 \\
\hline \hline$K[M P a]$ & 347.72 & 340.70 & 354.23 \\
$n$ & 0.256 & 0.263 & 0.297 \\
\hline \hline$Q[M P a]$ & 133.86 & 130.62 & 135.70 \\
$b$ & 30.97 & 33.57 & 33.75 \\
\hline
\end{tabular}




\subsubsection{Ensaio de anisotropia}

O ensaio de anisotropia do material foi realizado segundo as especificações da norma ASTM E517-96a. O procedimento indicado pela norma consiste na medição inicial da geometria do CDP (largura $w_{0}$ e o comprimento de calibragem $l_{0}$ ) dentro de uma tolerância especificada. Posteriormente o CDP deve ser tracionado além do limite elástico de forma que na região plástica sejam realizadas as medidas dos comprimentos finais $w_{f}$ e $l_{f}$ em cada nível de deformação de interesse para o cálculo do índice de anisotropia. Aqui dois procedimentos são possíveis, um usando-se uma aquisição automática das deformações e outro utilizando-se de um procedimento manual de medição das deformações. No primeiro caso, quando os índices de anisotropia são calculados, é necessário descontar a parcela elástica de deformação da medição. No caso manual, a medição das dimensões do CDP deve ser executada com a prensa descarregada, de forma que a parcela de deformação elástica fique automaticamente descontada.

O presente trabalho aplicou o procedimento manual na medição das dimensões do CPD. Para tal foi necessário desenvolver um programa para comandar as paradas regulares da prensa. Este programa é padrão do equipamento utilizado e apresentou limitações do número total de paradas de forma que foram realizadas apenas sete medições para cada CDP estudado. Com um número limitado de paradas optou-se por distribuir as medições até um deslocamento máximo de 5 [mm] do cabeçote da máquina. Isto representou uma deformação máxima de aproximadamente $10 \%$ nos CDPs, o que garante a uniaxialidade do estado de tensão.

Da mesma forma que no ensaio de tração realizou-se ensaios em $\alpha=0^{\circ}, 45^{\circ}$ e $90^{\circ}$ da direção de laminação. Para cada uma destas direções foram realizados ensaios com três CDPs. As medições manuais da largura $w$ em cada parada foram executadas com auxílio de um micrômetro, enquanto que os valores de estiramento devido a variação do comprimento $l$ foram obtidos pelo sistema de aquisição do equipamento. 
A Figura 6.17 ilustra o comportamento típico da curva força x deslocamento obtida nos ensaios. Os pontos numerados de 1 a 7 correspondem aos instantes de parada da máquina para a medição do CDP. Pode-se observar o patamar decrescente do nível de força quando o cabeçote da máquina pára. Com a retomada do carregamento a força volta a aumentar atingindo um pico antes de continuar a trajetória padrão de encruamento.

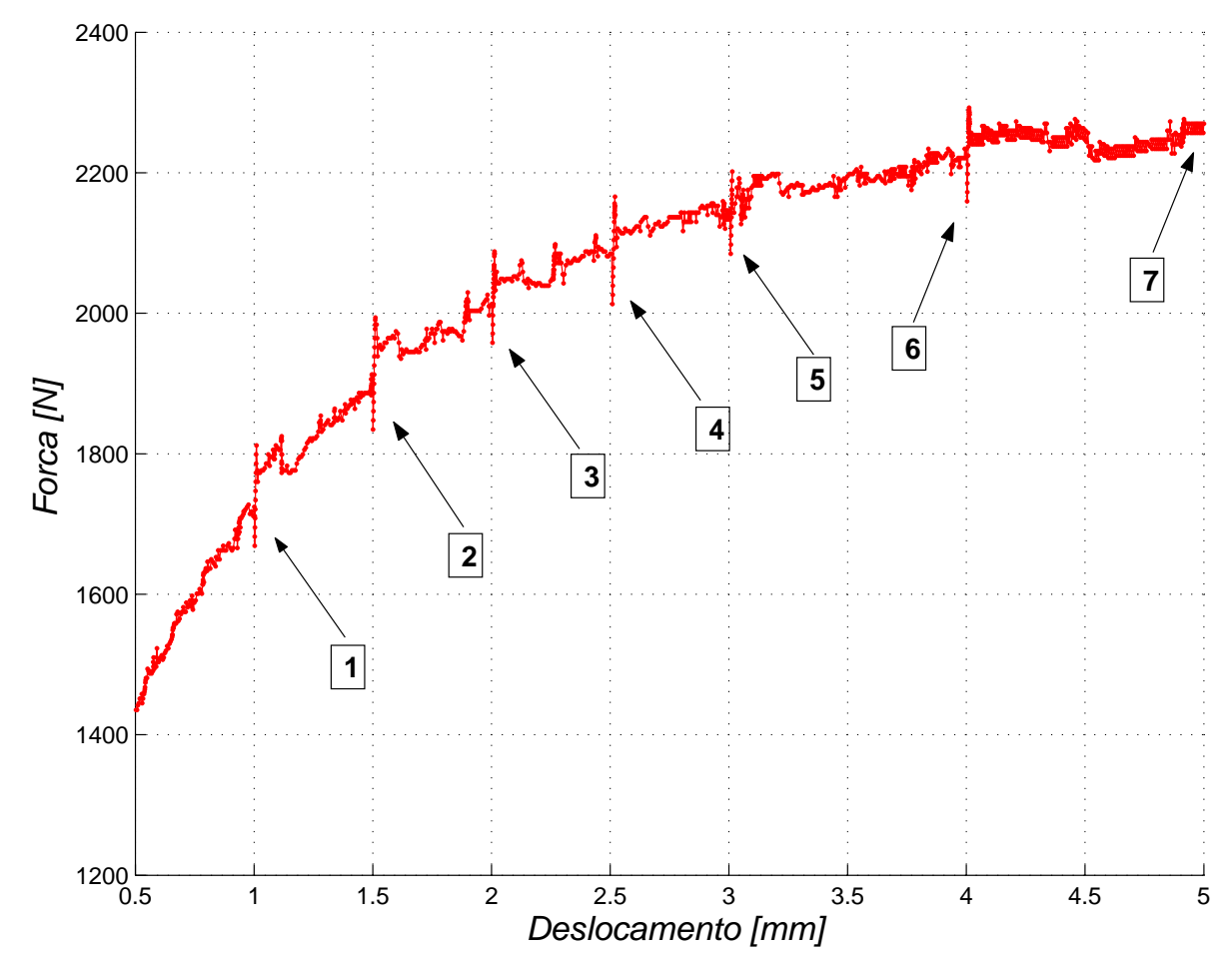

Figura 6.17: Diagrama Força x deslocamento CDP-0 : Ensaio 1

Efetuadas as medições do corpo de prova, o cálculo do índice de anisotropia $R_{\alpha}$ de uma dada direção $\alpha$, seguindo a definição da eq. 4.23, é dado por:

$$
R_{\alpha}=\frac{\ln \left(w_{0} / w_{f}\right)}{\ln \left(l_{f} w_{f} / l_{0} w_{0}\right)}
$$

As Figuras 6.18, 6.19 e 6.20 mostram os valores calculados dos índices de anisotropia $R_{0}, R_{45}$ e $R_{90}$ respectivamente, obtidos para cada um dos três CDPs ensaiados correspondentes direções $\alpha=0^{\circ}, 45^{\circ}$ e $90^{\circ}$ e para diferentes níveis de deformação medidos. 
Os valores médios dos índices de anisotropia dos três CDPs de cada direção $\alpha$ também são mostrados no gráfico. Esses valores correspondem a média simples dos três $R_{\alpha}$ calculados em cada instante do encruamento.

Para todos os casos observa-se uma leve tendência ao decréscimo nos valores dos índices de anisotropia com o aumento da deformação. Apenas no caso do CDP 1 de $\alpha=0^{\circ}$ que no início das medições, entre $2 \%$ e $3 \%$ de deformação, obteve-se um aumento de $R_{0}$ possivelmente ocasionado por erros durante a execução das medições.

No geral as curvas indicam que a anisotropia da liga de alumínio considerada não é muito acentuada, uma vez que os índices de anisotropia variam em faixas com valores próximos de 1 para todas as direções consideradas.

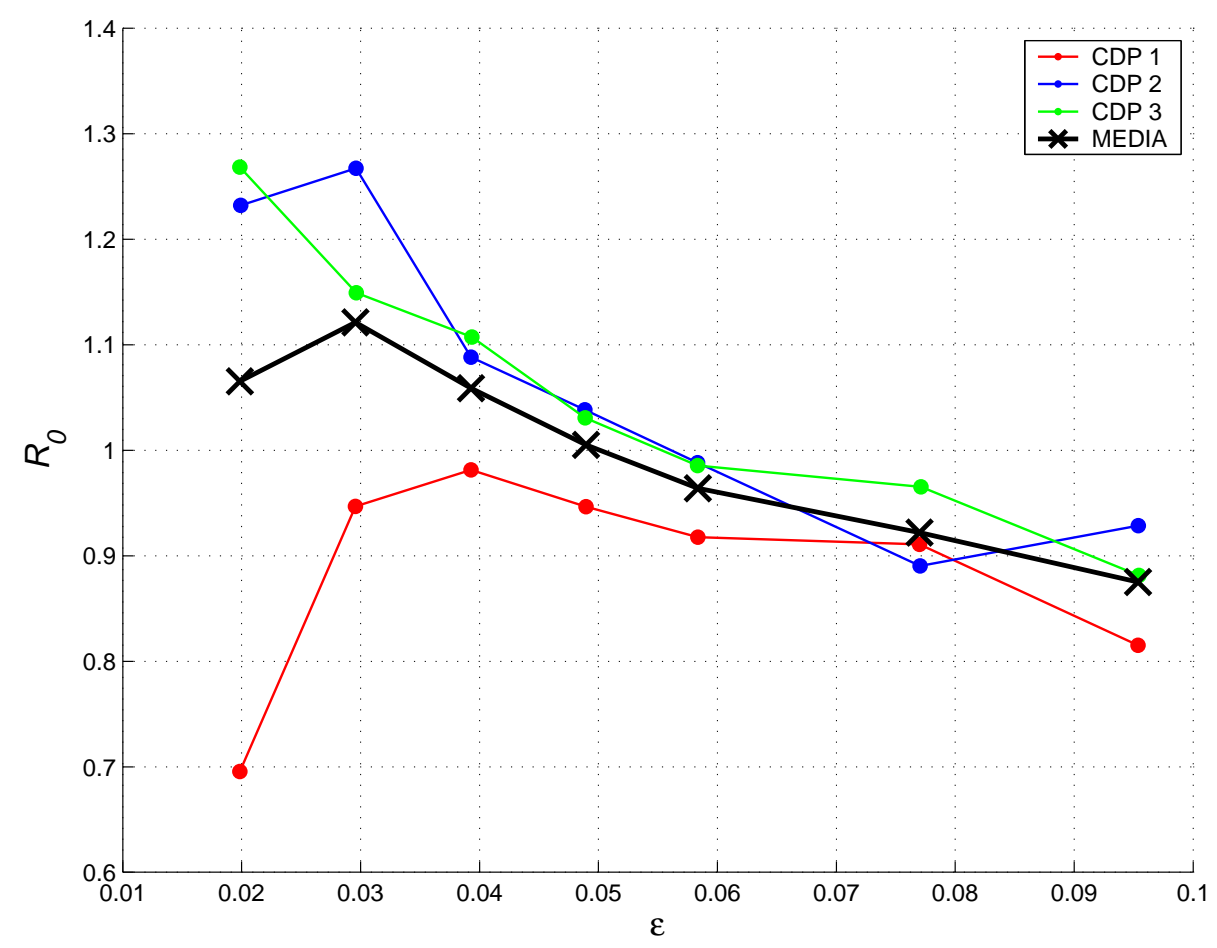

Figura 6.18: Evolução experimental de $R_{0}$ 


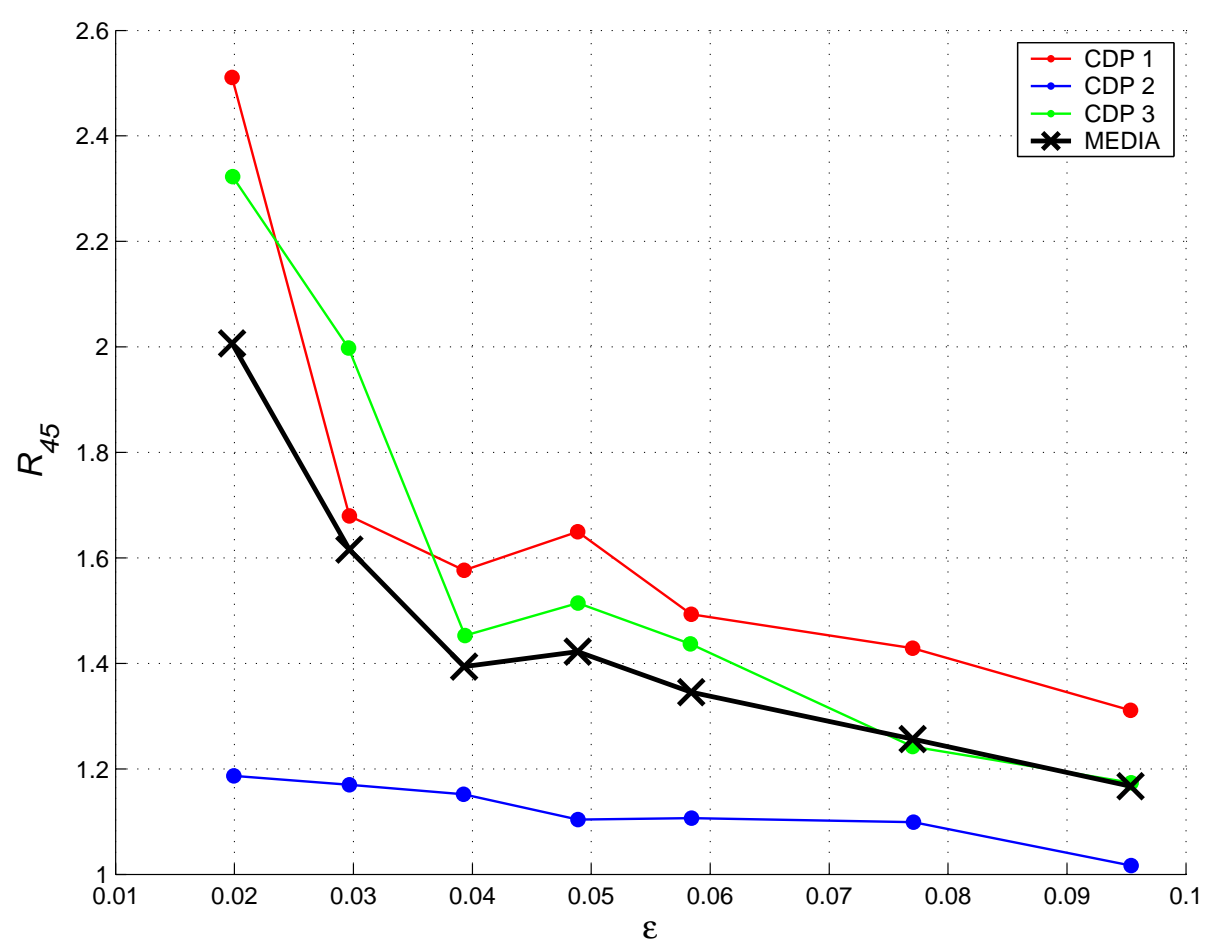

Figura 6.19: Evolução experimental de $R_{45}$

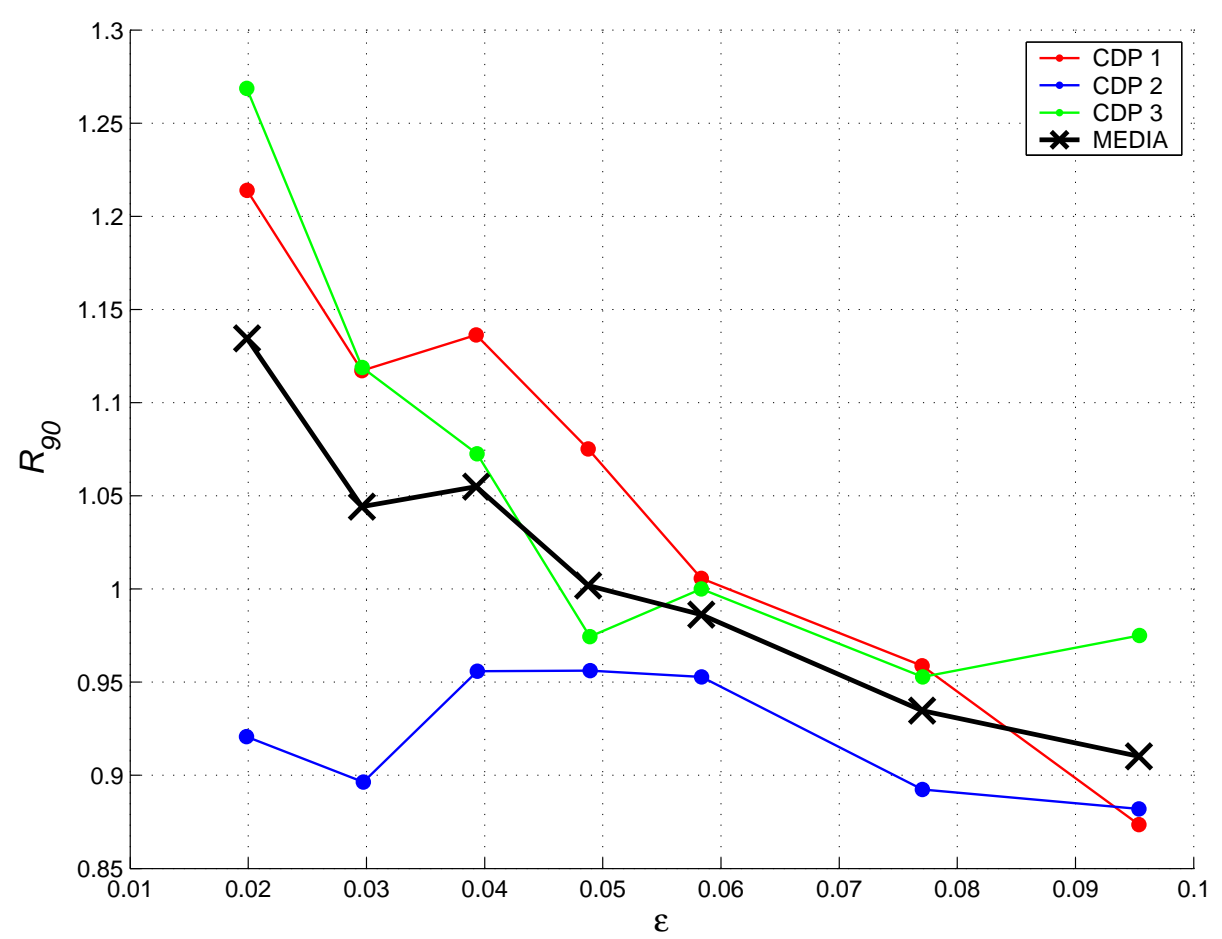

Figura 6.20: Evolução experimental de $R_{90}$ 
Apesar do ensaio de anisotropia permitir o cálculo de uma evolução experimental de $R_{\alpha}$, tradicionalmente apenas um valor é considerado nos modelos matemáticos representativos da anisotropia do material. Usualmente escolhe-se um nível de deformação e então é adotado o índice de anisotropia correspondente a este nível como valor de referência para cada direção $\alpha$. Para o material ensaiado, optou-se por adotar os índices de anisotropia correspondentes a deformação máxima de $10 \%$, de forma que $R_{0}=0.875, R_{45}=1.16$ e $R_{90}=0.91$.

A seguir são apresentados os resultados obtidos pela aplicação da metodologia proposta de cálculo de evolução dos parâmetros de anisotropia, utilizando-se como dados de entrada as constantes de material determinadas nestes ensaios de caracterização.

\subsection{Aplicação da metodologia}

Os resultados experimentais apresentados no tópico anterior são utilizados como dados de entrada e como fonte de comparação para a aplicação da metodologia de cálculo da evolução dos parâmetros de anisotropia e adicionalmente na determinação da nova superfície de escoamento proposta.

A idéia principal é comparar os valores dos índices de anisotropia obtidos experimentalmente para a liga de alumínio estudada, com a evolução obtida pelo procedimento teórico proposto, supondo-se um ponto material de análise submetido ao mesmo histórico de deformação e com as mesmas propriedades do material ensaiado. A partir da evolução teórica dos parâmetros de anisotropia, o fator de correção $\Psi$ é determinado através da eq. 5.88. Desta forma a nova superfície de escoamento é gerada, dada pela eq. 5.84, e sua evolução com o decorrer do encruamento é obtida permitindo comparações com a superfície original de Hill. Para tal, a metodologia descrita no capítulo anterior é aplicada conforme descrito a seguir.

O primeiro passo consiste na utilização das constantes de material, previamente determinadas nos ensaios de caracterização da liga de alumínio, como dados 
de entrada no algoritmo de previsão-correção. As constantes utilizadas são dadas conforme a Tabela 6.3, referente ao modelo de encruamento dado pela lei de potência e os índices de anisotropia foram assumidos $R_{0}=0.875, R_{45}=1.16 \mathrm{e}$ $R_{90}=0.91$ correspondentes a deformação máxima do ensaio, conforme discutido no tópico anterior.

Definidas as constantes de material, o procedimento considera como histórico de carregamento uma curva de deformação na maior direção principal $\varepsilon_{1}$ variando linearmente de zero a máximo. No caso estudado considerou-se a curva de deformação variando linearmente de zero a $10 \%$, correspondente a faixa de deformação do ensaio dos índices de anisotropia.

É importante destacar que o estado de tensão-deformação gerado no ensaio uniaxial de anisotropia é diferente do estado base da formulação. A Figura 6.21 ilustra os dois casos. O caso A corresponde ao estado de tensão-deformação do ensaio uniaxial. Aqui o estado de tensão é assumido ser uniaxial enquanto que o estado de deformação é triaxial. O caso B representa o estado base da formulação já discutido no capítulo anterior.

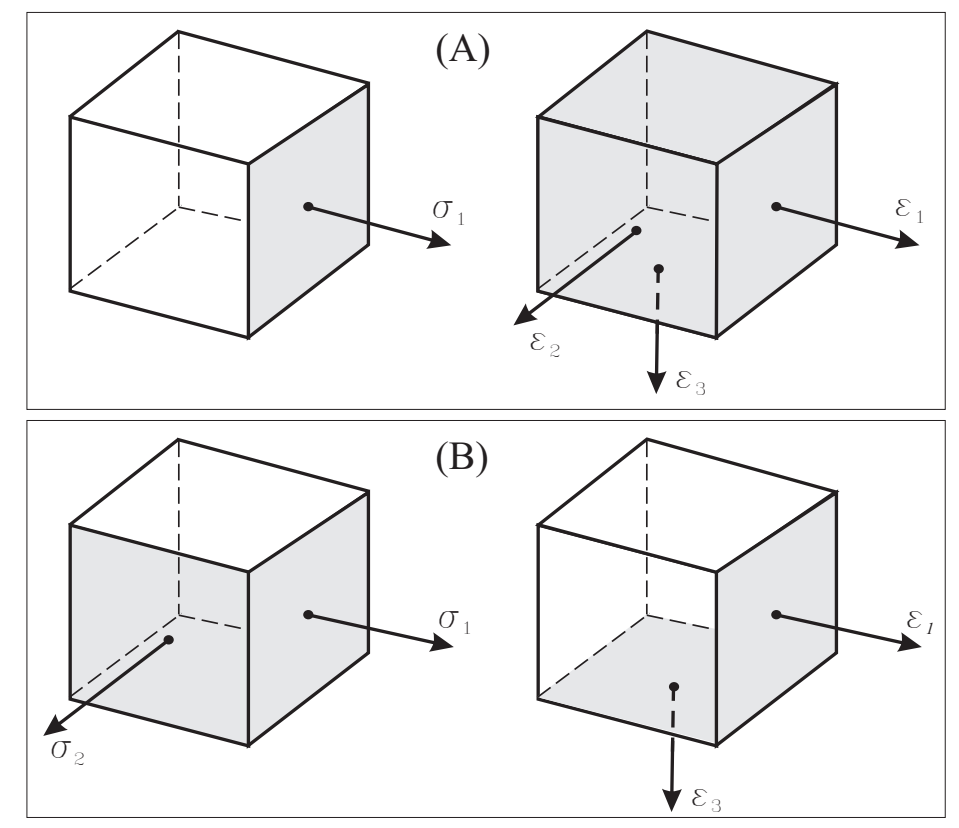

Figura 6.21: Comparação entre estados de tensão-deformação 
A seguir são apresentados os diversos resultados teóricos obtidos levando-se em consideração estes dados de entrada e assumindo-se que o ponto analisado satisfaz as hipóteses de carregamento definidas para a aplicação da metodologia, conforme discutidas no capítulo anterior.

\subsubsection{Curvas tensão x deformação}

Os resultados iniciais obtidos pela aplicação da metodologia consistem nas curvas de tensão x deformação determinadas a partir do algoritmo de previsãocorreção. Tais curvas compreendem, para cada direção $\alpha$ considerada, as componentes de tensão principal $\sigma_{1}, \sigma_{2}$ e a tensão equivalente $\sigma_{e q}$.

O comportamento da tensão equivalente e das componentes de tensão principal $\sigma_{1}$ e $\sigma_{2}$ para $\alpha=0^{\circ}$ e $90^{\circ}$, são mostradas na Figura 6.22 e 6.23 , respectivamente.

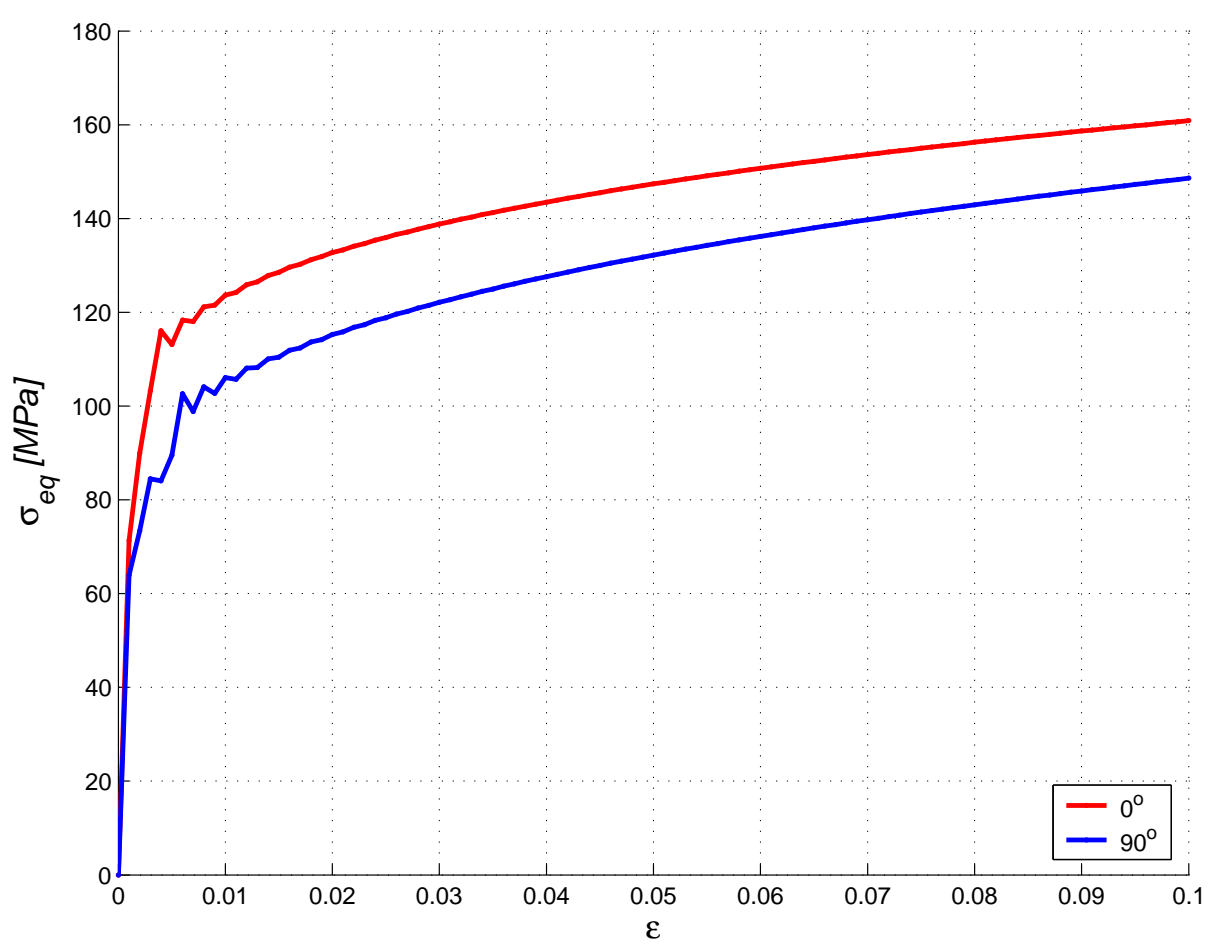

Figura 6.22: Tensão equivalente

Da mesma forma que observado em algumas das curvas de validação do algoritmo de previsão-correção, é possível observar na evolução destas tensões uma 

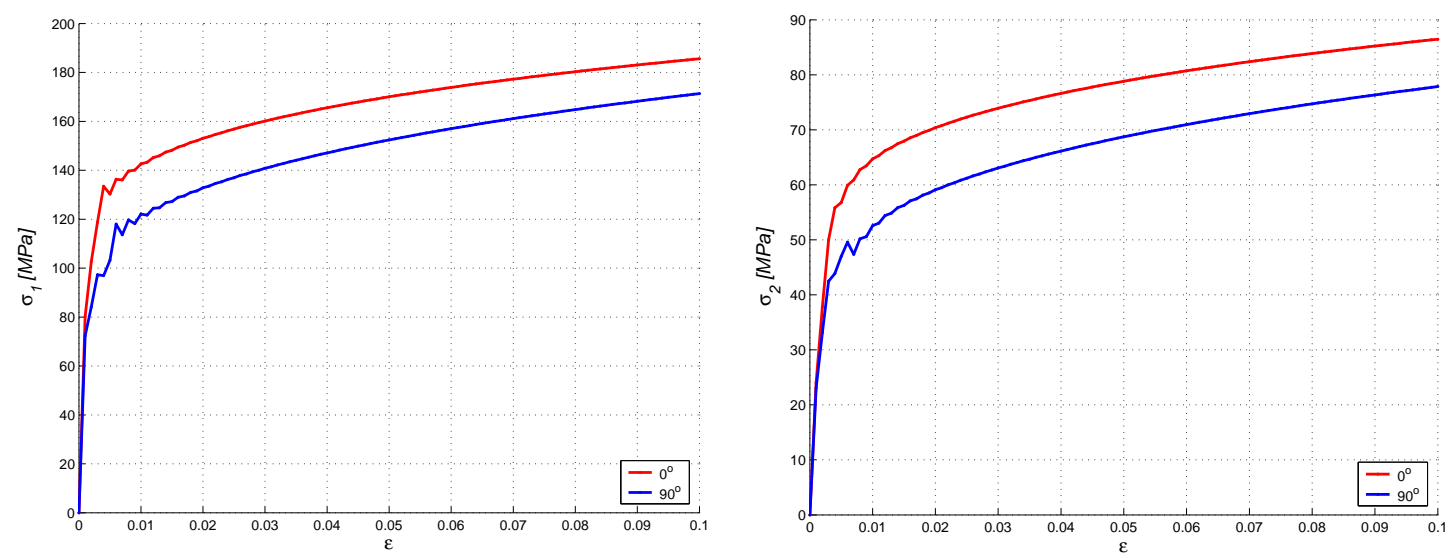

Figura 6.23: Tensões principais

leve oscilação após o início do escoamento. Esta oscilação é amortecida na medida em que ocorre o carregamento e as curvas permanecem com sua trajetória padrão de encruamento.

As componentes de tensão para o caso $\alpha=45^{\circ}$ são mostradas na Figura 6.24. As componentes $\sigma_{x}$ na direção de laminação e $\sigma_{y}$ perpendicular a esta direção apresentam uma diferença sútil em suas evoluções, enquanto que a componente de cisalhamento $\sigma_{x y}$ permanece praticamente constante.

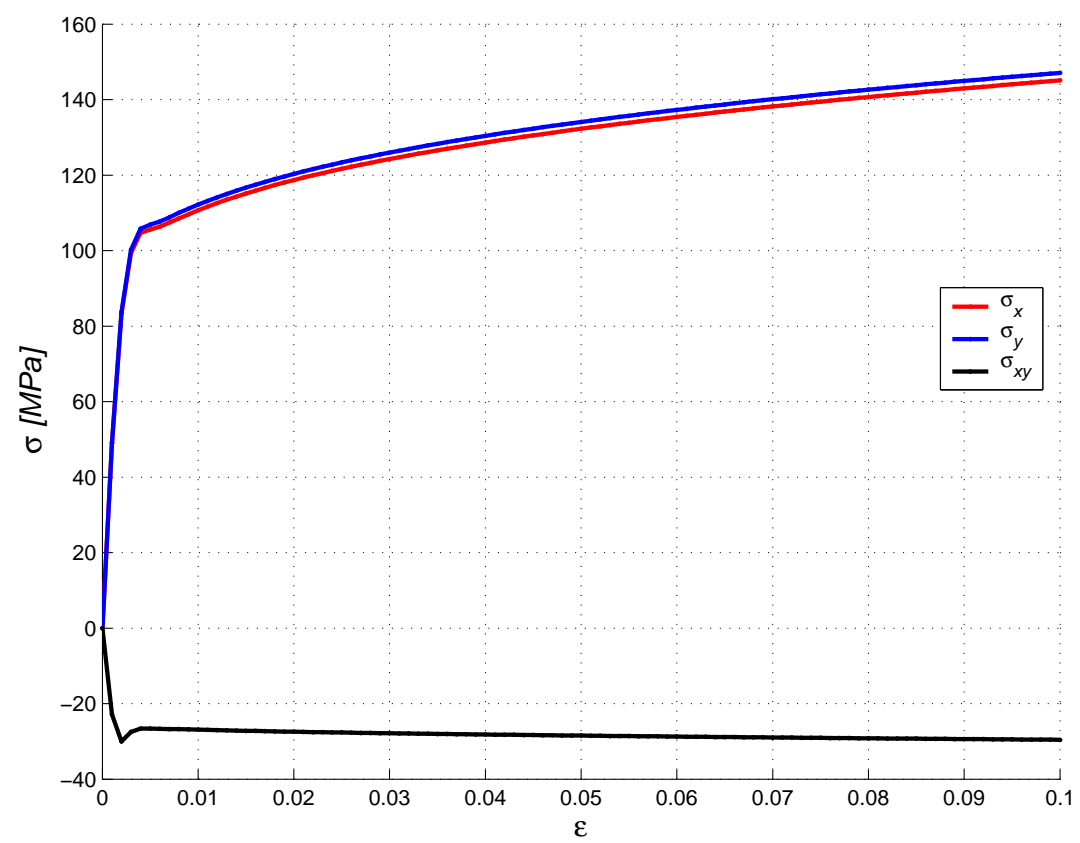

Figura 6.24: Componentes de tensão $\alpha=45^{\circ}$ 


\subsubsection{Coeficientes $\beta_{i}^{(\alpha)}$ do conjunto de equações}

Com a determinação das constantes de material a partir dos ensaios de caracterização e da evolução das componentes de tensão obtidas pelo algoritmo de previsão-correção, os coeficientes $\beta_{i}^{\left(0^{\circ}\right)}, \beta_{i}^{\left(90^{\circ}\right)}$ e $\beta_{i}^{\left(45^{\circ}\right)}$ podem ser determinados para cada incremento de deformação, conforme a eq. 5.65 para $\alpha=0^{\circ}$; eq. 5.66 para $\alpha=90^{\circ}$ e eq. 5.81 a 5.83 para $\alpha=45^{\circ}$.

A evolução destes coeficientes em função da deformação principal é mostrada nas Figuras 6.25, 6.26 e 6.27, para $\alpha=0^{\circ}, 90^{\circ}$ e $45^{\circ}$ respectivamente. Pelas curvas pode-se observar que estes coeficientes apresentam uma evolução suave, sem alterações bruscas, com o decorrer do carregamento. Apenas nos instantes iniciais, quando o ponto material está na fase de transição para o regime plástico é possível notar algumas oscilações nas curvas. Porém, para o cálculo de evolução dos parâmetros de anisotropia, esta faixa de valores dos coeficientes $\beta_{i}^{(\alpha)}$ não é considerada.

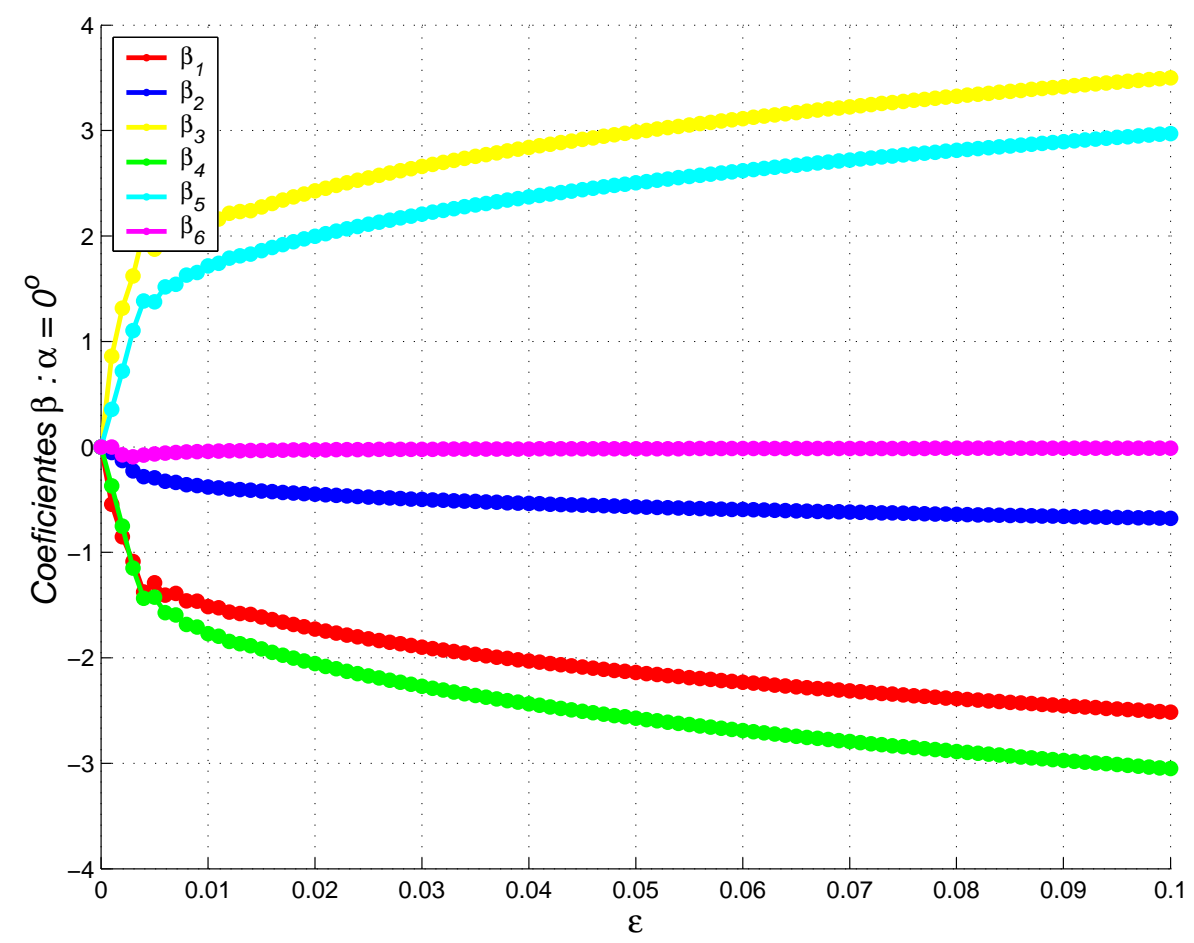

Figura 6.25: Evolução dos coeficientes $\beta_{i}^{\left(0^{\circ}\right)}$ para $\alpha=0^{\circ}$ 


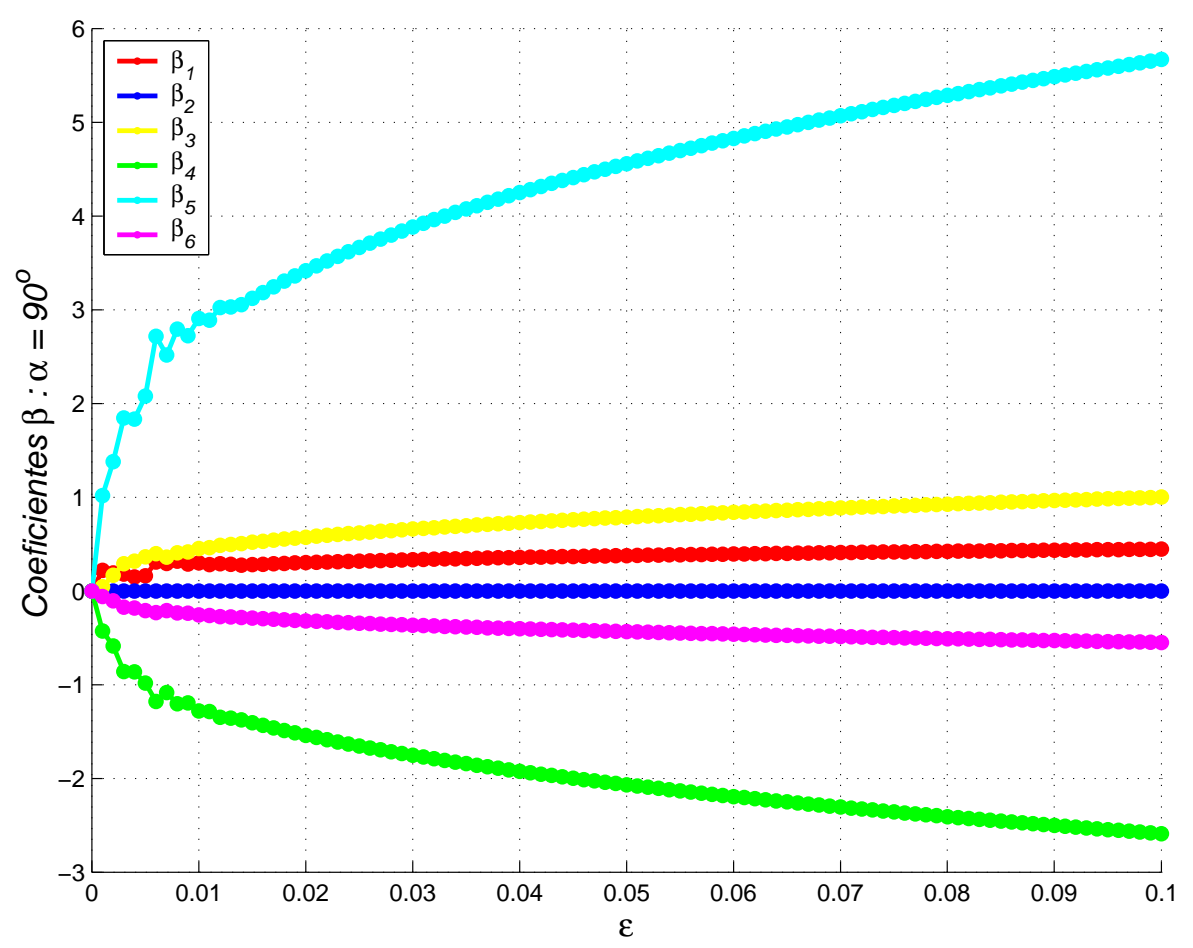

Figura 6.26: Evolução dos coeficientes $\beta_{i}^{\left(90^{\circ}\right)}$ para $\alpha=90^{\circ}$

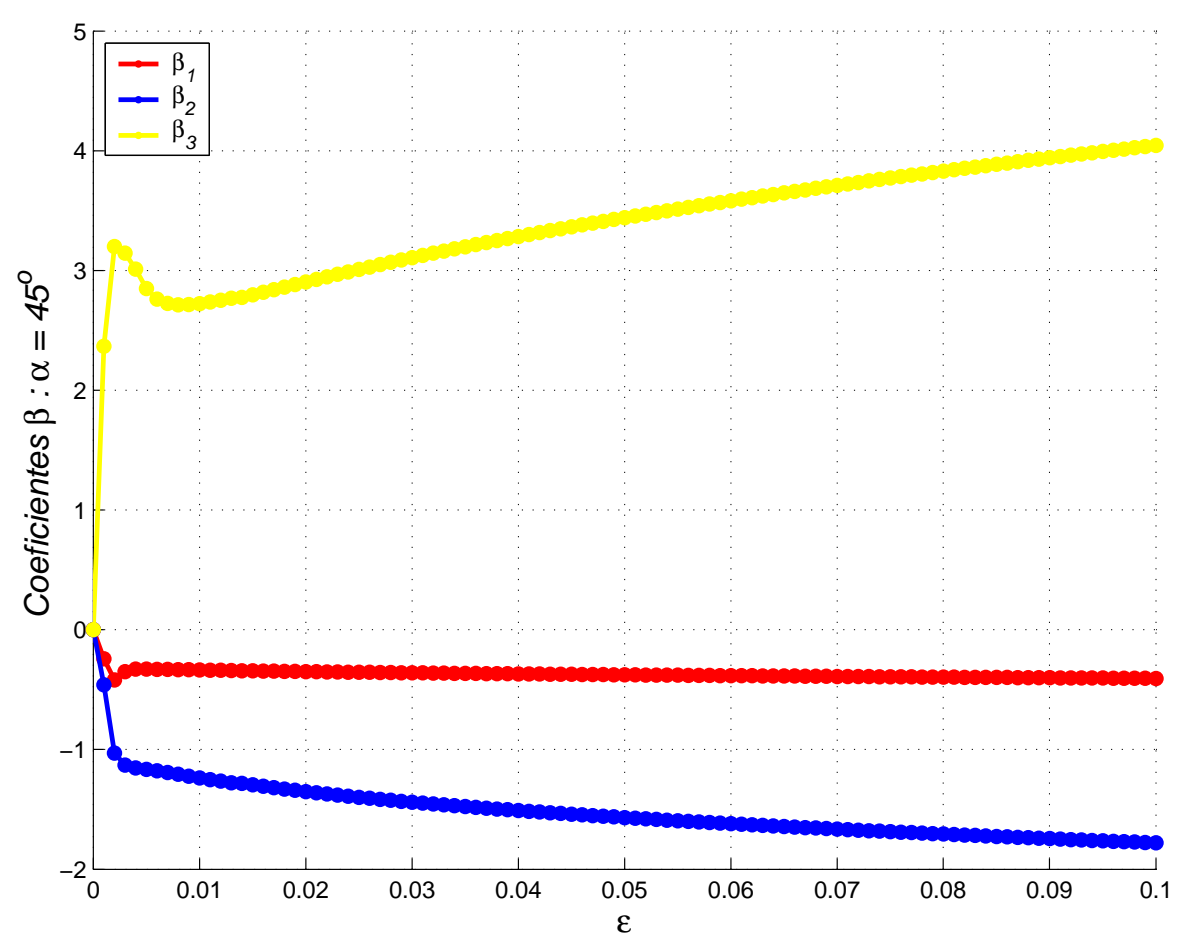

Figura 6.27: Evolução dos coeficientes $\beta_{i}^{\left(45^{\circ}\right)}$ para $\alpha=45^{\circ}$ 
Desta forma, para cada incremento de deformação, o conjunto de coeficientes $\beta_{i}^{(\alpha)}$ de cada direção $\alpha$ permite escrever o sistema de equações (eq. 5.64 e eq. 5.80) cuja solução fornece a evolução dos parâmetros de anisotropia $\hat{F}, \hat{G}, \hat{H}$ e $\hat{N}$. A seguir são apresentadas as evoluções destes parâmetros determinados a partir da solução do sistema de equações gerados para cada incremento de deformação.

\subsubsection{Evolução dos parâmetros de anisotropia}

Com os valores dos coeficientes $\beta_{i}^{(\alpha)}$ associados as direções $\alpha=0^{\circ}, 45^{\circ}$ e $90^{\circ}$, o sistema de equações é resolvido e a evolução dos parâmetros de anisotropia determinada.

As Figuras 6.28, 6.29, 6.30 e 6.31 mostra a evolução dos parâmetros $\hat{F}, \hat{G}, \hat{H}$ e $\hat{N}$ determinados em função da deformação principal, respectivamente. Para todos os casos, pode-se observar que a evolução destes parâmetros de anisotropia não foi muito acentuada.

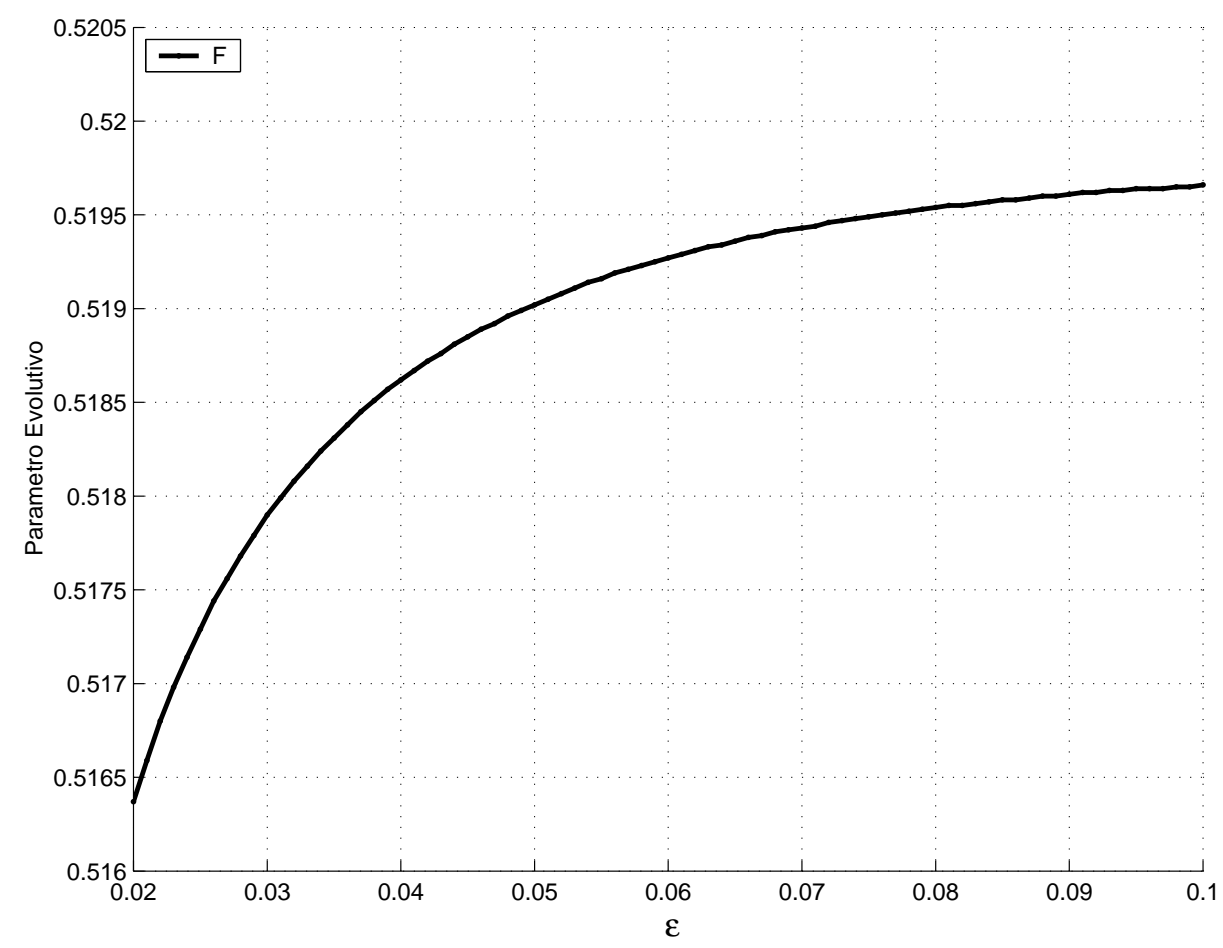

Figura 6.28: Evolução dos parâmetro $\hat{F}$ 


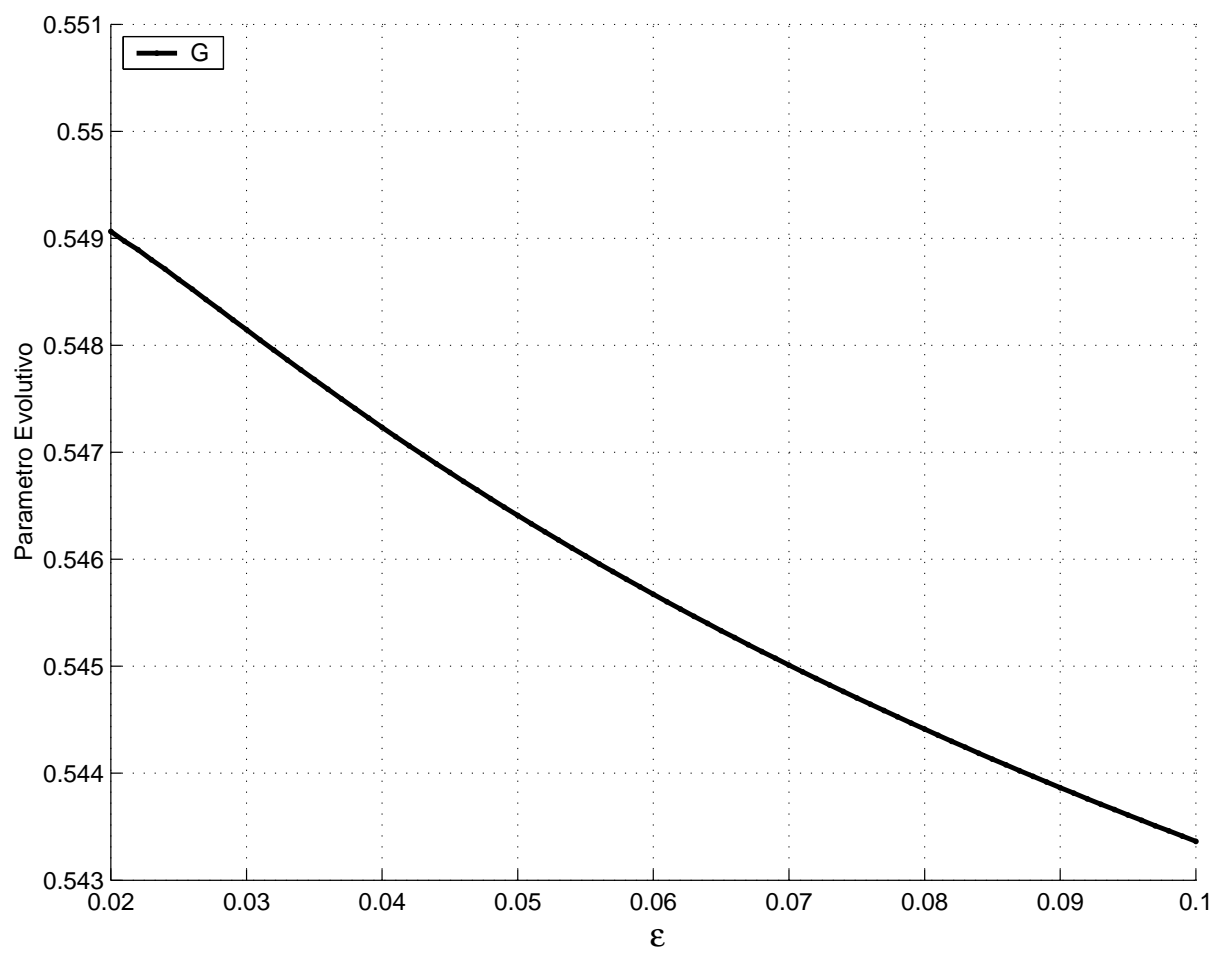

Figura 6.29: Evolução do parâmetro $\hat{G}$

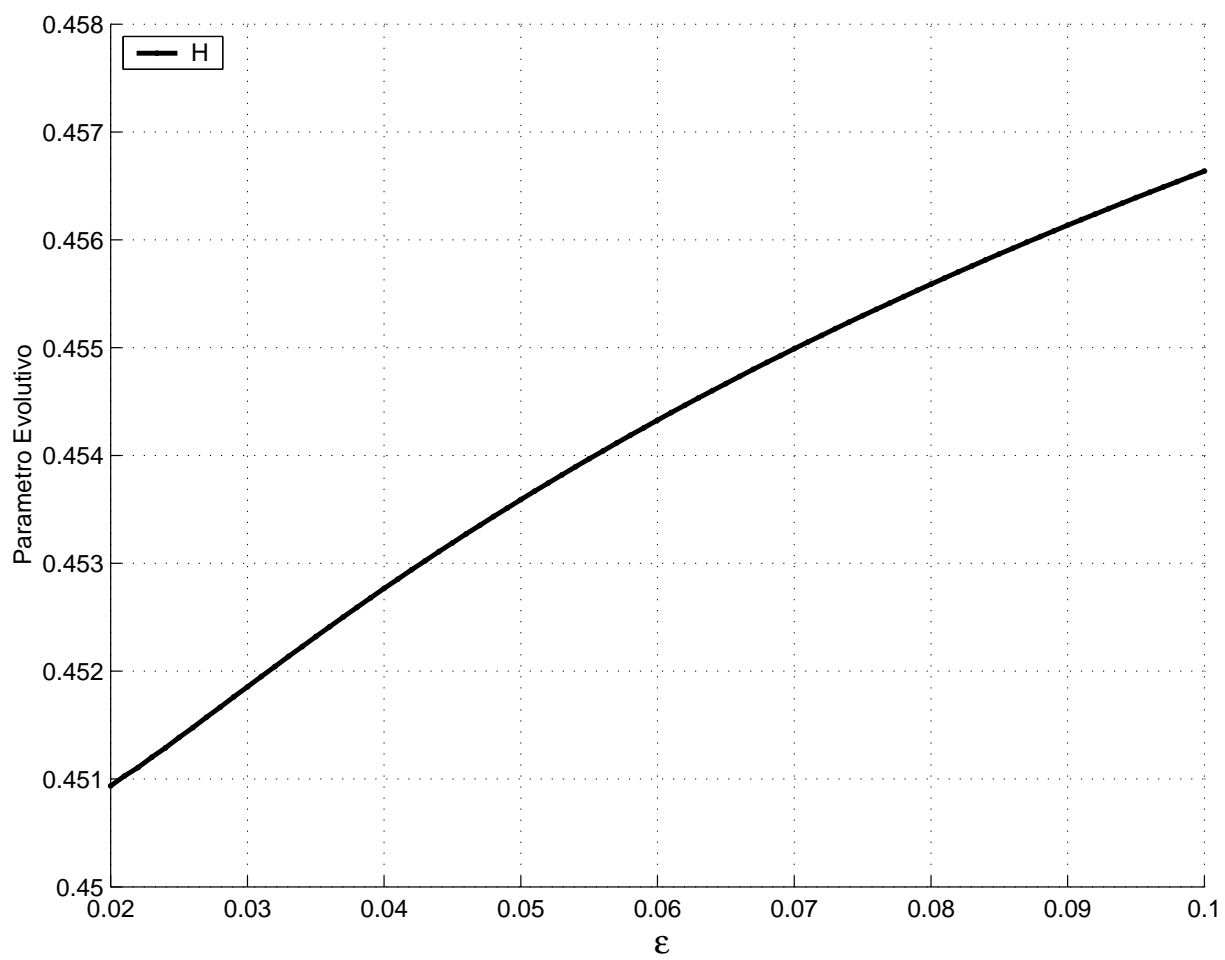

Figura 6.30: Evolução do parâmetro $\hat{H}$ 


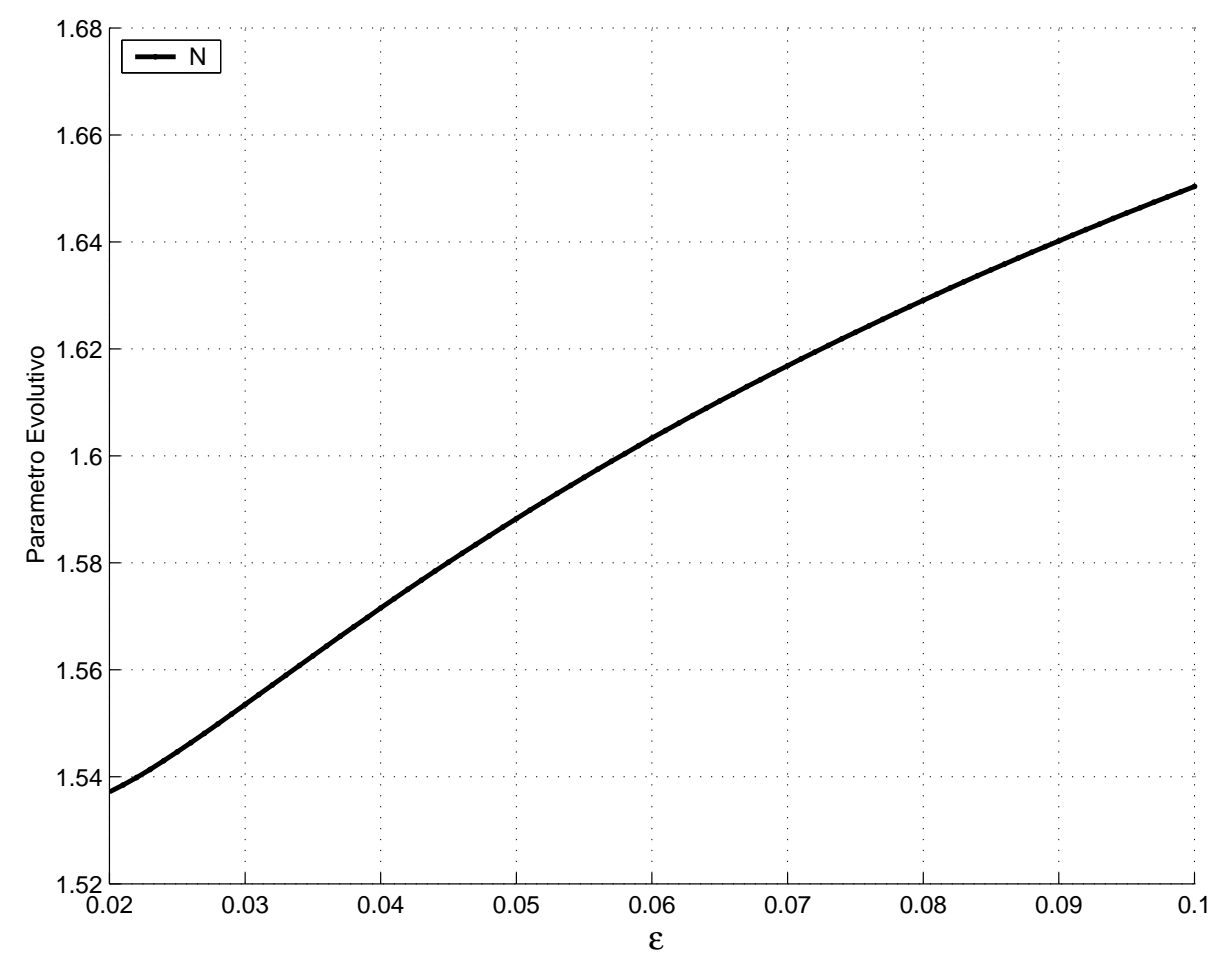

Figura 6.31: Evolução do parâmetro $\hat{N}$

Para comparar a evolução experimental dos índices de anisotropia $R_{\alpha}$ obtida pelo ensaio de anisotropia, com a evolução teórica fornecida pela metodologia proposta, os parâmetros evolutivos $\hat{F}, \hat{G}, \hat{H}$ e $\hat{N}$ são aplicados nas eq. 4.16, 4.17 e 4.18 fornecendo valores teóricos para os índices de anisotropia. A comparação da evolução entre os índices experimentais médios e teóricos é mostrada nas Figuras $6.32,6.33$ e 6.34 para $\alpha=0^{\circ}, 45^{\circ}$ e $90^{\circ}$, respectivamente.

O índice teórico $R_{0}$ apresentou um comportamento praticamente linear com a deformação variando entre o mínimo de 0.80 até um valor máximo de 0.84 ficando aproximadamente $4 \%$ abaixo do valor experimental adotado como entrada que foi de $R_{0}=0.875$. O índice teórico $R_{45}$ variou entre 0.95 e 1.05 também subestimando o valor experimental de entrada, $R_{45}=1.16$, em aproximadamente 9.5\%. O índice teórico $R_{90}$ teve um comportamento decrescente no início do encruamento entre $2.5 \%$ e $3.5 \%$ de deformação e então passou a variar linearmente até 0.879 , permanecendo $3.1 \%$ abaixo do valor de entrada, $R_{90}=0.91$. 


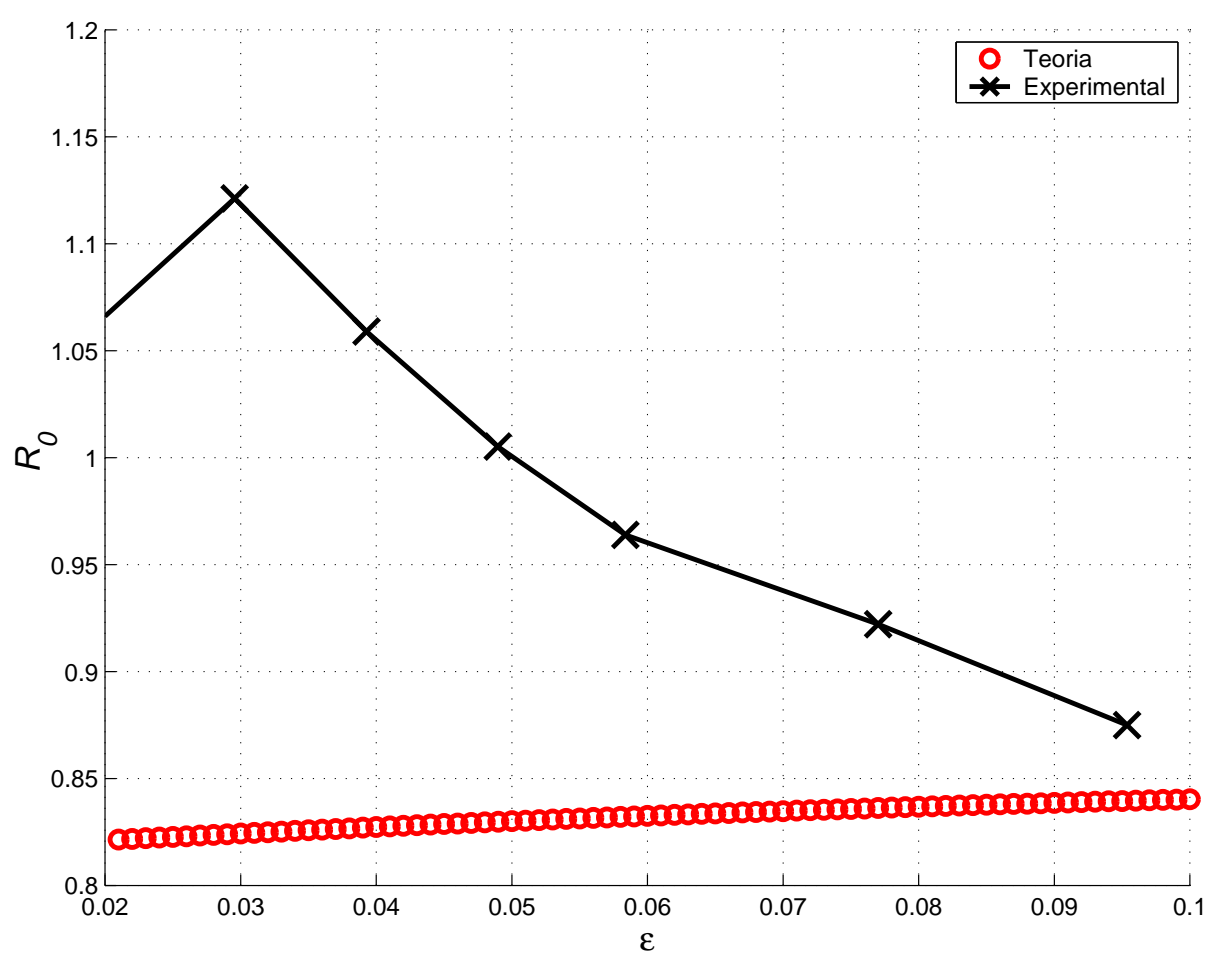

Figura 6.32: Comparação da evolução de $R_{0}$

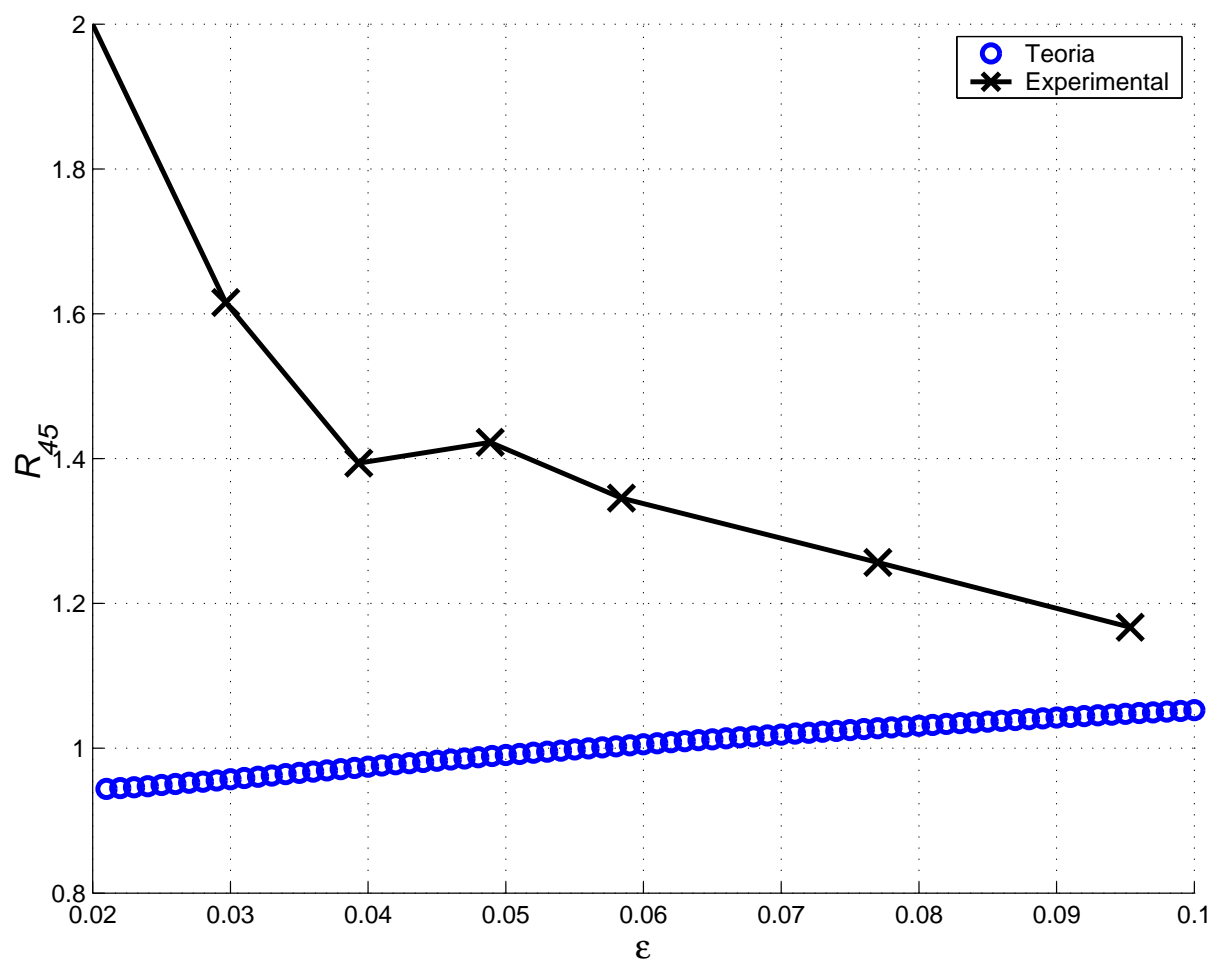

Figura 6.33: Comparação da evolução de $R_{45}$ 


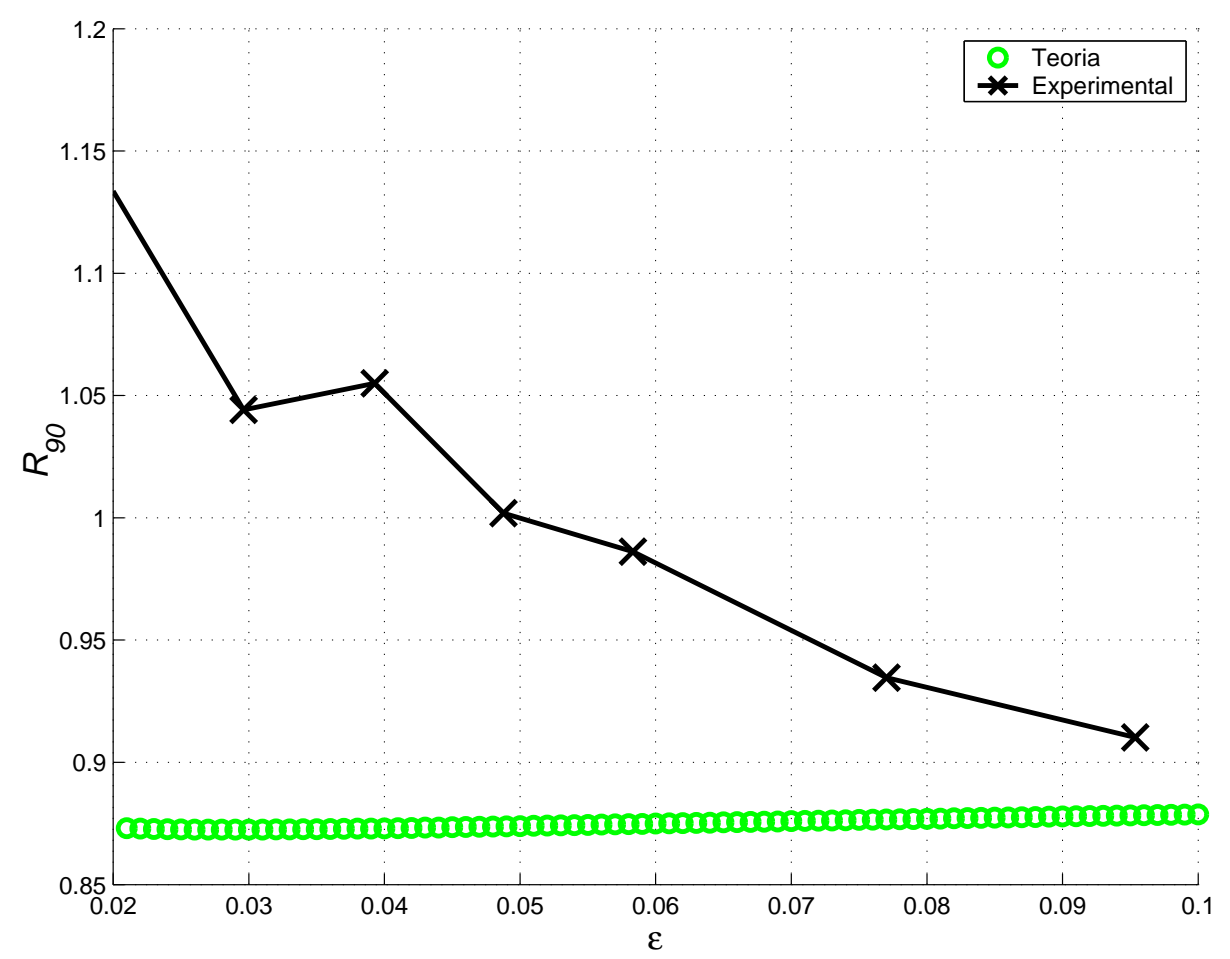

Figura 6.34: Comparação da evolução de $R_{90}$

Os resultados obtidos mostram que a evolução teórica obtida para os parâmetros de anisotropia ficou muita próxima de um estado isotrópico de tensão. Experimentalmente a liga de alumínio ensaiada também apresentou uma variação muito sutil entre as curvas de tensão para as direções $\alpha=0^{\circ}, 45^{\circ}$ e $90^{\circ}$ estudadas, bem como os valores dos índices de anisotropia experimentais próximos de 1. Isto pode ser explicado devido as características da liga de alumínio estudada que sofre um tratamento térmico de recozimento em sua fabricação.

\subsubsection{Fator de correção $\Psi$ e evolução da superfície de es- coamento $F_{m}$}

A partir dos parâmetros de anisotropia evolutivos $\hat{F}, \hat{G}, \hat{H}$ e $\hat{N}$ a eq. 5.88 é aplicada e a evolução do fator de correção $\Psi$ é obtida. A Figura 6.35 mostra a evolução do fator de correção $\Psi$ com a deformação principal. 


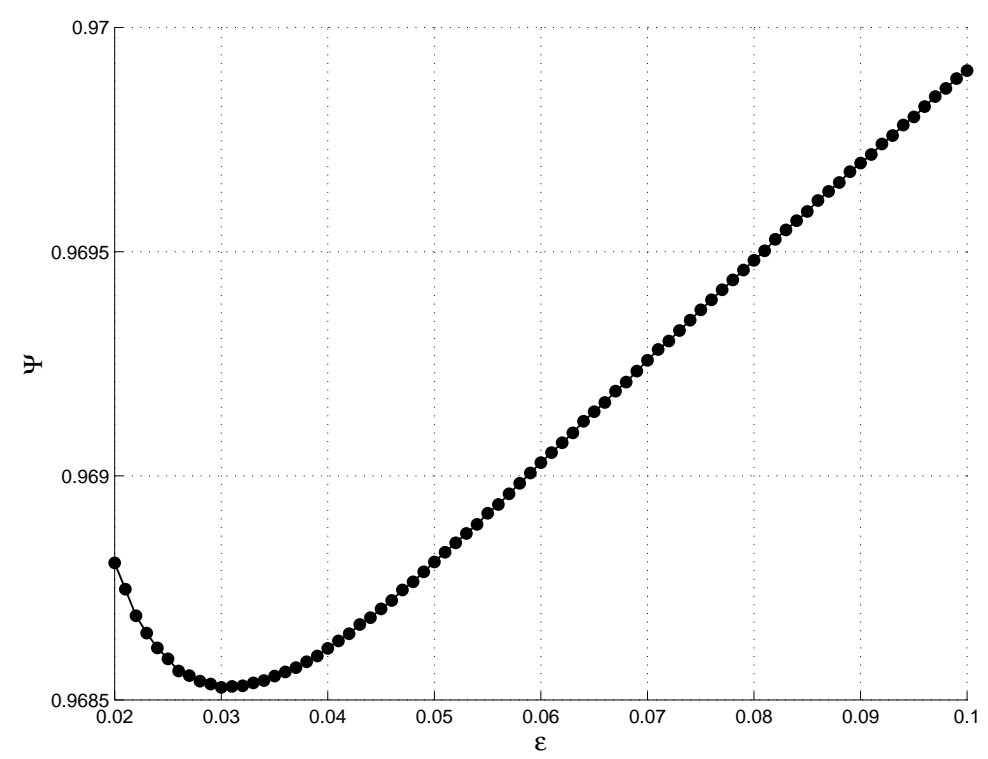

Figura 6.35: Evolução do fator de correção $\Psi$

Com o fator de correção $\Psi$, a nova superfície de escoamento $F_{m}$ dada pela eq. 5.84 pode ser determinada. A Figura 6.36 ilustra o comportamento da evolução da superfície $F_{m}$ com o encruamento, comparada com a superfície original de Hill.

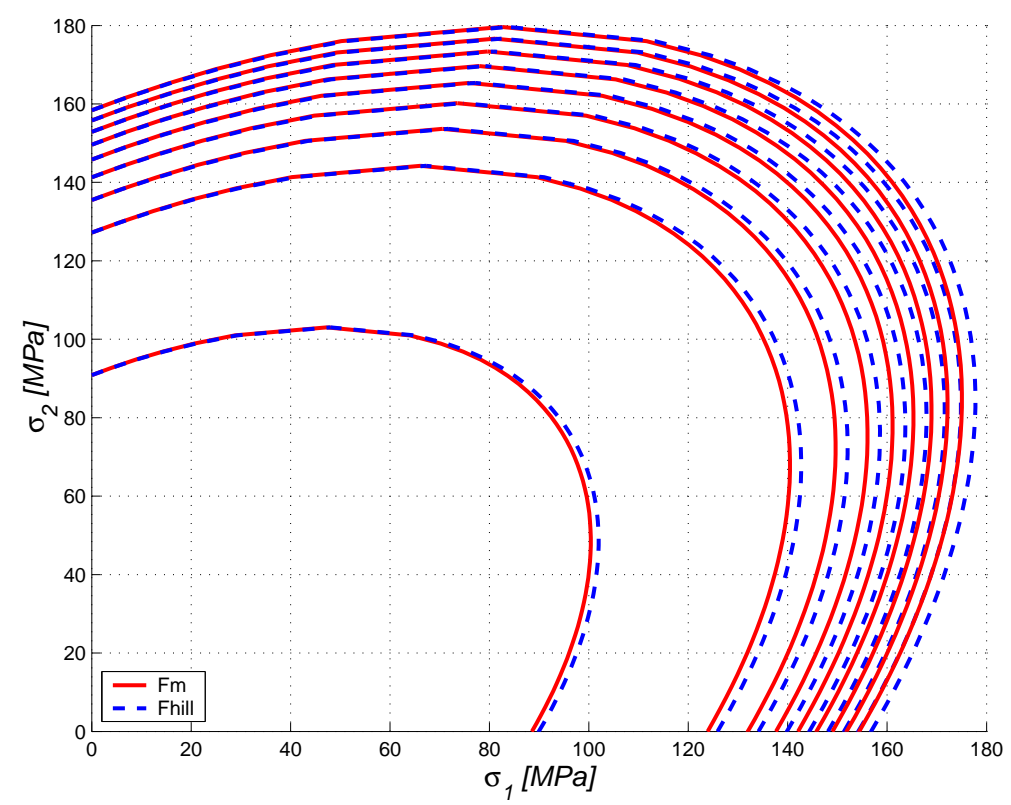

Figura 6.36: Comparação da evolução das superfícies de escoamento

Apesar do material analisado apresentar uma variação muita pequena dos índices de anisotropia, o que implicou na evolução do fator de correção $\Psi$ próxi- 
mo de 1 conforme observado na Figura 6.35, pode-se notar que a superfície $F_{m}$ apresenta uma tendência em torna-se mais "curta"com o decorrer do encruamento quando comparada com a superfície original de Hill. Este encurtamento implica em um nível de tensão equivalente menor, o que na prática pode representar que um modelo numérico utilizando a nova superfície de escoamento $F_{m}$ faria a predição, por exemplo de uma falha da peça devido ao nível de tensão, em um nível de encruamento menor quando comparado com um modelo que utiliza o critério de Hill.

\subsection{Resultados teóricos}

No intuito de aplicar o procedimento em uma situação na qual a anisotropia é mais preponderante, os dados de entrada foram gerados baseados em dados de material disponíveis na literatura. Uma vez que a metodologia desenvolvida foi implementada computacionalmente, é possível avaliar de forma rápida uma ampla gama de condições e dados de entrada distintos, de forma que o ponto material analisado tenha uma flexibilidade de avaliação de seu comportamento. A seguir são apresentados os resultados obtidos pela aplicação da metodologia proposta utilizando-se dados de entrada teóricos.

Para os índices de anisotropia $R_{\alpha}$ adotou-se os seguintes valores: $R_{0}=1.08$, $R_{45}=0.85$ e $R_{90}=0.25$. Estes índices de anisotropia são valores típicos para ligas de alumínio da série 3000. O modelo de encruamento adotado refere-se a lei de potência, eq. 3.52, cujas constantes para as direções $\alpha=0^{\circ}, 45^{\circ}$ e $90^{\circ}$ são dadas conforme a Tabela 6.4, que também apresenta as tensões de escoamento nas três direções.

Tabela 6.4: Dados de material

\begin{tabular}{|c|c|c|c|}
\hline & $0^{\circ}$ & $45^{\circ}$ & $90^{\circ}$ \\
\hline$\sigma_{y}[\mathrm{MPa}]$ & 57.24 & 55.17 & 53.79 \\
$K[M P a]$ & 186 & 191 & 178 \\
$n$ & 0.190 & 0.200 & 0.193 \\
\hline
\end{tabular}


No caso das constantes elásticas, o módulo de elasticidade $E$ e o coeficiente de Poisson $v$ são dados por $73[\mathrm{GPa}]$ e 0.3 , respectivamente, para todas as direções.

Importante salientar que a aplicação da metodologia assume que o ponto analisado satisfaz as condições e hipóteses de carregamento discutidas no capítulo anterior. Desta forma o histórico de deformação na direção principal $\varepsilon_{1}$ considerado neste estudo foi dado por uma rampa linear, variando de zero a $10 \%$.

Os valores dos parâmetros evolutivos de anisotropia $\hat{F}, \hat{G}, \hat{H}$ e $\hat{N}$ determinados pela aplicação da metodologia são ilustrados nas Figuras 6.37 a 6.40, respectivamente.

Neste caso a evolução obtida para estes parâmetros foi mais acentuada quando comparada com o caso anterior, uma vez que a anisotropia do material é mais preponderante.

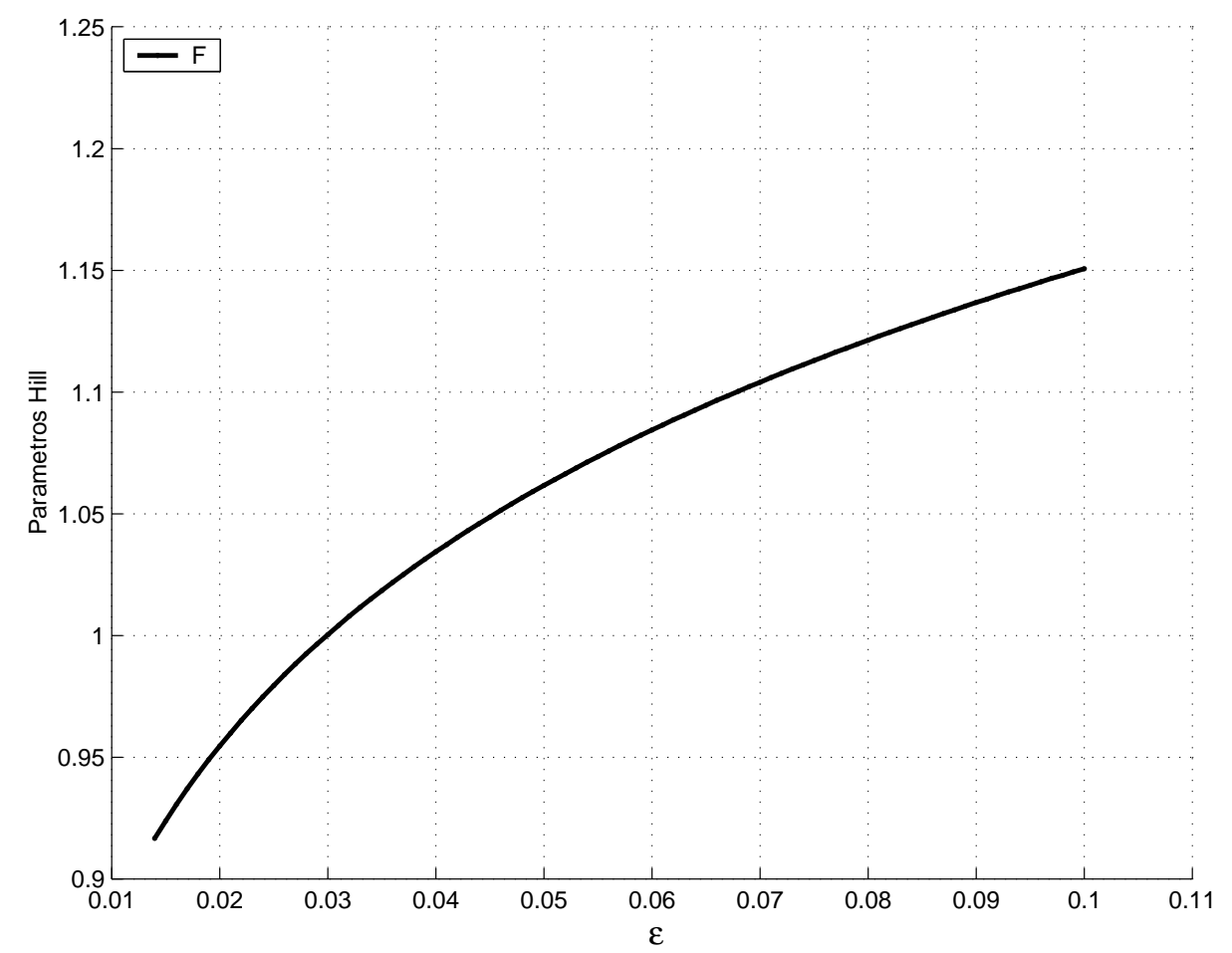

Figura 6.37: Evolução do parâmetro $\hat{F}$ - caso teórico 


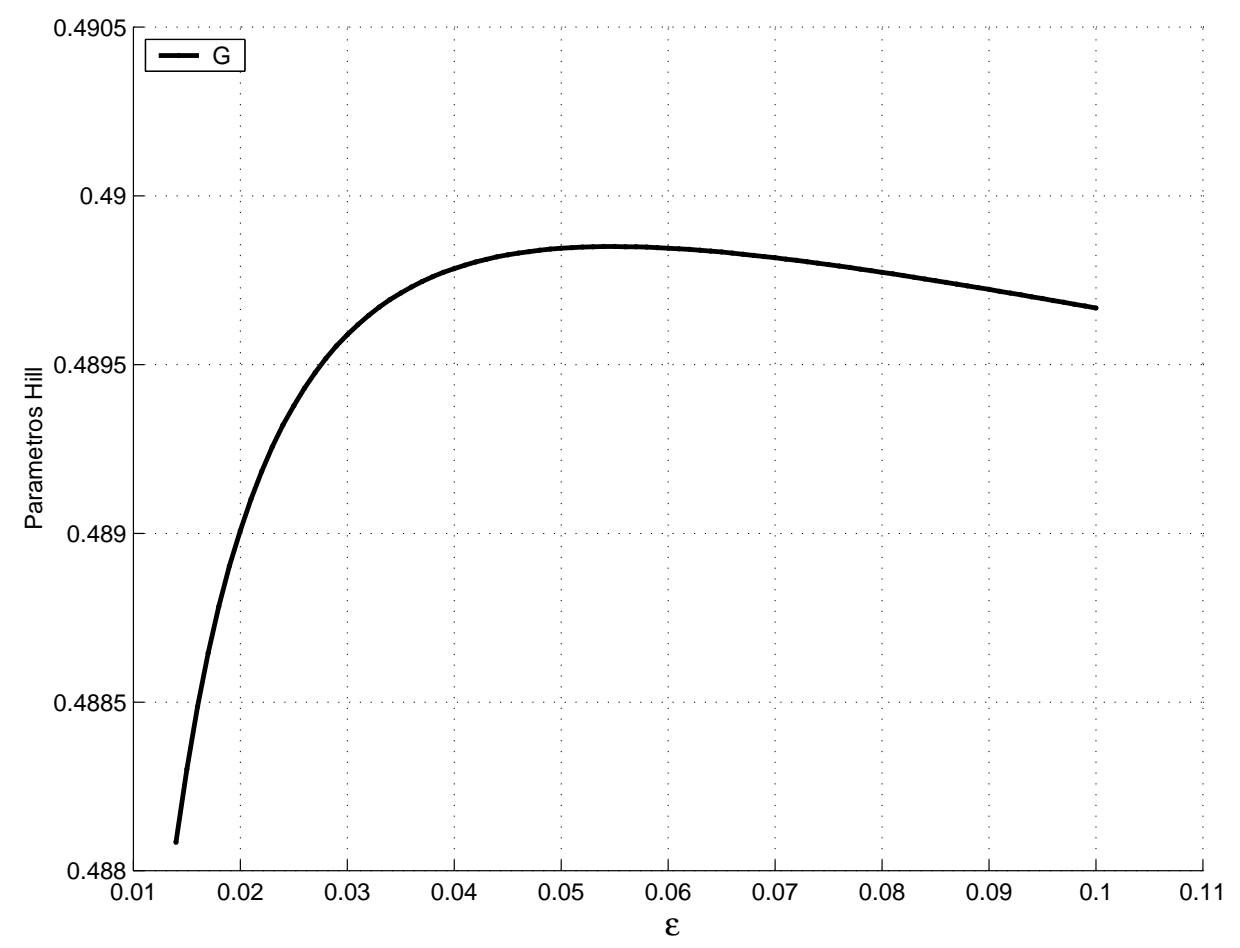

Figura 6.38: Evolução do parâmetro $\hat{G}$ - caso teórico

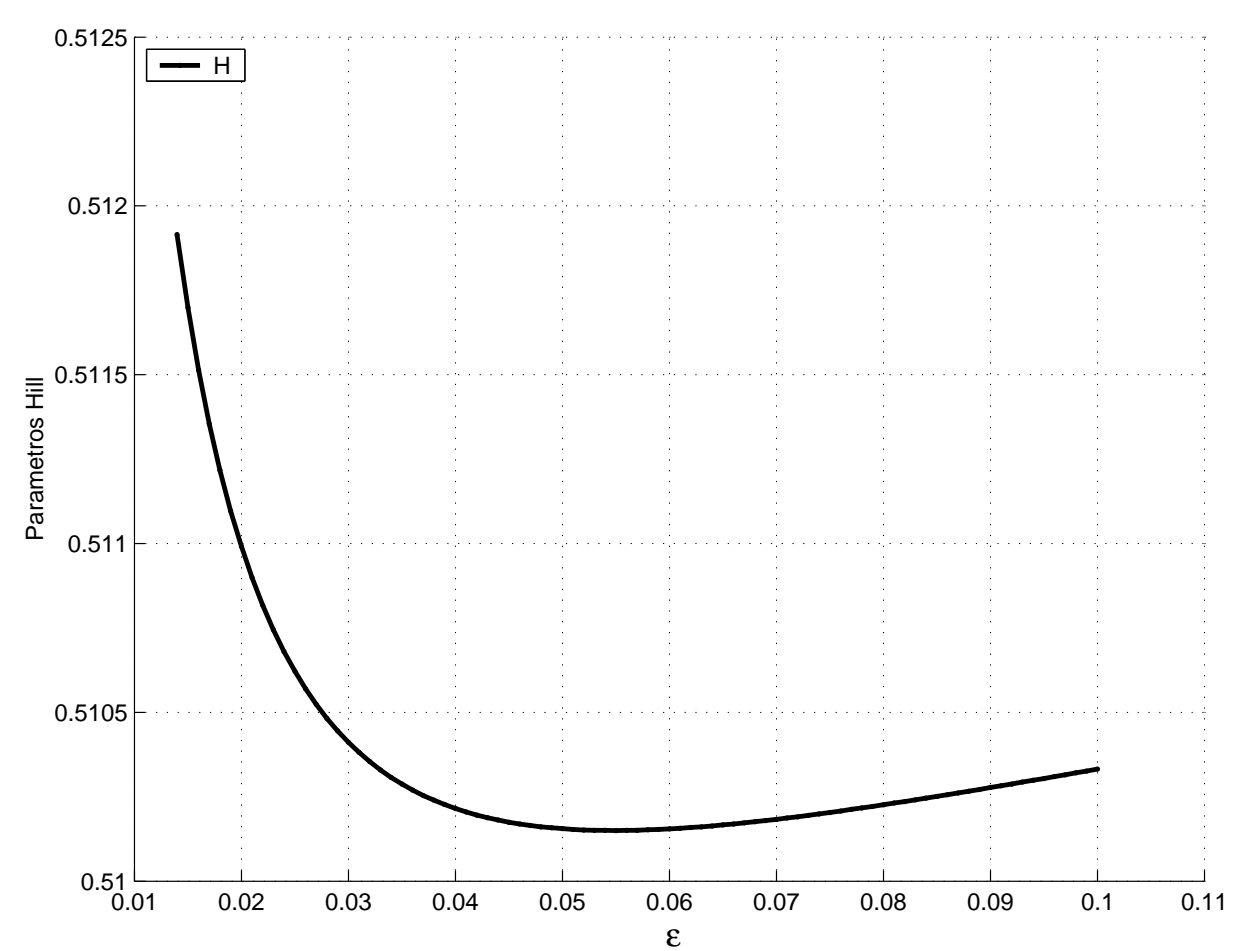

Figura 6.39: Evolução do parâmetro $\hat{H}$ - caso teórico 


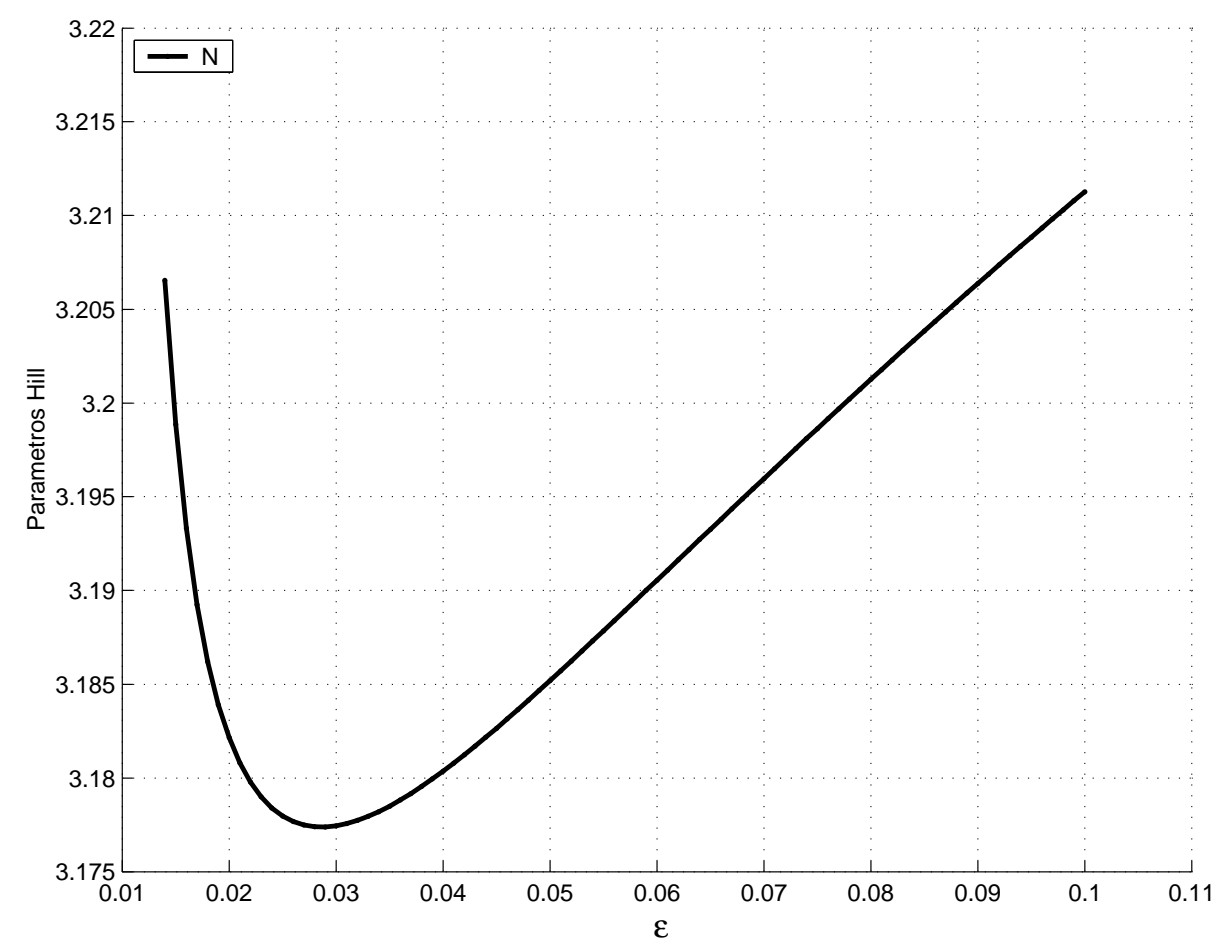

Figura 6.40: Evolução do parâmetro $\hat{N}$ - caso teórico

A evolução do fator de correção $\Psi$ em função da deformação principal é ilustrada na Figura 6.41. Na Figura 6.42 é ilustrada a evolução da superfície de escoamento anisotrópica $F_{m}$ obtida pela aplicação deste fator de correção. Podese observar claramente que a evolução da superfície $F_{m}$ deixa de ser isotrópica no sentido de sua expansão não ser uniforme com o encruamento.

Para este caso analisado, a evolução do conjunto de parâmetros de anisotropia determinada pela aplicação da metodologia proposta, implicou em uma distorção mais acentuada da superfície, a qual tende a rotacionar no sentido anti-horário com o decorrer do encruamento, indicando a tendência do ponto material estudado em tensão plana em apresentar incrementos de tensão na direção principal $d \sigma_{2}$ maiores que os incrementos de tensão na direção de laminação $d \sigma_{1}$.

A comparação das evoluções da superfície $F_{m}$ e da superfície original de Hill é apresentada na Figura 6.43. Pode-se observar o comportamento distinto das superfícies e que na maior parte do quadrante a superfície $F_{m}$ apresenta níveis de tensão equivalente menores que a superfície de Hill. 


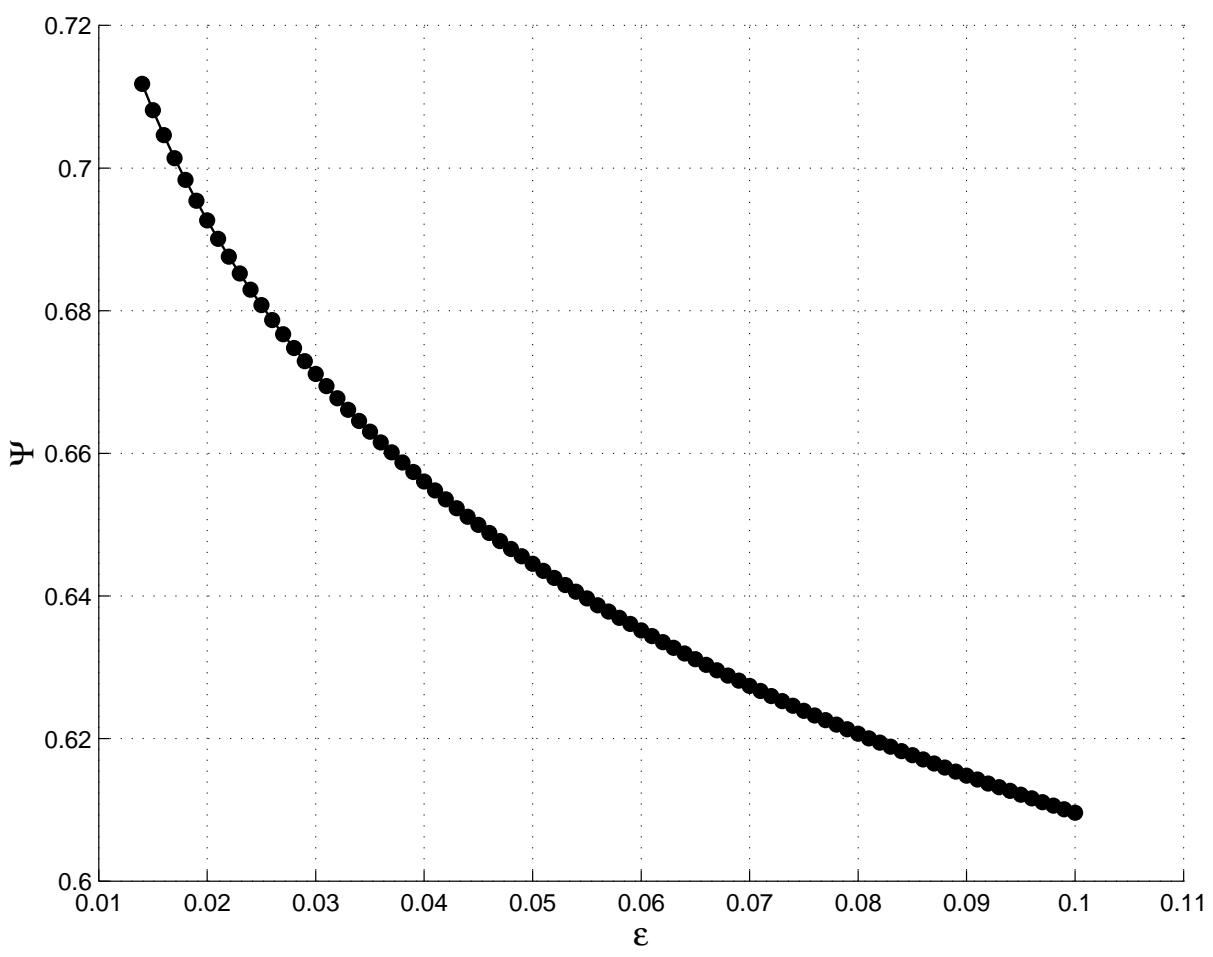

Figura 6.41: Evolução do fator de correção $\Psi$

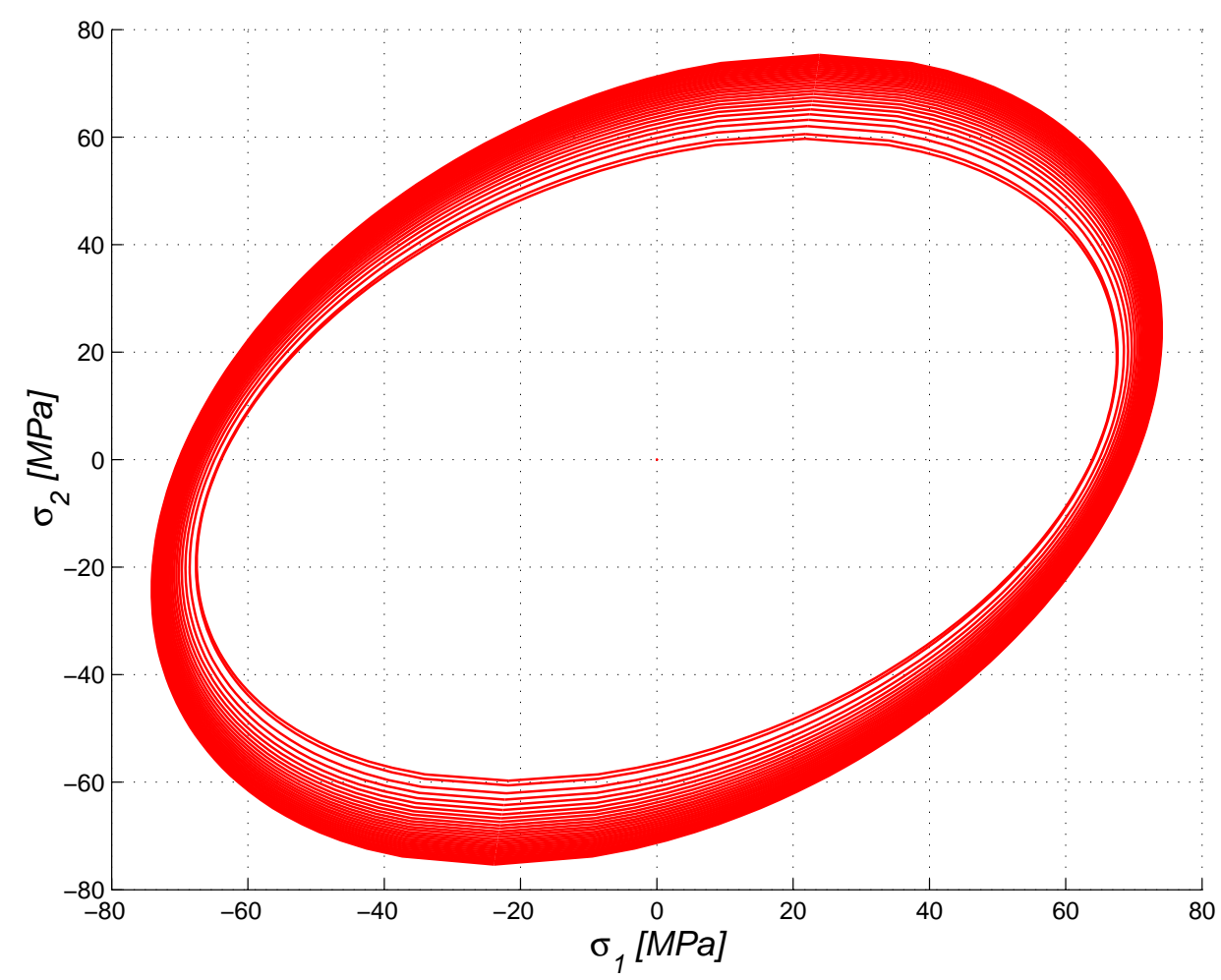

Figura 6.42: Evolução da superfície de escoamento Fm 


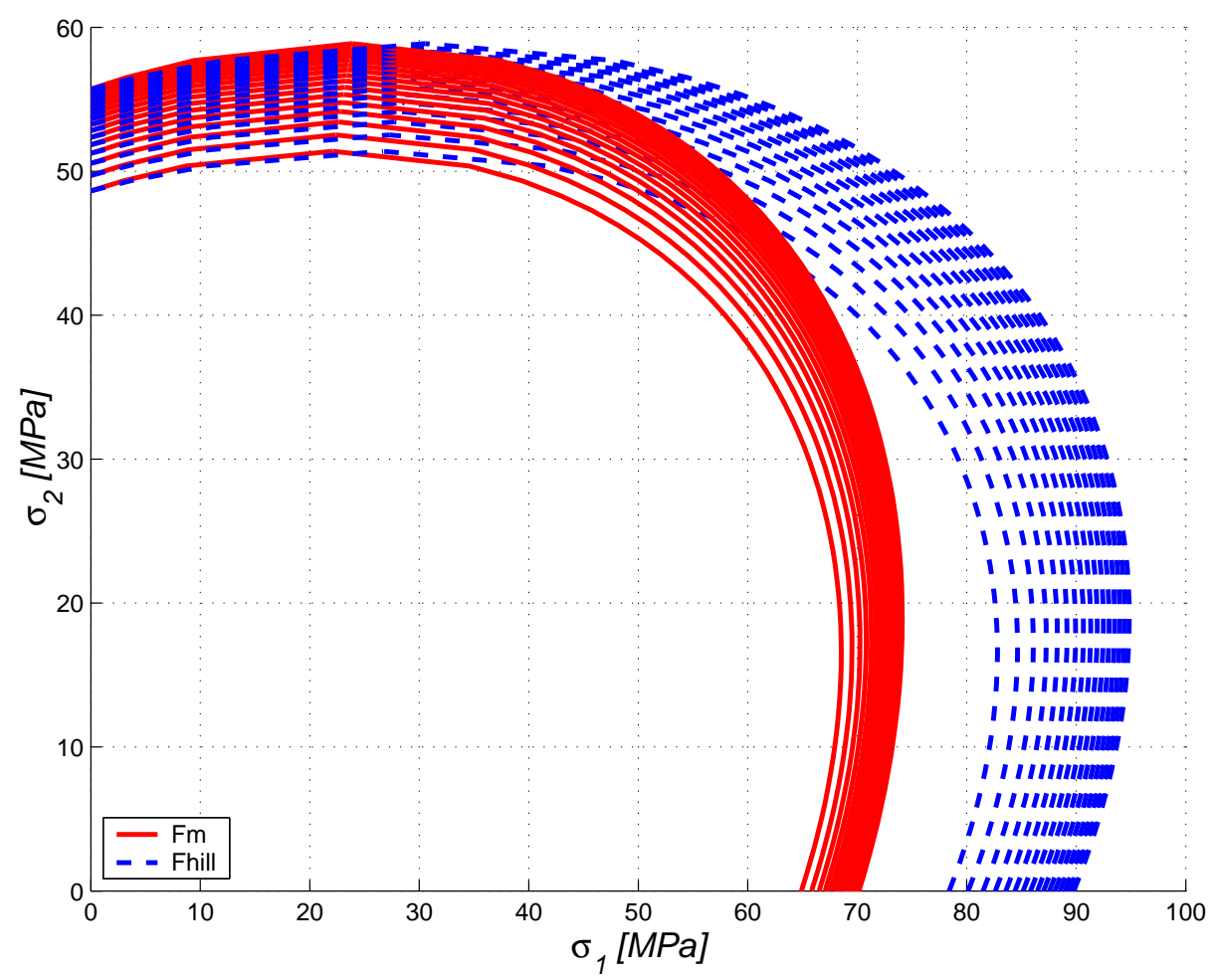

Figura 6.43: Comparação da evolução das superfícies de escoamento

\subsection{Exemplos de aplicação}

Neste tópico alguns exemplos de aplicação de processos de conformação de chapas metálicas anisotrópicas são modelados via Método dos Elementos Finitos. Da mesma forma que para os resultados experimentais apresentados anteriormente, os resultados obtidos pelo modelo numérico são aplicados como dados de entrada e fonte de comparação com resultados obtidos pela aplicação da metodologia de cálculo de evolução dos parâmetros de anisotropia e da nova superfície de escoamento proposta.

\subsubsection{Dobramento em $V$}

O primeiro exemplo de aplicação estudado foi o dobramento em $V$ de uma chapa metálica anisotrópica. A Figura 6.44 ilustra um esquema geral da configuração modelada contendo a matriz, punção e chapa. As dimensões consideradas no modelo são apresentadas na Tabela 6.5. 


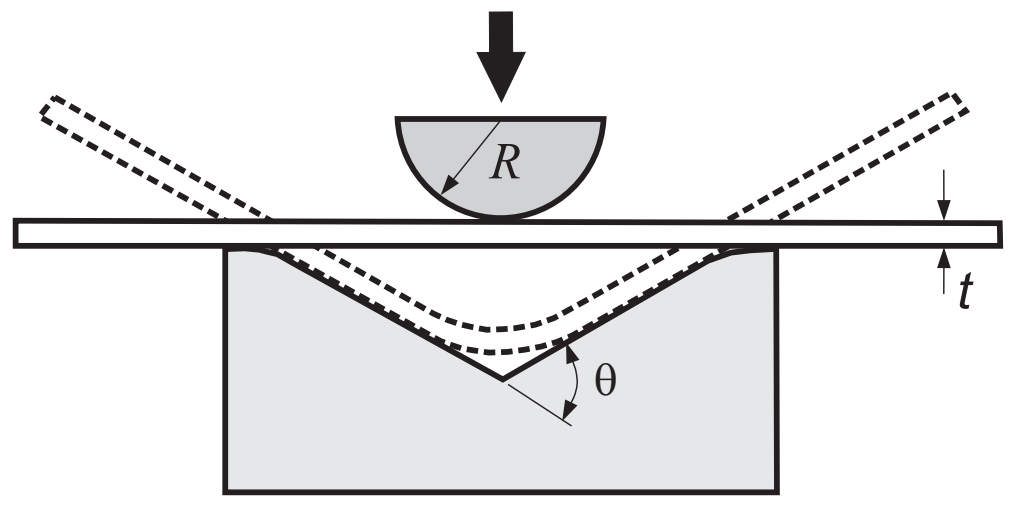

Figura 6.44: Esquema do processo de dobramento em $V$

Tabela 6.5: Dados de geometria do modelo

\begin{tabular}{|c|c|c|}
\hline Comprimento da chapa & $L$ & $200[\mathrm{~mm}]$ \\
\hline Largura da chapa & $b$ & $50[\mathrm{~mm}]$ \\
\hline Espessura da chapa & $t$ & $1[\mathrm{~mm}]$ \\
\hline Ângulo de abertura da matriz & $\theta$ & $60^{\circ}$ \\
\hline Raio do punção & $R$ & $40[\mathrm{~mm}]$ \\
\hline
\end{tabular}

O modelo de encruamento adotado na modelagem foi o isotrópico bilinear cujas propriedades de material consideradas são dadas na Tabela 6.6, que também apresenta os índices de anisotropia $R_{\alpha}$ para as direções $\alpha=0^{\circ}, 45^{\circ}$ e $90^{\circ}$.

Tabela 6.6: Dados de material do modelo

\begin{tabular}{|c|c|c|}
\hline Índice de anisotropia & $R_{0}$ & 2.0 \\
\hline Índice de anisotropia & $R_{45}$ & 0.5 \\
\hline Índice de anisotropia & $R_{90}$ & 1.0 \\
\hline Módulo tangente & $E_{t}$ & $2500[\mathrm{MPa}]$ \\
\hline Tensão de escoamento & $\sigma_{0}$ & $100[\mathrm{MPa}]$ \\
\hline
\end{tabular}

Os resultados do modelo MEF foram obtidos para três situações distintas. Cada uma destas situações são correspondentes a $\alpha=0^{\circ}, 45^{\circ}$ e $90^{\circ}$ relativas à orientação da direção de laminação em relação a maior tensão principal da chapa. Em todos os casos a matriz e o punção foram considerados rígidos e o atrito foi desprezado. Todos os componentes foram modelados com elemento do 
tipo casca Shell-181 com cinco pontos de integração ao longo da espessura. Para a diminuição do tempo total de processamento apenas um quarto do modelo foi considerado aplicando-se condições de contorno apropriadas para satisfazer a simetria. O contato entre os componentes foi aplicado com a escolha de parâmetros adequados e com um maior refinamento da malha nesta região. $\mathrm{O}$ dobramento ocorre devido à imposição de um deslocamento do punção de forma que ao final do carregamento a chapa assuma a geometria do punção e da matriz sem que ocorra afinamento da espessura. A Figura 6.45 mostra a malha Shell expandida do modelo.

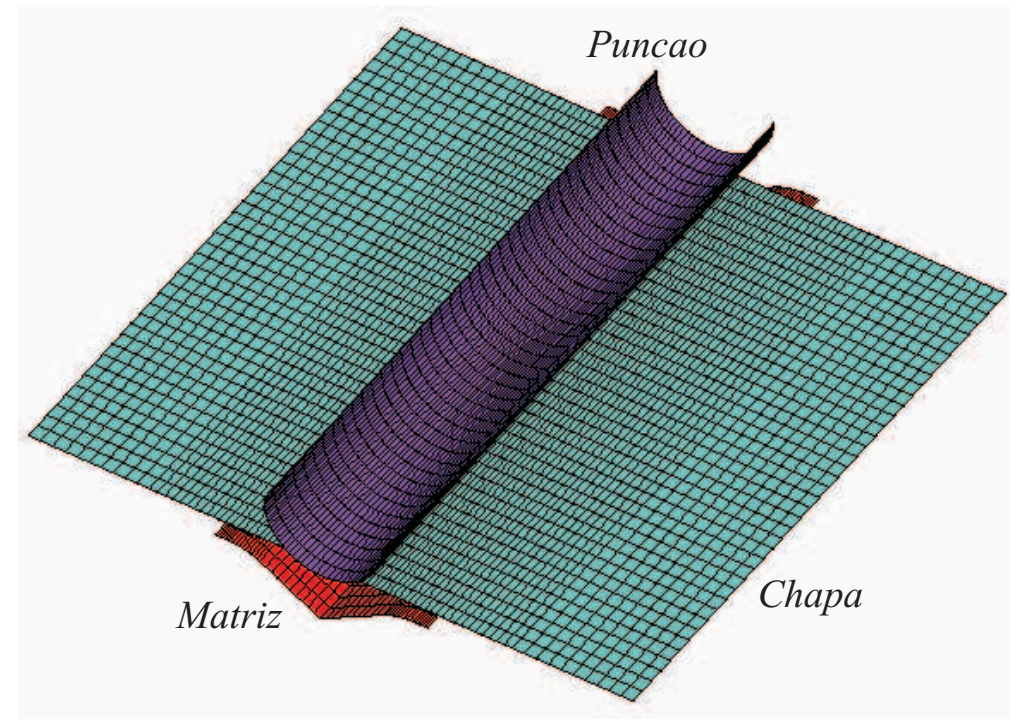

Figura 6.45: Malha do modelo MEF do dobramento em $V$

A distribuição da tensão equivalente para o caso $\alpha=0^{\circ}$, quando a direção de laminação da chapa esta alinhada com a maior direção principal, é mostrada na Figura 6.46. Para melhor visualização, os componentes da matriz e punção foram ocultados. Pode-se observar que apenas a região central da chapa em contato com o punção é que concentra os maiores níveis de tensão, alcançando a máxima tensão equivalente de 178 [MPa].

Conforme discutido no capítulo anterior, o modelo de elementos finitos representa uma ferramenta auxiliar que permite a identificação de pontos da peça que satisfazem o estado de tensão-deformação base da formulação, além de fornecer o histórico de deformação do ponto escolhido para a aplicação da metodologia 


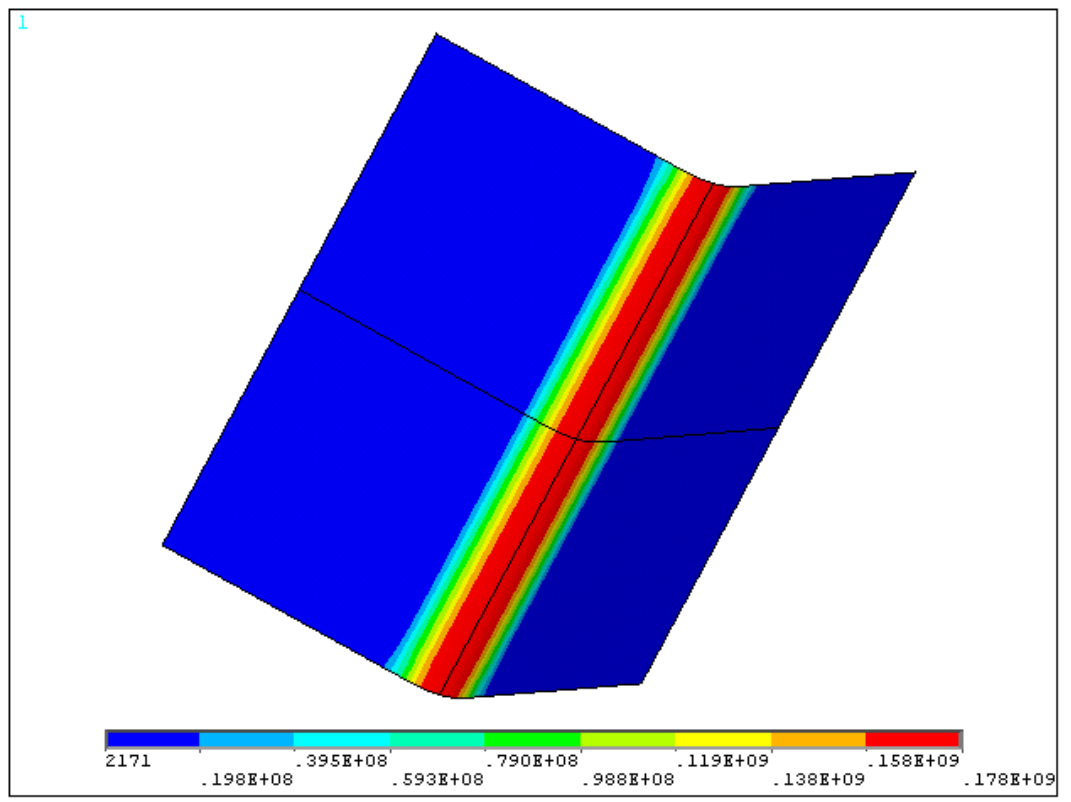

Figura 6.46: Distribuição da tensão equivalente $[\mathrm{Pa}]-\alpha=0^{\circ}$

proposta. Outro ponto a ser destacado é que o histórico de deformação é assumido ser a mesmo para qualquer orientação do ângulo $\alpha$ da chapa uma vez que o processo de dobramento é dado por uma imposição de deslocamento do punção sendo as deformações grandezas puramente geométricas e independentes do modelo de material.

Para o processo de dobramento estudado, a região central da chapa satisfaz o estado de tensão-deformação base da formulação e por este motivo o nó central da peça foi adotado como ponto de análise. A Figura 6.47 ilustra o histórico das componentes de deformação para o nó central da chapa na fibra tracionada. O eixo denominado de tempo é apenas uma variável auxiliar representativa da evolução do processo.

A componente $\varepsilon_{1}$ representa a deformação na direção da maior deformação principal, $\varepsilon_{2}$ na direção perpendicular e $\varepsilon_{3}$ ao longo da espessura da chapa. Pelo gráfico fica claro que este ponto se encontra no estado de deformação plana, uma vez que a componente $\varepsilon_{2}$ é praticamente nula, confirmando desta forma o estado de tensão-deformação base. 


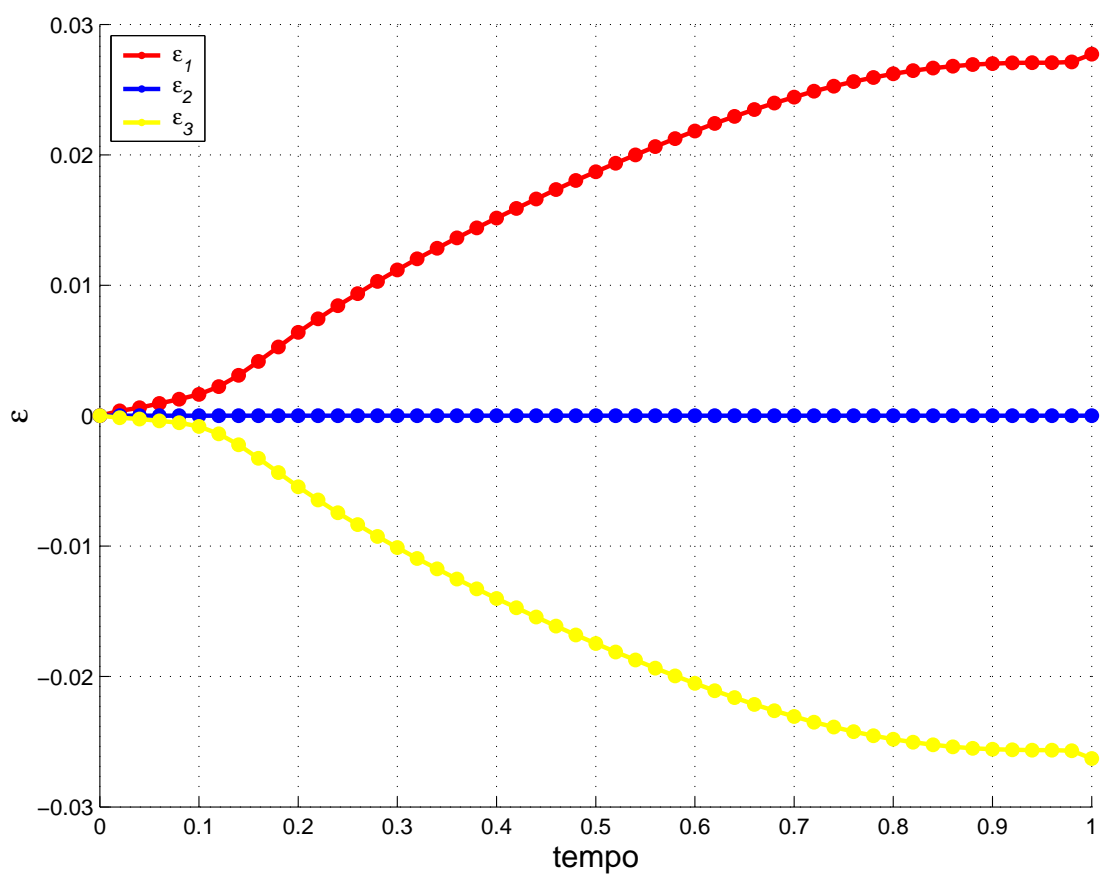

Figura 6.47: Histórico de deformação obtido via MEF

Pode-se observar que ao final do carregamento a deformação principal $\varepsilon_{1}$ tende a tornar-se constante. Desta forma a faixa de deformação adotada para a aplicação da metodologia limitou-se a um histórico de deformação variando linearmente de zero a deformação máxima de 0.025 .

Aplicando-se este histórico de deformação, juntamente com as propriedades do material apresentadas na Tabela 6.6, a metodologia de cálculo de evolução dos parâmetros de anisotropia pode ser executada. Inicialmente o algoritmo de previsão-correção é aplicado fornecendo as curvas de tensão para as três orientações do ângulo $\alpha=0^{\circ}, 45^{\circ}$ e $90^{\circ}$.

A Figura 6.48 compara os valores da tensão equivalente $\sigma_{e q}$ obtidos pelo modelo MEF e pela implementação externa do algoritmo de previsão-correção. Podese observar que os valores determinados pela implementação externa são coerentes com o pacote comercial para o ponto analisado nas três direções do ângulo $\alpha$. 


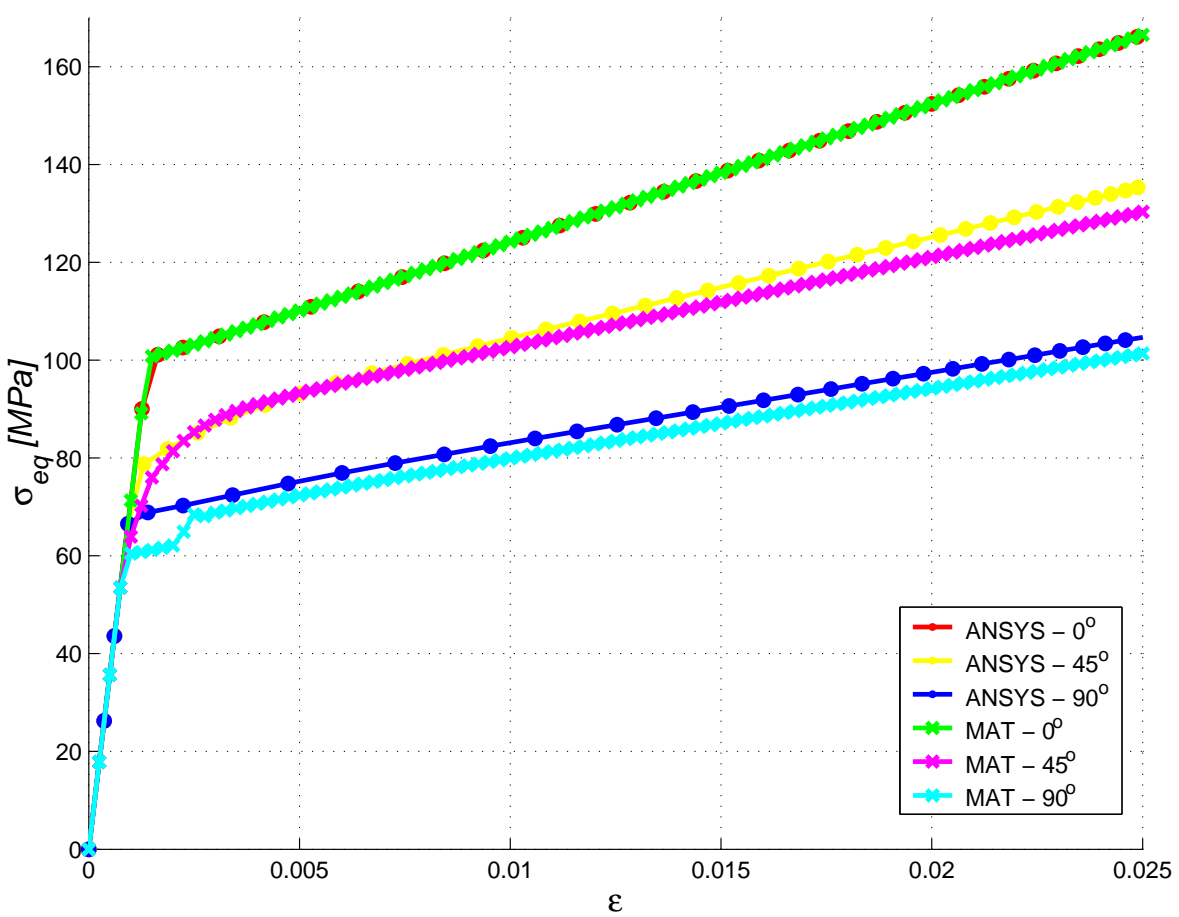

Figura 6.48: Evolução de $\sigma_{e q}$ - Dobramento

Da mesma maneira que para os casos estudados anteriormente, os parâmetros de anisotropia evolutivos, $\hat{F}, \hat{G}, \hat{H}$ e $\hat{N}$, são determinados a partir da solução do conjunto de equações gerado a cada incremento de deformação. Estes parâmetros evolutivos são então aplicados na determinação do fator de correção $\Psi$ que permite definir e avaliar o comportamento da nova superfície de escoamento anisotrópica $F_{m}$. Estes resultados são apresentados a seguir.

As Figuras 6.51, 6.50, 6.49 e 6.52 mostram o comportamento da evolução dos parâmetros de anisotropia determinados a partir da solução do sistema de equações gerado pela metodologia. A Figura 6.53 mostra a evolução do fator de correção $\Psi$ e a Figura 6.54 apresenta uma comparação entre a evolução da superfície $F_{m}$ e a superfície de Hill original que foi utilizada no modelo MEF. Novamente, a evolução da superfície $F_{m}$ proposta apresentou níveis de tensão equivalentes menores para a mesma condição de encruamento do material quando comparada com a superfície de Hill. 


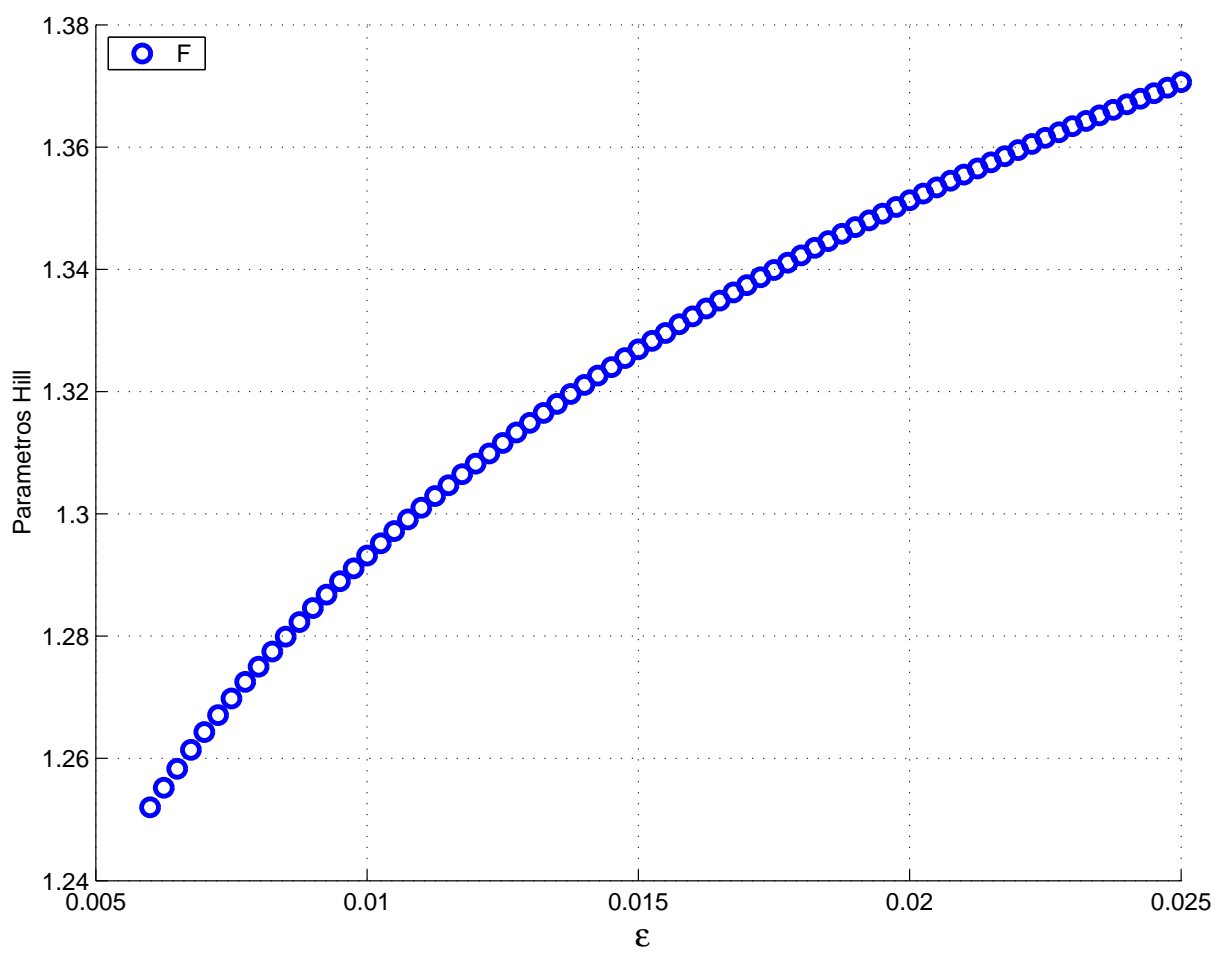

Figura 6.49: Evolução do parâmetro $\hat{F}$ - Dobramento

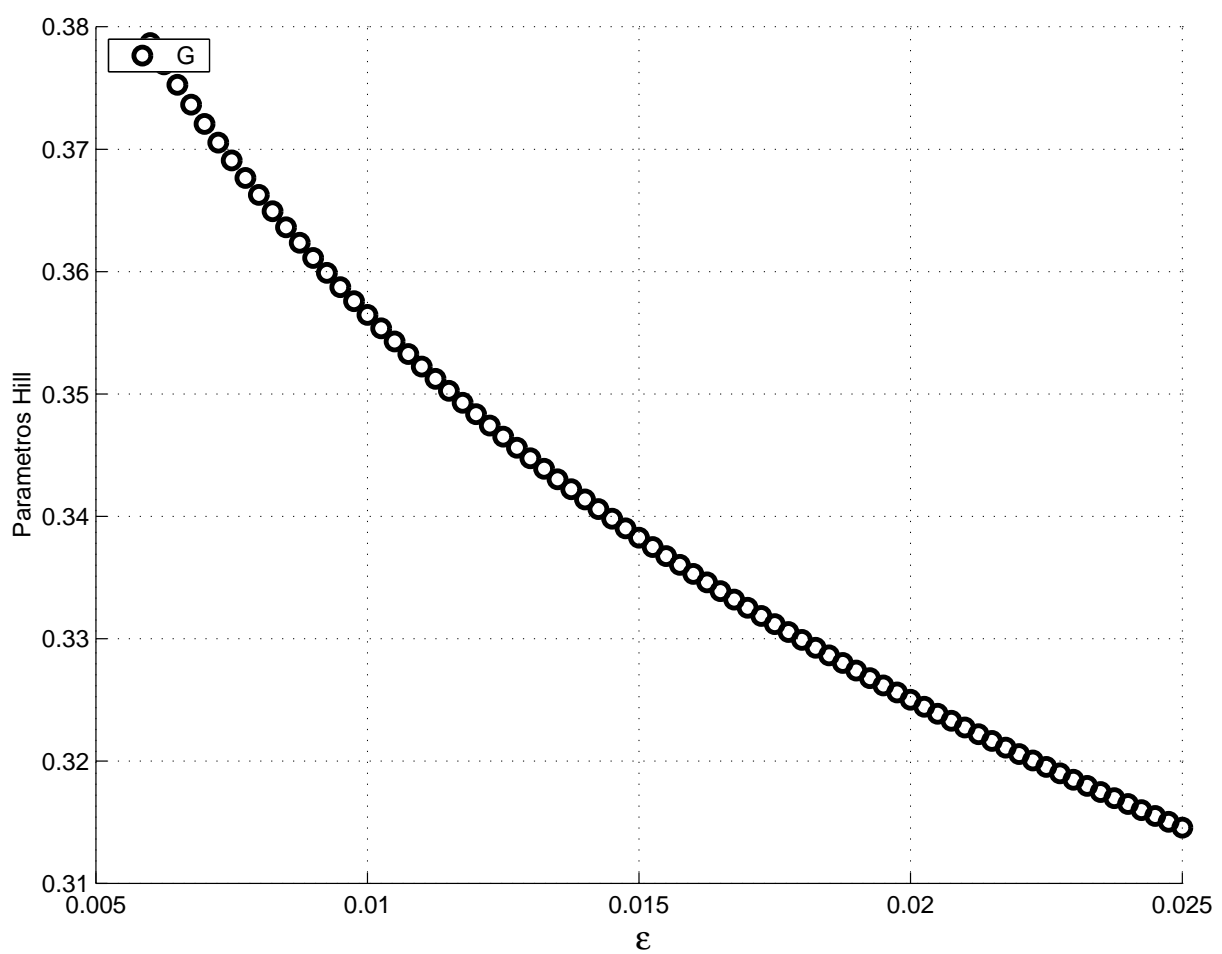

Figura 6.50: Evolução do parâmetro $\hat{G}$ - Dobramento 


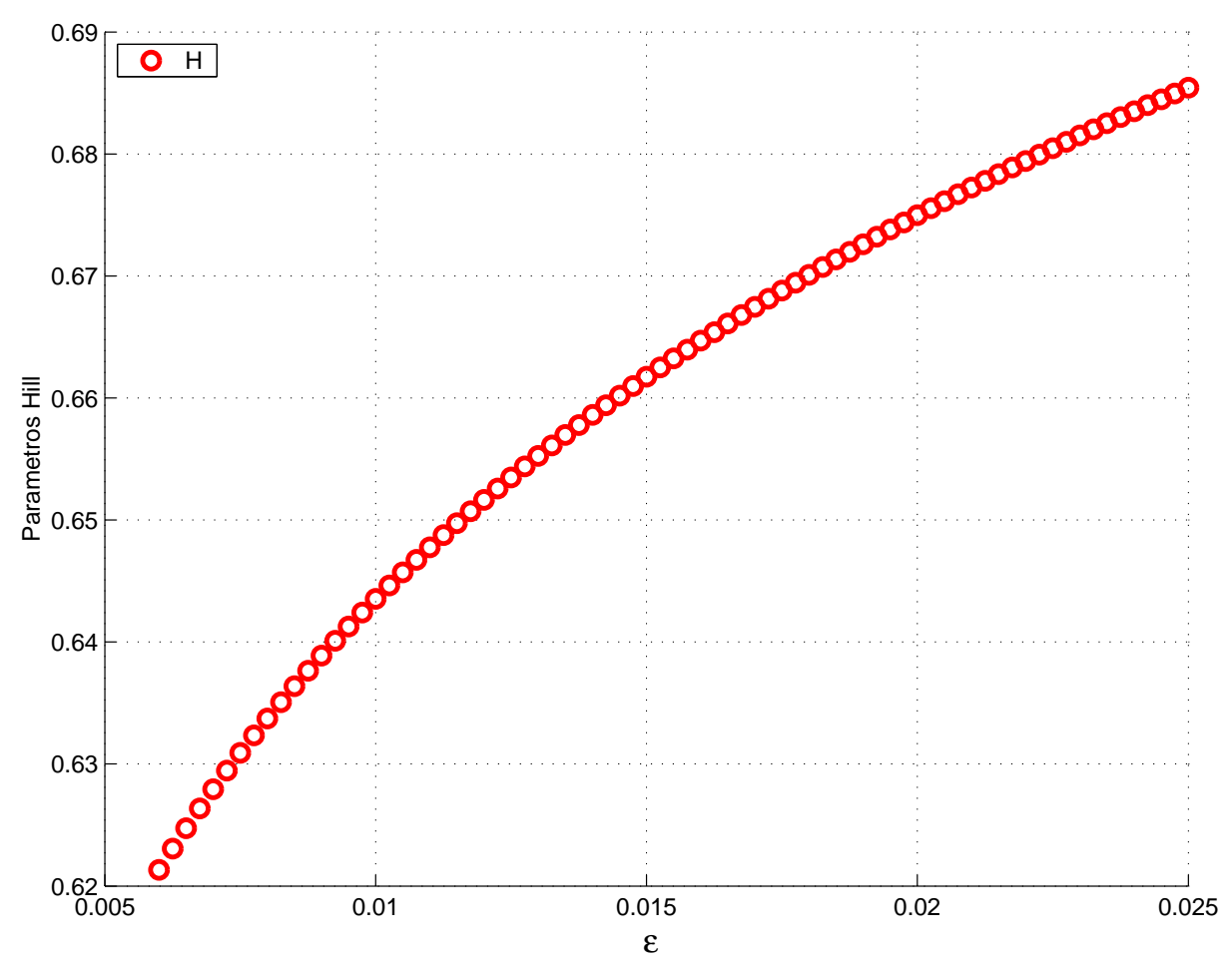

Figura 6.51: Evolução do parâmetro $\hat{H}$ - Dobramento

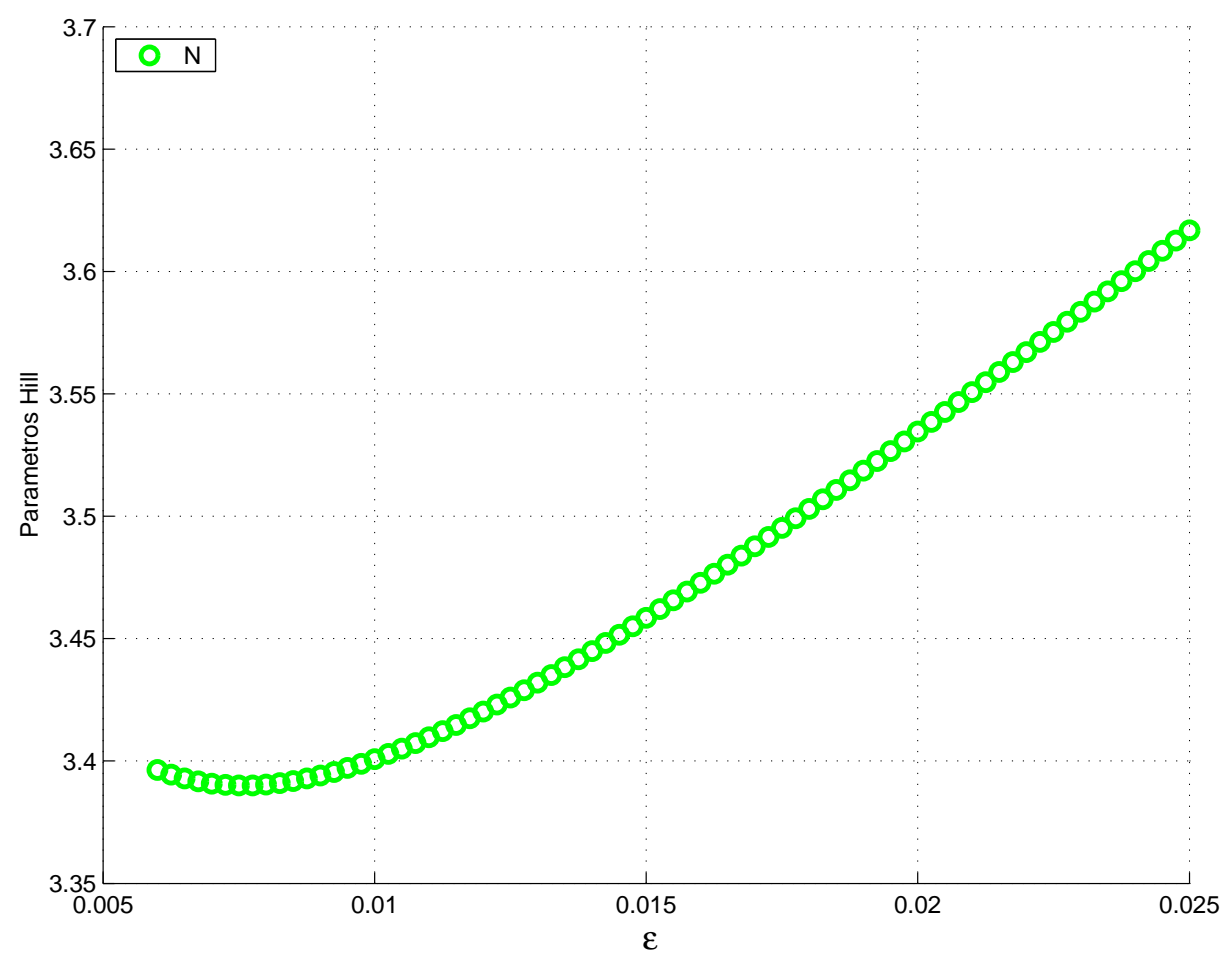

Figura 6.52: Evolução do parâmetro $\hat{N}$ - Dobramento 


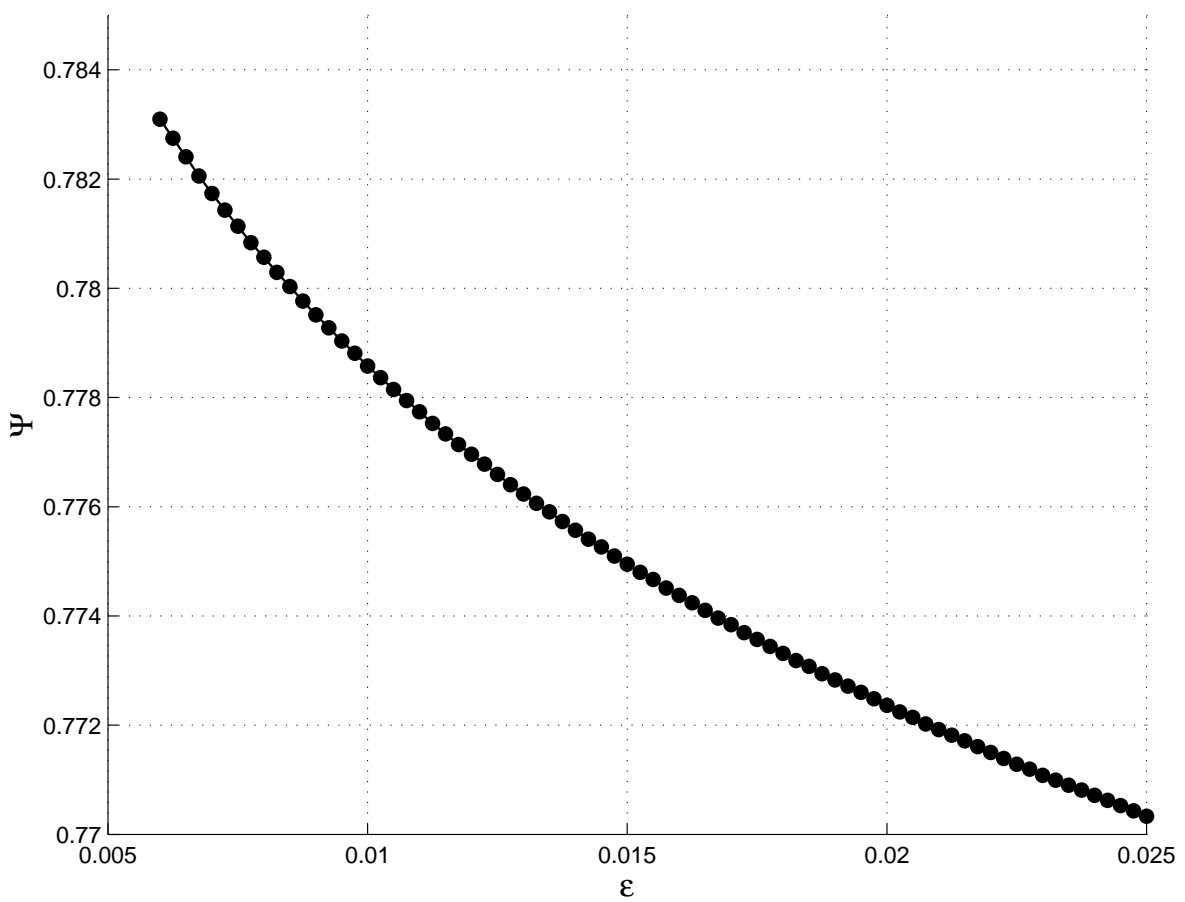

Figura 6.53: Evolução do fator de correção $\Psi$

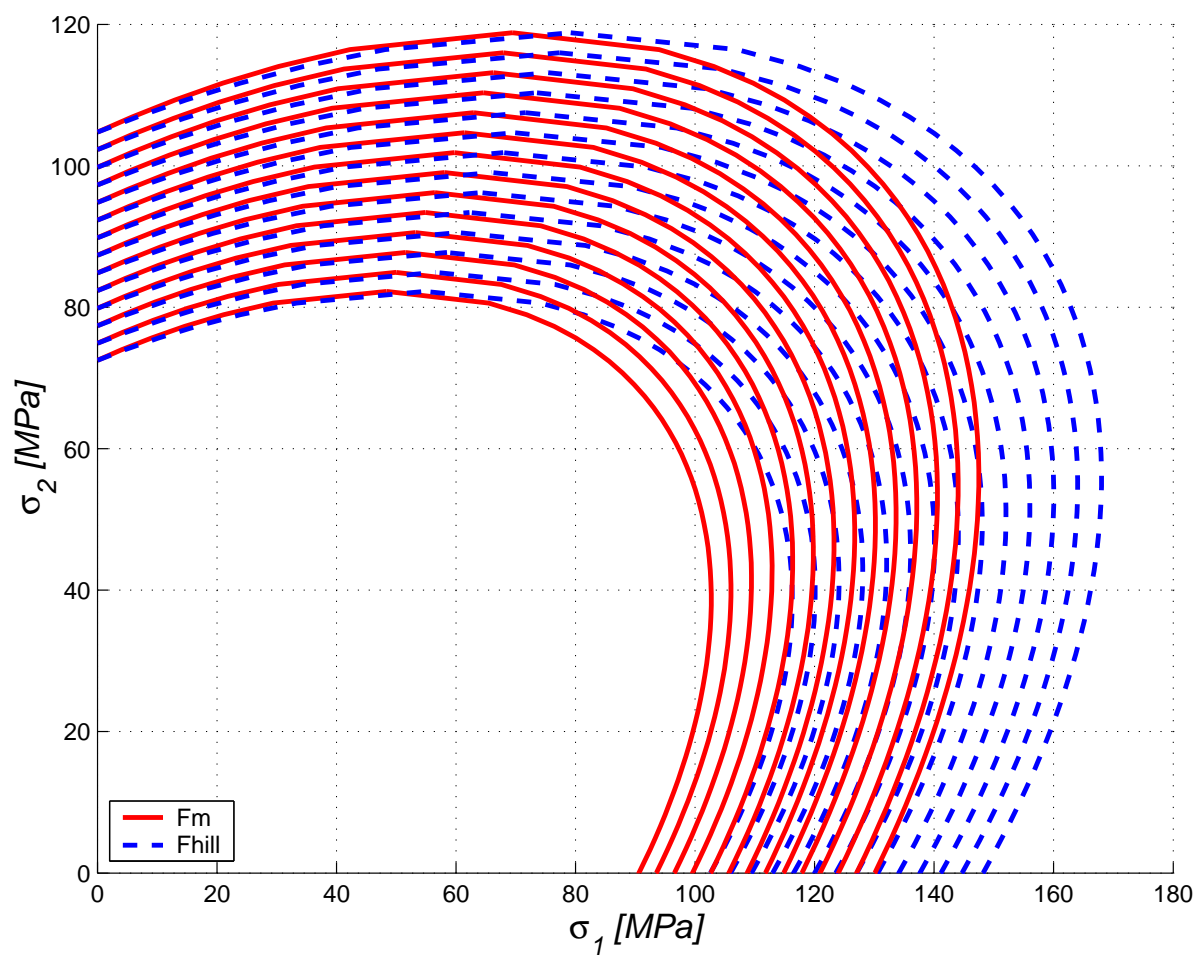

Figura 6.54: Comparação da evolução das superfícies de escoamento 


\subsubsection{Embutimento}

Outro exemplo de aplicação modelado via método dos elementos finitos foi o embutimento de um copo circular a partir de uma chapa metálica anisotrópica. As propriedades do material e da geometria dos componentes foram baseadas no trabalho de YOON et al. (2006).

As principais dimensões consideradas no modelo são ilustradas na Figura 6.55 e seus valores são apresentadas na Tabela 6.7. O modelo de encruamento adotado para a chapa foi o puramente isotrópico dado pela lei de potência com $K=$ $650[\mathrm{MPa}]$ e $n=0.23$. A tensão de escoamento inicial foi $\sigma_{0}=150[\mathrm{MPa}]$ e os índices de anisotropia utilizados foram $R_{0}=0.2, R_{45}=1.6$ e $R_{90}=0.7$.

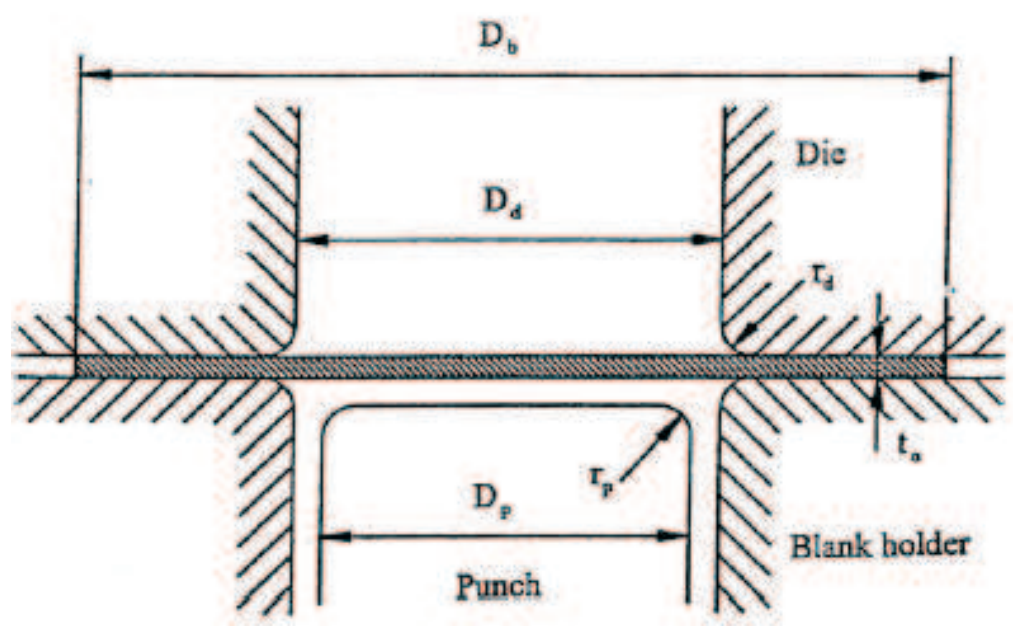

Figura 6.55: Esquema do embutimento, YOON et al. (2006)

Tabela 6.7: Dados de geometria do modelo de embutimento

\begin{tabular}{|c|c|c|}
\hline Diâmetro da chapa & $D_{b}$ & $160[\mathrm{~mm}]$ \\
\hline Espessura da chapa & $t$ & $1[\mathrm{~mm}]$ \\
\hline Diâmetro da matriz & $D_{d}$ & $105[\mathrm{~mm}]$ \\
\hline Raio de canto da matriz & $r_{d}$ & $12[\mathrm{~mm}]$ \\
\hline Diâmetro do punção & $D_{p}$ & $100[\mathrm{~mm}]$ \\
\hline Raio de canto do punção & $r_{p}$ & $12[\mathrm{~mm}]$ \\
\hline
\end{tabular}


A Figura 6.56 ilustra a malha Shell do modelo de elementos finitos composta pela chapa, matriz, punção e prensa chapas. Aqui também foi considerado apenas um quarto do modelo com condições de contorno apropriadas para satisfazer a simetria. Como condição de carregamento, aplicou-se uma pressão no prensa chapas da ordem de $10 \%$ do valor da tensão de escoamento do material. Esta pressão é necessária para evitar-se a formação de rugas durante o processo o que dificulta a convergência da solução do problema. A formação do copo é realizada a partir da imposição de deslocamento do punção.

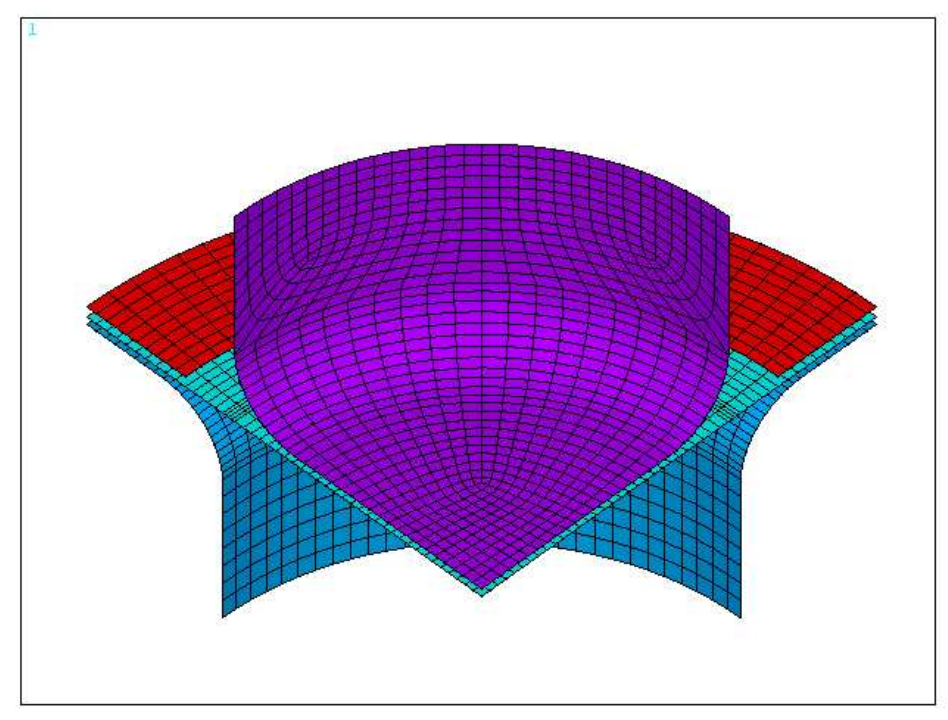

Figura 6.56: Malha do modelo MEF do embutimento

As Figuras 6.57 e 6.58 ilustram a distribuição da tensão equivalente na chapa no início e ao final do processo. Pode-se observar na Figura 6.58 a tendência de formação de orelhas no copo devido ao efeito da anisotropia do material.

Conforme anteriormente, o modelo de elementos finitos permitiu localizar as regiões do copo onde o estado de tensão-deformação satisfaz a hipótese assumida para a aplicação da metodologia. Como já poderia ser previsto, as partes do copo que sofrem uma forma de flexão na região de contato com o raio de canto do punção, são as que mais se aproximam do estado tensão-deformação necessário. 


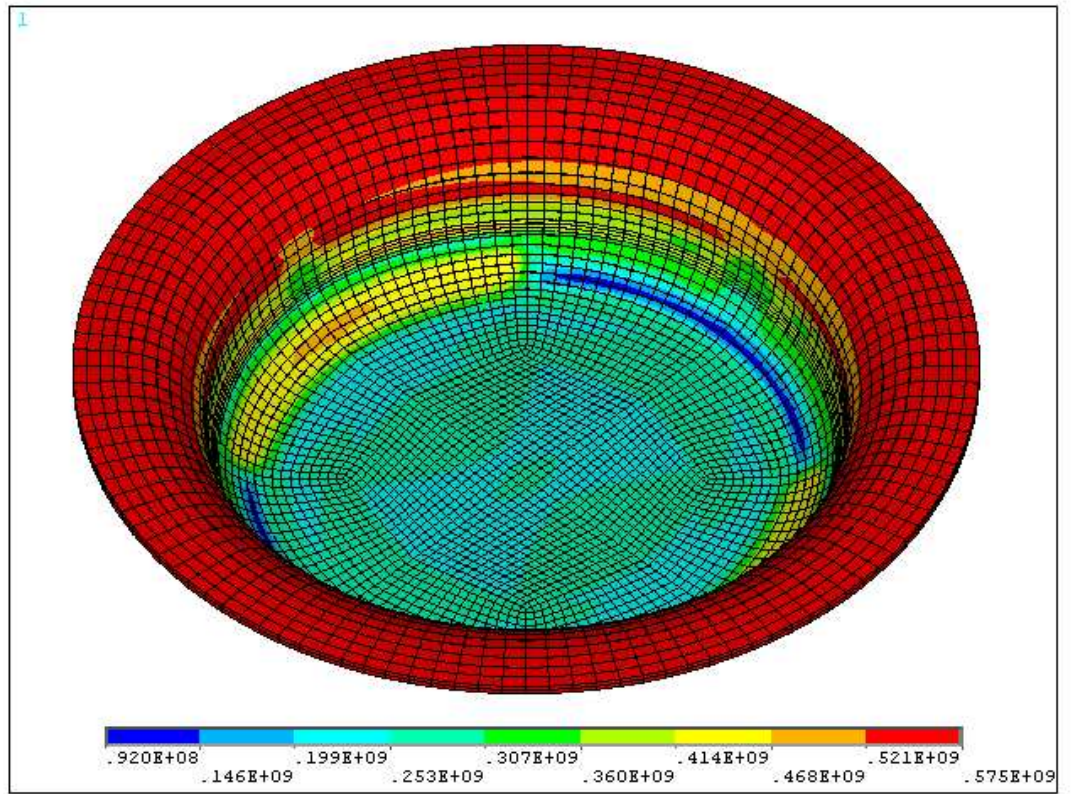

Figura 6.57: Tensão equivalente $[\mathrm{Pa}]$ no início do carregamento

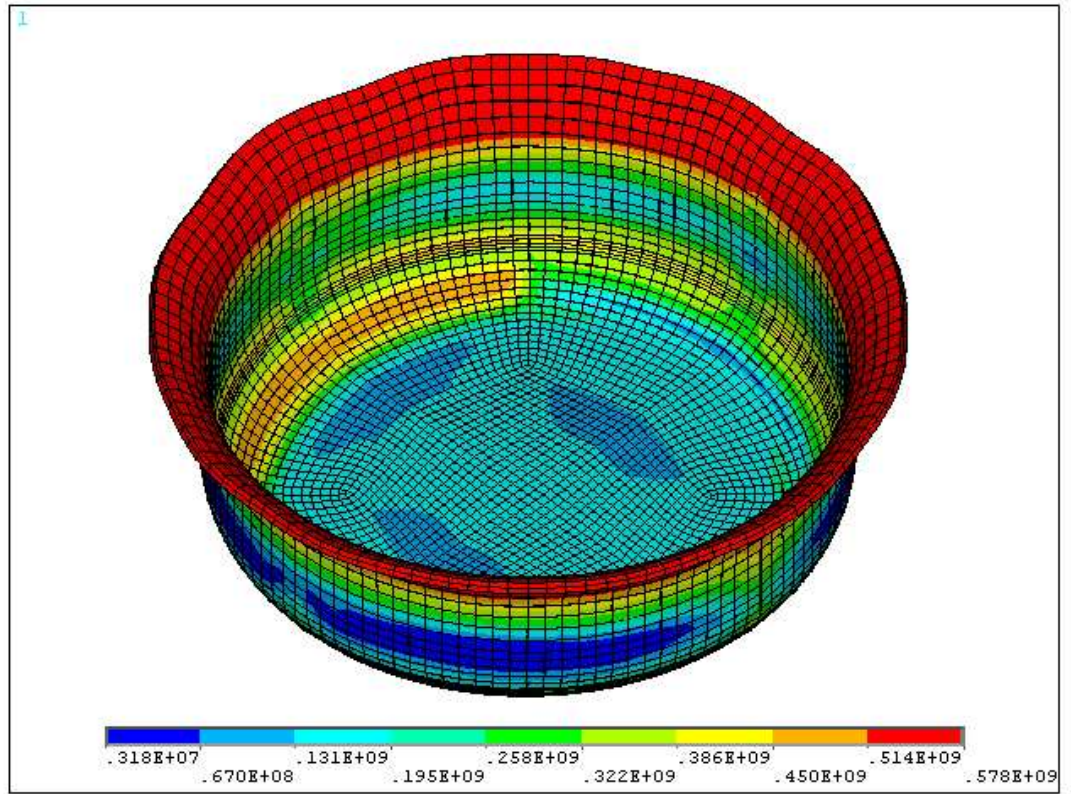

Figura 6.58: Tensão equivalente $[\mathrm{Pa}]$ no final do carregamento 
O gráfico da Figura 6.59 mostra a evolução típica das componentes de deformação nesta região do copo. Pode-se notar que a componente $\varepsilon_{2}$, associada com a direção radial do copo, é praticamente nula garantindo assim o estado de deformação necessário. Ainda observa-se que as componentes de deformação $\varepsilon_{1}$, na direção de estiramento do material, e $\varepsilon_{3}$, ao longo da espessura, têm um comportamento crescente até aproximadamente 5\%, a partir do qual permanecem praticamente constantes. Desta forma adotou-se como entrada para a aplicação da metodologia um histórico de deformação variando linearmente de zero até $5 \%$.

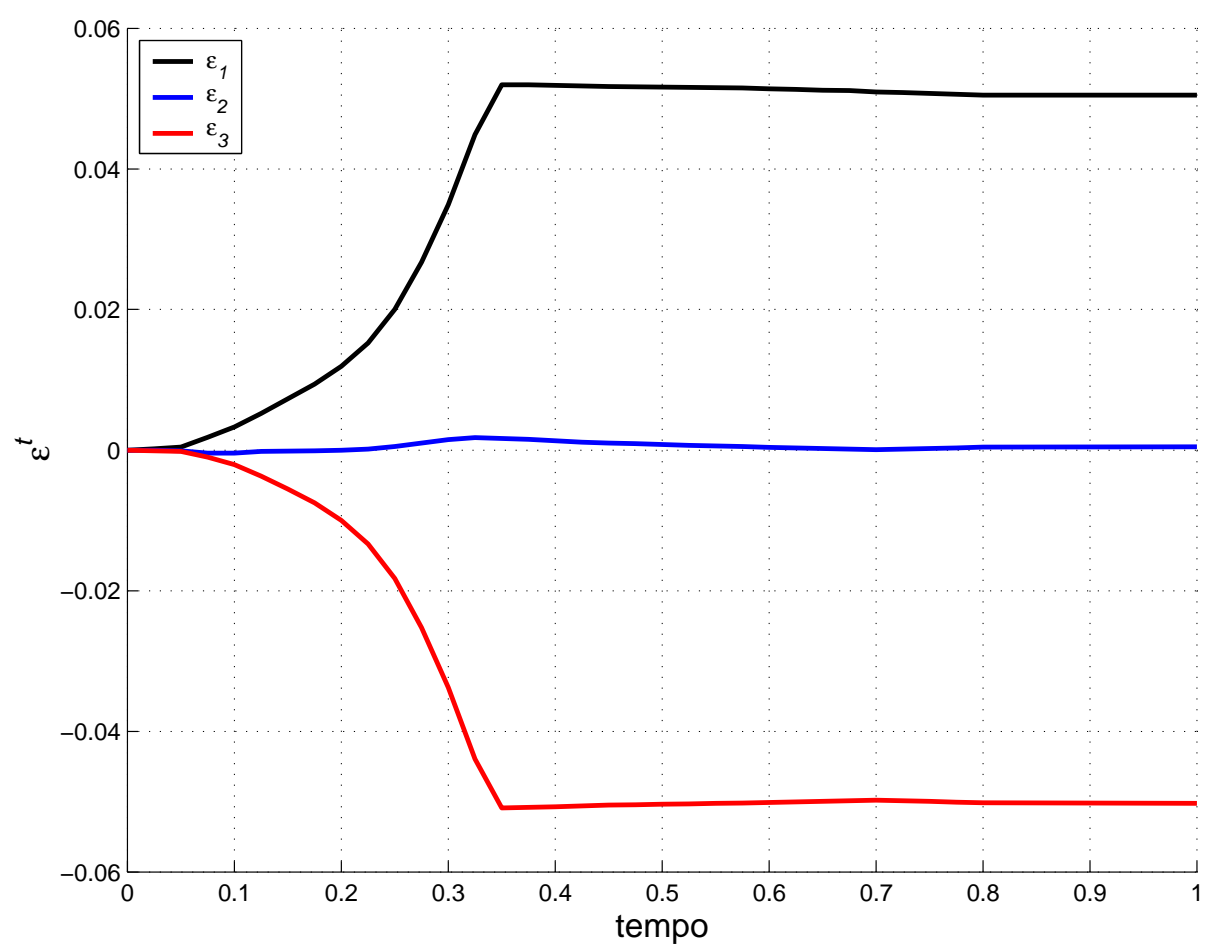

Figura 6.59: Evolução das componentes de deformação

Os resultado obtidos pela aplicação da metodologia são apresentados a seguir. O comportamento da evolução dos parâmetros de anisotropia determinados pela solução do conjunto de equações é dado nas Figuras 6.60 a 6.63. A Figura 6.64 mostra a evolução do fator de correção $\Psi$ determinado a partir dos parâmetros evolutivos. A comparação entre a evolução da superfície $F_{m}$ e da superfície de Hill utilizada no modelo MEF é mostrada na Figura 6.65. 


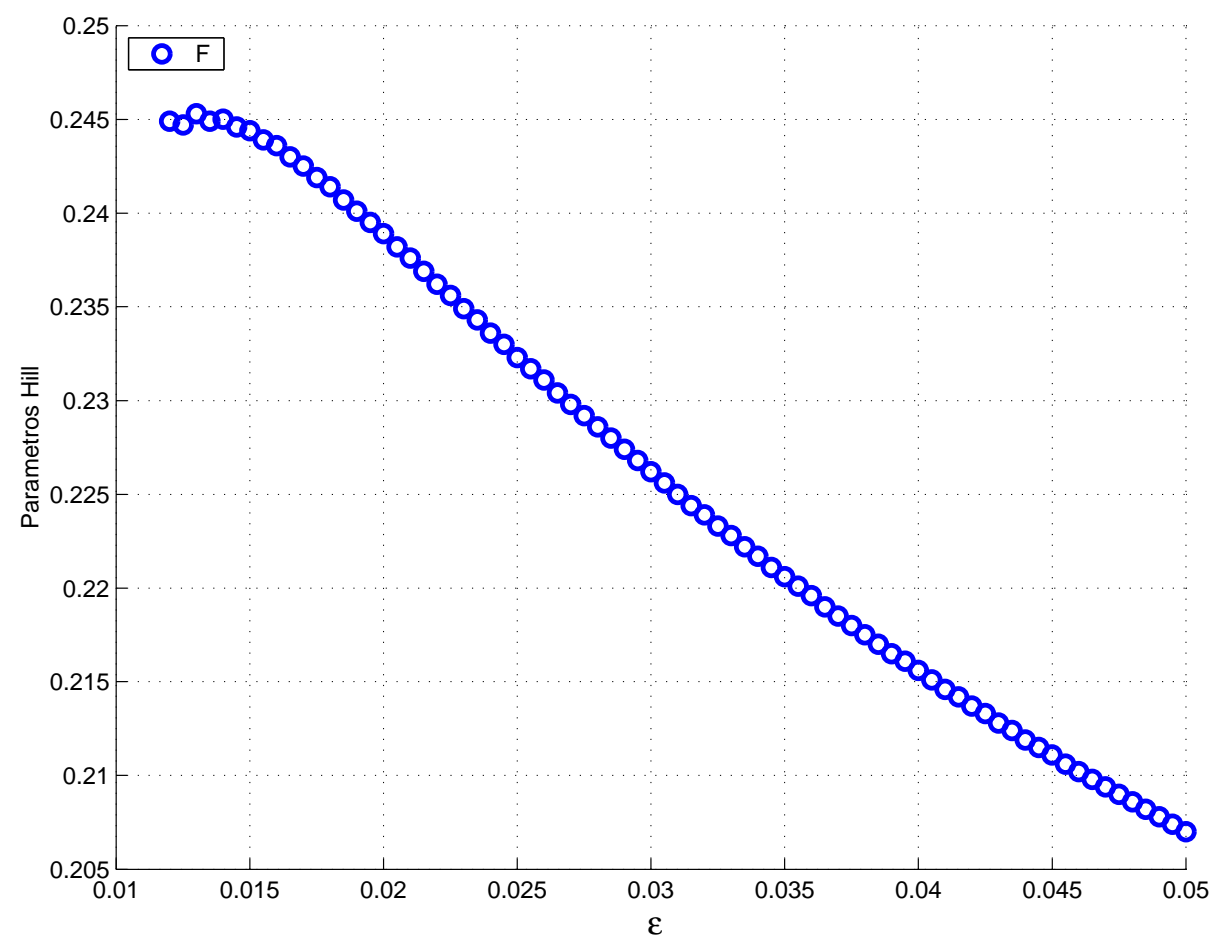

Figura 6.60: Evolução do parâmetro $\hat{F}$ - Embutimento

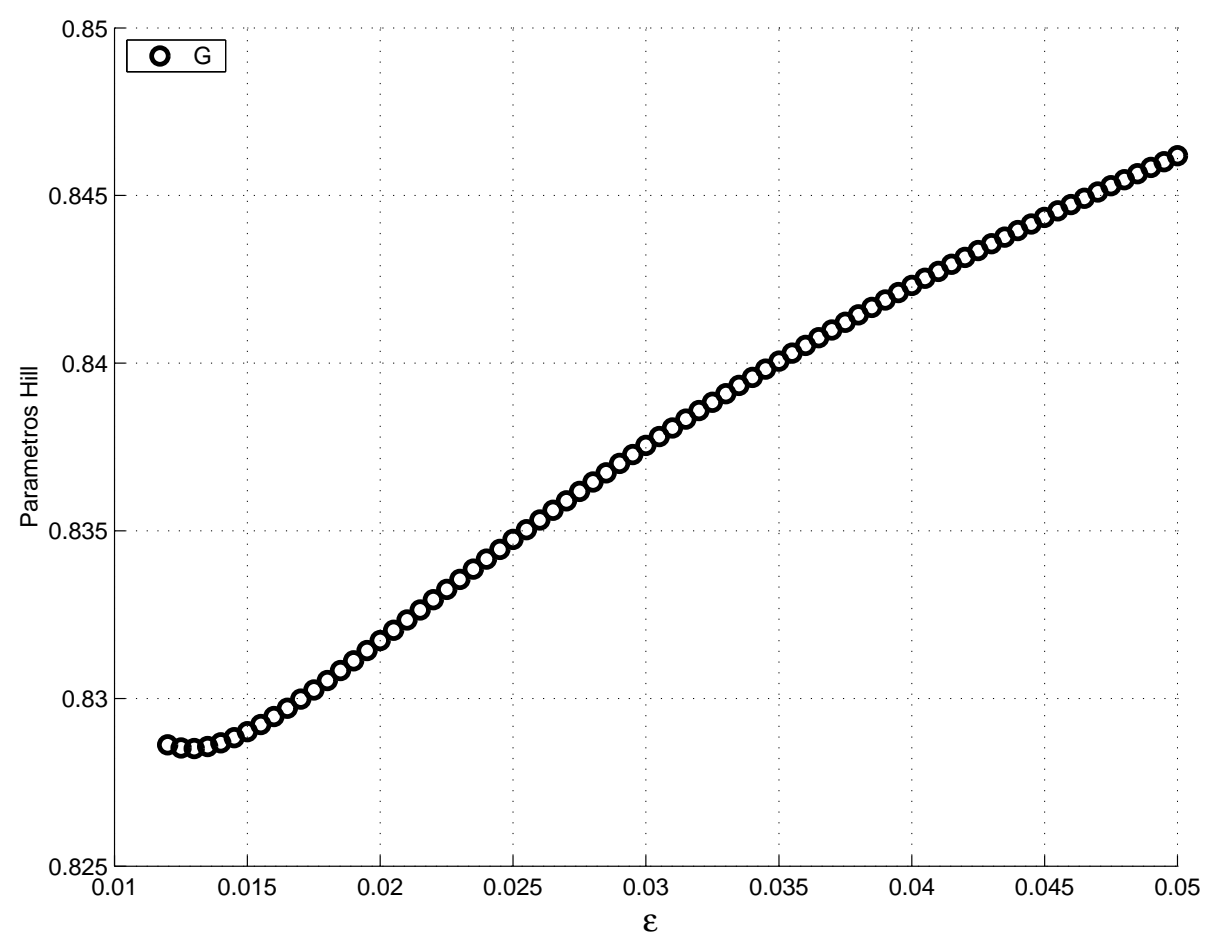

Figura 6.61: Evolução do parâmetro $\hat{G}$ - Embutimento 


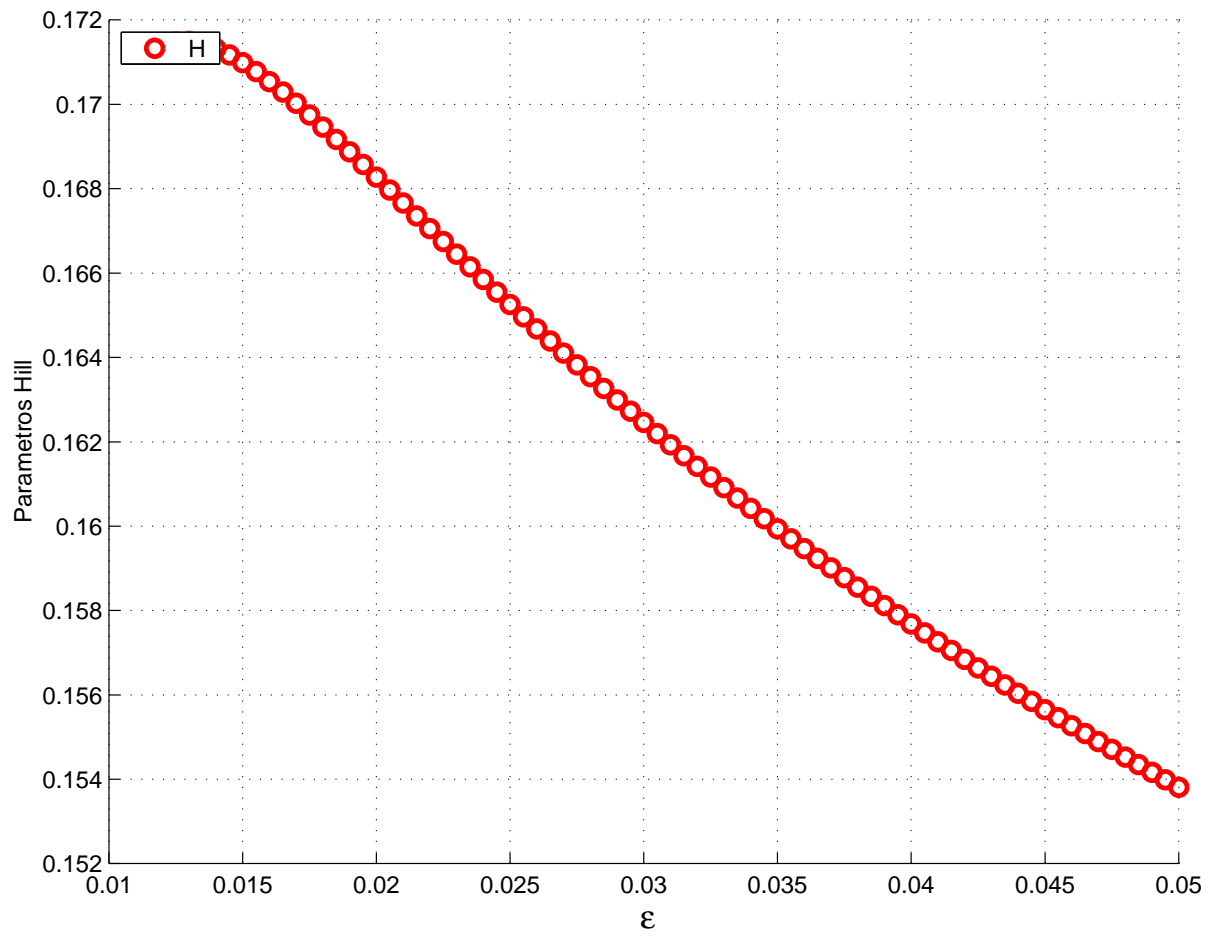

Figura 6.62: Evolução do parâmetro $\hat{H}$ - Embutimento

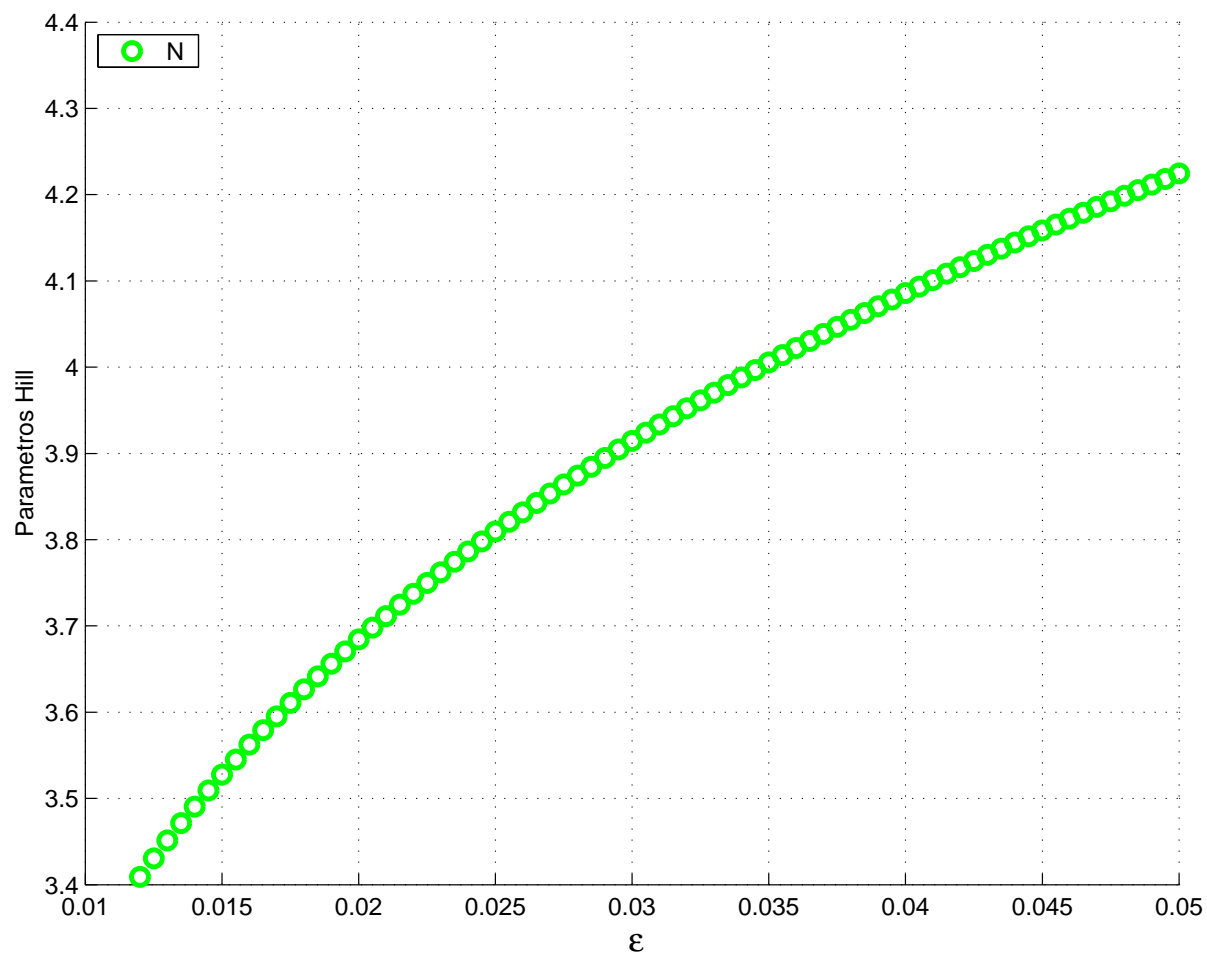

Figura 6.63: Evolução do parâmetro $\hat{N}$ - Embutimento 


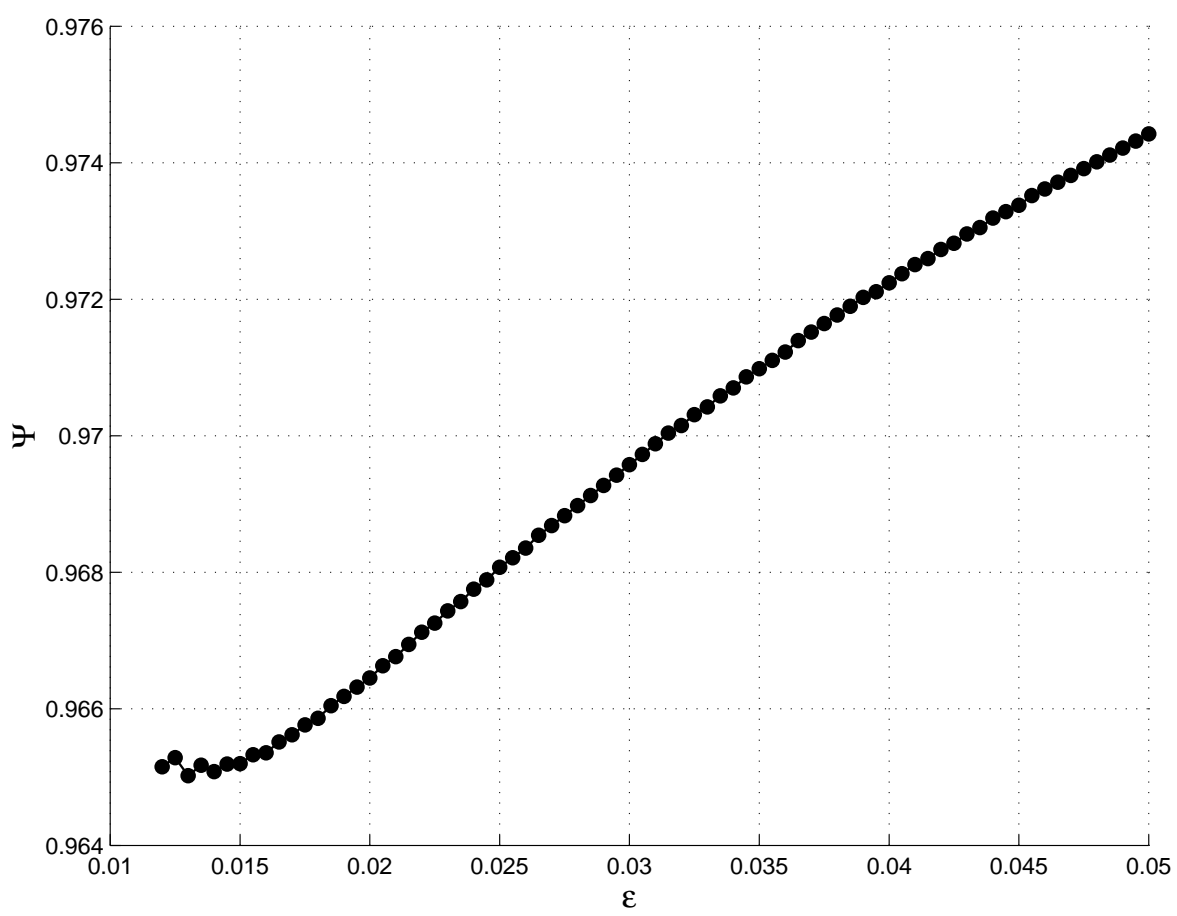

Figura 6.64: Evolução do fator de correção $\Psi$

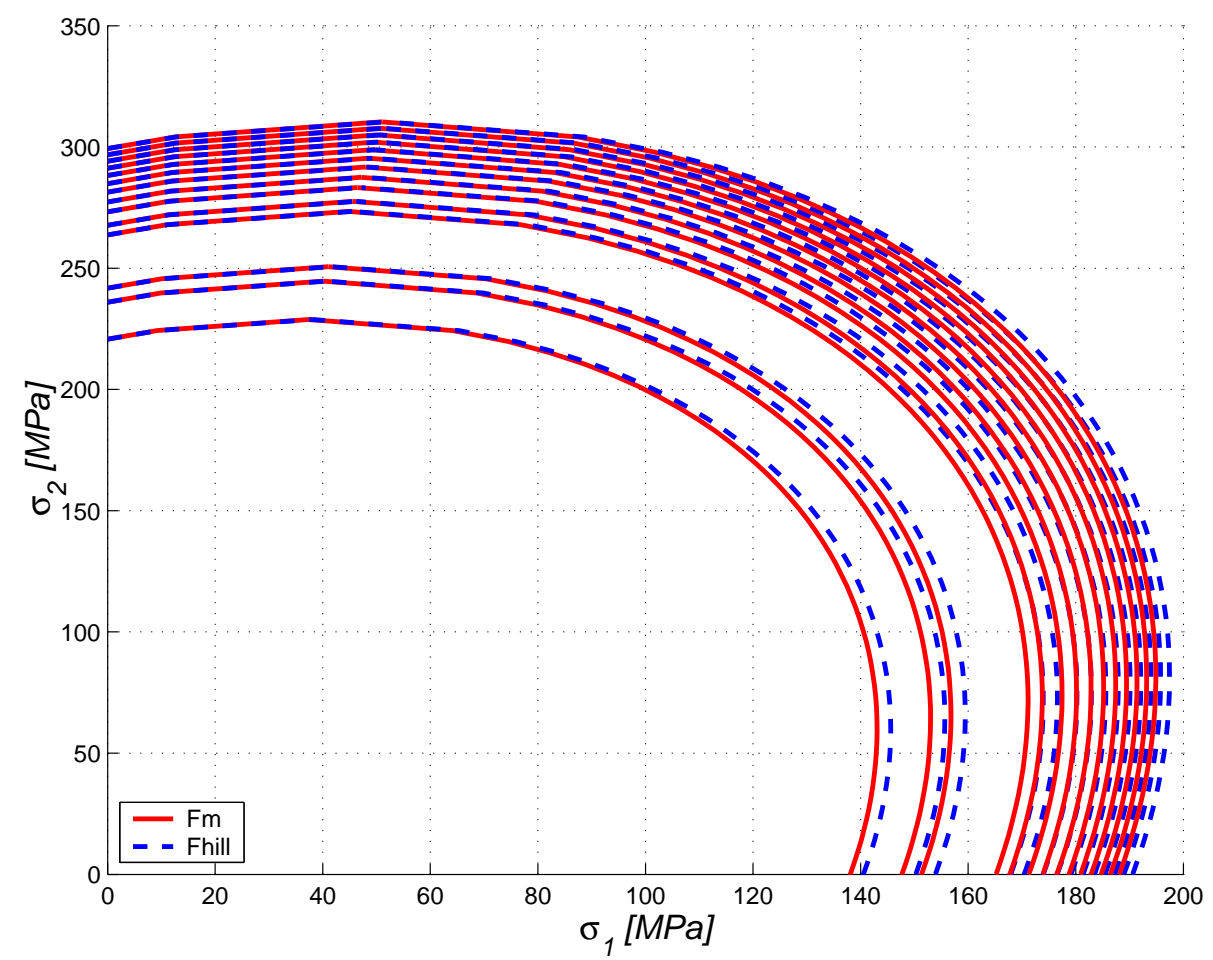

Figura 6.65: Comparação da evolução das superfícies de escoamento 


\subsection{Discussões gerais}

Os resultados obtidos para a validação do algoritmo de previsão-correção implementado externamente foram considerados satisfatórios. Em todos os casos estudados, o comportamento da evolução das tensões se mostraram coerente com os resultados obtidos pelo pacote comercial de elementos finitos.

A comparação da evolução dos índices de anisotropia obtidos experimentalmente para a liga de alumínio estudada e pela metodologia proposta foi efetuada. Os resultados mostraram uma evolução não muito acentuada com o decorrer do carregamento para ambos os casos, ficando muito próxima de um estado isotrópico de tensão. Desta forma outros estudos experimentais devem ser realizados, buscando-se materiais com propriedades anisotrópicas mais acentuadas.

Os exemplos de aplicação estudados indicam a possibilidade do uso da metodologia e da nova superfície de escoamento em conjunto com análises de elementos finitos para diferentes processos de conformação.

As comparações entre as superfícies de escoamento proposta $F_{m}$, e a superfície original de Hill para os diversos casos estudados, mostraram comportamentos evolutivos distintos. Isto indica a possibilidade da aplicação da nova superfície de escoamento como forma alternativa no estudo da formabilidade de chapas metálicas anisotrópicas.

Dentre as possíveis implicações do uso da metodologia proposta e da nova superfície de escoamento pode-se destacar, do ponto de vista prático de fabricação, a melhor caracterização do comportamento anisotrópico do material implicando em uma seleção mais adequada de chapas para determinado tipo de processo de conformação. Do ponto de vista teórico, tem-se uma contribuição para a elaboração de um modelo evolutivo, onde a superfície de escoamento apresenta uma distorção com o decorrer do carregamento. Outra contribuição trata do possível mapeamento do estado de anisotropia na chapa. Uma vez que o metodologia desenvolvida analisa um ponto material da peça, esta pode então ser aplicado para outras regiões, permitindo assim a geração de um campo de anisotropia na peça. 
Outra aplicação da determinação da evolução da anisotropia durante o carregamento plástico é a possibilidade de se identificar situações em que a peça tenha uma combinação desfavorável do conjunto de parâmetros anisotrópicos. Desta forma, pode-se gerar alguns critérios que direcionem por exemplo o nível de deformação limite e/ou a orientação da chapa para a execução do carregamento. 


\section{Capítulo 7}

\section{Conclusões e Sugestões para}

\section{Trabalhos Futuros}

Os objetivos estabelecidos no plano inicial deste trabalho foram alcançados. A metodologia de cálculo de evolução dos parâmetros de anisotropia associados com o critério de escoamento de Hill e a nova superfície de escoamento anisotrópica para chapas metálicas foram apresentadas.

A revisão dos conceitos relacionados com a Mecânica dos Sólidos juntamente com a Teoria Clássica da Plasticidade e Plasticidade Computacional, forneceu a fundamentação necessária para o desenvolvimento da metodologia e da nova superfície de escoamento.

O equacionamento para a geração do conjunto de equações que leva a determinação da evolução dos parâmetros de anisotropia foi elaborado a partir das relações incrementais entre tensão e deformação da teoria da plasticidade baseando-se em um estado de tensão-deformação particular, porém bastante comum em regiões da peça conformada onde ocorram dobras.

A nova superfície de escoamento foi definida a partir da superfície original de Hill, porém ponderada por um fator de correção escrito em função dos parâmetros de anisotropia evolutivos determinados pela aplicação da metodologia. A partir da definição adotada para este fator de correção, o comportamento da evolução 
da nova superfície de escoamento pode ser avaliado.

Os resultados obtidos para os diferentes casos estudados, mostraram evoluções distintas entre a superfície proposta e a superfície original de Hill, indicando a possibilidade de aplicar a nova superfície como uma forma alternativa de avaliar a formabilidade de chapas metálicas. Desta forma tem-se uma contribuição para a representação do fenômeno de anisotropia plástica em chapas metálicas através de um modelo evolutivo, em contraste com a grande maioria dos modelos atuais que assumem a anisotropia constante com o decorrer do carregamento.

A implementação computacional do algoritmo de previsão-correção e da metodologia foi executada. Esta implementação permitiu uma flexibilidade para estudar a evolução dos parâmetros de anisotropia utilizando-se diferentes condições de carregamento e modelos de encruamento que podem ser adotados na representação do fenômeno. A validação do algoritmo de previsão-correção implementado foi realizada por meio de comparações com componentes de tensão obtidas via pacote comercial de elementos finitos. Os resultados obtidos para os diferentes casos estudados com modelos de materiais isotrópicos e anisotrópicos não sofreram grandes divergências validando assim o algoritmo de previsão-correção implementado externamente.

Os ensaios experimentais normalizados para determinação das constantes de material e dos índices de anisotropia foram executados para a liga de alumínio aeronáutico Al 7475-O. Os resultados obtidos experimentalmente serviram como base de comparação e como dados de entrada para a aplicação da metodologia. Foram realizadas comparações entre a evolução experimental e teórica dos índices de anisotropia e os resultados obtidos indicaram a necessidade de escolha de um material com a anisotropia mais acentuada.

Os exemplos de aplicação estudados indicam a possibilidade da utilização da metodologia e da nova superfície de escoamento, em conjunto com análises numéricas de elementos finitos para diferentes processos de conformação de chapas metálicas. 


\section{Sugestões para Trabalhos Futuros}

Os estudos gerais apresentados indicaram alguns caminhos possíveis que podem ser seguidos em trabalhos futuros.

Inicialmente é sugerido avaliar mais profundamente a proposta da nova superfície de escoamento, a qual deve ser melhor fundamentada, verificando-se por exemplo sob quais condições esta superfície se mantem convexa, para não violar postulados básicos da teoria da plasticidade. Adicionalmente a execução de ensaios experimentais pode permitir a validação desta nova superfície.

Outro trabalho trataria da implementação computacional da nova superfície proposta em programas de elementos finitos a qual posteriormente poderia ser comparada com outras superfícies anisotrópicas disponíveis na literatura.

Também é possível estudar o comportamento da nova superfície de escoamento anisotrópica proposta considerando-se outros fatores de correção, determinados de forma alternativa, além da possibilidade de generalizar a nova superfície considerando-se os parâmetros evolutivos também na função de Hill.

Estudos adicionais acerca das hipóteses e considerações aplicadas na metodologia de cálculo de evolução dos parâmetros de anisotropia também podem ser trabalhados em conjunto com resultados experimentais.

Outro campo de trabalho sugere a generalização dos estudos apresentados no âmbito de grandes deslocamentos e deformações utilizando-se tensores de tensão e deformação que contemplem estas não linearidades, como o tensor de deformação de Green e tensor de tensão de Piola-Kirchhoff 2. 
162CAPÍTULO 7. CONCLUSÕES E SUGESTÕES PARA TRABALHOS FUTUROS 


\section{Referências Bibliográficas}

ASTM E-8M 97 (1997). Standard test methods for tension testing of metallic materials [Metric]. American Society for Testing and Materials.

ASTM E-517 96a (1996). Standard test method for plastic strain ratio $\mathrm{r}$ for sheet metal. American Society for Testing and Materials.

BANABIC, D.; KUWABARA, T.; BALAN, T.; COMSA, D.S. (2004). An anisotropic yield criterion for sheet metals. Journal of Materials Processing Technology. v.157-158, p.462-465.

BARLAT, F.; LIAN, J. (1989). Plastic behavior and strechability of sheet metals. Part I: A yield function for orthotropic sheets under plane stress conditions. International Journal of Plasticity. v.5, p.51-66.

BARLAT, F.; YOON, J.W.; YANG, D.Y.; CHUNG, K. (1999). A general elastoplastic finite element formulation based on incremental deformation theory for planar anisotropy and its application to sheet metal forming. International Journal of Plasticity. v.15, p.35-67.

BATHE, K.J. (1996). Finite element procedures. 1.ed. Upper Saddle River : Prentice Hall.

BELYTSCHKO, T.; LIU, W.K.; MORAN, B. (2000). Nonlinear finite elements for continua and structures. Chichester : John Wiley \& Sons.

BONET, J.; WOOD, R.D. (1997). Nonlinear continuum mechanics for finite element analysis. Cambridge University Press. 
BOUVIER, S.; HADDADI, H.; LEVEE, P.; TEODOSIU, C. (2006). Simple shear tests: Experimental techniques and characterization of the plastic anisotropy of rolled sheets at large strains. Journal of Materials Processing Technology. v.172, p.96-103.

BRUNET, M.; MORESTIN, F.; GODEREAUX, S. (2001). Nonlinear kinematic hardening identification for anisotropic sheet metals with bending-unbending tests. Journal of Engineering Materials and Technology. v.123, p.378-383.

CHAMANFAR, A.; MAHMUDI, R. (2005). Compensation of elastic strains in the determination of plastic strain ratio $(R)$ in sheet metals. Materials Science and Engineering A. v.397, p.153-156.

CHAMANFAR, A.; MAHMUDI, R. (2004). Ti sheet: The effect of gage length and width measurement on plastic strain ration. The Minerals, Metals 86 Materials Society. February, p.49-52.

CHEN, W.F.; HAN, D.J. (1988). Plasticity for structural engineers. New York: Springer-Verlag.

CHUN, B.K.; JINN, J.T.; LEE, J.K. (2002). Modelling the Bauschinger effect for sheet metals, part I: theory. International Journal of Plasticity. v.18, p.571-595.

CRISFIELD, M.A. (1991). Non-linear finite element analysis of solids and structures - Essentials. v.1. Chichester : John Wiley \& Sons Ltd.

CRISFIELD, M.A. (1997). Non-linear finite element analysis of solids and structures - Advanced Topics. v.2. Chichester : John Wiley \& Sons Ltd.

DANCKERT, J.; NIELSEN, K.B. (1998). Determination of the plastic anisotropic $r$ in sheet metal using automatic tensile test equipment. Journal of Materials Processing Technology. v.73, p.276-280.

EVANGELISTA, S.H. (2006). Determinação da anisotropia plástica em chapas metálicas através do ensaio de estiramento plano biaxial em corpos de prova cru- 
ciformes. Tese (Doutorado em Engenharia Mecânica) - Escola de Engenharia de São Carlos, Universidade de São Paulo, São Carlos, 2006.

FERRON, G.; MAKKOUK, R.; MORREALE, J. (1994). A parametric description of orthotropic plasticity in metal sheets. International Journal of Plasticity. v.10, n.5, p.431-449.

GENG, L.; SHEN, Y.; WAGONER, R.H. (2002). Anisotropic hardening equations derived from reverse-bend testing. International Journal of Plasticity. v.18, p.743767.

GILMOUR, K.R.; LEACOCK, A.G.; ASHBRIDGE, M.T.J. (2004). The influence of plastic strain ratio on the numerical modelling of stretch forming. Journal of Materials Processing Technology. v.152, p.116-125.

GREWOLLS, G.; KREI $\beta$ IG, R. (2001) Anisotropic hardening - numerical application of a cubic theory and consideration of variable r-values for sheet metal. European Journal of the Mechanics - A/Solids. v.20, p.585-599.

HILL, R. (1950). The mathematical theory of plasticity. v.1. London : Oxford University Press.

HILL, R. (1990). Contitutive modelling of orthotropic plasticity in sheet metals. Journal of the Mechanics and Physics of Solids. v.38, p.405-417.

HSU, Q.C. (2003). Comparison of different analysis models to measure plastic strains on sheet metal forming parts by digital image processing. International Journal of Machine Tools Manufacture. v.43, p.515-521.

HUGHES, T.J.R. (2000). The finite element method: linear static and dynamic finite element analysis. New York : Dover Publications.

JOHNSON, W.; MELLOR, P.B. (1962). Plasticity for mechanical engineers. London : Van Nostrand Reinhold Company Ltd. 
KARAFILIS, A.P.; BOYCE, M.C. (1993) A general anisotropic yield criterion using bounds and a transformation weighting tensor. Journal of the Mechanics and Physics of Solids.v.41,n.12, p.1859-1886.

KAWABE, H.; MATSUOKA, S.; SHIMIZU, T.; FURUKIMI, O.; SAKATA, K.; ITO, Y. (2002) Effect of increase in r-value on press formability for cold-rolled steel sheet. JSAE Review. v.23, p.139-141.

KAWKA, M.; MAKINOUCHI, A. (1996) Plastic anisotropic in FEM analysis using degenerated solid element. Journal of Materials Processing Technology. v.60, n.1-4, p.239-242.

KHAN, A.S.; HUANG, S. (1995). Continuum theory of plasticity. New York : John Wiley \& Sons, Inc.

KIM, K.H. (1997) Evolution of anisotropy under plane stress. Journal of the Mechanics and Physics of Solids.v.45,n.5, p.841-851.

KOBAYASHI, S.; OH, S.I.; ALTAN, T. (1989). Metal forming and the finiteelement method. New York : Oxford University Press.

LEMAITRE, J.; CHABOCHE, J.L. (1990). Mechanics of solid materials. Cambridge University Press.

LUBLINER, J. (1990). Plasticity theory. New York: Macmillan Publishing Company.

MAHMUDI, R.(1995). Yield loci of anisotropic aluminium sheets. International Journal of Mechanical Sciences. v.37, n.9, p.995-1010.

MALVERN, L.E. (1969). Introduction to the mechanics of a continuous medium. New Jersey : Prentice Hall, Inc.

MARCINIAK, Z.; DUNCAN, J.L. (1992). The mechanics of sheet metal forming. London : Edward Arnold. 
MENDELSON, A. (1968). Plasticity; theory and application. New York: Macmillan Publishing Company.

MULLER, W.; POHLANDT, K. (1996). New experiments for determining yield loci of sheet metal. Journal of Materials Processing Technology. v.60, p.643-648.

OWEN, D.R.J.; HINTON, E. (1980). Finite element in plasticity - Theory and Practice. 2.ed. Swansea : Pineridge Press.

RAO, K.P.; MOHAN, E.V.R. (2001). A unified test for evaluating material parameters for use in the modelling of sheet metal forming. Journal of Material Processing Technology. v.113, p.725-731.

SIMO, J.C.; HUGHES, T.J.R. (1998). Computational Inelasticity. v.7. New York : Springer-Verlag.

SINOU, J.J.; MACQUAIRE, B. (2003). Anisotropic behaviour law for sheets used in stamping: A comparative study of steel and aluminium. Mecanique. v.331, p.33-40.

WU, H.C.; HONG, H.K. (1999). Endochronic description of plastic anisotropy in sheet metal. International Journal of Solids and Structures. v.36, p.2735-2756.

WU, H.C.; HONG, H.K.; SHIAO Y.P. (1999). Anisotropic plasticity with application to sheet metals. International Journal of Mechanical Sciences. v.41, p.703-724.

WU, H.C. (2002). Anisotropic plasticity for sheet metal using the concept of combined isotropic-kinematic hardening. International Journal of Plasticity. v.18, p.1661-1682.

WU, P.D.; MACEWEN, S.R.; LLOYD D.J.; JAIN, M.; TUGCU, P.; NEALE, K.W. (2005). On pre-straining and the evolution of material anisotropy in sheet metals. International Journal of Plasticity. v.21, p.723-739. 
YOON, J.W.; BARLAT, F.; DICK, R.E.; KARABIN, M.E. (2006). Prediction of six or eight ears in a drawn cup based on a new anisotropic yield function. International Journal of Plasticity. v.22, p.174-193.

YOON, J.W.; HONG, S.H. (2006). Modeling of aluminum alloy sheets based on new anisotropic yield functions. Journal of Material Processing Technology. v.177, p.134-137.

ZHAO, K.M.; LEE, J.K.; (2001). Generation of cyclic stress strain curves for sheet metals. Journal of Engineering Materials and Technology. v.123, p.391-397.

ZIENKIEWICZ, O.C.; TAYLOR, R.L. (2000). The finite element method - Solids Mechanics. 5.ed. Boston : Butterworth-Heinemann. 